\title{
Halogen-Mediated Conversion of Hydrocarbons to Commodities
}

\section{Journal Article}

\section{Author(s):}

Pérez-Ramírez, Javier; Lin, Ronghe; Amrute, Amol P.

Publication date:

2017-03

Permanent link:

https://doi.org/10.3929/ethz-b-000129748

Rights / license:

In Copyright - Non-Commercial Use Permitted

\section{Originally published in:}

Chemical Reviews 117(5), https://doi.org/10.1021/acs.chemrev.6b00551

\section{Funding acknowledgement:}

156107 - Design of oxyhalogenation catalysts for hydrocarbon functionalization (SNF) 


\title{
Halogen-Mediated Conversion of Hydrocarbons to
}

\section{Commodities}

\author{
Ronghe Lin, Amol P. Amrute, and Javier Pérez-Ramírez*
}

Institute for Chemical and Bioengineering, Department of Chemistry and Applied Biosciences, ETH Zurich, Vladimir-Prelog-Weg 1, 8093 Zurich, Switzerland.

*E-mail: jpr@chem.ethz.ch.

\section{ABSTRACT}

Halogen chemistry plays a central role in the industrial manufacture of various important chemicals, pharmaceuticals, and polymers. It involves the reaction of halogens or halides with hydrocarbons leading to intermediate compounds which are readily converted to valuable commodities. These transformations, predominantly mediated by heterogeneous catalysts, have long been successfully applied in the production of polymers. Recent discoveries of abundant conventional and unconventional natural gas reserves have revitalized strong interest in these processes as the most cost-effective gas-toliquid technologies. This review provides an in-depth analysis of the fundamental understanding and applied relevance of halogen chemistry in polymer industries (polyvinyl chloride, polyurethanes, and polycarbonates) and in the activation of light hydrocarbons. The reactions of particular interest include

halogenation and oxyhalogenation of alkanes and alkenes, dehydrogenation of alkanes, conversion of alkyl halides, and oxidation of hydrogen halides, with emphasis on catalyst, reactor, and process design. Perspectives on the challenges and directions for future development in this exciting field are provided. 


\section{CONTENTS}

1. Introduction

1.1. Relevance of Halogen Chemistry

1.2. Chronology of Halogen-Mediated Processes

1.3. Scope of the Review

2. Halogen Chemistry in Polymer Manufacture

2.1. Acetylene Hydrochlorination for VCM Production

2.1.1. Mercuric Chloride-Based Catalysts

2.1.2. Gold-Based Catalysts

2.1.3. Bimetallic Catalysts

2.1.4. Process Design Aspects

2.2. Ethylene Chlorination for VCM Production

2.3. Ethylene Oxychlorination for VCM Production

2.3.1. Copper Chloride-Based Catalysts for EDC Production

2.3.2. Catalytic Dehydrochlorination of EDC to VCM

2.3.3. $\mathrm{CeO}_{2}$-Based Catalysts for Direct VCM Production

2.3.4. Reactors and Processes

2.4. Ethane Oxychlorination for VCM Production

2.4.1. Catalysts

2.4.2. Accounts of Developing Processes

2.5. Phosgene Chemistry in PU and PC Production

2.5.1. Phosgene Synthesis

2.5.2. Phosgenation of Amines and Alcohols

2.5.3. Chlorine Recycling via Catalyzed $\mathrm{HCl}$ Oxidation

3. Halogen-Mediated Functionalization of Light Hydrocarbons

3.1. Methane Halogenation 
3.1.1. Free Radical Halogenation

3.1.2. Electrophilic Halogenation

3.1.3. Halogenation Processes

3.1.4. Bromine Recycling via Catalyzed $\mathrm{HBr}$ Oxidation

3.2. Methane Oxyhalogenation

3.2.1. Catalysts for Methane Oxychlorination

3.2.2. Catalysts for Methane Oxybromination

3.3. Oxyhalogenation of Higher Hydrocarbons $\left(\mathrm{C}_{2}-\mathrm{C}_{4}\right)$

3.3.1. Oxybromination of Ethane

3.3.2. Oxyhalogenation of Propane/Propylene

3.3.3. Oxyhalogenation of Butane/Butadiene

3.4. Halogen-Assisted Dehydrogenation of Alkanes $\left(\mathrm{C}_{2}-\mathrm{C}_{5}\right)$

3.4.1. Iodine-Mediated Dehydrogenation

3.4.2. Alkali Metal Chloride-Catalyzed Oxidative Dehydrogenation

3.4.3. Metal Iodide-Catalyzed Oxidative Dehydrogenation

3.4.4. Bi-Halogens Interplay in Propane Dehydrogenation

4. Transformation of Alkyl Halides to Chemicals and Fuels

4.1. Methyl Halides to Hydrocarbons

4.1.1. Zeolite Catalysts

4.1.2. Reaction Mechanism

4.2. Methyl Halides to Oxygenates

4.2.1. Hydrolysis

4.2.2. Carbonylation

4.3. Transformation of Other Haloalkanes

4.3.1. Polyhalomethanes

4.3.2. Ethyl Halides 
4.4. Toxicity and Safe Handling of Halogen-Containing Compounds

4.4.1. Inorganic Halides

4.4.2. Halocarbons

4.4.3. Safe Handling

4.4.4. Materials of Construction

5. Conclusions and Outlook

Acknowledgements

List of Abbreviations and Techniques

References

Author Information

Corresponding Author

Notes

Biographies 


\section{INTRODUCTION}

\subsection{Relevance of Halogen Chemistry}

Sustainable developments for building modern society rely on the availability of raw materials and the technologies for the efficient utilization of the latter for energy and chemical production. With time, there is a clear shift in both energy resources and feedstocks for chemical industry, from coal at the beginning of the $20^{\text {th }}$ century to oil in the mid- $20^{\text {th }}$ century and from 1980 s natural gas is becoming a more important resource, while oil is dropping (Figure 1). ${ }^{1-3}$ These transitions are primarily driven by the steadily rising demands, the industrial revolution, and the access to a particular resource in that timeframe. The recent discovery of huge volumes of unconventional natural gas ${ }^{4}$ is particularly worth mentioning as it is changing the picture of our basic raw materials and it is projected that around 2035 all the three resources will contribute equally as feedstocks. ${ }^{1}$ This scenario at first glance seems to make us less dependence on oil, however, the conversion of natural gas to valuable products is challenging due to inertness of its predominant constituent, methane. Halogen chemistry has played and is expected to play a prominent role to enable the transformation of these different resources to commodities. The use of chlorine for the manufacture of a wide range of products, as summarized in the chlorine tree, is exemplary (Figure 2). ${ }^{5}$ It is estimated that over $50 \%$ of all the industrial chemicals and polymers, ${ }^{6} 20 \%$ of pharmaceutical small molecule drugs, and ca. $30 \%$ of all the active compounds in agrochemistry, ${ }^{7}$

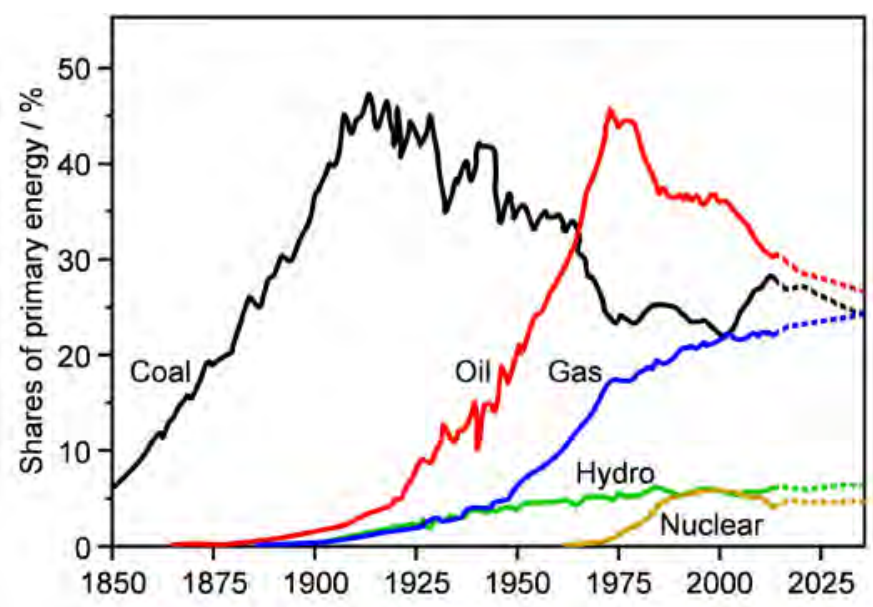

Figure 1. Evolution of primary sources for energy and feedstocks for chemical industry with projections (dashed line) until 2035. Adapted from refs 2,3. 


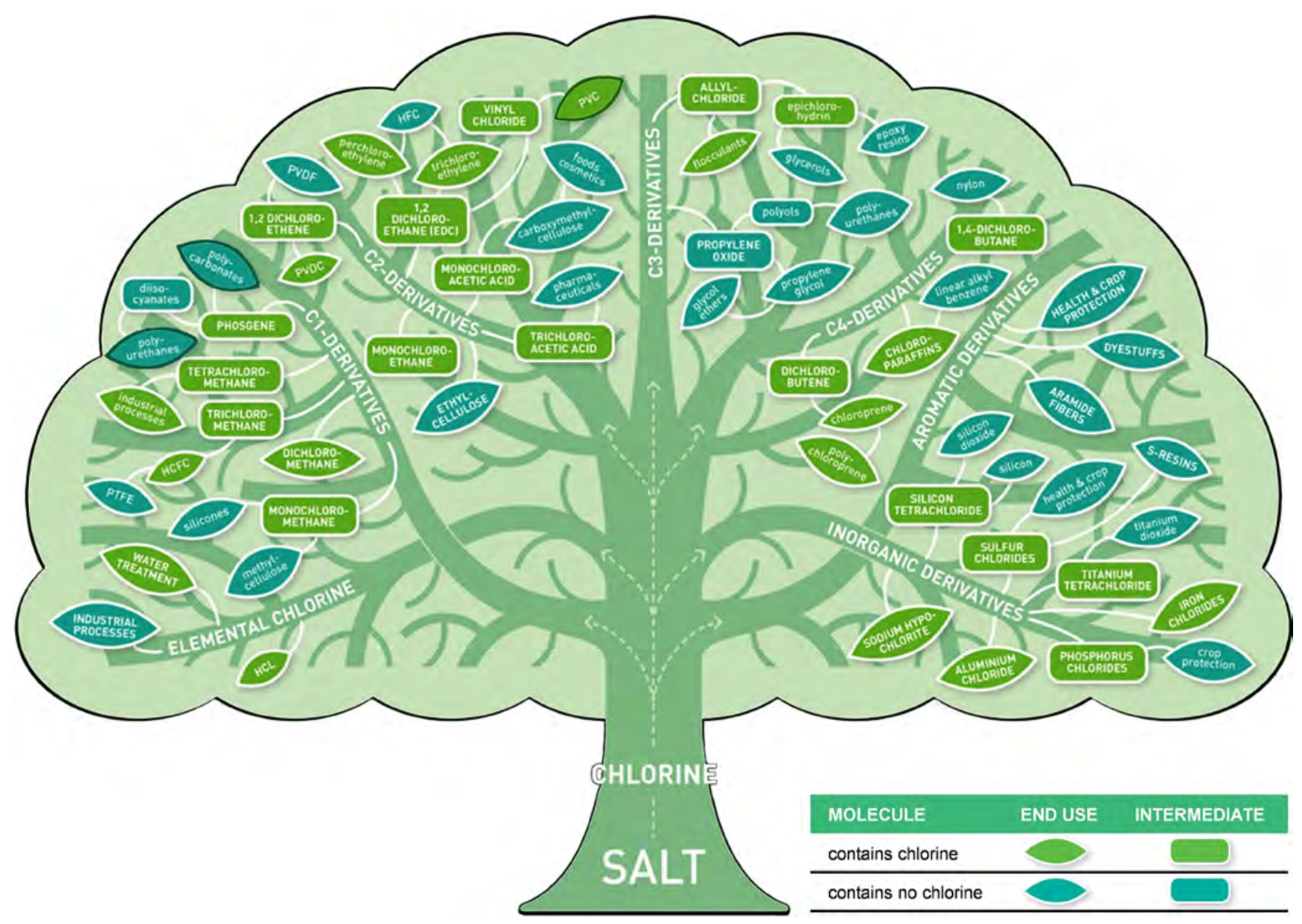

Figure 2. The chlorine tree highlights the range of products produced from chlorine. Reproduced with permission from ref 5. Copyright Euro Chlor.

depend on chlorine chemistry. Consequently, the production of this key building block of modern chemical industry has witnessed a strong growth from 18 Mton in 1965 to 75 Mton in recent times. ${ }^{8,9}$ The major application of chlorine is associated with polymer industry (polyvinyl chloride - PVC, polyurethanes - PU, and polycarbonates - PC), which accounts for $57 \%$ of the overall $\mathrm{Cl}_{2}$ demand worldwide (Figure 3). ${ }^{10}$ Bromine is the second most widely used halogen (0.8 Mton per annum), being largely applied in the manufacture of flame retardants and drilling fluids. ${ }^{11}$ The demands for both fluorine and iodine are less than 0.03 Mton per annum. Fluorine is predominantly consumed in the manufacture of $\mathrm{UF}_{6}$ and $\mathrm{SF}_{6},{ }^{12}$ while iodine is extensively employed in pharmaceuticals, contrast agent in medical imaging, and as catalyst. ${ }^{13}$ The differences in the applications of each halogen, as also reflected in their global demands, can be partly attributed to their different chemical properties. 


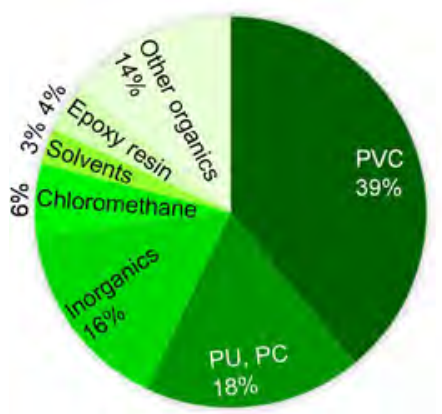

$\mathrm{Cl}_{2}, 75 \mathrm{Mton}$ per annum

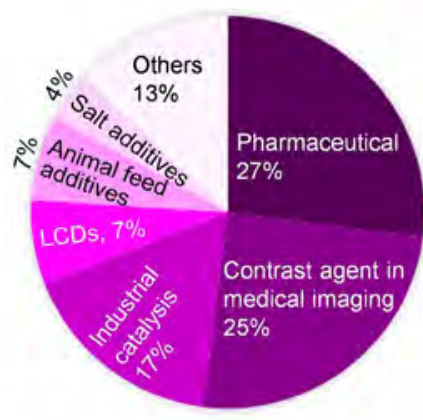

$\mathrm{I}_{2}, 0.027$ Mton per annum

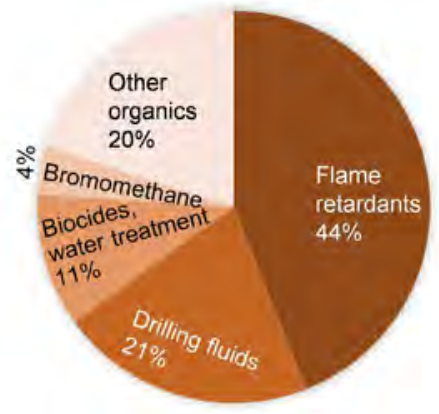

$\mathrm{Br}_{2}, 0.8$ Mton per annum

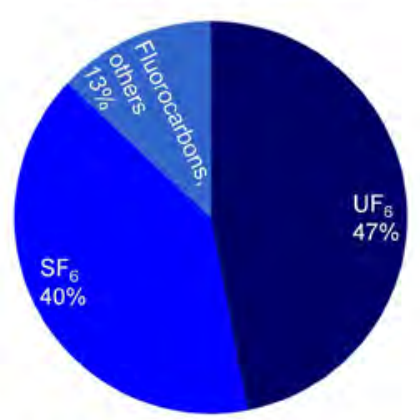

$F_{2}, 0.02$ Mton per annum

Figure 3. Production and applications of halogens in various sectors. Data for $\mathrm{Cl}_{2}, \mathrm{Br}_{2}, \mathrm{I}_{2}$, and $\mathrm{F}_{2}$ taken from refs $10,11,13$, and 12, respectively.

Halogen chemistry, in a broad sense, encompasses the reaction of halogens or halides with a substrate leading to intermediate compounds that are readily converted to commodities. The reactivity of halogens in these transformations is largely determined by the valence electrons in the outermost electron shell. Belonging to the same group in the periodic table, the general electronic configuration of halogens can be presented as $n s^{2} n p^{5}$. The potential to hold one more electron in a $p$ orbital makes them strong oxidizers, the reactivity of which weakening in the order of $\mathrm{F}>\mathrm{Cl}>\mathrm{Br}>\mathrm{I}$, with the increasing bond length between $\mathrm{X}-\mathrm{X}$ (X represents a halogen atom). Thanks to this key aspect of halogens, the electron affinity for the hydrogen atom is pronounced, ${ }^{14}$ rendering them ideal "mediators" in the functionalization of various hydrocarbon molecules. The term "mediator” is exclusively used hereafter for "halogen” or "halogen-containing compounds" employed in hydrocarbon functionalization as they can be recovered after reaction and reused. The section below provides a chronological overview on the catalyst and process developments in halogen chemistry. 


\subsection{Chronology of Halogen-Mediated Processes}

The halogen-mediated routes are not new and since the discovery of halogens in the late $18^{\text {th }}$ and early $19^{\text {th }}$ centuries, they are constantly employed in the industrial manufacture. Thus, it is interesting to examine the key milestones leading to a foundational basis for the current research activities in the field of hydrocarbon upgrading. The chronological developments of halogen-related discoveries and largescale manufacturing technologies are summarized in the timeline presented in Figure 4. Chlorine represents the first halogen discovered in the lab by Carl Wilhelm Scheele in 1774 by heating pyrolusite ( $\mathrm{MnO}_{2}$-based mineral) with $\mathrm{HCl} .{ }^{15}$ However, its industrial production was realized a century after when Henry Deacon and Ferdinand Hunter discovered a catalytic process in the 1870s for $\mathrm{HCl}$ oxidation to $\mathrm{Cl}_{2},{ }^{16}$ which was superseded by electrochemical route in 1920 s. ${ }^{17,18}$ The latter was in fact discovered by William Cruickshank as early as 1800 but implemented only with the development of suitable generators by Siemens and by Acheson and Castner in 1892. The manufacture of iodine, the second discovered halogen, followed a decade after its identification in 1811 by Bernard Courtois, ${ }^{19}$ while those of bromine (1826, Carl Jacob Löwig and Antoine Jérôme Balard) ${ }^{20}$ and fluorine (1886, Henri Moissan) ${ }^{21}$ took more than five decades after their discoveries (Figure 4). The Leblanc process, named after the French chemist Nicolas Leblanc, was developed in 1791 that represents the first halogen-aided industrial process utilizing sodium chloride to produce sodium sulfate. ${ }^{22}$ However, the pivotal role of halogens in chemical industry was realized with the commercialization of chlorine production processes, which lays a solid foundation for the extensive exploration for their applications. This is especially exemplified in the development of several polymer industries that are heavily relying on chlorine. As one of the oldest synthetic materials, PVC has been accidentally discovered from the exposure of vinyl chloride monomer (VCM) to light by Henri Victor in $1838 .{ }^{23}$ However, it has not received importance until 1912 when Fritz Klatte found the basis for the synthesis of VCM by the hydrochlorination of acetylene in the presence of a metal chloride catalyst. ${ }^{24}$ Since then, increasingly recognized applications of PVC have been found following the commercialization of the technology in 


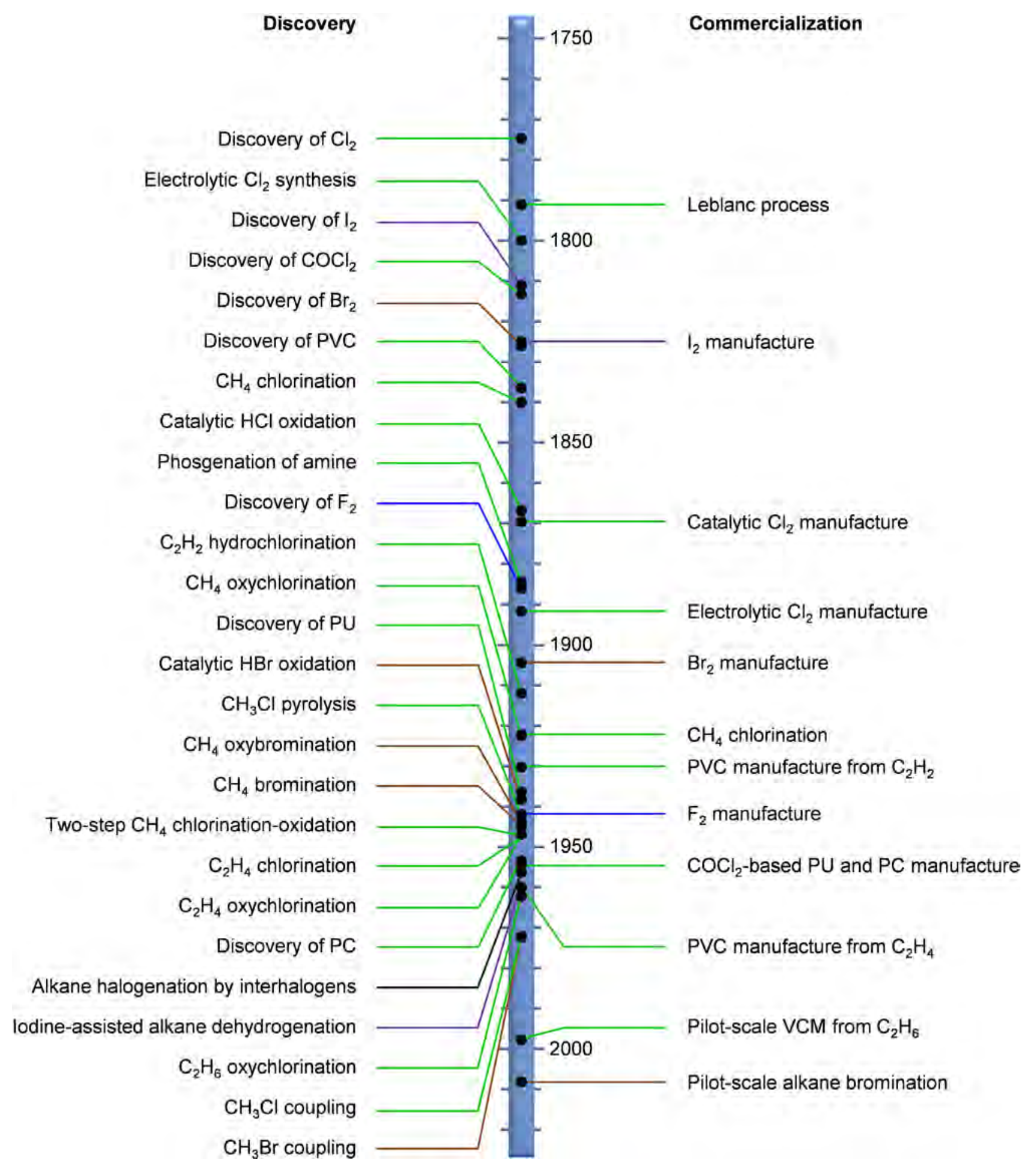

Figure 4. Chronological development of halogen-mediated processes (left) and their implementation in industry (right) for hydrocarbon conversion to commodities. Events associated with fluorine, chlorine, bromine, and iodine are represented by blue, green, brown, and purple lines, respectively. Black lines display processes involving interhalogen compounds (i.e. $\mathrm{BrCl}$ or $\mathrm{ICl}$ ).

the 1930s. ${ }^{25}$ With the huge boost of petrochemical industry in the 1950s, cheap ethylene became available. Consequently, the pure acetylene-based route for PVC production was gradually shifted to the 
balanced ethylene-acetylene process, and later to the modern "balanced process" relying fully on ethylene since the mid-1960s. ${ }^{26}$ The desire of capitalizing on even low-cost natural gas resource stimulated great interest on the one-step VCM synthesis via ethane oxychlorination after the late 1960s, ${ }^{27,28}$ which ultimately culminated with a pilot project in Germany by EVC (now INEOS) in 1999. ${ }^{29}$ In the meantime, PU and PC have been commercially manufactured by Bayer using phosgene chemistry around the mid-1950s. ${ }^{30,31}$ On the other hand, halogen-mediated functionalization of hydrocarbons to chemical and fuels has a long history. The first gas-phase halogenation, more precisely chlorination, of an alkane dates back more than 150 years. Jean-Baptiste Dumas first synthesized tetrachloromethane by the chlorination of marsh gas (consisting predominantly of methane) in 1840 and is often credited for the discovery of the gas-phase halogenation of alkanes. ${ }^{32-34}$ Berthelot isolated methyl chloride from the above process in $1858,{ }^{32}$ which can be readily hydrolyzed to methanol and thus providing an opportunity to utilize methane as a feedstock for chemicals and fuels. Accordingly, companies such as Roessler \& Hasslacher and Hoechst patented the process. ${ }^{35,36}$ A commercial facility for methane chlorination was first started by Farbwerke Hoechst in $1923 .^{32,36}$ However, the contemporary development of high-pressure methanol synthesis from syngas diverted the focus of methane activation from gas-phase chlorination. ${ }^{37}$ The basic difficulty associated with direct gas-phase chlorination is the underutilization of chlorine $-50 \%$ of the $\mathrm{Cl}_{2}$ used is reduced as $\mathrm{HCl}$ byproduct which did not have a stable market by then. ${ }^{38}$ This stimulated a search for new chemistry and in the late 1920 s resulted in the demonstration of a reaction (later known as oxychlorination) of hydrocarbons with $\mathrm{HCl}$ and $\mathrm{O}_{2}$ in the presence of heterogeneous catalysts based principally on copper and iron chlorides, ${ }^{39,40}$ which allowed to use chlorine with $100 \%$ atom efficiency. These processes however were associated with methane combustion and incomplete hydrogen chloride conversion. ${ }^{38}$ This is substantiated by performing the process in two steps: (i) chlorination of hydrocarbons by copper chloride, employed as the chlorinating agent, and (ii) regeneration of the reduced copper chloride by reacting with $\mathrm{HCl}$ and $\mathrm{O}_{2}$ or air. ${ }^{38,41,42}$ Although the process was claimed to be very effective for selective halogenation of hydrocarbons, the commercialization was not reached. Interest in the single-stage halogenation and 
oxyhalogenation continued owing to the simplicity of operation. ${ }^{38,43}$ Since the 1960 s, several new concepts and processes have emerged, including halogen-mediated alkane dehydrogenation, ${ }^{44-46}$ halogenation of alkanes by interhalogen compounds, ${ }^{47-49}$ zeolite-catalyzed coupling of methyl halides $\left(\mathrm{CH}_{3} \mathrm{X}\right)$ to higher hydrocarbons, ${ }^{50,51}$ high-temperature pyrolysis of methyl halides to chemicals, ${ }^{52}$ superacid-aided selective alkane halogenation, ${ }^{53,54} \mathrm{FeBr}_{3}$-base methane-to-methanol, ${ }^{55}$ and integrated bromine-mediated light alkane transformation to chemicals and fuels. ${ }^{56,57}$ Catalyzed oxybromination of light alkanes regained much research interest in recent years. ${ }^{58-62}$ Among these, only the bromine-aided upgrading process was demonstrated at a pilot scale. ${ }^{63,64}$ It should be emphasized that the implementation of a halogen-mediated process relies on a number of factors, such as the availability and efficiency of utilization of feedstocks, halogen recycling technologies, management of corrosion issues, etc. The renaissance in this well-known area could be ascribed to the recent developments in the abovementioned field.

\subsection{Scope of the Review}

Since halogen-mediated routes are very relevant in the industrial manufacture of an array of valuable products and offer exceptional potential to capitalize on emerging vast natural gas reserves, we aim to provide the reader with a complete overview of the catalytic processes and reaction chemistry developed so far, with possible directions for future developments. First, we will introduce the progress made in commercial polymer (PVC, PU, and PC) manufacture technologies through halogen chemistry considering catalysts, reactors, and process aspects. The focus will be placed on understanding the structure-function relationships and the stability aspects of the catalysts. Next, we will discuss the halogen-mediated functionalization of light alkanes, covering direct halogenation, oxyhalogenation, and halogen-assisted dehydrogenation with related catalysts, mechanisms, and processes. The catalytic chlorine and bromine recycling technologies, which are highly relevant in the polymer manufacture and natural gas valorization, will also be discussed in Sections 2 and 3, respectively. Finally, we will examine the advances in the transformation of alkyl halides i.e. functionalized alkanes in the previous step, to commodities with emphasis on differences and parallels with respect to methanol-to- 
hydrocarbons (MTH), catalysts, and mechanisms. We will also devote a subsection to the hazards and safe handling of halogen-containing compounds. To the best of our knowledge, no such comprehensive review of the topic has emerged during the last two decades. These processes have been only briefly alluded in previous reviews focusing on methane activation. For example, Engloff et al. wrote a review in 1931 on processes for the halogenation of hydrocarbons. ${ }^{65}$ A review article by Treger et al. published in 1988 targeted the oxidative chlorination of aliphatic hydrocarbons $\left(\mathrm{C}_{1}-\mathrm{C}_{3}\right)$ on copper chloride-based catalysts, covering thermodynamics, kinetics, catalysts, and briefly the reactors. ${ }^{66} \mathrm{~A}$ recent review of Over in 2012, concentrating on surface chemistry of $\mathrm{RuO}_{2}$ in heterogeneous catalysis and electrocatalysis, has a concise section on $\mathrm{HCl}$ oxidation. ${ }^{67}$ Olsbye et al. in 2012 reviewed the MTH process emphasizing zeolite's topology on product selectivity, with brief attention on methyl halides conversion. ${ }^{68}$ Other two reviews by Guo et al. (2014), ${ }^{69}$ and Horn and Schlögl (2015) ${ }^{70}$ on heterogeneous selective oxidation catalysis for alkanes, CO, and alcohols conversions and catalytic methane activation, respectively, discussed the concept of halogen-mediated activation with limited details. A more recent perspective article by Gascon et al. (2016) analyzed the mechanistic aspects of direct methane activation with emphasis on both the $\mathrm{C}-\mathrm{H}$ bond cleavage and oxidant activation on heterogeneous catalysts, with only a short discussion on the halogenation route. ${ }^{71}$

\section{HALOGEN CHEMISTRY IN POLYMER MANUFACTURE}

Synthetic polymers came into prominence in the early $20^{\text {th }}$ century and nowadays they are playing important roles in almost every aspect of our modern life. Halogen chemistry is crucial in the manufacture of different polymers, such as PVC, polytetrafluoroethylene, PU, and PC. PVC is a representative example where chlorine is consumed and ends up in the product. Among plastics, PVC ranks number three in terms of global production after polyethylene and polypropylene. ${ }^{72}$ Owing to its excellent properties such as light weight and chemical resistance, PVC is widely used in construction, piping, and many other industries. Thanks to its versatility, the PVC demand reached 43.6 Mton in 2015 (Figure 5), and is expected to grow with an annual rate of $3.2 \%$ in the future. ${ }^{73} \mathrm{PU}$ and PC are the most 


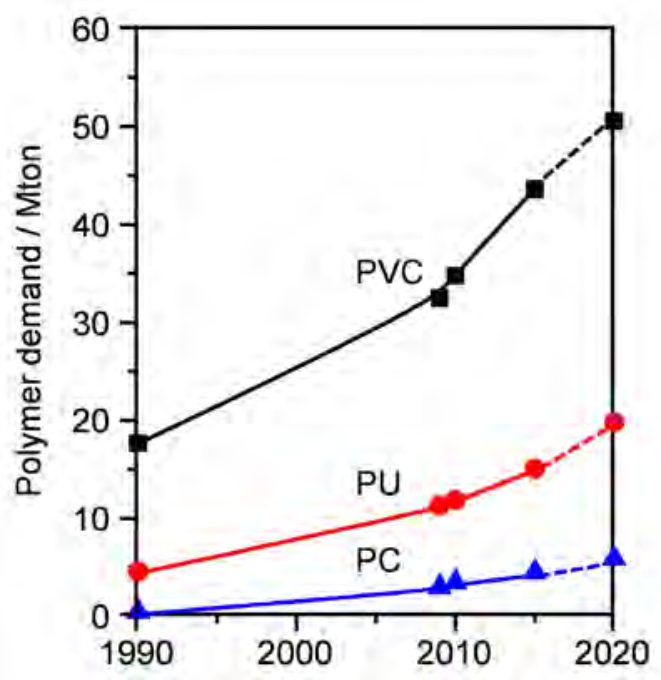

Figure 5. The annual global demand of PVC, PU, and PC with projections (dashed line) up to 2020. Data taken from refs $72,74,75$.

representative chlorine-free end materials obtained using chlorine chemistry. They possess unique characteristics, such as good tensile strength and high impact-resistance, making them useful in fastgrowing sectors like construction, transportation, electronics, etc. and thus, leading to fast annual growth rates (6.3\% for PU and 6.2\% for PC) than that of PVC. ${ }^{72,74,75}$

The synthesis of PVC is achieved by the polymerization of VCM, a chemical intermediate manufactured predominantly for the purpose of PVC. Processes and chemistry for the production of VCM vary according to the feedstocks and catalysts (Figure 6). An industrial VCM production originally started in the 1920 s through acetylene hydrochlorination over mercuric chloride catalysts, ${ }^{76}$ which is still used in countries, such as China, where acetylene can be obtained cost-effectively from abundant coal. However, the increasing demand of PVC and rising prices of acetylene coupled to the toxicity of mercury-based catalysts prompted a shift of feedstock in 1950s to more economic ethylene from petroleum in Europe and the U.S. ${ }^{77}$ This resulted in the development of a new alternative route for VCM manufacture, entailing ethylene chlorination to ethylene dichloride (EDC) followed by the thermal cracking of EDC to VCM. Acetylene was still used to make the chlorine balance by recycling $\mathrm{HCl}$ from the cracking step to the hydrochlorination unit. The first breakthrough in VCM manufacture 


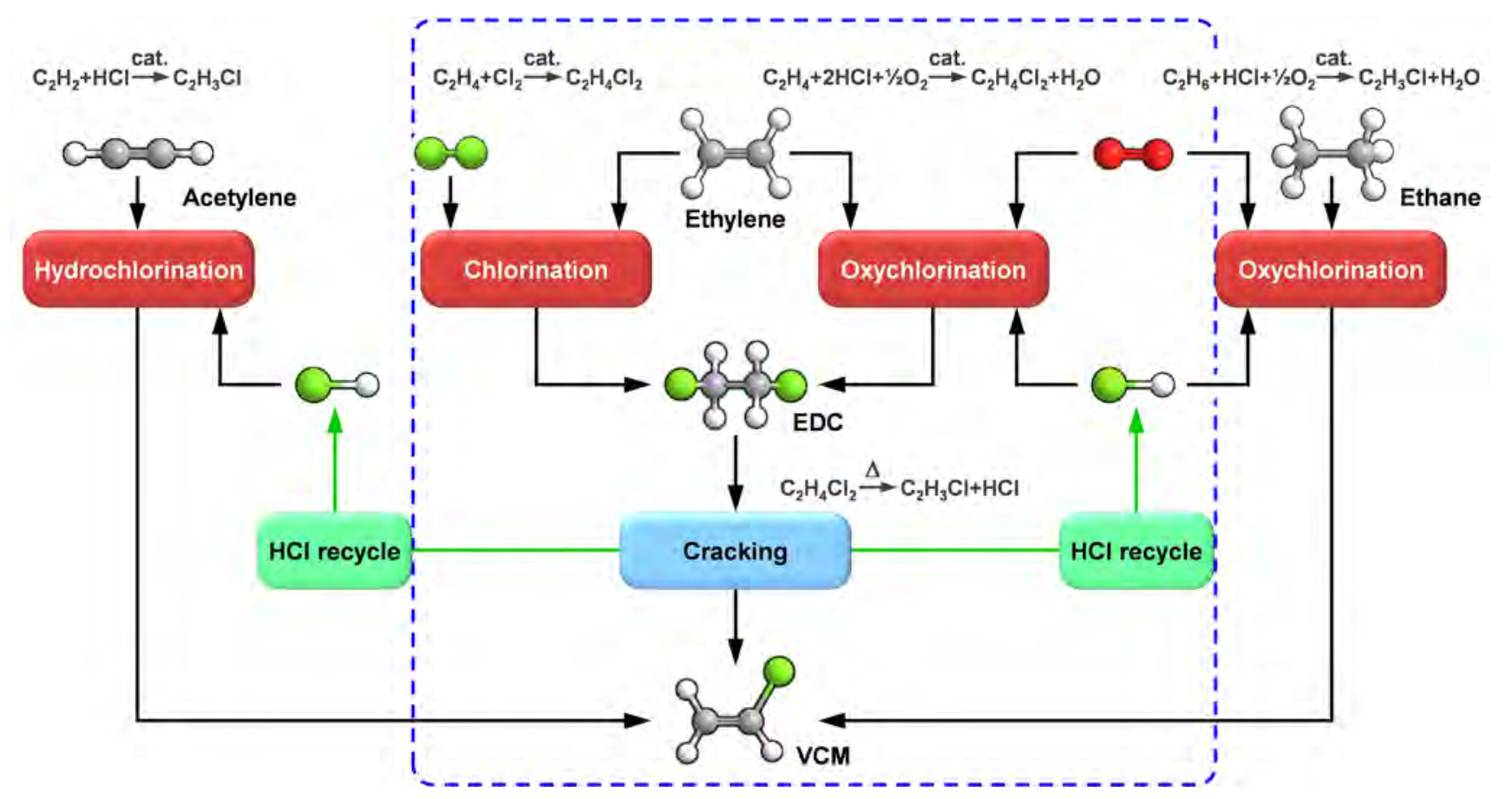

Figure 6. Production of vinyl chloride from acetylene, ethylene, and ethane via hydrochlorination, chlorination, or oxychlorination.

was achieved with the establishment of the modern "balanced process" (Figure 6, dashed box), which includes ethylene chlorination and oxychlorination. The latter process involves the reaction of ethylene with $\mathrm{O}_{2}$ and the $\mathrm{HCl}$ byproduct of the cracking step to produce EDC and thus close the chlorine loop in VCM manufacture from ethylene. Today, more than $90 \%$ of the vinyl chloride produced in the western world is exclusively based on the ethylene route encompassing balanced process. With the incentive of further economizing the PVC production, industry has undertaken considerable efforts to replace ethylene by ethane as the key feedstock and to obtain VCM by oxychlorination of ethane in one step and thus to bypass the EDC cracking step. ${ }^{27,78}$

The current production of PU and PC is based on the use of phosgene. PU was originally synthesized from aliphatic diisocyanate and diamine forming polyuria, till interesting properties of PU obtained from diisocyanate and glycol were discovered. The commercial scale production of PU however was realized using toluene diisocyanate (TDI) and polyester polyols, where the precursor TDI is obtained by the reaction of toluene diamine and phosgene. ${ }^{31}$ The original method to prepare PC was 
based on the transesterification of bisphenol A monomer with diphenyl carbonate. ${ }^{79}$ This process was later surpassed by the polymerization of bisphenol A with phosgene, a modernized route for the manufacture of PC.

In pursuit of way from acetylene to ethane as a feedstock for PVC and establishment of PU and PC manufacturing technologies, several improvements in terms of process chemistries, catalysts, and reactors have been achieved. These aspects are tackled herein chronologically first for PVC followed by PU and PC business, with special attention paid to the catalyst developments in each case. The chlorine recycling technologies, which are key in PU and PC manufactures, based on catalytic oxidation of hydrogen chloride to molecular chlorine are also discussed.

\subsection{Acetylene Hydrochlorination for VCM Production}

The acetylene hydrochlorination process based on mercuric chloride catalysts still holds importance in the developing countries having abundant coal but a shortage of oil and gas, e.g., China, where $80 \%$ of VCM is produced from acetylene. ${ }^{80}$ The low-cost and good activity of the catalyst make this process still attractive. However, the toxicity of mercury and stringent government policies for the use of such materials triggered scientists to hunt for alternative catalytic technologies, which resulted in the identification of interesting catalyst families based on gold, ruthenium, bismuth, copper, and carbonbesd materials. ${ }^{81-85}$ These developments are recently reviewed by Hutchings et al., ${ }^{86}$ presenting a comprehensive overview on the gold-based catalysts, and Dai et al., ${ }^{87}$ discussing the development of non-mercury catalysts. Therefore, key aspects, such as catalyst design criteria, synthesis, mechanism, deactivation, and pilot evaluations of important systems are discussed in the following sections.

2.1.1. Mercuric Chloride-Based Catalysts. The current acetylene-based industrial process for the manufacture of VCM is catalyzed by activated carbon (AC) supported mercuric chloride, typically operated at $373-433 \mathrm{~K}$ and $1-2$ bar. $^{88}$ The preparation of the catalysts includes impregnation of the support with an aqueous solution of metal precursor to obtain a high $\mathrm{HgCl}_{2}$ loading of $10-15$ wt.\%. ${ }^{87}$ The choice of high surface area AC carrier was based on: (i) its robustness under the harsh conditions of hydrochlorination, (ii) the attainment of high dispersion of active components, and (iii) the plausible 
strong metal-support interaction leading to enhanced catalyst stability. ${ }^{89}$ The mechanism of acetylene hydrochlorination over $\mathrm{HgCl}_{2} / \mathrm{AC}$ based on kinetic studied remains controversial. ${ }^{90-94}$ Wesselhoft et al . proposed that a Langmuir-Hinshelwood (L-H) rate expression gave the best fit of the experimental results from a differential reactor, assuming that acetylene and $\mathrm{HCl}$ were adsorbed at different sites and the formation of VCM from the two adsorbed molecules was the rate-determining step. ${ }^{90}$ Bremer and Lieske argued that the previous kinetic models cannot explain well their results from a differential circulation flow reactor. They concluded an Eley-Rideal (E-R) mechanism with a more complicated model including at least two parallel partial reactions on the presumed active sites of $\mathrm{HgCl}_{2}, \mathrm{HgCl}_{2} \cdot \mathrm{HCl}$, and $\mathrm{HgCl}_{2} \cdot 2 \mathrm{HCl}^{93}$ Agnew and coworkers assessed the steady-state and transient kinetic data from continuous stirred-tank reactor in a wide temperature range of 348-513 K. ${ }^{91,94}$ They found that while the low-temperature results fitted well with the previous kinetic models, there is an abrupt change of slope at $c a .413 \mathrm{~K}$ for the Arrhenius plot in both studies. These deviations cannot be ascribed to catalyst deactivation encountered at elevated temperature as the authors claimed the decay has been corrected. ${ }^{94}$ Comparing the parameter values of an L-H model at different temperatures reveals significant decrease in the equilibrium constant of acetylene adsorption above $453 \mathrm{~K}$. This indicates the acetylene surface coverage becomes much lower at high temperatures. Therefore, the reaction appears to proceed by collision between the adsorbed $\mathrm{HCl}$ and the gas-phase acetylene i.e. E-R mechanism prevails in this case.

Albeit industrially used for several decades, the $\mathrm{HgCl}_{2}$-catalyzed hydrochlorination reaction suffers from a number of major drawbacks including the pulverization of AC, catalyst deactivation due to the leaching of active components, and the toxicity of mercury. ${ }^{86,87}$ Besides, the reaction is highly exothermic. Insufficient heat removal can lead to hot spots of $140-200 \mathrm{~K}$ in a commercial reactor, which causes the volatilization of $\mathrm{HgCl}_{2}$ and consequently the catalyst deactivation. ${ }^{91}$ The statistics from China shows that the manufacture of 1 ton of PVC requires $1.02-1.41 \mathrm{~kg}$ of $\mathrm{HgCl}_{2}$ catalyst (10-15 wt.\% $\mathrm{HgCl}_{2}$ loading), a quarter of which is not possible to recycle. ${ }^{95}$ This issue, to some extent, can be alleviated with the usage of low-mercury catalyst with different metal promoters, and appropriate process 
engineering such as absorbing the lost mercury with AC. ${ }^{80,96}$ However, the potential harms of the heavy metal pollution and toxicity are not eliminated. Thus, developing non-mercury catalysts is the only way for a sustainable application of the acetylene route.

2.1.2. Gold-Based Catalysts. Discovery. Screening of non-mercury catalysts and the identification of descriptors for a good hydrochlorination catalyst have been the major objectives in the early research activities since the 1960s. ${ }^{97-100}$ Smith et al. studied the adsorption of acetylene and its hydrochlorination over silica-supported metal chlorides catalysts with divalent cations. ${ }^{97}$ They observed bigger shifts of the adsorption bands of propyne $-\mathrm{C} \equiv \mathrm{C}-$ and acetylene $\equiv \mathrm{C}-\mathrm{H}$ vibrations to lower frequencies with increasing electron affinity of the metal cations. The first correlation between the electron affinity and activity was reported by Shinoda based on the screening of thirty metal chlorides supported on AC (Figure 7a). ${ }^{98}$ The data were fitted with two opposite trends: (i) increase of acetylene conversion with electron affinity, and (ii) drop of acetylene conversion with electron affinity over metal chlorides of Friedel-Crafts type catalysts. Thus, electron affinity seems to be not able to predict an appropriate catalyst formulation, which might be due to the mismatch of electrons between electron affinity (oneelectron addition) and the hydrochlorination reaction (two-electron addition). Using this hint, Hutchings proposed a new correlation between the standard electrode potential of cations involving two-electron addition (e.g. $\mathrm{M}^{2+}+2 \mathrm{e}^{-} \rightarrow \mathrm{M}$ and $\mathrm{M}^{3+}+2 \mathrm{e}^{-} \rightarrow \mathrm{M}^{+}$) and the hydrochlorination activity (Figure $7 \mathrm{~b}$ ), ${ }^{99}$ which suggests that the higher the standard electrode potential of a metal cation, the higher will be its hydrochlorination activity. Thus, gold with its highest standard electrode potential would lead to the highest hydrochlorination rate. This prediction was later experimentally proved to be viable (Figure 7c). However, considering the empirical nature of this correlation, the standard electrode potential should be used cautiously to predict a good acetylene hydrochlorination catalyst.

Hydrochlorination Mechanism. The reaction mechanism over gold catalysts has been probed by replacing symmetric $\mathrm{C}_{2} \mathrm{H}_{2}$ molecules with longer-chain alkynes such as hex-1-yne and ethynylbenzene. ${ }^{101}$ It was found that both reactions gave high selectivity to the Markovnikov products. 

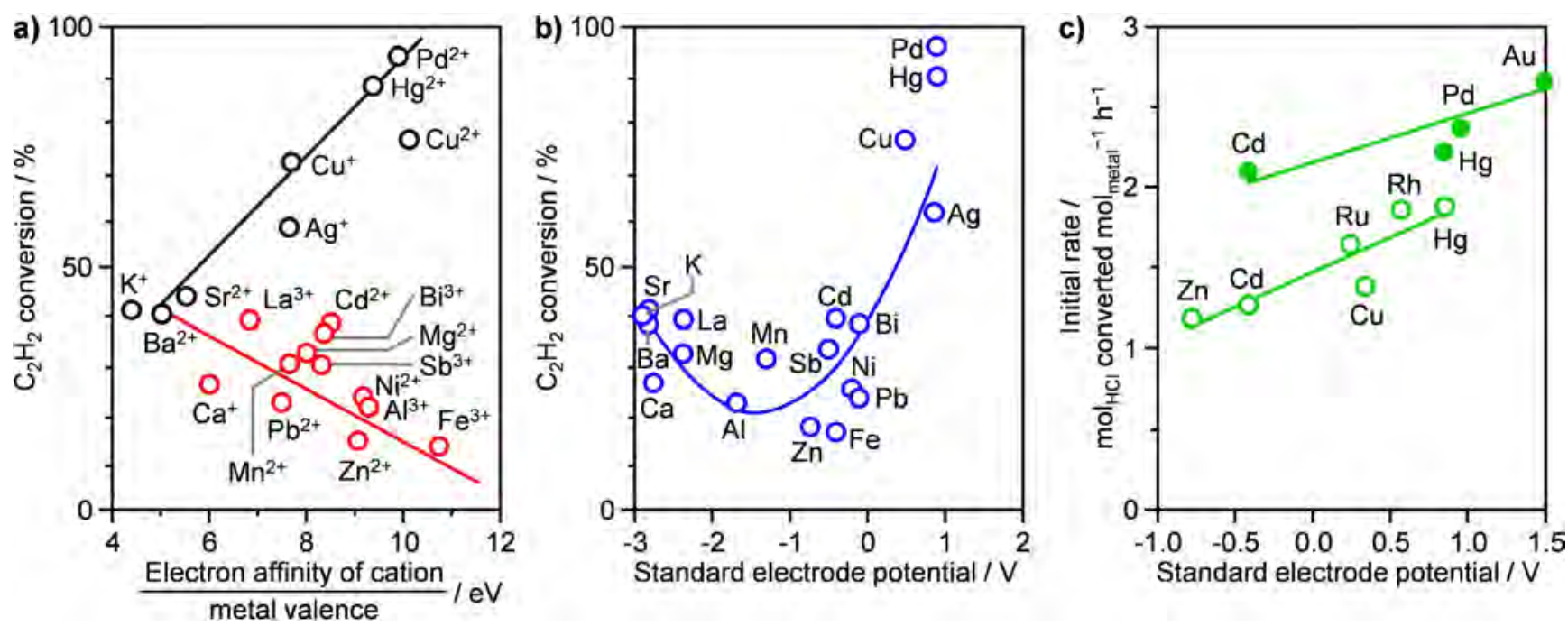

Figure 7. Correlation of the activity of activated carbon supported metal chlorides: a) with the electron affinity of the metal cation divided by corresponding metal valence, reproduced with permission from ref 98. Copyright 1975 the Chemical Society of Japan, and $\mathbf{b , c}$ ) with the standard electrode potential for the reaction $\mathrm{M}^{2+}+2 \mathrm{e}^{-} \rightarrow \mathrm{M}$ and for $\mathrm{M}^{3+}+2 \mathrm{e}^{-} \rightarrow \mathrm{M}^{+}$. Reproduced with permissions from refs 99,100.

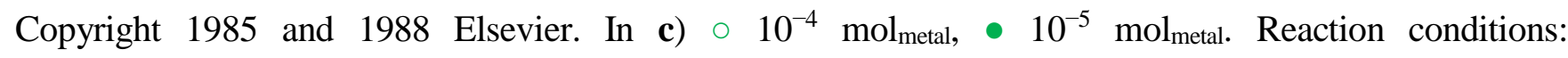
$\mathrm{C}_{2} \mathrm{H}_{2}: \mathrm{HCl}=1: 1.1$, gas hourly space velocity $(\mathrm{GHSV})=1080 \mathrm{~h}^{-1}, T=453 \mathrm{~K}$.

The stereochemistry of acetylene hydrochlorination over $\mathrm{Au} / \mathrm{AC}$ catalyst was further confirmed by density functional theory (DFT) calculations. ${ }^{101}$ It is suggested that $\mathrm{HCl}$ adds in an anti configuration to the alkyne, following the Markovnikov rule. The size of gold clusters has been found to affect the position of the active sites, namely the active sites could be at the top (in the $\mathrm{Au}_{4,6,8,9}$ clusters) or bridge sites (in the $\mathrm{Au}_{3,5,7,10}$ clusters) depending on the number of gold atoms in the cluster. ${ }^{102}$ In either case, the gold catalysts act as a bridge for electron transfer from the highest occupied molecular orbital (HOMO) $\mathrm{Au}_{n}-\mathrm{C}_{2} \mathrm{H}_{2}$ complexes to the lowest unoccupied molecular orbital (LUMO) of $\mathrm{HCl}$. It should be noted that these conclusions were derived from neutral gold clusters while it was suggested that the most active catalysts contain gold cations. Hutchings et al. inferred that the redox pair of $\mathrm{Au}^{3+}$ and $\mathrm{Au}^{+}$ could be responsible for the activation of $\mathrm{HCl}$ and $\mathrm{C}_{2} \mathrm{H}_{2}$ molecules, respectively, which also explains the correlation between the catalyst activity and the standard electrode potential. ${ }^{86}$

Deactivation and Regeneration. Although $\mathrm{AuCl}_{3} / \mathrm{AC}$ showed the highest initial activity, the biggest drawback hindering its large-scale commercialization is the inadequate long-term stability at a 
minimal Au loading. This is generally caused by a combination of several factors. Among these, the reduction of $\mathrm{Au}^{3+}$ or $\mathrm{Au}^{+}$to $\mathrm{Au}^{0}$ was suggested to be the main reason for the deactivation. ${ }^{103}$ Another reason could be the aggregation of gold clusters, as it is well known that the gold catalysis is closely associated with the particle size. Both the reduction of gold cations and the growth in particle size have been observed in the deactivated catalysts indeed. ${ }^{104,105}$ Hutchings et al. suggested that the size effect might not contribute significantly to the overall catalyst deactivation since the mean size only increased moderately while the surface $\mathrm{Au}^{3+}$ was almost totally reduced to metallic Au (Figures 8a,b). ${ }^{101}$ It could also be possible that metallic gold nanoparticles are more prone to aggregation. The deposition of carbonaceous residuals has been occasionally identified in the spent catalysts. ${ }^{103,106}$ Acetylene polymerization at strong acid sites generated by aqua regia treatment can lead to the formation of carbon-containing nanotubes. ${ }^{107}$ As a consequence, the catalysts need to be regenerated so as to recover the activity. A treatment of the spent catalysts with aqua regia can reoxidize $\mathrm{Au}^{0}$ to $\mathrm{Au}^{3+}$ and fully restore the activity. ${ }^{108}$ Recently, Yuan et al. reported a new method by using iodohydrocarbon as the medium for ex situ catalyst regeneration. ${ }^{104}$ This treatment not only reoxidized $\mathrm{Au}^{0}$ but also led to redispersion of the gold particles in a controllable way, both accounting for the restored activity in five consecutive runs. Alternatively, the regeneration can be attained during the process by introducing strong oxidants. For instance, coke residuals can be removed by flowing air, whereas $\mathrm{Cl}_{2}, \mathrm{NO}$, and $\mathrm{N}_{2} \mathrm{O}$ can oxidize $\mathrm{Au}^{0}$ to $\mathrm{Au}^{+}$and $\mathrm{Au}^{3+} \cdot 85$

Preparation. The performance of gold-based catalysts has been shown to be greatly affected by the way they are prepared. It was found that the catalysts synthesized in water or dilute acid solvents were less active than those obtained using aqua regia, which enabled to maintain the ionic forms of gold species during the impregnation step. ${ }^{107}$ This finding clearly demonstrates the importance of stabilizing gold cations during the preparation. Ideally, the use of environmentally benign solvents such as waterwould be a better choice for the scale up purpose. This seemingly simple solution has been realized only recently which includes the addition of different ligands containing soft donor atoms 
a)
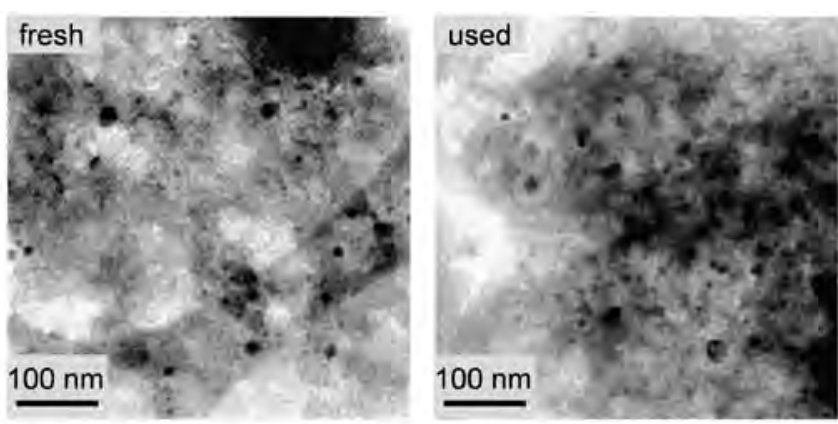

b)
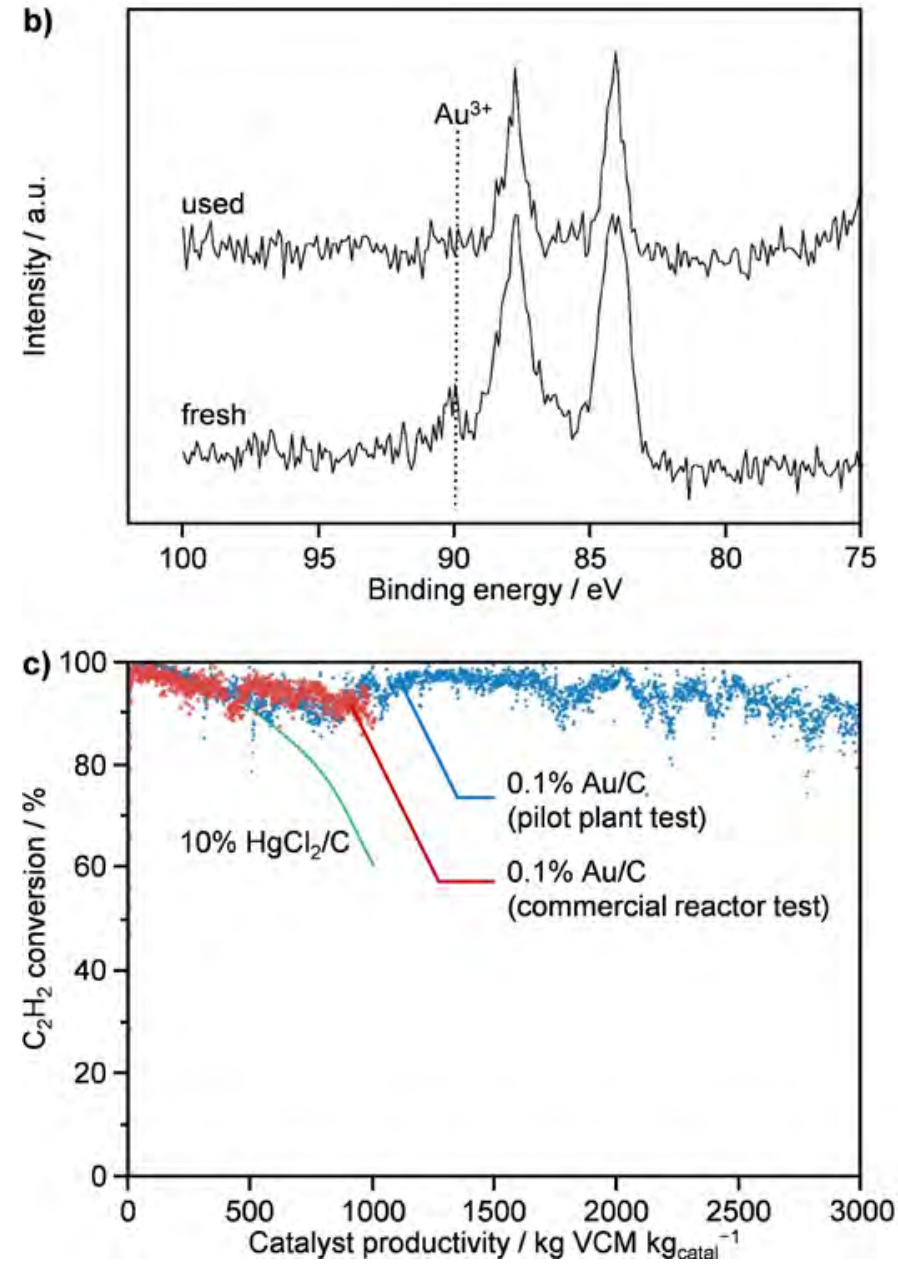

Figure 8. a) Transmission electron microscopy (TEM) and b) X-ray photoelectron spectroscopy (XPS) of fresh and used $\mathrm{Au} / \mathrm{C}$ catalysts. Reproduced with permission from ref 101. Copyright 2007 Elsevier. c) Comparison of $\mathrm{HgCl}_{2} / \mathrm{C}$ performance in primary reaction with that of $0.1 \% \mathrm{Au} / \mathrm{C}$ in pilot plant operation and in full commercial reactor. Reproduced with permission from ref 86. Copyright 2015 American Chemical Society. Au/C was prepared by supporting $\mathrm{Na}_{3} \mathrm{Au}\left(\mathrm{S}_{2} \mathrm{O}_{3}\right)_{2}$ on carbon extrudates.

(cyanides, thiourea, thiosulfate, thiocyanate, etc.) in the impregnation step. ${ }^{109}$ The suitable ligands with high stability constants of the resulting Au complexes are shown to be beneficial for maintaining the higher oxidation states of gold during the hydrochlorination reaction. In addition, Wei et al. found that 
the electric potential was greatly reduced for these complexes and they obviously disobeyed the correlation between activity and standard electrode potential discussed above. ${ }^{105}$ This reduced electric potential would probably weaken the interaction with $\mathrm{C}_{2} \mathrm{H}_{2}$, thus preventing the reduction of Au cations. Furthermore, modification of carbon support has also been attempted to improve the catalytic performance. For instance, N-doping on both multiwalled carbon nanotubes and AC was proved to enhance the adsorption of $\mathrm{HCl}$ and stabilize Au cations. ${ }^{110,111}$ Incorporation of phosphorous groups $\left(\mathrm{PO}_{4}{ }^{3-}\right.$ and $\left.\mathrm{PO}_{3}{ }^{-}\right)$on carbon can improve the dispersion of the active site and reduce coke deposition on catalyst surface. $^{112}$

Pilot-Scale Demonstrations. Several pilot trials have been conducted on these highly efficient catalytic entities. $^{86,105,113}$ A sulfur-containing gold catalyst ( 0.1 wt.\% Au) with $2 \mathrm{~kg}$ was loaded in a single tube reactor of $3000 \times 50 \mathrm{~mm}$ (length $\times$ diameter). ${ }^{86}$ The operation was run at the temperature range of 383$403 \mathrm{~K}$ with a feed rate of $0.6 \mathrm{~kg} \mathrm{~h}^{-1}$. Hotspots were observed with the highest temperature approaching $498 \mathrm{~K}$, and the exothermic region migrated continuously down the catalyst bed with time-on-stream. The catalyst performed for ca.18 months with stable acetylene conversion (> 85\%) and VCM selectivity (> 99\%) (Figure 8c). Another pilot trial with a 4 ton of VCM per annum scale was evaluated in a single tube fixed-bed reactor packed with $4.6 \mathrm{~L}$ of the thiocyanate-modified catalyst with $0.25 \mathrm{wt} . \%$ gold loading. ${ }^{105}$ After $3000 \mathrm{~h}$ evaluation, the acetylene conversion and VCM selectivity remained $>95 \%$ and $>99 \%$, respectively, at a GHSV of $60 \mathrm{~h}^{-1}$. Furthermore, it is found that the deactivation rate of the catalysts was relevant to the packed positions, which accelerated from the top to the bottom of the catalyst bed. This is in line with the gradual migration of hot spots along the reactor. Although no studies mentioned the loss of gold after such long-term stability test, results in a lab suggested that the leaching of gold was indistinguishable. ${ }^{103}$ These exciting results therefore represent a giant step toward the commercialization of Au-based catalysts and will pave the way to revolutionize the current acetylene hydrochlorination process.

2.1.3. Bimetallic Catalysts. Au-M Catalysts. It is well established in catalysis that the performance of a catalyst can be tuned by the addition of an auxiliary metal component, whether functioning as a 
structural and/or electronic promoters. Bimetallic gold catalysts for acetylene hydrochlorination have been studied mainly to reduce the gold content and to enhance the structural stability. The first attempt to examine the effect of a series of Au-M bimetallic catalysts ( $\mathrm{M}=\mathrm{Pd}, \mathrm{Pt}, \mathrm{Ir}, \mathrm{Ru}$, and $\mathrm{Rh}$ ) was made by Hutchings et al. ${ }^{114}$ Slightly higher activity was observed over Au-Ir and Au-Rh, while Au-Ru showed no apparent improvements, and a significant loss in the selectivity together with rapid deactivation were found over Au-Pd and Au-Pt. Therefore, they inferred that there is no synergistic effect in these bimetallic catalysts, and any improvement in the activity is possibly due to the increase in the dispersion of gold by the second metal. ${ }^{86}$ These arguments are rooted in the previously discussed activity-standard electrode potential relationships, which predicted that the monometallic gold could be among the best candidate for the hydrochlorination reaction. A decrease of standard electrode potential will occur when Au-M bimetallic system is present in a homogeneous alloy form, thus leading to a poor activity. However, this is not always the case. Wei et al. demonstrated the presence of a synergy in Au-Bi/AC, which outperformed the monometallic $\mathrm{Au} / \mathrm{AC}$ or $\mathrm{Bi} / \mathrm{AC}$ catalysts and the mechanical mixture of the two. ${ }^{95}$ They reported that the bimetallic catalyst with Bi:Au $=3(0.3 \mathrm{wt} . \% \mathrm{Au})$ can give a comparable activity to the 1 wt.\% Au counterpart (turnover frequency (TOF) ca. $3 \mathrm{~s}^{-1}$ ) and a significantly improved stability. The promotional effect of bismuth was ascribed to its ability to stabilize $\mathrm{Au}^{+}$by inhibiting the reduction to metallic Au. Besides, there are a large number of research devoted to the study of other non-noble metal promoters (Ba, Sr, Co, Cu, Sn, Ce, etc.) for Au-based catalysts. ${ }^{83,113,115-118}$ Although the synergistic effect is not clear in these systems, probably because of the use of a relatively high loading of gold (ca. 1 wt.\%), beneficial aspects in suppressing coke deposition and in stabilizing the cationic gold species were claimed which ultimately enhanced the catalyst stability.

Ru-M Catalysts. As expected from its low standard electrode potential (Figure 7c), the rutheniumbased catalysts are less active than Au/AC. ${ }^{100}$ However, a significant increase in the hydrochlorination activity of Ru catalysts was achieved they were when doped with an additive. For instance, the addition of a small amount of $\mathrm{K}$ or Co to Ru/AC (1 wt.\%) increased the conversion of acetylene and reduced the coke formation. ${ }^{119,120}$ The enhanced performance was partly attributed to the increased $\mathrm{RuO}_{2}$ species in 
the catalyst. In contrast, $\mathrm{Cu}$ doping favored $\mathrm{RuCl}_{3}$ formation, and therefore caused a decreased in the activity. ${ }^{120}$ Nonetheless, Li et al. reported Ru-Cu supported on carbon nanotubes with 400 ppm Ru as an efficient catalyst for the hydrochlorination reaction, the TOF of which was even higher than that of the $\mathrm{HgCl}_{2}$ catalyst. $^{121}$ The promotional phenomenon has not been well assessed though, likely because of the low Ru content.

Bi-Cu Catalysts. Developing efficient non-noble metal catalysts for the hydrochlorination process is demanding. Wei et al. evaluated the performance of silica-supported Bi-Cu catalysts in a fluidizedbed reactor. ${ }^{122}$ An industrial trial of a 10 ton VCM per annum scale was conducted for $700 \mathrm{~h}$ with the replenishing of catalysts after $400 \mathrm{~h}$. A stable performance in the first $200 \mathrm{~h}$ was observed under the conditions of $360 \mathrm{~h}^{-1}$ and $473 \mathrm{~K}\left(X\left(\mathrm{C}_{2} \mathrm{H}_{2}\right) \approx 80 \%, \mathrm{~S}(\mathrm{VCM})>99 \%\right)$. After that a continuous drop in activity was evidenced. The inferior stability of the catalysts can be ascribed to the severe leaching of bismuth (> 85\% Bi loss in $700 \mathrm{~h})$.

2.1.4. Process Design Aspects. The catalytic acetylene hydrochlorination can be operated either in the gas- or liquid-phase, while the gas-phase reaction is preferred in industrial manufactures. A simplified flowsheet for the VCM production via the acetylene-based route is presented in Figure $9 .{ }^{123}$ The gaseous reactants, with over stoichiometric $\mathrm{HCl}: \mathrm{C}_{2} \mathrm{H}_{2}$, are well mixed before being fed to the hydrochlorination reactor. Fixed-bed multitubular reactors are exclusively used, equipped with external cooling systems for reaction heat removal. The reaction effluent was separated in a distillation column, where the unreacted feed gases $\left(\mathrm{C}_{2} \mathrm{H}_{2}, \mathrm{HCl}\right)$ as the light ends can be recycled. Crude VCM from the bottom of the column is directed into another tower for purification. The heavies from the bottom of the second column was stripped with the underflow of a washing tower and removed for further uses or for incineration. Depending on the catalyst performance, acetylene conversions of $95-100 \%$ at almost quantitative yields can be achieved with an average space time yield (STY) of $70-80 \mathrm{~kg} \mathrm{~h}^{-1} \mathrm{~m}^{-3}$ in fixed-bed reactor systems. ${ }^{123}$ The hydrochlorination is known to be strongly exothermic with generation of hot spots above $100 \mathrm{~K}$ in fixed-bed reactors. ${ }^{86,91}$ Thus, the reaction heat management is critical to avoid temperature runaway and catalyst deactivation. Even though the fluidized-bed reactor technology can offer high heat transfer 


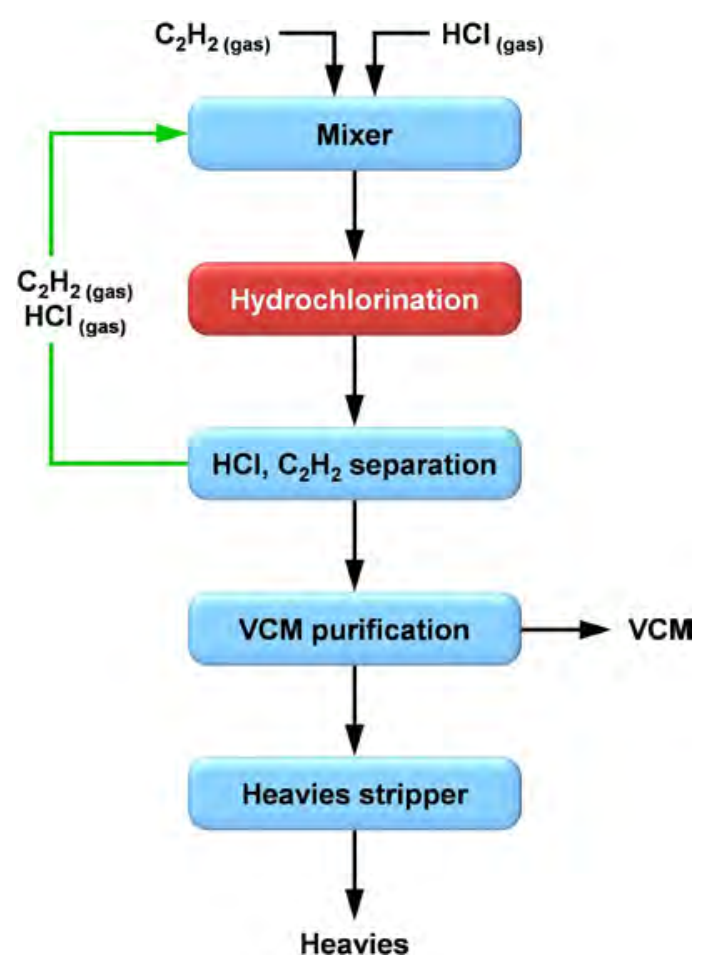

Figure 9. Simplified flowsheet for the production of vinyl chloride from acetylene and hydrogen chloride, showing the general sequence of unit operations.

efficiency, it has rarely been employed. One possible reason could be that the carbon materials are by far the most suitable support for the best performed hydrochlorination catalysts, but they are easily prone to pulverization in the high velocity regime during fluidization.

\subsection{Ethylene Chlorination for VCM Production}

VCM can be prepared from ethylene through a two-step process involving ethylene chlorination to EDC, followed by the thermal cracking of EDC to VCM. The direct chlorination of ethylene is performed in the gas-liquid or liquid phase where chlorine and pure ethylene are reacted in the presence of Lewis acid type catalysts, such as $\mathrm{FeCl}_{3} .{ }^{124}$ The reaction follows a typical electrophilic addition mechanism, yielding a high purity EDC that, sometimes, can be immediately used for cracking. The most important byproduct is 1,1,2-trichlorethane, likely originating from the further chlorination of EDC. The reaction can be carried out at either low (323-343 K) or high (363-423 K) temperatures. In the low-temperature process, the reactor is a simple gas-liquid contact column, operated at temperatures 
below the boiling point of EDC. The produced EDC is discharged continuously in the liquid phase. Heat removal can be managed by using either an internal heat transfer device such as a cooling coil, or an external heat exchanger with recycling of cold EDC. This route possesses the advantage of low byproduct formation, but requires more energy to recover the EDC. Another major drawback arises from the separation of the catalyst from the liquid EDC produced that inevitably increases the operation costs. In contrast, the high-temperature process, operated at the boiling point of EDC at 1.5-5 bar, utilizes the reaction heat for the distillation of EDC, leading to substantial energy savings. ${ }^{125}$ The chlorination reactor may be integrated as a reboiler of a distillation column, or designed as an independent equipment. Since the EDC leaves the reactor in the gas phase, there is no catalyst consumption hence the catalyst refill is not required.

\subsection{Ethylene Oxychlorination for VCM Production}

The oxychlorination method, involving the reaction of ethylene with $\mathrm{HCl}$ and $\mathrm{O}_{2}$, comprises the key technology in the contemporary VCM manufactures to close the chlorine loop by consuming the $\mathrm{HCl}$ byproduct released from the EDC cracking step. The process is applied in parallel with chlorination and they together are referred as "balanced process" (Figure 6). The reaction is exclusively practiced in the gas-phase over a heterogeneous catalyst at 473-773 $\mathrm{K}$ and 1-5 bar. The oxychlorination reaction network is rather complex as numerous routes, such as substitution, addition, elimination, and oxidation, leading to a series of chlorinated and oxidized products, can take place (Figure 10). ${ }^{126}$ Therefore, the product distribution is strongly dependent on the nature of catalyst and conditions. Industrial oxychlorination catalysts consist of $\mathrm{CuCl}_{2}$ supported on $\gamma-\mathrm{Al}_{2} \mathrm{O}_{3}$ and promoted with various dopants, which lead to excellently EDC yield (ca. 90-99\%) in the typical temperature range of $473-733 \mathrm{~K}$ (Table 1). Albeit being used for several decades, the copper catalysts suffer from deactivation due to volatilization and/or agglomeration of active phase. Very few studies were attempted to find stable copper-free systems, advantageously leading to VCM formation. Herein, we first systematically review the copper chloride-based catalysts with emphasis on the reaction mechanism and the role of different dopants, taking into account of recent findings acquired by advanced characterization techniques. A 


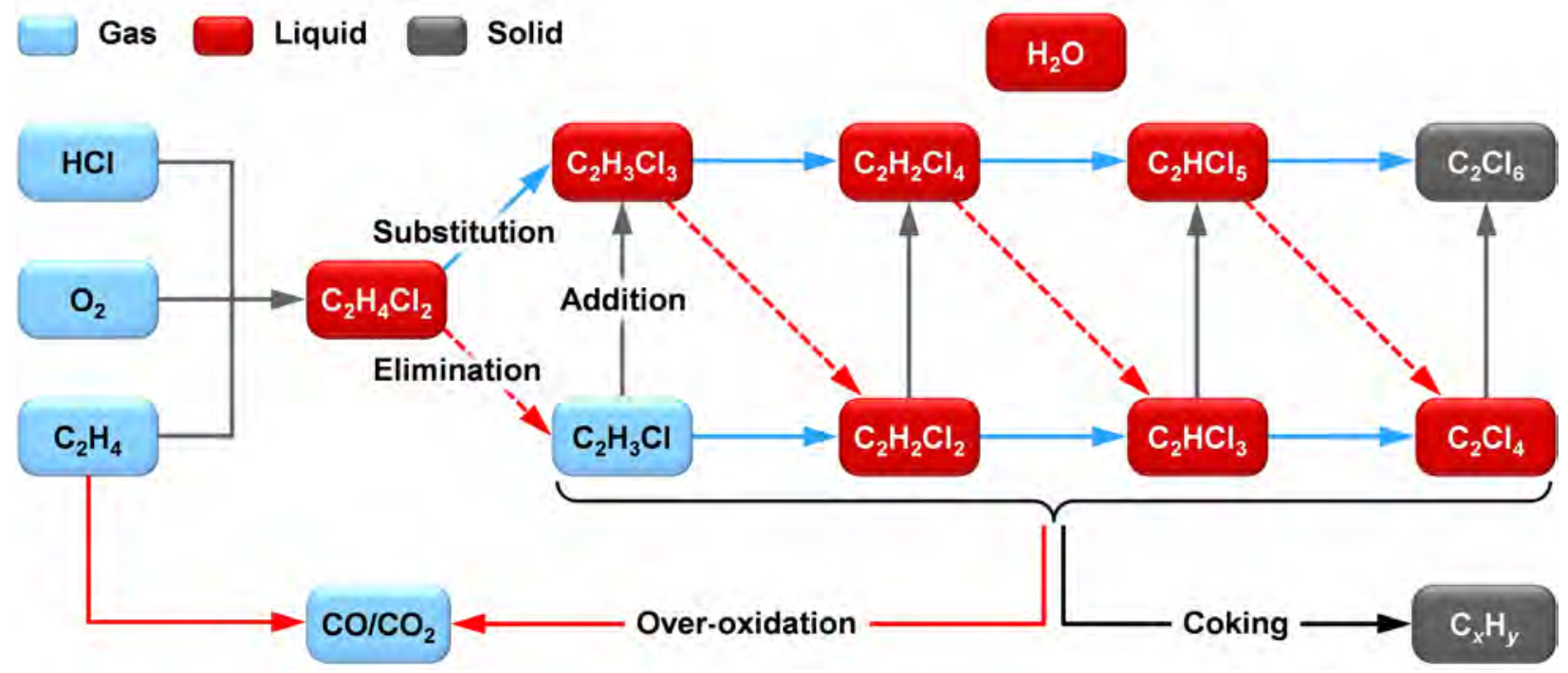

Figure 10. The multiple products of ethylene oxychlorination emphasize the key importance of the selectivity in the design of an optimal catalytic process. ${ }^{126}$ The desired product, ethylene dichloride, can be irreversibly over-chlorinated through addition, substitution, and elimination reactions leading to a wide range of chlorohydrocarbons. In addition, ethylene and the chlorinated compounds can be over-oxidized to $\mathrm{CO}$ and $\mathrm{CO}_{2}$.

Table 1. Catalysts for Ethylene Oxychlorination

\begin{tabular}{|c|c|c|c|c|c|c|}
\hline \multirow{2}{*}{ catalyst } & \multicolumn{2}{|c|}{ reactivity $^{a}$} & \multicolumn{3}{|c|}{ conditions } & \multirow{2}{*}{ ref } \\
\hline & $X / \%$ & $S / \%$ & reactor & $\mathrm{GHSV}^{b} / \mathrm{h}^{-1}$ & $T / \mathrm{K}$ & \\
\hline $\mathrm{CuNaRCl} / \mathrm{Al}_{2} \mathrm{O}_{3}{ }^{c}$ & 99 & 94 (EDC) & fluidized & - & 533 & 127 \\
\hline $\mathrm{CuKCl}_{x} / \mathrm{MgO}-\mathrm{SiO}_{2}{ }^{d}$ & 34 & 95 (EDC) & fluidized & 760 & 633 & 128 \\
\hline $\mathrm{CuMgNaCl}_{x} / \gamma-\mathrm{Al}_{2} \mathrm{O}_{3}$ & 99 & 97 (EDC) & fixed & - & 553 & 129 \\
\hline $\mathrm{CuPdNaCl} / \mathrm{Al}_{2} \mathrm{O}_{3}$ & 97 & 82 (EDC) & fixed & 200 & 547 & 130 \\
\hline $\mathrm{PdFeNaCl}{ }_{x} / \mathrm{Al}_{2} \mathrm{O}_{3}$ & 88 & 60 (VCM) & fixed & 200 & 560 & 130 \\
\hline $\mathrm{RhFeZnLiCl} l_{x} / \alpha-\mathrm{Al}_{2} \mathrm{O}_{3}$ & $29-46$ & $42-77$ (VCM) & fluidized & - & 623 & 131 \\
\hline $\mathrm{LaOCl}$ & 33 & 87 (VCM) & fluidized & 62 & 672 & 132 \\
\hline $\mathrm{CeO}_{2}$ & 35 & 85 (EDC) & fixed & - & 673 & 133 \\
\hline $\mathrm{CeO}_{2}-\mathrm{ZrO}_{2}$ & 60 & 50 (VCM) & fixed & - & 673 & 133 \\
\hline
\end{tabular}

${ }^{a}$ Conversion of ethylene and selectivity were denoted as $X$ and $S$, respectively. ${ }^{b} \mathrm{GHSV}$ was calculated based on ethylene. The voidage of catalyst bed was estimated as $50 \%$. ${ }^{c} \mathrm{~A}$ small amount of rare earth metal $(R)$ chlorides was added. ${ }^{d} \mathrm{NH}_{4} \mathrm{Cl}$ as halogenating agent that decomposes to $\mathrm{HCl}$ and $\mathrm{NH}_{3}$ during reaction. 
short discussion is then made on the emerging processes and catalysts for the dehydrochlorination of EDC to VCM. This is followed by examining the direct VCM production from ethylene over noncopper catalysts. The last section is dedicated to discuss the reactor technology and processes.

2.3.1. Copper Chloride-Based Catalysts for EDC Production. The copper-based catalysts are of predominant interest for both academia and industry in ethylene oxychlorination. The developments in this field will be assessed form the aspects of choice of support, reaction mechanism, side reactions, and the role of promoters.

Choice of Support. The most commonly used support is $\gamma$-alumina, though in rare cases, other inert carriers such as $\alpha$-alumina, silica, silica-magnesia, and natural pumice were also reported. ${ }^{134-136}$ The unique role of $\gamma$-alumina can be generalized as follows. Firstly, $\gamma$-alumina influences the reducibility and mobility of copper chloride phase. Rouco found that a stronger salt-support interaction occurred in $\gamma$ alumina, compared with $\mathrm{SiO}_{2}$ - and $\alpha$-alumina-supported catalysts, and the mobility of copper chloride was only confirmed on $\gamma$-alumina rather than on the other two supports. ${ }^{137}$ The author indicated the mobile copper species was cuprous chloride, but no further efforts were made to study the influence on the catalytic performance. Secondly, the formation of various copper species was at least partially influenced by the nature of alumina. Lamberti et al. have found that different copper species can be formed, namely, surface aluminate (isolated $\mathrm{Cu}^{2+}$ ions occupying octahedral vacancies on the alumina surface), amorphous $\mathrm{CuCl}_{2} \cdot 2 \mathrm{H}_{2} \mathrm{O}$, and insoluble copper hydroxychloride, depending on the copper content. ${ }^{138,139}$

Reaction Mechanism. A molecular level understanding of the reaction mechanism, kinetics on solid surfaces, and the determination of structure-performance relationships hold fundamental importance in the rational development of any heterogeneously-catalyzed process. Such knowledge is limited in the oxychlorination of ethylene. ${ }^{140-144}$ In depth investigation of the chemistry has been hampered by the demanding experimental conditions involving corrosive, flammable, and toxic compounds, which make it extremely difficult to apply suitable techniques to tackle mechanistic investigations. There have been several speculations on the chemistry of an alkene oxychlorination reaction. Due to the similarity 
between $\mathrm{HCl}$ oxidation and oxychlorination reaction, a Deacon mechanism was conceived involving the formation of chlorine over catalyst surface and gas-phase alkene addition. ${ }^{145}$ Disadvantageously, the hypothesis cannot well explain the high EDC selectivity in view of radical reactions. A L-H mechanism was proposed by Carruba and Spencer to explain their kinetic model. ${ }^{145}$ They suggested that oxygen and ethylene were adsorbed on the surface sites and the formation of ethylene oxide was the ratedetermining step. However, this proposal is not in line with the findings of Lamberti et al. who carried out a thorough study on the fresh, aged, as well as ethylene, oxygen or $\mathrm{HCl}$ treated catalysts by using ex situ X-ray absorption spectroscopy. ${ }^{138,139,143,144,146}$ They pointed out that the oxychlorination of ethylene is catalyzed by a highly dispersed $\mathrm{CuCl}_{2}$ phase following a three-step redox mechanism: (i) ethylene chlorination with $\mathrm{CuCl}_{2}$ which was reduced to $\mathrm{CuCl}$, (ii) oxidation of $\mathrm{CuCl}$ to an oxychlorides $\left(\mathrm{Cu}_{2} \mathrm{OCl}_{2}\right)$, and (iii) chlorination of oxychloride to regenerate $\mathrm{CuCl}_{2}$. Both cupric and cuprous chlorides have been experimentally confirmed by X-ray absorption near edge structure (XANES), while the oxychloride was not detected which is explained by its fast chlorination (Figure 11a). The reoxidation of $\mathrm{CuCl}$ was shown to be the rate-determining step for the undoped $\mathrm{CuCl}_{2}$, which is further delayed in the presence of $\mathrm{HCl}^{144}$ In this mechanism, cupric chloride was supposed to act as the chlorinating agent rather than the molecular chlorine, which may reasonably explain the high selectivity to EDC. It should be noted that these conclusions are based on-transient experiments $138,139,143,146$ or the temperatureprogrammed reactions. ${ }^{144}$ Therefore, they allow a limited extrapolation to the industrial process for which steady-state mechanistic information is crucial. This highlights the need of developing novel experimental and theoretical approaches to unravel the oxychlorination chemistry.

Side Reaction. In ethylene oxychlorination, a series of side reactions can accompany, leading to the production of chlorocarbons and carbon oxides (Figure 10), thus inevitably decreasing EDC selectivity. Based on pulse reactor studies and in situ infrared spectroscopy (IR), Busca et al. demonstrated that the free alumina surface could play a negative role in ethylene oxychlorination, due to its ability to dehydrochlorinate EDC and other chloroalkanes. ${ }^{147}$ Among others, VCM and 1,1,2-trichloroethane (TCE) were the predominant byproducts, which were suggested to originate from the 

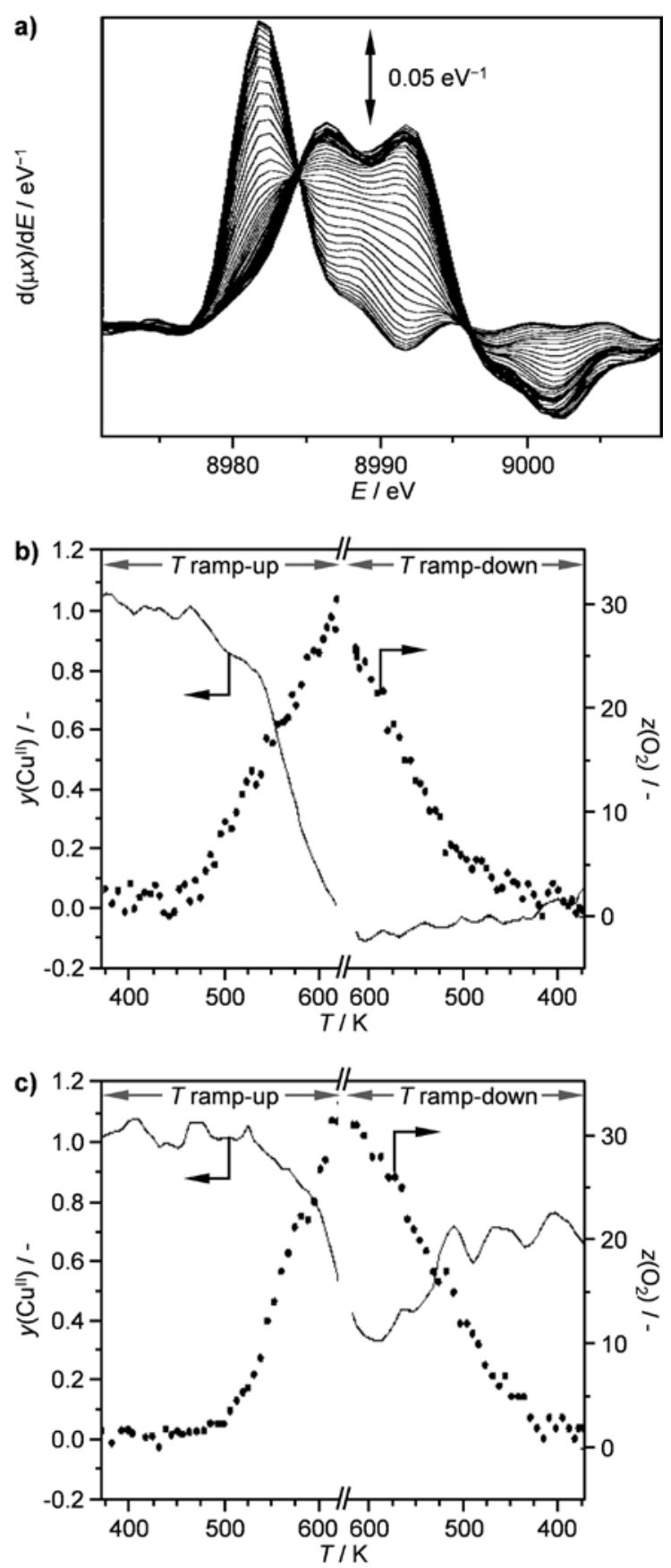

Figure 11. a) Derivative (Fourier filtered to remove the high frequency noise) of three-dimensional XANES spectra (collected every $30 \mathrm{~s}$ ) of $\mathrm{CuCl}_{2}(5 \mathrm{wt} . \% \mathrm{Cu}) / \gamma-\mathrm{Al}_{2} \mathrm{O}_{3}$ during heating from 373 to $623 \mathrm{~K}$ $\left(12 \mathrm{~K} \mathrm{~min}^{-1}\right) . E=$ photon energy, $\mu x=$ normalized absorption, assuming $\mu x=1$ at $E=9035 \mathrm{eV}$ ). The presence of two isosbestic points at 8984 and $8995 \mathrm{eV}$ is direct proof for only two species being present on the catalyst in significant amounts: $\mathrm{CuCl}_{2}$ and $\mathrm{CuCl}$ in mutual transformation. The oxychloride $\left(\mathrm{Cu}_{2} \mathrm{OCl}_{2}\right)$ is not detected because of the fast re-chlorination step. $\mathrm{O}_{2}$ conversion (representative for the catalyst's activity; $z$, full dots, right axis) and $\mathrm{Cu}^{\mathrm{II}}$ fraction ( $y$, full line, left axis) for b) $\mathrm{CuCl}_{2}(5 \mathrm{wt} \% \mathrm{Cu}) / \gamma-\mathrm{Al}_{2} \mathrm{O}_{3}$ and c) $\mathrm{KCl}(3.6 \mathrm{wt} . \%)-\mathrm{CuCl}_{2}(5 \mathrm{wt} . \% \mathrm{Cu}) / \gamma-\mathrm{Al}_{2} \mathrm{O}_{3}$ during temperature ramps. The time axis runs in all diagram parts from left to right. $y\left(\mathrm{Cu}^{\mathrm{II}}\right)=1-y\left(\mathrm{Cu}^{\mathrm{I}}\right)$, where $y\left(\mathrm{Cu}^{\mathrm{I}}\right)$ has been determined by the relative intensity of the first derivative maximum at $8982 \mathrm{eV}$ (see a) compared to the value obtained on a totally reduced sample. Reproduced with permission from ref 144. Copyright 2002 Wiley-VCH. 
dehydrochlorination and re-chlorination of EDC, respectively. An early literature by Shalygin et al. reported that EDC dehydrochlorination to VCM occurred on the Lewis acid sites of alumina surface. ${ }^{148}$ This agrees with a recent report by Lamberti et al. who studied various promoted copper chloride catalysts supported on $\gamma$-alumina for ethylene oxychlorination, and found a positive trend between the density of Lewis acid sites and byproduct selectivity in the temperature range of 503-573 K. ${ }^{149}$ However, such correlation was not found for the density and strength of Brønsted acid sites. Muddada et al. ${ }^{150}$ further proposed that TCE can be produced from VCM by interacting with cupric chloride sites through $\pi$-complexation and extracting two chloride ions from copper chloride, and VCM can be further halogenated to 1,1-dichloroethane by adsorbed $\mathrm{HCl}$. These findings are consistent with the speculation of Feijen-Jeurissen et al. ${ }^{151}$ based on the investigation of the destruction mechanism of $\mathrm{C}_{2}$-chlorinated hydrocarbons on alumina and alumina-supported chromium and palladium catalysts. As a relatively less pronounced byproduct, ethyl chloride (EC), was believed to be produced by the direct addition of $\mathrm{HCl}$ to ethylene. ${ }^{152}$ Carbon oxides were suggested to result from ethylene oxidation since the combustion of haloalkanes requires higher reaction temperatures. ${ }^{153}$

Role of Promoter. Pristine $\mathrm{CuCl}_{x} / \gamma-\mathrm{Al}_{2} \mathrm{O}_{3}$ is rarely used in the oxychlorination reaction due to the poor stability of cupric chloride. ${ }^{133,144}$ The addition of promoters can reduce the metal loss and/or influence the activity and selectivity. ${ }^{140,154,155}$ The most commonly applied dopants are alkali metals (Li, $\mathrm{Na}$, and $\mathrm{K}$ ), alkaline earth metals ( $\mathrm{Mg}$, Ca, and Cs), and rare earth metals ( $\mathrm{La}$ and $\mathrm{Ce}$ ). These metals can exert various effects on the physicochemical properties of the catalysts and improve the catalytic performance. A summary of the impacts of different promoters on the modification of aluminasupported copper chloride catalysts is presented in Table $2 . \mathrm{KCl}$ is the most widely used and studied additive, especially for the catalyst used in fixed-bed reactor technologies. The presence of $\mathrm{KCl}$ was reported to cause structural change in $\mathrm{KCl}-\mathrm{CuCl}_{2} /$ fumed silica and in $\mathrm{KCl}-\mathrm{CuCl}_{2} / \mathrm{Al}_{2} \mathrm{O}_{3}$ catalyst. ${ }^{144,156}$ Probe molecule FTIR spectroscopy was applied as the suitable method to detect these subtle structural differences. For instance, a new mixed chloride phase $\mathrm{K}_{x} \mathrm{CuCl}_{2+x}$ was found for the $\mathrm{KCl}$-promoted $\mathrm{CuCl}_{2} / \mathrm{Al}_{2} \mathrm{O}_{3}$ catalyst when reduced in ethylene. This was suggested based on the blue-shift of $v(\mathrm{CO})$ 
Table 2. Impact of Different Promoters on the Modification of Alumina-Supported Copper Chloride Catalysts for Ethylene Oxychlorination

\begin{tabular}{|c|c|c|c|c|c|c|c|}
\hline \multirow{3}{*}{ promoter } & \multicolumn{6}{|c|}{ modification effects } & \multirow{3}{*}{ ref } \\
\hline & \multirow{2}{*}{$\begin{array}{c}D_{\mathrm{Cu}}{ }^{a} \\
/ \%\end{array}$} & \multirow{2}{*}{ phase } & \multirow{2}{*}{ reducibility $^{b}$} & \multicolumn{2}{|c|}{ acid property $^{c}$} & \multirow{2}{*}{ Stickiness $^{d}$} & \\
\hline & & & & Lewis & Brønsted & & \\
\hline $\mathrm{LiCl}$ & 78 & $\mathrm{CuLi}_{x} \mathrm{Cl}_{2+x}$ & increased & $\mathrm{Li}^{+}$ & $\mathrm{Al}-\mathrm{OH}(\uparrow)$ & none & $149,154,155,157$ \\
\hline $\mathrm{KCl}$ & 46 & $\mathrm{CuK}_{x} \mathrm{Cl}_{2+x}$ & reduced & few & $\mathrm{Al}-\mathrm{OH}(\uparrow)$ & none & $149,154,155,157$ \\
\hline $\mathrm{MgCl}_{2}$ & 69 & - & increased & $\mathrm{Mg}^{2+}$ & $\mathrm{Al}-\mathrm{OH}(\uparrow)$ & - & $149,154,155$ \\
\hline $\mathrm{CaCl}_{2}$ & - & - & - & $\mathrm{Ca}^{2+}$ & $\mathrm{Al}-\mathrm{OH}(\uparrow)$ & - & 149 \\
\hline $\mathrm{CsCl}_{2}$ & 45 & $\mathrm{CuCs}_{x} \mathrm{Cl}_{2+x}$ & reduced & none & $\mathrm{Al}-\mathrm{OH}(\downarrow)$ & none & $149,154,155,157$ \\
\hline $\mathrm{BaCl}_{2}$ & - & - & - & - & - & none & 157 \\
\hline $\mathrm{LaCl}_{3}$ & 79 & - & increased & $\mathrm{La}^{3+}$ & $\mathrm{Al}-\mathrm{OH}(\uparrow)$ & none & $149,154,155,157$ \\
\hline $\mathrm{CeCl}_{3}$ & - & - & - & - & - & none & 155,157 \\
\hline
\end{tabular}

${ }^{a}$ Dispersion $(D)$ of copper calculated by the ratio between adsorbed CO molecules and the total number of $\mathrm{Cu}$ atoms. The value for undoped $\mathrm{CuCl}_{2} / \mathrm{Al}_{2} \mathrm{O}_{3}$ was $45 \%$. ${ }^{b}$ Estimated from $\mathrm{CuCl}_{2}$ reduction by ethylene in a pulse reactor. ${ }^{C}$ Lewis acidity of alumina was strongly suppressed with the addition of all dopants (new Lewis acid sites formed in some cases), while the influence on Brønsted acidity was marked by the arrow in the bracket ( $\uparrow$ : increased; $\downarrow$ : decreased). ${ }^{d}$ Stickiness of the catalysts was evaluated in fluidized-bed reactors.

due to the formation of $\mathrm{Cu}^{+} \cdot \cdots \mathrm{CO}$ adducts. ${ }^{144}$ In another study, UV-Vis-NIR was used to identify the effect of $\mathrm{KCl}$ promotion. It was found that a significant fraction of $\mathrm{Cu}^{2+}$ was located at the strongly distorted octahedral sites induced by the modification of potassium. ${ }^{140,154,155}$ Generally, addition of $\mathrm{KCl}$ led to a decrease of the overall activity, as evidenced by the pulse experiments, and a higher apparent activation energy for the doped catalyst. ${ }^{137,140,154,155}$ This might be related to the decreased reducibility of $\mathrm{K}_{x} \mathrm{CuCl}_{2+x}$, which eventually altered the rate-determining step of the reaction. The direct evidence comes from Fourier-transformed XANES spectroscopy, indicating that the doping with KCl favors the $\mathrm{Cu}^{2+}$ valence state of the catalyst (Figures 11b,c). From the technological viewpoint, the copper catalyst in $\mathrm{Cu}^{2+}$ valence state is beneficial for minimizing $\mathrm{Cu}$ loss from the volatilization of cuprous species, 
albeit a fully oxidized copper catalyst was suggested to be inactive for ethylene oxychlorination. ${ }^{140,154,155}$ Additionally, $\mathrm{KCl}$ doping can greatly diminish Lewis acid sites of alumina, which is deemed to be responsible for the enhanced EDC selectivity. ${ }^{149,150}$

A systematic investigation of various effects of promoters on the alumina-supported copper chloride catalysts was carried out by Lamberti and coworkers. ${ }^{149,154,155}$ Some major conclusions were summarized in Table 2 and drawn as follows:

(i) Promoters competed with copper ions to occupy the octahedral vacancy sites of $\gamma-\mathrm{Al}_{2} \mathrm{O}_{3}$ in the order: $\mathrm{K}<\mathrm{Cs}<\mathrm{Li}<<\mathrm{Mg}<\mathrm{La}^{154}$

(ii) $\mathrm{Cu}$ dispersion increased with the doping of $\mathrm{Li}$, $\mathrm{La}$, and $\mathrm{Mg}$, whereas it decreased with the presence of $\mathrm{K}$ and Cs. ${ }^{154}$

(iii) A cation mixed phase $\mathrm{CuM}_{x} \mathrm{Cl}_{2+x}$ formed with the addition of $\mathrm{KCl}$ and $\mathrm{CsCl}_{2}$, whereas it did not form in the presence of $\mathrm{MgCl}_{2}$ and $\mathrm{LaCl}_{3}$, no mixed halides were formed, and the formation depended on the treatment temperature for $\mathrm{LiCl}^{140,154,155}$

(iv) The overall reducibility of doped catalysts by ethylene followed the order: $\mathrm{La}>\mathrm{Mg}>\mathrm{Li}>$ undoped $>\mathrm{K}>\mathrm{Cs} .^{154}$

(v) Lewis acid sites were masked by doping with $\mathrm{LiCl}, \mathrm{MgCl}_{2}, \mathrm{CaCl}_{2}$, and $\mathrm{LaCl}_{3}$, while new Lewis acid sites related to the doping cations emerged; Brønsted acid sites increased remarkable with the presence of all the dopants, except CsCl. ${ }^{149}$

The physical changes (attrition and stickiness) of the catalysts applied in the fluidized-bed reactors are scarcely studied. $\mathrm{CuCl}_{2} / \gamma-\mathrm{Al}_{2} \mathrm{O}_{3}$ catalysts are prone to become sticky in fluidization. Addition of different promoters such as $\mathrm{Li}, \mathrm{K}, \mathrm{Cs}, \mathrm{Ba}, \mathrm{La}$, and Ce can suppress the catalyst stickiness. ${ }^{157}$ It is important to emphasize that the “additive approach” can bring only incremental improvements and does not eliminate the intrinsic drawbacks of copper chloride associated with its poor chemical and mechanical stability under reaction conditions. Virtually little research is devoted to the development of copper-free catalysts with a superior EDC selectivity and lifetime. Industrial conservatism and the 
deterrence of academia to undertake studies due to the high demands associated with this reaction can be postulated as the main reasons for the lack of new catalysts in this area.

2.3.2. Catalytic Dehydrochlorination of EDC to VCM. The predominant use of EDC is to prepare VCM by the gas-phase pyrolysis at 773-823 K and 25-35 bar. The existing cracking route has the intrinsic disadvantages such as low single-pass EDC conversions (50-60\%), and the formation of byproducts and cokes at elevated temperatures. Alternative methods have been explored in order to overcome these drawbacks, which include the low-temperature catalytic dehydrochlorination of EDC to VCM. Earlier results showed that polyacrylonitrile-based active carbon fiber (PAN-ACF) catalyzes the reaction at 573-623 $\mathrm{K}$ with $99.9 \% \mathrm{VCM}$ selectivity at 21-63\% conversions. ${ }^{158}$ More recently, Zhang et al. reported a more effective $\mathrm{N}$-doped coconut activated carbon (N-AC) catalyst with a VCM yield above $80 \%$ at $523 \mathrm{~K} .{ }^{159}$ Different zeolites have also been studied. An initial total conversion of EDC with a VCM yield of 92\% was achieved over ZnO/HZSM-5 at $670 \mathrm{~K} \cdot{ }^{160}$ A full VCM selectivity was attained with a hydrogen-assisted dehydrochlorination route over Ni-modified BEA zeolites. ${ }^{161}$ All the above zeolite-based catalytic systems show comparable or even superior conversion rates than the pyrolysis process. However, a gradual decline in the activity is observed on all the catalysts during a long-term stability assessment, although the high selectivity was maintained. Additionally, the coke deposition has been commonly identified in these materials, which might block the active sites and cause the deactivation. ${ }^{159,161,162}$ Recently, a novel approach was reported by De Vos et al. based on the vapor phase dehydrochlorination reaction in tetrabutylphosphonium chlorides $\left(\mathrm{C}_{4444} \mathrm{P}^{+} \mathrm{Cl}^{-}\right)$ionic liquid. ${ }^{163}$ A remarkable EDC conversion of 95\% with a > 99.6\% VCM selectivity was obtained at $513 \mathrm{~K}$ with a stable activity over $50 \mathrm{~h}$ by conducting the reaction with four chain reactors. However, long-term stability test on the phosphonium cations at relevant conditions is required in order to make this process applicable in industry. Another new route from EDC to VCM has been demonstrated by reacting EDC with acetylene (Eq. 1). ${ }^{164}$ The nitrogen-doped activated carbon-supported Ru catalyst (Ru/N-AC) gave a VCM yield above $90 \%$ during $180 \mathrm{~h}$ time on stream at $523 \mathrm{~K} .{ }^{165}$ This route, using both acetylene and ethylene (for EDC synthesis) as the feedstocks, can overcome the drawbacks of EDC pyrolysis and 
avoid the current pollution-causing acetylene hydrochlorination step. Therefore, those regions where the PVC industries are still heavily relying on the acetylene-based process can take advantage of this method.

$$
\mathrm{CH}_{2} \mathrm{ClCH}_{2} \mathrm{Cl}+\mathrm{C}_{2} \mathrm{H}_{2} \rightarrow 2 \mathrm{C}_{2} \mathrm{H}_{3} \mathrm{Cl} \quad \Delta H=-52 \mathrm{~kJ} \mathrm{~mol}^{-1}
$$

2.3.3. $\mathrm{CeO}_{2}$-Based Catalysts for VCM Production. The development of advanced technologies in chemical industry depends heavily on the discovery of multifunctional catalytic materials and innovative processes. The current ethylene-to-VCM route relies on the two-step process, entailing ethylene oxychlorination to EDC, followed by EDC thermal cracking to VCM. One-step VCM production is highly desirable in light of the greatly simplified process. However, this goal has not been achieved yet due to the lack of a suitable catalyst to perform the above-mentioned two reactions on the same surface. The copper chloride-based catalysts, exclusively employed in industry nowadays, cannot bridge the temperature gap between the two steps. Namely, the pyrolysis occurs at a higher temperature of $773-823 \mathrm{~K}$ at which the volatilization of active metal components becomes remarkable. Palladium and rhodium chloride-based catalysts with different promoters have been disclosed in earlier patents, showing appreciable initial activity and selectivity to VCM (Table 1$).{ }^{130,131}$ However, the stability should be assessed for practical considerations of these systems. LaOCl has also been reported to produce VCM with a high selectivity of $78 \%$, however, the intrinsic low activity of LaOCl requiring a long residence time of 3.6-8.7 s ${ }^{-1}$, might restrict the productivity in large-scale implementation. ${ }^{132}$

A recent study demonstrated an exceptional performance of ceria for the direct VCM production in a high yield (Figure 12a). ${ }^{133}$ An investigation of representative $\mathrm{HCl}$ oxidation catalysts, in comparison to $\mathrm{CuKLaCl}_{x} / \mathrm{Al}_{2} \mathrm{O}_{3}$, was conducted (Figure 12b). The results revealed a full EDC selectivity at $c a$. $12 \%$ $\mathrm{C}_{2} \mathrm{H}_{4}$ conversion, as expected, over copper catalysts at $473 \mathrm{~K}$. However, this sample exhibited a significant copper and lanthanum loss during reaction. The oxide catalysts required higher temperatures to reach the similar conversion levels as that of copper system. Both $\mathrm{IrO}_{2}$ and $\mathrm{RuO}_{2}$ led to a significant combustion forming $\mathrm{CO}$ and $\mathrm{CO}_{2}$ at $673 \mathrm{~K}$, whereas a high selectivity to chlorinated products 
(92\% EDC, 6\% VCM) at similar conversion levels was obtained over $\mathrm{CeO}_{2}$ at $623 \mathrm{~K}$. This difference was substantiated based on the strong redox properties of the former two oxides, which are modulated over $\mathrm{CeO}_{2}$ under oxychlorination environment enabling it to suppress the over oxidation causing $\mathrm{CO}_{x}$ formation. The high selectivity to chlorinated products was also maintained at $673 \mathrm{~K}$ over $\mathrm{CeO}_{2}$. Under these conditions $35 \%$ of $\mathrm{C}_{2} \mathrm{H}_{4}$ conversion was obtained with $85 \%$ EDC and 13\% VCM selectivity. Besides, $\mathrm{CeO}_{2}$ preserved its textural and bulk properties with no hints for the metal loss, and demonstrated a stable activity for more than $10 \mathrm{~h}$ on stream with no hint for the metal loss. ${ }^{133}$ The formation of VCM was noteworthy over this system. Based on this outstanding results on $\mathrm{CeO}_{2}$, efforts were made to improve the VCM yields through the optimization of reaction conditions and material properties. ${ }^{133}$ It was found that high residence times are beneficial to increase the VCM selectivity and yield, but this also leads to the formation of unwanted $\mathrm{CO}_{x}$. $\mathrm{HCl}$-rich conditions were evidenced to further suppress the $\mathrm{CO}_{x}$ formation and enhance the EDC production, while the VCM selectivity remained unaltered. ${ }^{133}$ Tuning of properties of ceria demonstrated that nanocrystalline, high surface area materials lead to the highest VCM yield of $25 \%$ at a residence time of $0.14 \mathrm{~s}$, which is much higher than that reported for lanthanum-based systems (11-18\%) at a contact time of 3.6-8.7 s. ${ }^{132}$ Furthermore, mixed ceria-zirconia catalysts was shown to improve the conversion while maintaining the same high selectivity of chlorinated products in a $30 \mathrm{~h}$ on stream test. ${ }^{133}$

The origin of VCM formation on ceria was understood by different experiments. It was revealed that VCM comes consecutively from in situ EDC dehydrochlorination which was hinted by an experiments involving the variation of residence time, which evidenced an increase of VCM selectivity at the expense of EDC formation. To support this, separate EDC dehydrochlorination tests and acidity characterization of sample prior to (fresh) and after (used) the oxychlorination tests were conducted. Feeding of only EDC over ceria showed no VCM generation until $723 \mathrm{~K}$, while addition of $\mathrm{HCl}+\mathrm{O}_{2}$ to EDC feed (i.e. mimicking the reaction conditions) evidenced ca. 90\% yield of VCM at $673 \mathrm{~K}$ (Figure 12c). This is explained on the basis of acidity characterization by temperature-programmed desorption of ammonia ( $\mathrm{NH}_{3}-\mathrm{TPD}$ ) on these two samples (Figure 12d). While fresh $\mathrm{CeO}_{2}$ showed very 
a)

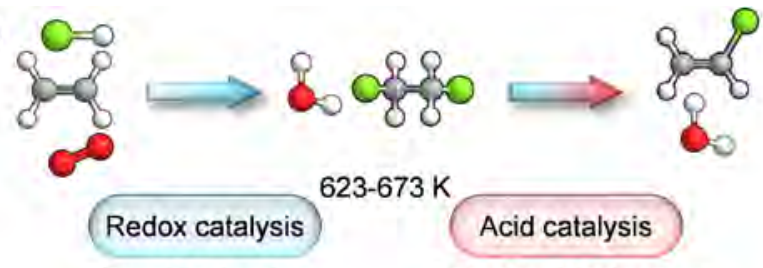

Oxychlorination

Dehydrochlorination

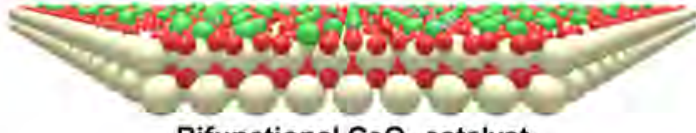

Bifunctional $\mathrm{CeO}_{2}$ catalyst
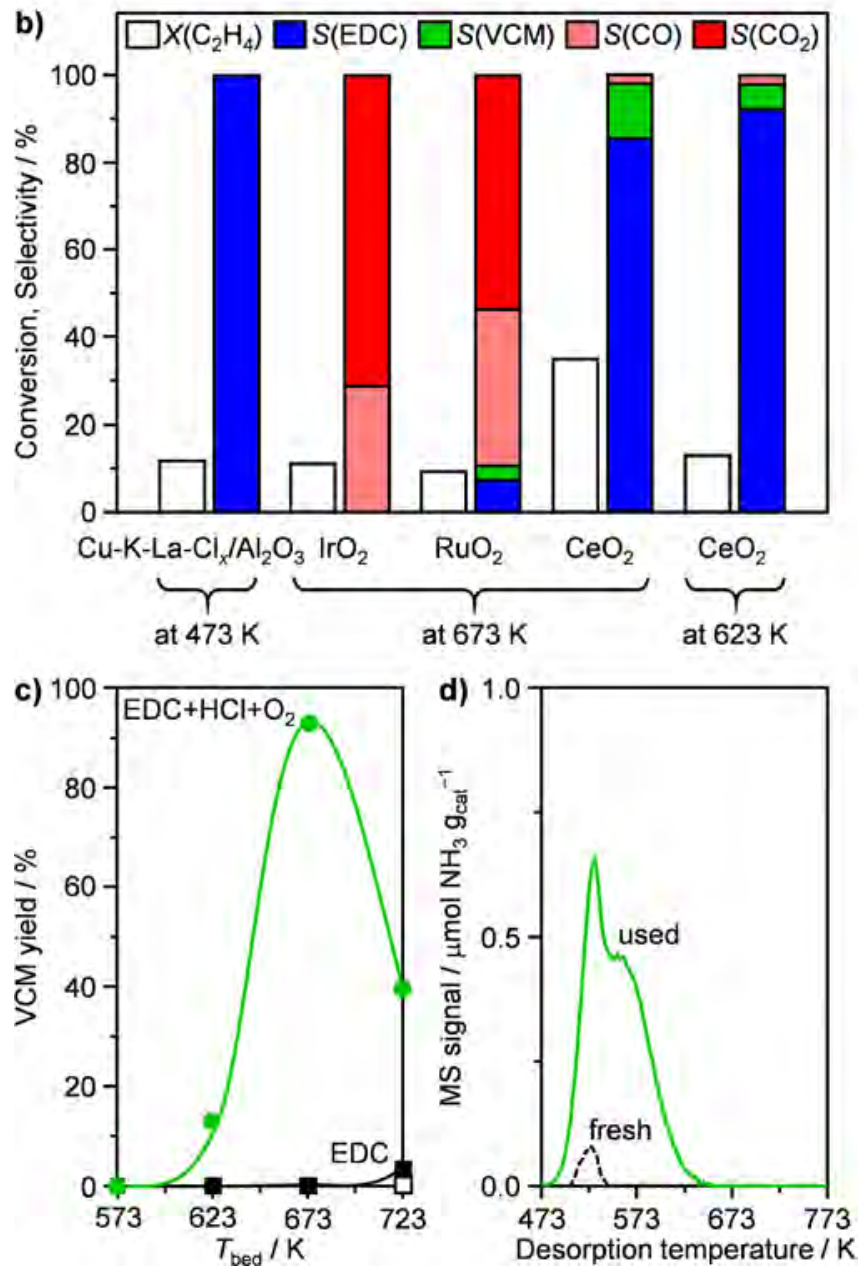

Figure 12. a) The bifunctional ceria catalyst integrates both oxychlorination catalyzed by redox sites and dehydrochlorination led by acid sites on a single surface, thereby leading to intensified VCM production. b) Performance of selected catalysts in ethylene oxychlorination. Conditions: $W_{\text {cat }}=0.5 \mathrm{~g}$; $F=100 \mathrm{~cm}^{3} \mathrm{STP} \mathrm{min}^{-1}$ containing 3 vol.\% $\mathrm{C}_{2} \mathrm{H}_{4}, 4.8$ vol.\% $\mathrm{HCl}$, and 1.2 vol.\% $\mathrm{O}_{2}\left(3\right.$ vol.\% for $\left.\mathrm{CeO}_{2}\right)$ balanced in He; $P=1$ bar. c) VCM yield versus bed temperature in the dehydrochlorination of EDC with or without addition of $\mathrm{O}_{2}$ (3 vol.\%) and $\mathrm{HCl}$ (4.8 vol.\%) over $0.5 \mathrm{~g}$ of $\mathrm{CeO}_{2}$ (solid symbols) and quartz (open symbols). Other conditions: $F=100 \mathrm{~cm}^{3} \mathrm{STP} \mathrm{min}^{-1}, P=1$ bar. d) Temperature-programmed desorption of $\mathrm{NH}_{3}$ over $\mathrm{CeO}_{2}$ in its fresh form and after use in ethylene oxychlorination. Adapted with permission from ref 133. Copyright 2016 Wiley-VCH. 
few acid centers at $523 \mathrm{~K}$, the used sample displayed a huge increase in acid sites density and their strength. Thus, the unique performance of $\mathrm{CeO}_{2}$ for one-step VCM production was explained by its bifunctional character: redox centers oxychlorinate ethylene to EDC, which is subsequently dehydrochlorinated to VCM over in situ generated strong acid sites. These findings open new doors for the optimization and the intensification of the current two-step process within PVC production involving $\mathrm{CuCl}_{2}$-catalyzed oxychlorination and thermal cracking

2.3.4. Reactors and Processes. Reactor Technologies. The highly exothermic ethylene oxychlorination reaction is carried out in staged multitubular fixed-bed or fluidized-bed reactors over promoted copper chloride catalysts, $M \mathrm{CuCl}_{x} / \gamma-\mathrm{Al}_{2} \mathrm{O}_{3}(M=$ alkali metal, alkaline earth metal, and rare earth metal), at 493-573 K and 2-14 bar. ${ }^{16,166}$ Both reactor technologies have their own advantages and disadvantages (Figure 13). Operation in fixed-bed reactors, hosting a bundle of tubes of 2-3 cm inner diameter and filled with millimeter-sized catalyst bodies, brings heat removal issue due to the inevitable formation of hot spots at some location in the reactor tube. The temperature rise, that can exceed $100 \mathrm{~K},{ }^{167}$ has two dramatic consequences: (i) a decreased catalyst lifetime due to the volatilization of copper chlorides, and (ii) a decreased EDC selectivity arising from the total oxidation of ethylene, and/or the formation of undesired chlorinated compounds. ${ }^{126}$ Therefore, the control of reaction temperatures is of utmost importance for the operation in fixed-bed reactors which directly determines the catalyst performance. Several approaches can be employed in order to eliminate the hot spots. The dilution of the catalyst bed, the grading of catalyst activity, and the staging of air or oxygen feed in reactor cascades can be applied to flatten the temperature profile and allow improved temperature control. In this sense, fluidized-bed reactors are preferred as they offer better temperature control of the catalyst bed. Due to the enhanced heat transfer efficiency, more uniform temperature profiles are attained in fluidized-bed reactors using micron-sized catalyst particles. However, there are a number of intrinsic drawbacks, such as unsteady operation, poor selectivity owing to the gas and catalyst solids back mixing, loss of heat transfer due to fouling of the cooler bundle, and limit in reagent velocity imposed by the need to avoid catalyst loss by elutriation from the reactor. On top of these, the 
fluidization is particularly critical. A declining fluidization quality gradually occurs due to the progressive enlargement of catalyst particles, especially when the $\mathrm{Cl}$ : $\mathrm{C}$ ratio is close to 1 . Under these conditions, the excess of $\mathrm{HCl}$ induces the formation of inter-particle $\mathrm{CuCl}_{x}$ bridges, a phenomenon commonly referred to as stickiness, and leads to bigger agglomerates which settle and cause operating setbacks and even reactor shutdowns. ${ }^{166}$
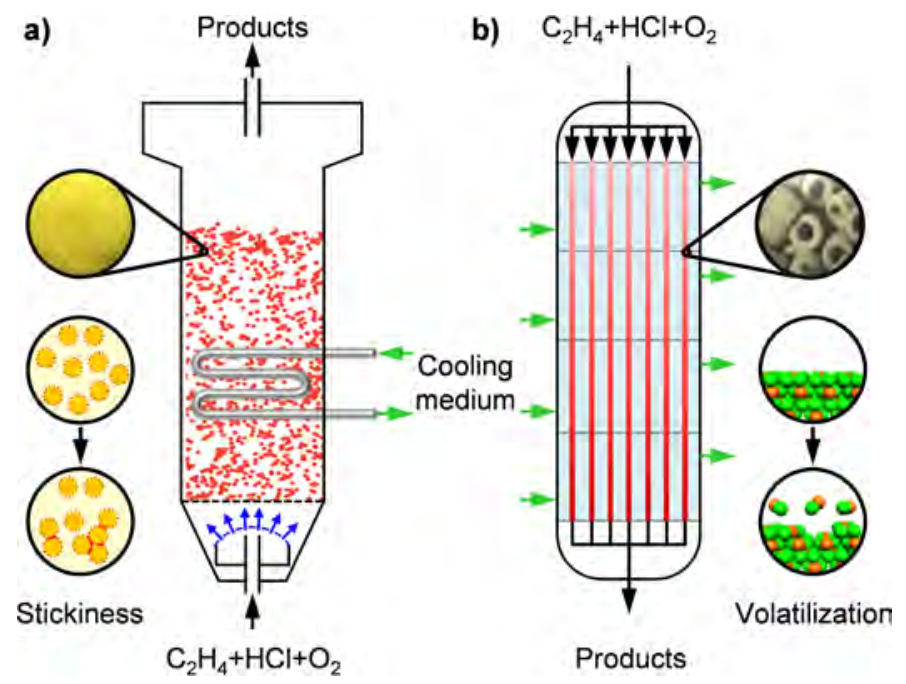

Figure 13. a) Fluidized- and b) multitubular fixed-bed reactor technologies in ethylene oxychlorination.

Processes. Ethylene oxychlorination is at the heart of the modern balanced VCM process. To date, many distinctive processes have been developed by different companies with regard to two distinguished characteristics: oxygen feed (pure oxygen or air) and reactors (fixed- and fluidized-bed reactors). Herein, we examine the representative processes based on fixed- and fluidized-bed reactors technologies, developed by Stauffer/EVC and B.F. Goodrich (now Geon), respectively.

Stauffer/EVC Processes. In the Stauffer process, the reactants $\left(\mathrm{C}_{2} \mathrm{H}_{4}, \mathrm{HCl}\right)$ are preheated to 403 $458 \mathrm{~K}$ before entering the reactors, while oxygen is divided into three equal portions and introduced, respectively, into three consecutive tubular reactors. ${ }^{168}$ The reactors comprising multiple nickel tubes were stacked together within a single coolant jacket in which steam at $c a .483 \mathrm{~K}$ is used to control the temperature of the reaction. Besides, the catalyst loading is crucial for temperature control. Within each reactor, the catalyst bed is split into two stages: the upper catalyst bed containing a less active KCl- 
$\mathrm{CuCl}_{2} / \gamma-\mathrm{Al}_{2} \mathrm{O}_{3}$ catalyst and the below one comprising a more active one, differing in metal loading and the $\mathrm{Cu} / \mathrm{K}$ ratio (shown in Figure $13 \mathrm{~b}$ by color gradient from light showing less active to dark showing more active one). The hot spots are typically managed within $613 \mathrm{~K}$. In the EVC process, a $\mathrm{KCl}-$ $\mathrm{CuCl}_{2} / \gamma-\mathrm{Al}_{2} \mathrm{O}_{3}$ catalyst in the form of hollow cylinders are packed in the reactors in a manner of multiple layers (first an active catalyst layer, followed by a less active one and then again a highly active one). ${ }^{169}$ In this way, the number of reactors were reduced to two, but the same EDC productivity was maintained with a better temperature control $\left(T_{\max }<558 \mathrm{~K}\right)$. In these processes, the $\mathrm{HCl}$ and oxygen conversions are typically above 98\% and 99\%, respectively, and the EDC selectivity is above $99 \%$ with only a few combustion products $(<1 \%)$ and halogenated hydrocarbons in ppm level.

Geon Process. For the Geon process, compressed air, ethylene, and HCl from the EDC cracking section are pretreated to $c a .423-443 \mathrm{~K}$ and introduced into the bottom of the reactor to fluidize the catalyst. $^{26}$ Stoichiometric excess of ethylene and air are used to maximize the HCl conversion. Temperature is controlled by internal cooling coils directly submerged in the fluid bed, and maintained in the range of 493-498 K. Pressures are slightly elevated (1.7-2.4 bar) to increase the reaction efficiency and to aid the downstream EDC condensation. To recover the catalyst, the effluents leaving the reactor are directed into a cyclone where catalyst powders are separated and returned to the reactor. The rest stream is further directed to two sequential hot and cold quench columns, where all the $\mathrm{HCl}$ and some of the water are condensed in the first column while the remaining water and most of the EDC are captured in the second one. The EDC-containing mixtures are further separated in a decanter. A small amount of EDC (5\%) from the gas stream of the cold quench column is absorbed by solvent extraction. With another separation step, the solvent can be recycled to the absorber, while the wet EDC from both sections should be dried and purified before cracking. The oxychlorination reaction is very selective, with EDC yields of $>98 \%$ based on $\mathrm{HCl}$ and $96 \%$ based on ethylene and only minor amount of chlorinated hydrocarbon byproducts. 


\subsection{Ethane Oxychlorination for VCM Production}

The strong incentive to use economic feedstocks triggered continued interests in the exploration of new technologies. Developing an ethane-based oxychlorination technology for VCM production would be another breakthrough in the vinyl chloride industry after the establishment of the balanced process, and exerts a profound impact on the PVC manufacture in future. Ethane is principally obtained from abundant natural gas, the quantity of which has been increasing enormously due to the widespread commercialization of hydraulic fracturing combined with horizontal drilling technology. The price advantage of ethane over ethylene can be understood by the fact that its major large-scale commercialized chemical use is to produce ethylene by steam cracking. ${ }^{170}$ Thus, devising a one-step ethane-to-VCM process will be an ideal solution to further complement the ever-increasing PVC demand by utilizing the low-cost natural gas. For these reasons, tremendous efforts from both the academia and industry have been devoted to the development of novel catalysts and processes. $27,78,132,171-173$

2.4.1. Catalysts. The oxychlorination of ethane has been investigated extensively over both copperbased and non-copper catalysts. Regardless of the catalysts employed, this reaction is generally conducted at much higher temperatures (ca. $713 \mathrm{~K}$ for $90 \%$ alkane conversion) owing to the difficulty of activating the strong $\mathrm{C}-\mathrm{H}$ bond in ethane molecule. ${ }^{174-177}$ At these temperatures, the formation of undesired over-chlorinated compounds (both saturated and unsaturated) and carbon oxides is observed. Results in a laboratory fixed-bed reactor showed the low selectivity to VCM (ca. 50\%), with ethylene being the major by-product. ${ }^{176,178}$ In general, ethylene, ethyl chloride, and VCM are the major products of this reaction. Copper-based catalysts usually show a better selectivity to VCM, while ethyl chloride and ethylene are the predominant products over non-copper catalysts (Table 3). Exceptions have also been reported in both cases. An exceptionally high EDC yield of $90 \%$ over $\mathrm{CuCl}_{2} /$ desiccant catalysts was claimed in an early patent. ${ }^{78}$ On the other hand, a porous $\mathrm{LaOCl}$ catalyst ${ }^{179}$ demonstrated to be highly selective for VCM production. 
Copper-Based Catalysts. Pure copper chloride catalysts are scarcely utilized for ethane oxychlorination due to the inferior stability at high temperatures needed for this reaction. Different dopants have been added to improve the thermal stability. However, it is inappropriate to simply consider these dopants as structural promoters (e.g. improved melting temperature and higher

Table 3. Performance of Cu-Based and Non-Copper Catalysts for Ethane Oxychlorination

\begin{tabular}{|c|c|c|c|c|c|c|}
\hline \multirow{2}{*}{ catalyst } & \multicolumn{2}{|c|}{ reactivity ${ }^{a}$} & \multicolumn{3}{|c|}{ conditions } & \multirow{2}{*}{ ref } \\
\hline & $X / \%$ & $S / \%$ & reactor & $\mathrm{GHSV}^{b} / \mathrm{h}^{-1}$ & $T / \mathrm{K}$ & \\
\hline \multicolumn{7}{|l|}{ copper-based catalysts } \\
\hline $\mathrm{CuKLaCl}_{x} / \gamma-\mathrm{Al}_{2} \mathrm{O}_{3}$ & $>90$ & 2-38 (VCM) & fixed & 470 & 773 & 174 \\
\hline $\mathrm{CuO}-\mathrm{Cs}_{2} \mathrm{O} /$ cement & 81 & 42 (VCM) & fixed & 600 & 673 & 180 \\
\hline $\mathrm{CuKCeCl}_{x} / \mathrm{MgO}-\gamma-\mathrm{Al}_{2} \mathrm{O}_{3}$ & 98 & $55(\mathrm{VCM})$ & fixed & 8 & $723-823$ & 176 \\
\hline $\mathrm{CuKCeCrCl}{ }_{x} / \gamma-\mathrm{Al}_{2} \mathrm{O}_{3}$ & 98 & 68 (VCM) & fixed & 424 & 783 & 181 \\
\hline $\mathrm{CuKCeCl}_{x} / \alpha-\mathrm{Al}_{2} \mathrm{O}_{3}$ & 98 & $44(\mathrm{VCM})$ & fixed & 900 & 803 & 182 \\
\hline $\mathrm{CuKPrCl}_{x} / \mathrm{MgO}-\gamma-\mathrm{Al}_{2} \mathrm{O}_{3}$ & 98 & $52(\mathrm{VCM})$ & fixed & 38 & $723-823$ & 178 \\
\hline $\mathrm{La}_{1.7} \mathrm{~K}_{0.3} \mathrm{NiMnO}_{6}-\mathrm{CuCl}_{2} / \gamma-\mathrm{Al}_{2} \mathrm{O}_{3}$ & 100 & $40-60$ (VCM) & fixed & 424 & 773 & 183 \\
\hline $\mathrm{CuCO}_{3}-\mathrm{CeO}_{2}$ & 88 & 28 (VCM) & fixed & 13 & 773 & 28 \\
\hline $\mathrm{CuKCl} / \mathrm{Al}_{2} \mathrm{O}_{3}$ & 90 & 33 (VCM) & fluidized & 94 & 753 & 172 \\
\hline $\mathrm{CuLiPtCl}_{x}-\mathrm{K}_{3} \mathrm{PO}_{4} / \alpha-\mathrm{Al}_{2} \mathrm{O}_{3}$ & - & $88(\mathrm{VCM})^{c}$ & fluidized & 150 & 823 & 184 \\
\hline $\mathrm{CuCl}_{2} /$ montmorillonite & - & $90(\mathrm{EDC})^{c}$ & fluidized & - & 525 & 78 \\
\hline \multicolumn{7}{|l|}{ non-copper catalysts } \\
\hline $\mathrm{Fe}_{2} \mathrm{O}_{3} / \gamma-\mathrm{Al}_{2} \mathrm{O}_{3}$ & $>92$ & 23-35 (VCM) & fluidized & $77-105$ & 823 & 171 \\
\hline $\mathrm{LaOCl}$ & 27 & 79 (VCM) & fluidized & 96 & 673 & 185 \\
\hline $\mathrm{CeO}_{2}-\mathrm{Li}_{2} \mathrm{O} / \alpha-\mathrm{Al}_{2} \mathrm{O}_{3}$ & 99 & 26 (VCM) & fixed & 38 & 923 & 186 \\
\hline $\mathrm{Fe}_{2} \mathrm{O}_{3}-\mathrm{Li}_{2} \mathrm{O} / \alpha-\mathrm{Al}_{2} \mathrm{O}_{3}$ & 99 & 42 (VCM) & fixed & 38 & 923 & 186 \\
\hline $\mathrm{Fe}\left(\mathrm{P}_{2} \mathrm{O}_{7}\right)_{x} / \mathrm{SiO}_{2}$ & 15 & $92\left(\mathrm{C}_{2} \mathrm{H}_{4}\right)$ & fixed & 345 & 773 & 27 \\
\hline $\mathrm{Fe}\left(\mathrm{P}_{2} \mathrm{O}_{7}\right)_{x} / \mathrm{SiO}_{2}$ & 14 & $93\left(\mathrm{C}_{2} \mathrm{H}_{5} \mathrm{Cl}\right)$ & fixed & 257 & 648 & 27 \\
\hline $\mathrm{MnO}_{x}-\mathrm{CeO}_{2}$ & 91 & $67\left(\mathrm{C}_{2} \mathrm{H}_{4}\right)$ & fixed & 3670 & 723 & 187 \\
\hline $\mathrm{K}_{4} \mathrm{Ru}_{2} \mathrm{OCl}_{10} / \mathrm{TiO}_{2}$ & 13 & $82\left(\mathrm{C}_{2} \mathrm{H}_{5} \mathrm{Cl}\right)$ & fixed & 900 & 573 & 188 \\
\hline
\end{tabular}

${ }^{a}$ Conversion of ethane and selectivity were denoted as $X$ and $S$, respectively. ${ }^{b} \mathrm{GHSV}$ was calculated based on ethane. The voidage of catalyst bed was estimated as 50\%. ${ }^{c}$ Yield. 
dispersion) since in many cases, electronic effects (e.g., acid-base and redox properties) are more prominent, which can lead to enhanced hydrochlorination performance.

Different dopants such as alkali (K and Li) and rare-earth (La, Ce, and Pr) metals have been studied (Figure 14a). Results from an early patent show that pure alkali metal-doped catalysts were not selective for VCM (33\% selectivity at $753 \mathrm{~K}$ over $\mathrm{CuKCl}_{x} / \mathrm{Al}_{2} \mathrm{O}_{3}$ ), leading to a spectrum of polychlorinated compounds. ${ }^{172}$ These dopants are thus almost exclusively used together with other additives instead of
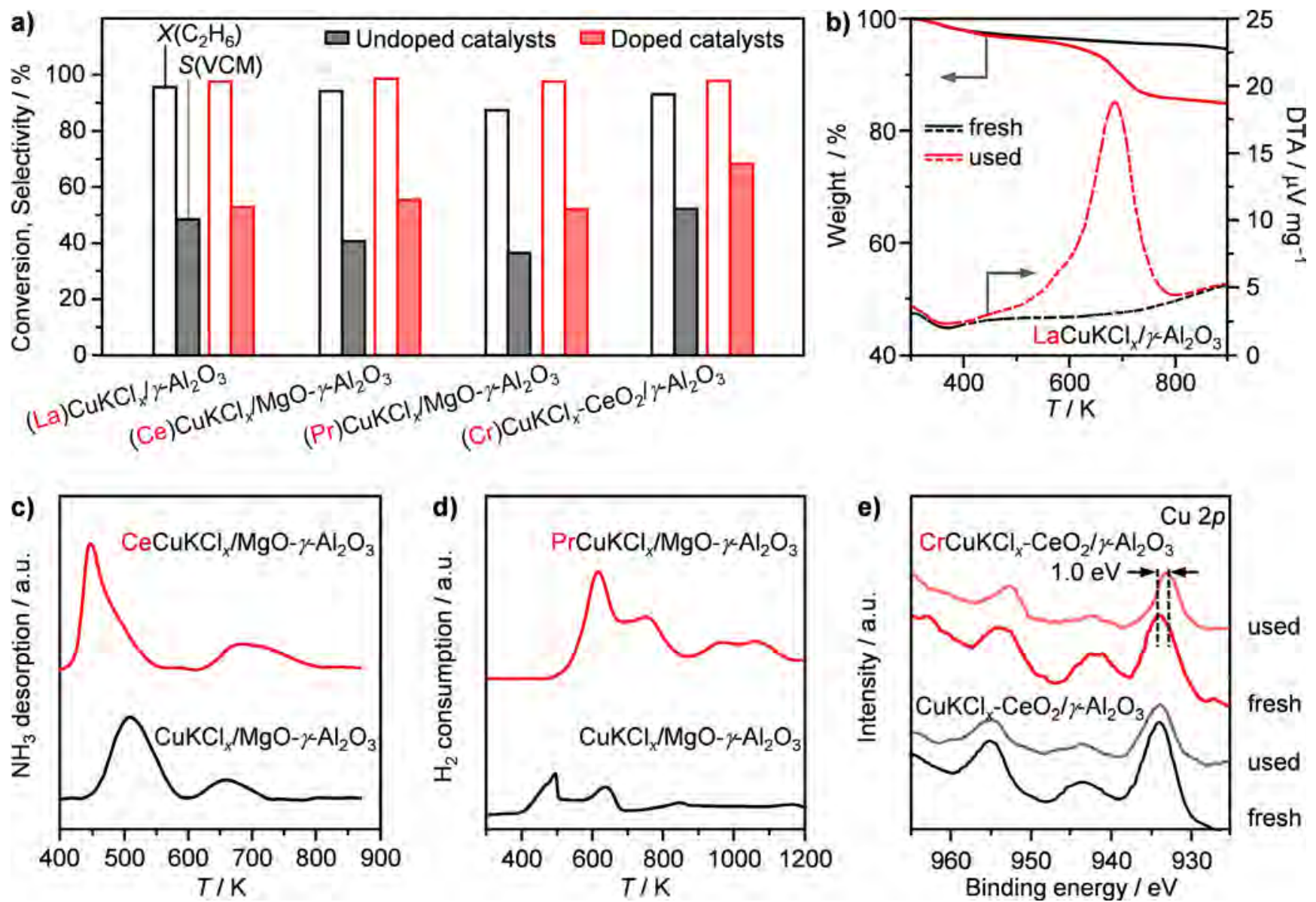

Figure 14. Effect of different promoters on copper-based catalysts for ethane oxychlorination. a) Comparison of reactivity between undoped- and doped-copper catalysts (promoters are highlighted in red in the bracket). Data taken from refs 174, 176, 178, 181. b) Thermogravimetric and differential thermal analysis (TGA-DTA) profiles of fresh (dark) and used (red) $\mathrm{LaCuKCl}_{x} / \gamma-\mathrm{Al}_{2} \mathrm{O}_{3}$ catalysts, showing coke deposition on the used catalyst. Adapted with permission from ref 174. Copyright 2005 Springer. c) $\mathrm{NH}_{3}-\mathrm{TPD}$ profiles. Adapted with permission from ref 176. Copyright 2011 Elsevier. d) Temperature-programmed reduction with hydrogen $\left(\mathrm{H}_{2}-\mathrm{TPR}\right)$ profiles. Adapted with permission from ref 178. Copyright 2013 Elsevier. e) Cu 2p XPS spectra. Adapted with permission from ref 181. Copyright 2015 Elsevier. 
alone to further enhance the stability and selectivity. As mentioned earlier, the stability is a big issue for the Cu-based catalysts. A study on $\mathrm{LaKCuCl}_{x} / \gamma-\mathrm{Al}_{2} \mathrm{O}_{3}$ revealed gradual catalyst deactivation with decreased VCM selectivity due to severe copper leaching (24\% Cu loss after $100 \mathrm{~h}$ ) and coke deposition. The latter was confirmed by the sharp weight loss accompanied with a exothermic peak from TGA/DTA profiles (Figure 14b). ${ }^{174}$ To date, the highest yield of VCM (88\% at $823 \mathrm{~K}$ ) was obtained over $\mathrm{CuLiPtCl}_{x}-\mathrm{K}_{3} \mathrm{PO}_{4} / \alpha-\mathrm{Al}_{2} \mathrm{O}_{3}$ catalysts reported by the researchers in Monsanto Company. ${ }^{184}$ The catalysts were prepared by sequential impregnation of first a mixture of metal chlorides and then $\mathrm{K}_{3} \mathrm{PO}_{4}$, and tested in a fluidized-bed reactor. Ethyl chloride and VCM are observed to be the main products in the temperature range of 623-873 K, while higher temperature is apparently more favorable for higher selectivity of VCM irrespective of contact times. Acid-base property of catalysts can be an important factor for the selective formation of VCM. An improved VCM selectivity was observed on $\mathrm{CeO}_{2}$-doped $\mathrm{CuKCl}_{x} / \mathrm{MgO}-\gamma-\mathrm{Al}_{2} \mathrm{O}_{3}$ catalysts compared to that on the undoped sample (Figure 14a). ${ }^{176}$ The addition of $\mathrm{CeO}_{2}$ led to increased intensity of acidic sites (Figure 14c), probably attributed to the generation of surface capping oxygen species $\left(\mathrm{O}^{-}\right.$and $\left.\mathrm{O}_{2}{ }^{-}\right)$. These acidic sites might facilitate the dehydrochlorination of EDC to VCM. As the most crucial component, the dispersion and redox properties of copper chlorides can directly influence the catalytic performance. For example, the $\mathrm{H}_{2}$ consumption corresponding to the reduction of $\mathrm{Cu}^{2+}$ to $\mathrm{Cu}^{0}$ was greatly increased over praseodymiumpromoted $\mathrm{CuKCl}_{x} / \mathrm{MgO}-\gamma-\mathrm{Al}_{2} \mathrm{O}_{3}$ catalysts (Figure 14d). ${ }^{178}$ Calculation of the surface $\mathrm{Cu}$ content from the above results showed two times enhanced copper dispersion with an addition of $5 \mathrm{wt} \%$ Pr. Consequently, a higher ethane conversion and a higher VCM selectivity were achieved over the Prdoped catalysts. Chromium has been recognized as an electronic promoter to $\mathrm{CuKCl}_{x}-\mathrm{CeO}_{2} / \gamma-\mathrm{Al}_{2} \mathrm{O}_{3}$ catalysts. Comparison of the Cu $2 p$ XPS spectra of fresh and used catalysts revealed that the redox capacity of $\mathrm{Cu}^{2+} / \mathrm{Cu}^{+}$can be facilitated by $\mathrm{Cr}$ addition (Figure 14e). Consequently, an improved performance was obtained over the catalyst with $3 \mathrm{wt} . \%$ Cr addition. ${ }^{181}$

Promoters for Cu-based catalysts in ethane oxychlorination are generally introduced in the form of metal chlorides or oxides by impregnation. Recently, Hu et al. reported a striking promotional effect of 
a perovskite compound, $\mathrm{La}_{2} \mathrm{NiMnO}_{6}$, on the performance of $\mathrm{CuCl}_{2} / \gamma-\mathrm{Al}_{2} \mathrm{O}_{3}$ catalyst. ${ }^{183}$ After further modified with potassium, the catalyst afforded a total ethane conversion with a VCM yield of $c a$. 40\% at $773 \mathrm{~K}$ during $95 \mathrm{~h}$ on stream (Figure 15a). The main side-product was ethylene. The promotional effects of both $\mathrm{K}$ and $\mathrm{La}_{2} \mathrm{NiMnO}_{6}$ were demonstrated by comparing the performance of relevant catalysts (Figure 15b). The K promoter can further modify the electronic properties of the catalyst, as demonstrated by XPS and $\mathrm{H}_{2}$-TPR techniques, leading to higher amounts of surface $\mathrm{Mn}^{4+}$ and adsorbed
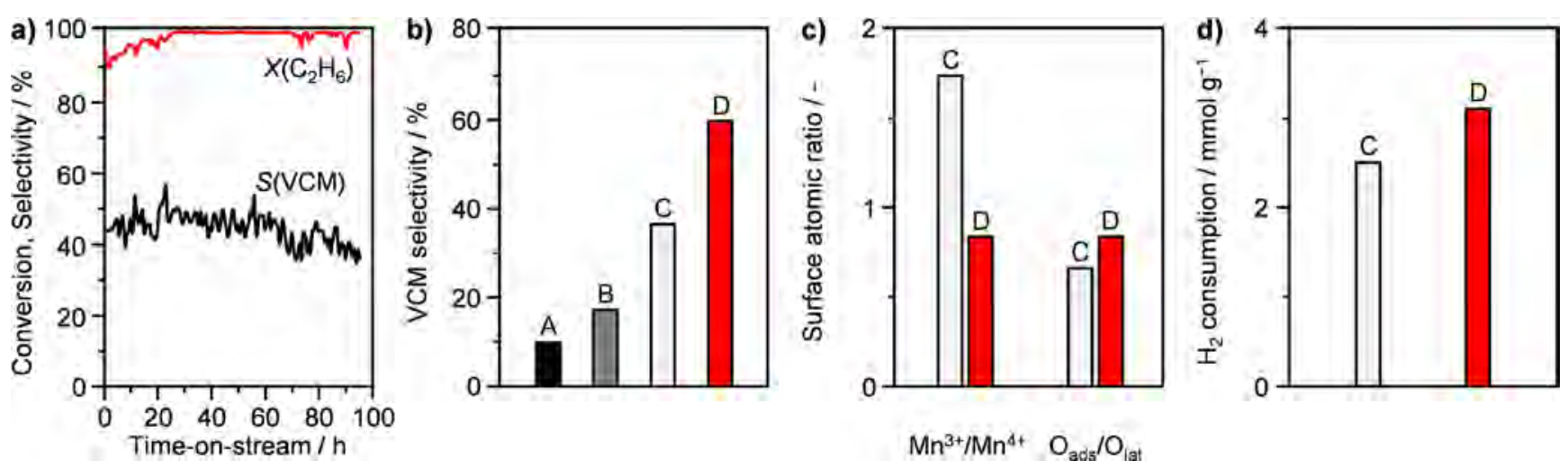

Figure 15. Ethane oxychlorination over $\mathrm{La}_{1.7} \mathrm{~K}_{0.3} \mathrm{NiMnO}_{6}-\mathrm{CuCl}_{2} / \gamma-\mathrm{Al}_{2} \mathrm{O}_{3}$ (D) catalysts. a) Conversion and selectivity versus time-on-stream. b) Comparison of VCM selectivity with reference catalysts (A: $\mathrm{CuCl}_{2} / \gamma-\mathrm{Al}_{2} \mathrm{O}_{3}$, B: $\mathrm{La}_{1.7} \mathrm{~K}_{0.3} \mathrm{NiMnO}_{6} / \gamma-\mathrm{Al}_{2} \mathrm{O}_{3}$, and $\left.\mathrm{C}: \mathrm{La}_{2} \mathrm{NiMnO}_{6}-\mathrm{CuCl}_{2} / \gamma-\mathrm{Al}_{2} \mathrm{O}_{3}\right)$ showed the promotional effect of the perovskite composition and potassium. The effect of $\mathrm{K}$ doping on the redox properties of perovskite catalysts: c) Surface atomic ratios, derived from XPS spectra, and d) $\mathrm{H}_{2}$ uptake, calculated from the first two peaks of $\mathrm{H}_{2}$-TPR profiles, corresponding to the sequential reduction of $\mathrm{Cu}^{2+} \rightarrow \mathrm{Cu}^{+} \rightarrow \mathrm{Cu}^{0}$. Adapted with permission from ref 183. Copyright 2016 Elsevier.

oxygen species (Figure 15c), as well as higher reducibility of $\mathrm{Cu}^{2+}$ (Figure 15d). All these factors contribute to the better VCM selectivity and catalyst stability.

Non-Copper Catalysts. The failures in ethane oxychlorination might be explained by the approach which is based on the extrapolation of Cu-based catalysts applied in ethylene oxychlorination. ${ }^{174,176,184,189,190}$ These systems are not suitable in the case of ethane, because the operating temperature of alkane oxychlorination is much higher than that of alkene oxychlorination and thus compromises the stability of copper catalysts. ${ }^{174,191}$ 
While Cu-based catalysts usually provide appreciable VCM selectivity, the product distribution differs significantly over non-copper catalysts. Instead of VCM, ethylene and ethyl chloride might dominate in the products. For example, A study on silica-supported iron pyrophosphates doped with various metal cations showed that ethyl chloride and ethylene were the main products. ${ }^{27}$ Higher temperature facilitates the dehydrochlorination of ethyl chloride and leads to an enhanced selectivity of ethylene. Bal'zhinimaev et al. investigated a novel $\mathrm{K}_{4} \mathrm{Ru}_{2} \mathrm{OCl}_{10} / \mathrm{TiO}_{2}$ catalyst for the low-temperature ethane oxychlorination (523-573 K). ${ }^{188}$ An ethyl chloride selectivity of $80 \%$ at $13 \%$ ethane conversion was achieved at $573 \mathrm{~K}$. However, above this temperature, the formation of carbon oxides prevailed and the selectivity to ethyl chloride dropped drastically. It was reported that nanosized $\mathrm{CeO}_{2}$ was suitable for ethane oxychlorination, giving ethylene as the only predominant product $\left(S\left(\mathrm{C}_{2} \mathrm{H}_{4}\right)=67 \%\right.$, $T=723 \mathrm{~K}) .{ }^{187}$ A solution catalyst containing iron cations, used in a fluidized-bed reactor technology, showed a high ethane conversion (92-98\%) with 23-35\% selectivity to VCM, but the serious leaching of iron led to drastic catalyst deactivation. ${ }^{171}$ Doping with La was suggested to alleviate the iron leaching and thus improved the catalyst lifetime. ${ }^{192}$ To date, the highest VCM selectivity of 79\% was achieved over $\mathrm{LaOCl}$ catalysts among non-copper materials (Table 3), operated at $673 \mathrm{~K}$ in a fluidized-bed reactor. ${ }^{179,185,193}$ The porous LaOCl catalysts, obtained by a precipitation method, was used as the precursor, which after activation by a gas mixture of $5 \% \mathrm{HCl} / \mathrm{N}_{2}$ at $623 \mathrm{~K}$ can be converted to highly active $\mathrm{LaCl}_{3}$ form.

Reaction Mechanism. Regarding the reaction mechanism of ethane oxychlorination, it is expected that there will be a competition among chlorination (both addition and substitution), oxidation, and dehydrochlorination. The specific reaction routes can be fundamentally different depending on the catalysts applied. The mechanism over Cu-based catalysts has been proposed which mimics that in ethylene oxychlorination. ${ }^{180}$ The activation of ethane can be initiated by free chlorine radicals, with the formation of chloroethanes. The $\mathrm{Cu}^{2+} / \mathrm{Cu}^{+}$redox pair was acknowledged to manipulate the release of $\mathrm{Cl}_{2}$ by the decomposition of $\mathrm{CuCl}_{2}$ to $\mathrm{Cu}_{2} \mathrm{Cl}_{2} \cdot{ }^{176,183}$ Ethyl chloride was regarded as the primary product, and ethylene was obtained by its dehydrochlorination. The rest of the reaction network follows roughly the 

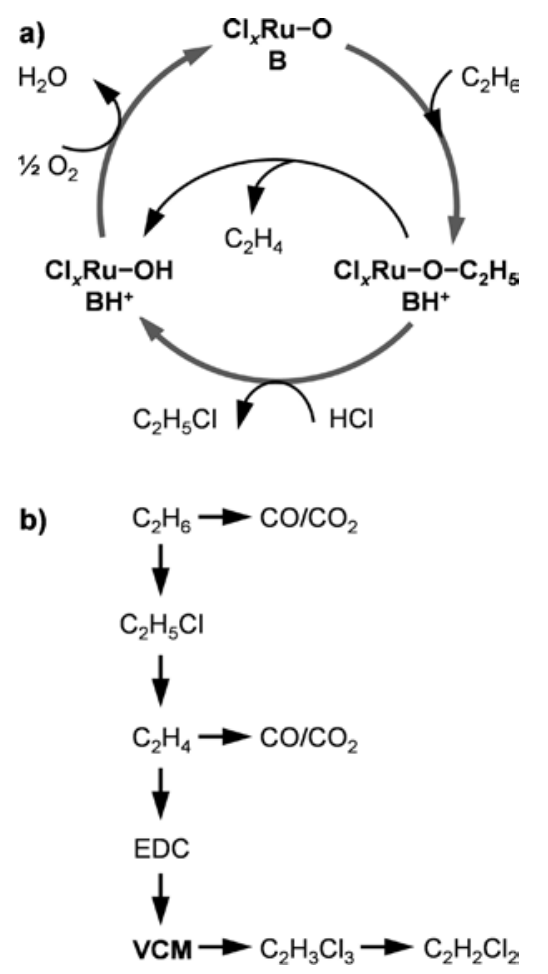

Figure 16. Reaction pathways of ethane oxychlorination over metal oxychloride catalysts: a) $\mathrm{K}_{4} \mathrm{Ru}_{2} \mathrm{OCl}_{10} / \mathrm{TiO}_{2}$. Reproduced with permission from ref 188. Copyright 2013 Springer. B stands for basic oxygen species. Ethoxy groups were formed by the adsorption of $\mathrm{C}_{2} \mathrm{H}_{6}$ on the catalyst surface and served as the reaction intermediates. The direct dehydration and substitution of $\mathrm{HCl}$ lead to $\mathrm{C}_{2} \mathrm{H}_{4}$ and $\mathrm{C}_{2} \mathrm{H}_{5} \mathrm{Cl}$, respectively. b) $\mathrm{LaOCl}$. Reproduced with permission from ref ${ }^{179}$. Copyright 2010 American Chemical Society.

same paths as in ethylene oxychlorination. Another two different reaction mechanisms, emphasizing the role of surface or lattice chloride, have been proposed over $\mathrm{K}_{4} \mathrm{Ru}_{2} \mathrm{OCl}_{10} / \mathrm{TiO}_{2}{ }^{188}$ and $\mathrm{LaOCl}^{179}$ catalysts. Ethane oxychlorination over both catalysts can take place readily below $673 \mathrm{~K}$. Besides, the valence states of $\mathrm{Ru}$ and La were stable after these catalysts were subjected to oxychlorination ambience. The ruthenium oxychloride species in $\mathrm{K}_{4} \mathrm{Ru}_{2} \mathrm{OCl}_{10} / \mathrm{TiO}_{2}$ were believed to be the active sites for ethane activation. Experiments on a reference $\mathrm{RuO}_{2} / \mathrm{TiO}_{2}$ catalyst showed a poor ethyl chloride selectivity ( $\leq 30 \%)$, and large amounts of EDC and combustion products were present. ${ }^{188}$ In situ IR experiments further confirmed the immediate formation of ethoxy groups after the $\mathrm{K}_{4} \mathrm{Ru}_{2} \mathrm{OCl}_{10} / \mathrm{TiO}_{2}$ catalysts were exposed to the reaction feeds. It is suggested that the surface-bound ethoxy groups can release ethylene, or ethyl chloride by $\mathrm{HCl}$ addition (Figure 16a). For LaOCl catalysts, hydrocarbon chlorination was 
supposed to occur through lattice chlorine based on reactive pulse techniques, as the presence of gas phase $\mathrm{HCl}$ or $\mathrm{Cl}_{2}$ was not necessary. ${ }^{194}$ The surface chlorination level of the catalysts played a vital role in regulating the product distribution, with the highest chlorination rates and selectivity observed on fully chlorinated catalysts. ${ }^{179}$ A specific reaction pathway was proposed for the LaOCl catalysts, where VCM was deemed to be the dehydrochlorination product of EDC while carbon oxides were formed solely by the oxidation of hydrocarbons (Figure 16b).

2.4.2. Accounts of Developing Processes. Devising alternative routes to VCM and $\mathrm{C}_{2}$ compounds from ethane has long been an objective of the chemical industry. Among these, ethane oxychlorination to VCM have been actively explored for more than half a century. To date, a number of processes have been disclosed in patents, but none has been commercialized yet. ${ }^{29,195-198}$ Since ethane oxychlorination is highly demanding in terms of selective formation of VCM, the role of catalysts is extremely prominent. This is because the reactor technologies and process design are closely related to the catalysts used. Thus, it is of our interest to compare the developing processes based on different catalysts, and point to the main hurdles constraining their implementation.

Lummus Process. An earlier fixed-bed reactor technology developed by Lummus using conventional $\mathrm{CuCl}_{x} / \mathrm{Cu}_{2} \mathrm{OCl}_{2}$ catalysts yielded a $\mathrm{VCM}$ selectivity of $37 \%$ at $28 \%$ ethane conversion (Figure 17). ${ }^{29,195}$ In this process, three consecutive reactors were operated in a temperature range of 643923 K. Ethane oxychlorination occurred in the first reactor, where the effluents, after a separation section, were split: ethyl chloride was recycled to the first reactor, while EDC was directed to dehydrochlorination to VCM in the second reactor with the same melt salt catalysts. In order to recover chlorine, the other chlorinated hydrocarbons from the first two reactors were combusted to enrich chlorine/hydrogen chloride-rich effluent. The recovered catalysts from the first two reactors, after passing a heat exchange vessel, were directed into the regeneration reactor to contact with the effluent from the combustion reactor. The molten salt catalysts can adsorb chlorine/hydrogen chloride from the effluent, and after partially oxidized, convert to the original mixture components $\left(\mathrm{CuCl}_{x} / \mathrm{Cu}_{2} \mathrm{OCl}_{2}\right)$. Since these melt catalysts can easily volatilize at such high temperatures, a quench system inside each 


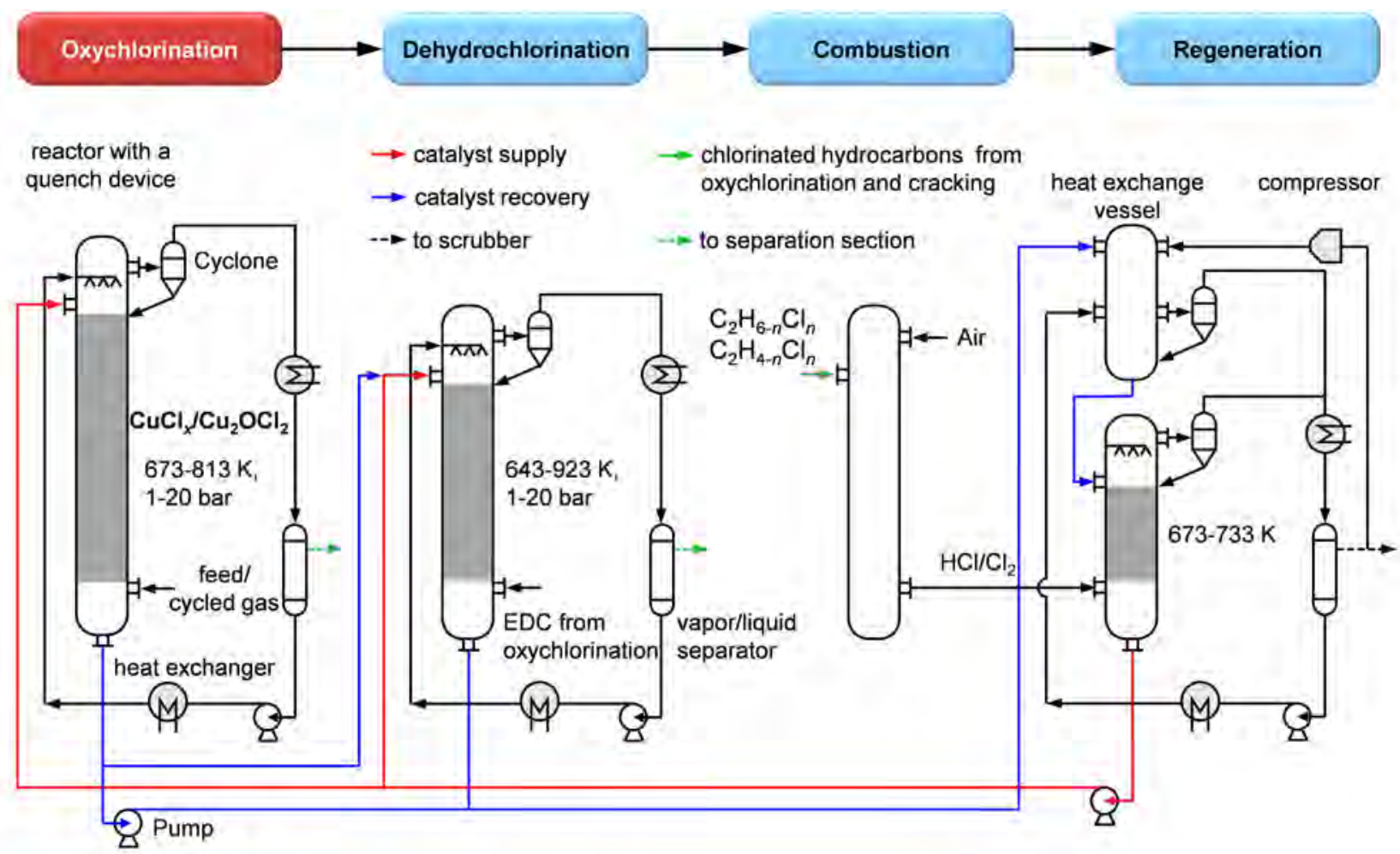

Figure 17. A simplified scheme of the Lummus process for ethane oxychlorination over $\mathrm{CuCl}_{x}$-based catalysts relied on the fixed-bed reactor technology, comprising ethane oxychlorination, dehydrochlorination of EDC to VCM, combustion of chlorinated hydrocarbons to enrich chloride-rich effluent, and the regeneration of used melt salt catalysts with the effluent from combustion. The three reactors with catalysts loaded were installed with an internal quench system and an external cyclone separator to ease catalyst volatilization. The catalysts were recovered (blue lines) to regenerate in a separate reactor, and cycled to replenish the catalyst beds (red lines). Adapted from ref 195.

reactor, with an external cyclone separator, was installed to ease the supply of fresh catalysts. Apparently, the low catalyst efficiency and energy-intensive nature due to continuous catalysts cycling render this process unattractive.

EVC Process. EVC made a breakthrough for VCM production from ethane via an integrated multistep process whose viability was assessed by a pilot plant in 1999 (1000 ton per annum). ${ }^{29}$ In this process (Figure 18a), the oxychlorination was catalyzed by $\mathrm{Cu} / \mathrm{K} / \mathrm{Ce}$ components supported on fluidizable low-surface area $\mathrm{Al}_{2} \mathrm{O}_{3}$, and operated in a fluidized-bed reactor at $723-743 \mathrm{~K} .{ }^{196} \mathrm{VCM}$ and anhydrous $\mathrm{HCl}$ in the effluent were separated, and the latter was directly cycled in the oxychlorination reactor. The other stream first passed by a chlorinator, where chlorine was introduced, to convert ethylene into EDC. Then the effluents containing both saturated and unsaturated chlorinated 
hydrocarbons were further directed to a trickle bed reactor where unsaturated products were hydrogenated over precious metal catalysts (Pt, $\mathrm{Pd}$, and $\mathrm{Rh}$ ), and directed into the oxychlorination reactor for VCM production. In this way all the organic compounds are finally dehydrochlorinated to VCM, except $\mathrm{CCl}_{4}{ }^{197}$ In the oxychlorination reactor, an excess of recycled $\mathrm{HCl}$ suppresses ethane

a)
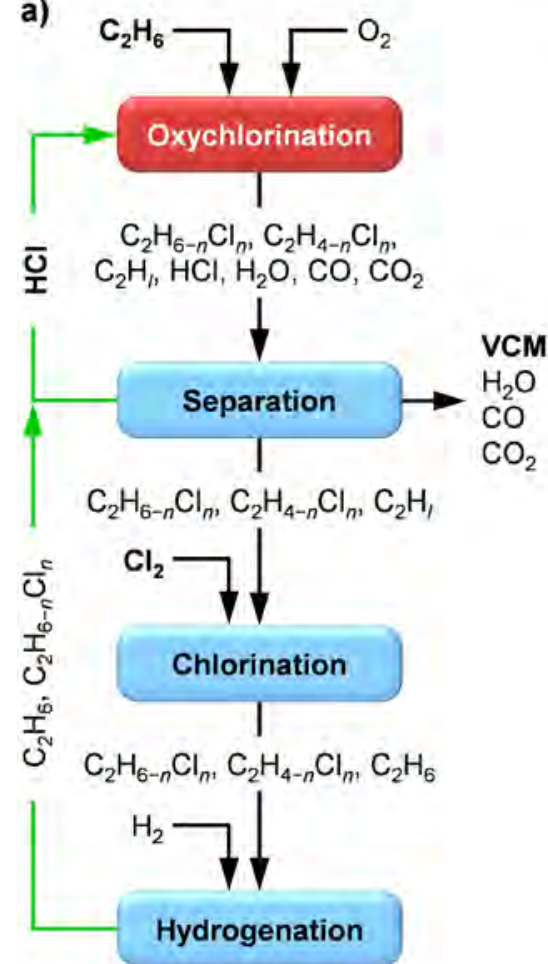

b)

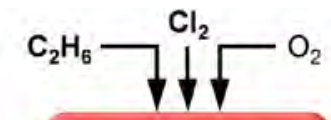

Oxychlorination

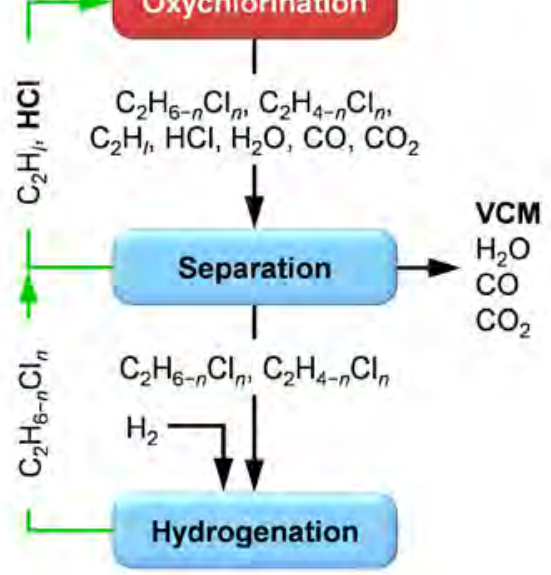

c)

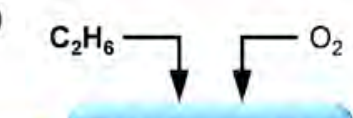

Dehydrogenation
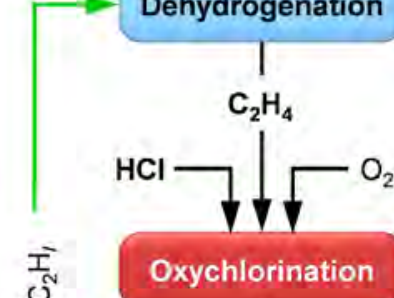

$\mathrm{C}_{2} \mathrm{H}_{6-n} \mathrm{Cl}_{n}, \mathrm{C}_{2} \mathrm{H}_{4-n} \mathrm{Cl}_{n}$ $\mathrm{C}_{2} \mathrm{H}_{1}, \mathrm{HCl}, \mathrm{H}_{2} \mathrm{O}, \mathrm{CO}, \mathrm{CO}_{2}$

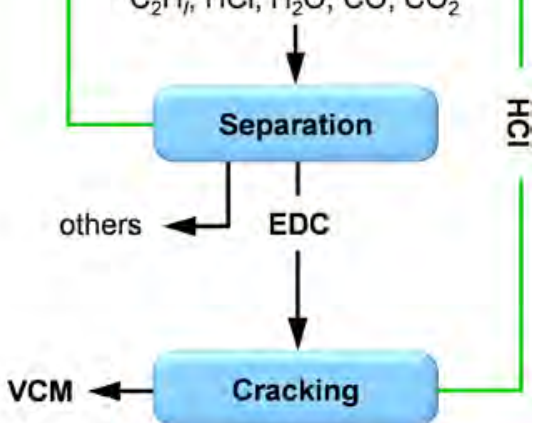

Figure 18. Simplified schemes of processes of VCM production from ethane. a) The EVC process based on ethane oxychlorination over $\mathrm{CuKCeCl}_{x} / \mathrm{Al}_{2} \mathrm{O}_{3}$ in a fluidized-bed reactor. ${ }^{197} \mathrm{HCl}$ from the separation was recycled in the oxychlorination reactor. Ethylene from the oxychlorination reactor was converted to EDC in a vapor-phase chlorinator where chlorine was introduced as the halogen source. All the Clcontaining unsaturated hydrocarbons $\left(\mathrm{C}_{2} \mathrm{H}_{4-n} \mathrm{Cl}_{n}\right)$ were further hydrogenated to saturated ones $\left(\mathrm{C}_{2} \mathrm{H}_{6-n} \mathrm{Cl}_{n}\right)$ and fed back to the oxychlorination reactor to generate VCM by dehydrochlorination. $\mathrm{HCl}$ was cycled in the oxychlorination reactor. b) An envisioned VCM production process based on the fluidized-bed reactor technology via oxychlorination of ethane over the LaOCl catalyst, developed by the Dow Chemical Company. Elemental chlorine together with the cycled $\mathrm{HCl}$ was directed into the oxychlorination reactor. The mixture of $\mathrm{C}_{2}$ hydrocarbons were also recycled after separation, while the rest chlorinated compounds were converted to EDC in a hydrogenation unit and then merged with the cycled hydrocarbons and $\mathrm{HCl}$. Adapted with permission from ref 179. Copyright 2010 American Chemical Society. c) The ethane-to-VCM process developed by BASF that integrates essentially the dehydrogenation of ethane to ethylene, subsequent oxychlorination to EDC, and a cracking step. ${ }^{198}$ $n=0-6, l=4$ or 6 . 
combustion and enables to decrease the reaction temperature below $723 \mathrm{~K}$ with acceptable conversion and selectivity. By recycling the byproducts, a very high overall VCM yield $>90 \%$ was claimed. The pilot test over 2000 h has shown no corrosion problems and the catalyst has been observed to be stable. EVC claimed this novel process reduces the production cost over the PVC chain by 20-30\%. ${ }^{199}$

Dow Process. More recently, the Dow Chemicals Company envisioned a new fluidized-bed reactor technology for the direct conversion of ethane to VCM at low temperatures $(T<700 \mathrm{~K})$, enabled by the discovery of novel catalytically active materials, $\mathrm{LaOCl} / \mathrm{LaCl}_{3}$ (Figure $18 \mathrm{~b}$ ). ${ }^{132}$ The process based on the catalysts is quite similar to the EVC route, as both employed the fluidized-bed reactor for the oxychlorination section and an additional hydrogenation step for chlorinated byproduct recycling. However, chlorine can be directly introduced in the oxychlorination reactor in this newly developed process, thus the chlorination step is omitted. Furthermore, this process is suitable for the co-feeding of ethane and ethylene that can be recycled with $\mathrm{HCl}$. In this way, the ethylene byproduct can also be consumed in the oxychlorination reactor, thus enabling a full recycle of the major byproducts. It was reported that a VCM yield of $79-81 \%$ and a productivity of $0.050-0.055 \mathrm{~g}(\mathrm{VCM}) \mathrm{h}^{-1} \mathrm{~g}_{\text {cat }}{ }^{-1}$ can be achieved under conditions that simulated a complete recycle of the reaction byproducts in a pilot plant. ${ }^{179}$ However both cold flow and hot flow tests in pilot plant reactor system indicate poor gas-solid contacting for some catalysts. Fluidization engineering, with regard to the reactor design and catalyst preparation, still presents a big technical hurdle to the commercial scale implementation of this process.

BASF Process. Another process has been conceived by BASF, using ethane as a raw material for the production of EDC, followed by EDC cracking to VCM (Figure 18c). ${ }^{198}$ It essentially merges ethane dehydrogenation to ethylene, whether by means of thermal cracking or catalytic dehydrogenation, with ethylene oxychlorination to produce EDC by the known copper chloride-based catalysts. The unreacted hydrocarbons can be recycled to the dehydrogenation reactor, while EDC after separation by distillation can be cracked into VCM. HCl produced in the pyrolysis of EDC is separated and recycled to the oxychlorination reactor. It is claimed that this process can be implemented by modification of existing 
processes for the preparation of EDC/VCM from ethylene. ${ }^{198}$ However, one-step VCM formation from ethane should be more straightforward and thus advantageous over this indirect route.

\subsection{Phosgene Chemistry in PU and PC Production}

Carbonic acid dichloride, better known as phosgene, was discovered in 1812 by John Davy. ${ }^{200}$ Despite the high toxicity, it has been widely used in the production of fine chemicals since the beginning of the chemical industry due to the remarkable chemical properties. Phosgene chemistry, albeit somewhat arbitrary in classification, encompasses phosgenation reactions of two main categories: those that introduce the building block "carbonyl” as a structural unit, and those involving phosgene and its derivatives as reagents. ${ }^{201}$ The most representative examples of the first type of phosgenation are manifested in the manufacture of PU and PC (Figure 19).

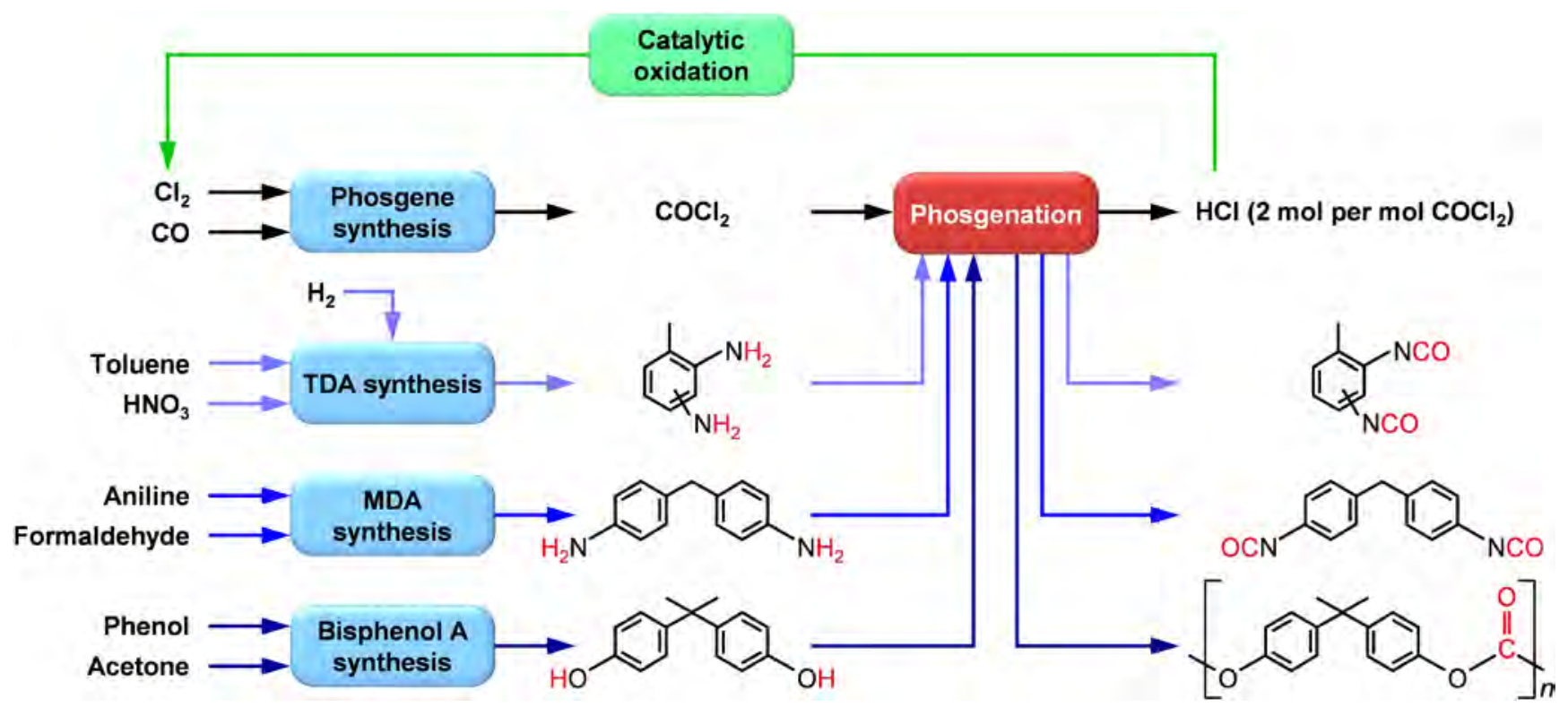

Figure 19. Simplified scheme showing application of phosgenation route in manufacture of PU and PC.

2.5.1. Phosgene Synthesis. Phosgene is synthesized on an industrial scale with an annual global production of several million tons by a catalyzed reaction between gaseous chlorine and CO at elevated temperature (323-423 K). ${ }^{202}$ The reaction is selectively catalyzed by pristine high surface area activated carbon materials, with the only byproduct of carbon tetrachloride within 1000 ppm levels. ${ }^{202-204}$ It seems that the utilization of carbon materials promotes the adsorption of both reactants on the catalyst surface 
and thus enhances the performance. This is supported by the early kinetic studies on phosgene formation over commercial catalysts, which indicated that the reaction can be described by a L-H model. ${ }^{205}$ Based on similar characteristics of the ample presence of bent carbon layers, semi-spheres, and carbon cages in activated carbon and fullerene $\left(\mathrm{C}_{60}\right)$, Lercher et al. conducted a combined experimental and theoretical study on the reaction mechanism over $\mathrm{C}_{60}$ as a model system. ${ }^{203}$ They suggest that the reaction may follow a two-step E-R mechanism (Figure 20). ${ }^{203}$ The reaction is found to be initiated by $\mathrm{Cl}_{2}$ activation over the triplet excited potential energy surface of $\mathrm{C}_{60}$, forming the surface bound $\left[\mathrm{Cl}_{2} \cdots \mathrm{C}_{60}\right]$ species. The attack of gaseous $\mathrm{CO}$ leads to another intermediate $\left[\mathrm{COCl} \cdots \mathrm{ClC}_{60}\right]$. Once it is generated, $\mathrm{COCl}_{2}$ can be formed from a barrierless reaction between $\mathrm{COCl}^{\bullet}$ and another $\mathrm{Cl}_{2}$ molecule or with the adjacent $\mathrm{Cl}^{\bullet}$ radicals. These seemingly contradictory conclusions about the reaction mechanism might be originated from the material gap between the model catalysts with a well-defined structure and the real catalysts for which the structure is even more complex.

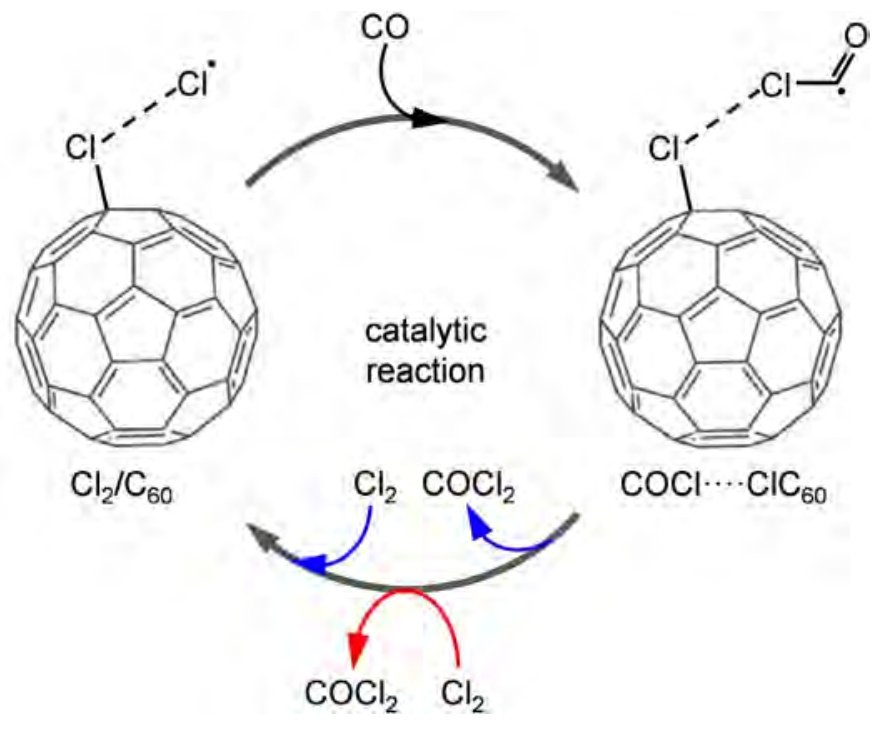

Figure 20. Proposed mechanism for $\mathrm{Cl}_{2} / \mathrm{C}_{60}$ catalyzed $\mathrm{COCl}_{2}$ formation following Eley-Rideal mechanism. Reproduced with permission from ref 203. Copyright 2016 Wiley-VCH.

2.5.2. Phosgenation of Amines and Alcohols. PU and PC are the most representative chlorine-free end materials produced using phosgene chemistry. Methylene diphenyl diisocyanate (MDI) and TDI are the key precursors in the manufacture of PU which account for $61 \%$ and $34 \%$, respectively, in the world 
isocyanate market. ${ }^{9}$ As shown in Figure 19, the most effective method to prepare these precursors is by phosgenation of respective amines (TDA or MDA) with $\mathrm{COCl}_{2}$. Likewise, PC is synthesized by replacing the amines with bisphenol A. Disadvantageously, all these synthesis routes exclusively produced stoichiometric $\mathrm{HCl}\left(2 \mathrm{~mol}\right.$ per $\mathrm{mol} \mathrm{COCl}_{2}$ ) as a byproduct. Considering the huge and ever increasing global demand of these polymers (Figure 5), development of effective technologies for chlorine recycling will make the processes more sustainable.

2.5.3. Chlorine Recycling via Catalyzed HCl Oxidation. The establishment of the balanced process for EDC production enables the recovery of chlorine dispensed as $\mathrm{HCl}$ byproduct in the thermal cracking step via the oxychlorination reaction (Figure 6). Besides, PVC business also serves to recycle $\mathrm{HCl}$ released from other commercial processes. However, demand for other plastics manufactured via chlorine chemistry, particularly PU and PC, grows at a higher pace than that of PVC, leading to a growing excess of $\mathrm{HCl}$ byproduct in the chemical industry. Moreover, the emerging natural gas upgrading through halogen chemistry will also lead to the generation of $\mathrm{HX}$ in the functionalization and elimination steps (Section 3, Figure 27, vide infra). Therefore, technologies enabling the valorization of the $\mathrm{HCl}$ surplus into $\mathrm{Cl}_{2}$ are highly requisite. Electrochemical routes are highly attractive for this purpose, but they suffer from high power consumption, making the overall process energyintensive. ${ }^{206,207}$ The oxygen-depolarized cathode (ODC) technology, jointly developed by Bayer MaterialScience (BMS) and UHDENORA in the 1990s, lowers the power consumption of the conventional diaphragm electrolysis process by up to $30 \% .^{206,207}$ Still, the heterogeneously catalyzed $\mathrm{HCl}$ oxidation to $\mathrm{Cl}_{2}$ (Eq. 2) is a more attractive method to recover chlorine, particularly because of its markedly lower unit power consumption even when compared to the ODC-based $\mathrm{HCl}$ electrolysis. ${ }^{208}$ Catalytic $\mathrm{HCl}$ oxidation was originally conceived and implemented by Henry Deacon and Ferdinand Hurter in 1870 over $\mathrm{CuCl}_{2} /$ pumice catalysts in a fixed-bed reactor at $693-723 \mathrm{~K}$ to curb $\mathrm{HCl}$ emissions from the Leblanc process. ${ }^{16}$

$$
2 \mathrm{HCl}+1 / 2 \mathrm{O}_{2} \rightarrow \mathrm{Cl}_{2}+\mathrm{H}_{2} \mathrm{O} \quad \Delta H=-57 \mathrm{~kJ} \mathrm{~mol}^{-1}
$$


Over the years, significant efforts regarding both catalyst formulation and reactor configuration were made to improve the original Deacon-Hurter process. ${ }^{209-214}$ The catalyst formulation was modified through additives, such as didymium and/or potassium chlorides, which form molten salts and improve the catalyst stability. ${ }^{211,212,215}$ Besides, owing to the exothermic nature of the process, fluidized-bed reactor technology was conceived which allowed isothermal operation at reduced temperature. ${ }^{211-213}$ Nevertheless, industrial technologies developed in the second half of the $20^{\text {th }}$ century for chlorine production via $\mathrm{HCl}$ oxidation in fluidized-bed reactors, such as the Shell-Chlor process established in the 1960s $\left(\mathrm{CuCl}_{2}-\mathrm{KCl} / \mathrm{SiO}_{2} \text { catalyst, } 638 \mathrm{~K}, 30 \mathrm{kton} \mathrm{Cl}_{2} \text { per annum facility }\right)^{211,212}$ and the MTChlor process established in the late $1980 \mathrm{~s}\left(\mathrm{Cr}_{2} \mathrm{O}_{3} / \mathrm{SiO}_{2}\right.$ catalyst, $653 \mathrm{~K}, 60 \mathrm{kton} \mathrm{Cl}_{2}$ per annum facility), ${ }^{213,214}$ were progressively abandoned. The key hurdles with these systems are (i) low single pass $\mathrm{HCl}$ conversion, (ii) loss of activity due to the volatilization of the active phase, (iii) environmental concerns associated with the use of a chromium-based material, and (iv) corrosion issues related to the presence of unreacted $\mathrm{HCl}$ and product $\mathrm{H}_{2} \mathrm{O} \cdot{ }^{210,216}$ Moreover, the noxious and corrosive characters of the reaction, which demand stringent safety precautions, have hindered academic research on $\mathrm{HCl}$ oxidation. Still, the limited selling option and high cost for neutralizing HCl triggered the industrial and academic research in the last decade to hunt for novel catalysts capable of overcoming the above issues, particularly in relation to chlorine recycling in PU and PC manufactures. Extensive research efforts have culminated in the identification of $\mathrm{RuO}_{2}$-based materials, exhibiting outstanding activity and stability and thus fulfilling the expectations for an industrial catalyst.

HCl Oxidation on $\mathbf{R u O}_{2}$-Based Catalysts. A recent review by Pérez-Ramírez et al. summarized the chlorine recycling via $\mathrm{HCl}$ oxidation, with particular focus on $\mathrm{RuO}_{2}$-based catalysts from fundamental understanding to implementation. ${ }^{8}$ Thus, a brief overview, with important findings reported afterwards, is provided herein. The key features of $\mathrm{RuO}_{2}$-based catalysts are: (i) high activity at low temperatures (Figure 21a) and (ii) preservation of bulk structure i.e. chlorination is confined to the surface layers (Figure 21b). ${ }^{217,218}$ In contrast, archetypical copper-based catalysts need at least $100 \mathrm{~K}$ higher 

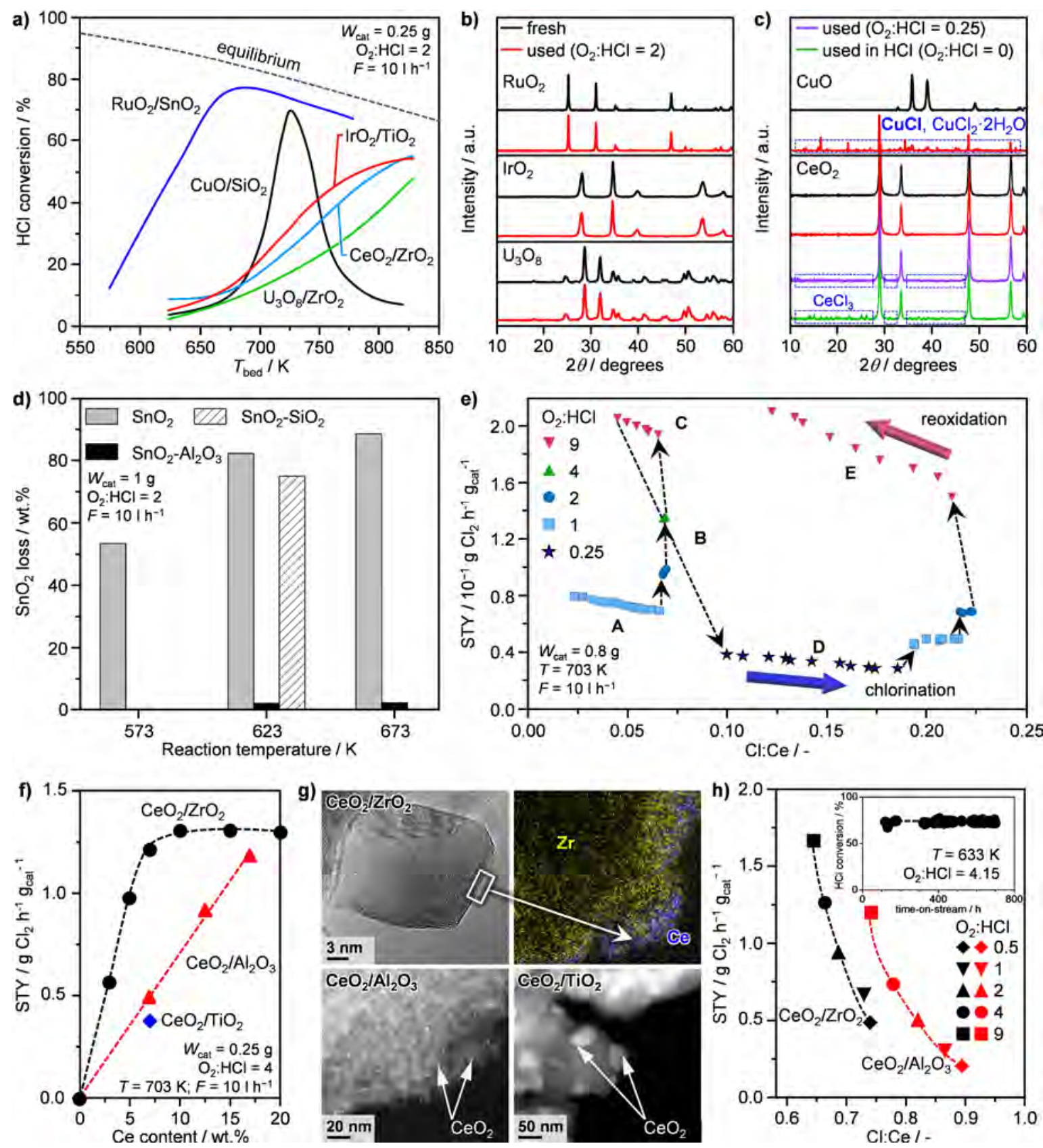

Figure 21. a) Performance of the most prominent catalysts for $\mathrm{HCl}$ oxidation. Reproduced with permission from ref 225. Copyright 2013 The Royal Society of Chemistry. b,c) XRD patterns of samples prior to (fresh) and after (used) $\mathrm{HCl}$ oxidation. Data in $\mathbf{b}$ and $\mathbf{c}$ were taken from refs 218,225,226 and 191,227, respectively. d) $\mathrm{SnO}_{2}$ loss for $\mathrm{SnO}_{2}$ and $\mathrm{SnO}_{2}-\mathrm{Al}_{2} \mathrm{O}_{3}$ at different reaction temperatures and for $\mathrm{SnO}_{2}-\mathrm{SiO}_{2}$ at $623 \mathrm{~K}$ for $2 \mathrm{~h}$. Adapted with permission from ref 228. Copyright 2013 Wiley-VCH. e) STY versus the Cl:Ce ratio in operando PGAA experiments, showing the dynamic nature of $\mathrm{CeO}_{2}$ surface. Reproduced with permission from ref 229. Copyright 2013 Elsevier. f) STY versus Ce content on supported $\mathrm{CeO}_{2}$ catalysts. g) Electron microscopy analysis of supported ceria catalysts. h) STY versus Cl:Ce in PGAA experiments over supported ceria samples (conditions as detailed in g). Inset in $\mathbf{h}$ shows a pilot evaluation data on shaped $\mathrm{CeO}_{2} / \mathrm{ZrO}_{2}$ (pellet diameter $=3 \mathrm{~mm}$ ). $\mathbf{f}$ h, adapted with permission from ref 230. Copyright 2012, Elsevier. All experiments reported were performed at 1 bar. 
temperature to reach a reasonable activity level compared to $\mathrm{RuO}_{2}$ and undergo deactivation due to structural transformation forming fugitive copper chloride phases (Figures 21a,c). Ruthenium-based catalysts for $\mathrm{HCl}$ oxidation to $\mathrm{Cl}_{2}$, first patented by Shell, have been known since the 1970 s. ${ }^{219}$ Different carriers like silica gel, $\mathrm{Al}_{2} \mathrm{O}_{3}$, and pumice were used to disperse ruthenium-containing phase. However, pilot trials or industrial applications are not reported. Recently, $\mathrm{RuO}_{2}$ supported on $\mathrm{TiO}_{2}$ rutile is commercialized by Sumitomo ${ }^{208}$ and that on $\mathrm{SnO}_{2}$ cassiterite developed by BMS, ${ }^{220,221}$ is ready for large-scale application. ${ }^{8}$ The key reason for the success of the latter formulations was shown to be the structural matching between the active phase and support, and thus both the rutile and cassiterite carriers enable the epitaxial growth of $\mathrm{RuO}_{2}$ on the surface. This improves the metal dispersion as well as the activity and stability. ${ }^{208,222,223}$ Besides, recently it was demonstrated that the solid solution of $\mathrm{RuO}_{2}$ and $\mathrm{TiO}_{2}$ obtained through the synthesis of mixed $\mathrm{RuO}_{2}-\mathrm{TiO}_{2}$ nanofibers by an electrospinning method can also improve the catalyst stability. ${ }^{224}$ Despite of the strong active phase-support interaction in $\mathrm{RuO}_{2} /$ rutile or $\mathrm{RuO}_{2} /$ cassiterite systems, $\mathrm{RuO}_{2}$ is prone to sintering in a long-term use. ${ }^{208}$ Therefore, the incorporation of a nanosized oxide to the catalyst formulation was found as a suitable strategy to ensure the long-term durability. Sumitomo used silica, ${ }^{208}$ whereas, Bayer opted for alumina which also served as a binding agent for the shaping of millimeter-sized bodies. ${ }^{220,221}$ The above review also sheds light on the mechanistic aspects gathered in the literature through advanced in situ and operando methods, such as temporal analysis of products (TAP-2), prompt gamma activation analysis (PGAA), ultra-high vacuum (UHV) studies, and DFT calculations. Surface $\mathrm{RuO}_{2-x} \mathrm{Cl}_{x}(110)$ was shown to catalyze the oxidation of $\mathrm{HCl}$ to $\mathrm{Cl}_{2}$ and $\mathrm{H}_{2} \mathrm{O}$ via a $\mathrm{L}-\mathrm{H}$ scheme along the rows of $\mathrm{Ru}_{\text {cus }}$ (coordinatively unsaturated ruthenium). Recombination of surface chlorine atoms to the gas-phase $\mathrm{Cl}_{2}$ molecules was demonstrated as the most energy demanding step in $\mathrm{HCl}$ oxidation over $\mathrm{RuO}_{2}$. Besides, process and reactor design aspects were also described. For the latter, two main reactor technologies have been developed for the implementation of $\mathrm{RuO}_{2}$-based catalyst, namely: (i) multitubular fixed-bed reactors by Sumitomo, where the heat of reaction was continuously removed using a heat transfer salt, and (ii) adiabatic reactor 
cascade by BMS, where the intermediate heat exchangers and dosing of $\mathrm{HCl}$ were introduced to efficiently use the heat of reaction.

Carrier Stabilization, Active Phase Optimization, and Technical Catalyst Manufacture. The BMS system, $\mathrm{RuO}_{2} / \mathrm{SnO}_{2}-\mathrm{Al}_{2} \mathrm{O}_{3}$, was further optimized by understanding the role of $\mathrm{Al}_{2} \mathrm{O}_{3}$ binder on the carrier stabilization. Comparative studies on $\mathrm{RuO}_{2} / \mathrm{SnO}_{2}$ and $\mathrm{RuO}_{2} / \mathrm{SnO}_{2}-\mathrm{Al}_{2} \mathrm{O}_{3}$ demonstrated a stable $\mathrm{Cl}_{2}$ production in a pilot reactor for $7000 \mathrm{~h}$ on stream on the latter whereas the former rapidly deactivated. ${ }^{220}$ The Ru loading of 2 wt.\% in the catalyst was based on the theoretical amount needed to secure the full coverage of the $\mathrm{SnO}_{2}$ surface to prevent its chlorination and volatilization as $\mathrm{SnCl}_{4}{ }^{220} \mathrm{In}$ both alumina-free and alumina-containing catalysts, $\mathrm{RuO}_{2} / \mathrm{SnO}_{2}$ was shown to be composed by carrier grains coated by a layer of active phase, which displayed a combination of film-like structures and protruding nanoparticles. ${ }^{220,222}$ The apparent similarity of the $\mathrm{RuO}_{2}$ morphologies in both catalysts and the proven robustness of the alumina-containing system hinted a beneficial effect of alumina on the carrier stabilization. Thus, a more extensive investigation of the deactivation mechanism of $\mathrm{RuO}_{2} / \mathrm{SnO}_{2}$ and of the role of the binder has been undertaken. The testing of $\mathrm{SnO}_{2}, \mathrm{SnO}_{2}-\mathrm{Al}_{2} \mathrm{O}_{3}\left(10\right.$ wt.\% $\left.\gamma-\mathrm{Al}_{2} \mathrm{O}_{3}\right)$, and $\mathrm{SnO}_{2}-\mathrm{SiO}_{2}$ (the latter two samples were obtained by mechanical mixing of the two oxides, followed by calcination at high temperature) under relevant $\mathrm{HCl}$ oxidation conditions demonstrated that $\mathrm{SnO}_{2}$ and $\mathrm{SnO}_{2}-\mathrm{SiO}_{2}$ both suffered from a significant $\mathrm{SnO}_{2}$ loss (up to 90\%) in $2 \mathrm{~h}$ (Figure 21d) due to its transformation to volatile $\mathrm{SnCl}_{4}{ }^{220}$ In stark contrast, $\mathrm{SnO}_{2}-\mathrm{Al}_{2} \mathrm{O}_{3}$ showed $\mathrm{SnO}_{2}$ loss of less than $2 \%$ under the same conditions. These key findings were understood through extensive characterizations by bulk (X-ray diffraction pattern - XRD, $\mathrm{H}_{2}-\mathrm{TPR}$, and ${ }^{27} \mathrm{Al}$ MAS NMR) and surface (XPS, and HRTEM) techniques which indicated that the binder $\mathrm{Al}_{2} \mathrm{O}_{3}$ produced electronic and geometric effects on cassiterite, rendering it resistant to chlorination. $\mathrm{SiO}_{2}$, which was also investigated as an alternative stabilizer, did not show any interaction with $\mathrm{SnO}_{2}$.

Next important step comprises the transformation of powder catalyst into a technical form, the successful attainment of which relies on several factors, including the shaping conditions and sequence of shaping and $\mathrm{Ru}$ incorporation. For the BMS catalyst, precalcination of $\mathrm{SnO}_{2}$ carrier at temperature 
above $973 \mathrm{~K}$ is necessary to ensure the formation of cassiterite at surface to favor the epitaxial growth of $\mathrm{RuO}_{2}{ }^{8}$ The second important aspect is the calcination of the as-impregnated catalyst which should be as low as $523 \mathrm{~K}$ to minimize the sintering of the active phase. ${ }^{8}$ Taking these things into account, $\mathrm{SnO}_{2}$ $\mathrm{Al}_{2} \mathrm{O}_{3}\left(10\right.$ wt. $\left.\% \gamma-\mathrm{Al}_{2} \mathrm{O}_{3}\right)$ powder was first shaped into spherical granules of $c a .2 \mathrm{~mm}$ and subjected to hardening, followed by impregnation with aqueous $\mathrm{RuCl}_{3}$ solutions $(0.5-3 \mathrm{wt} . \% \mathrm{Ru})$ and calcination at $523 \mathrm{~K} .{ }^{228}$ It should be emphasized that during impregnation of the $\mathrm{SnO}_{2}-\mathrm{Al}_{2} \mathrm{O}_{3}$ body $\mathrm{Ru}$ species can be deposited on the high surface area $\mathrm{Al}_{2} \mathrm{O}_{3}$ component, and thus to achieve a selective impregnation on $\mathrm{SnO}_{2}$, choice of $\mathrm{Al}_{2} \mathrm{O}_{3}$ is crucial. It is suggested that acidic $\mathrm{Al}_{2} \mathrm{O}_{3}$ binders are more effective for this purpose. The shaped $\mathrm{RuO}_{2} / \mathrm{SnO}_{2}-\mathrm{Al}_{2} \mathrm{O}_{3}$ catalysts with different $\mathrm{Ru}$ contents were evaluated in $\mathrm{HCl}$ oxidation. The Ru-specific activity increased with the decrease in the Ru content in the catalyst. ${ }^{228}$ $\mathrm{RuO}_{2}(0.5$ wt.\% Ru$) / \mathrm{SnO}_{2}-\mathrm{Al}_{2} \mathrm{O}_{3}$ doubled the Ru-specific activity of the 2 wt.\% Ru catalyst. ${ }^{228}$ The longterm performance of $\mathrm{RuO}_{2}(0.5 \mathrm{wt} . \% \mathrm{Ru}) / \mathrm{SnO}_{2}-\mathrm{Al}_{2} \mathrm{O}_{3}$ in $\mathrm{HCl}$ oxidation was evaluated in a pilot plant test, demonstrating a stable activity for $4000 \mathrm{~h}$ on stream and thus highlighting its outstanding durability. $^{228}$

HCI Oxidation on Alternative Catalysts. Albeit $\mathrm{RuO}_{2}$-based systems are very effective for $\mathrm{HCl}$ recycling, they also leave significant room for improvements. First of all, the high and fluctuating price of $\mathrm{Ru}$ leads to a substantial capital investment $\operatorname{cost}^{8}{ }^{8}$ which is disadvantageous for the wide application of the catalytic $\mathrm{HCl}$ recycling technology. Secondly, $\mathrm{RuO}_{2}$-based catalysts pose operating temperature limitation due to possibility of the formation of volatile $\mathrm{RuO}_{4}$ at higher temperatures under $\mathrm{HCl}$ oxidation conditions. Since the reaction is exothermic, heat of the reaction must be removed to ensure a stable operation of $\mathrm{RuO}_{2}$. Thus, the development of an industrially viable catalyst based on cheaper and more abundant metals is very appealing. This objective motivated the theoretical and systematic experimental investigations. ${ }^{67,191,225,227,228,231-233}$ The former studies proposed descriptors such as oxygen dissociation energy over rutile oxides and explained the highest activity of $\mathrm{RuO}_{2}$ and provided guidelines for superior active materials, however, they did not suggest what is crucial for catalyst stability. A later review by Over and Schomäcker extended the oxygen dissociation energy to describe 
the Deacon activity of the first-row transition metal and lanthanide oxides in contrast to $\mathrm{RuO}_{2}{ }^{234} \mathrm{They}^{2}$ also proposed the stability descriptors for Deacon catalysts in the form of the formation energy of the chlorides and the volatility of these chlorides under reaction conditions. $\mathrm{La}_{2} \mathrm{O}_{3}$ was suggested to be a possibly stable catalyst that may also be active. However, catalytic tests at $673 \mathrm{~K}$ showed a significantly inferior activity compared to $\mathrm{RuO}_{2}$. Besides, the structural robustness after $\mathrm{HCl}$ oxidation and a longterm evaluation of $\mathrm{La}_{2} \mathrm{O}_{3}$ is unknown. Parallel experimental studies demonstrated $\mathrm{IrO}_{2}, \mathrm{U}_{3} \mathrm{O}_{8}, \mathrm{CuCrO}_{2}$, and $\mathrm{CeO}_{2}$-based materials to be active in $\mathrm{HCl}$ oxidation at higher (ca. $100 \mathrm{~K}$ ) temperatures than $\mathrm{RuO}_{2}$ (Figure 21a). 225-227,233 Most importantly, these catalysts preserve their bulk structures in the $\mathrm{HCl}$ oxidation conditions (Figures 21b,c). Although resistant to over-oxidation at high temperature in contrast to $\mathrm{RuO}_{2}, \mathrm{IrO}_{2}$ still poses a drawback of high cost, while $\mathrm{U}_{3} \mathrm{O}_{8}$ and $\mathrm{CuCrO}_{2}$ suffer from the toxicity of uranium and chromium metals which limits their industrial application. $\mathrm{CeO}_{2}$ is promising in terms of its abundance, stability, and reasonable Deacon activity and thus this system is reviewed herein in depth.

HCl Oxidation on $\mathrm{CeO}_{2}$-Based Catalysts. Integrated approach combining theoretical and experimental investigations has been applied to understand the Deacon chemistry on $\mathrm{CeO}_{2}$-based catalysts from atomic level to pilot evaluation..$^{227,230}$

Performance-Structure-Mechanism Relationships on $\mathrm{CeO}_{2}$. Studies on bulk $\mathrm{CeO}_{2}$, undertaken to shed light on the basic system first, demonstrated its robustness under Deacon reaction conditions. Calcination of the ceria sample at $1173 \mathrm{~K}$ has been reported to produce stabilized material that can preserve its textural properties, such as surface area and morphology, under standard reaction conditions $\left(\mathrm{O}_{2}: \mathrm{HCl}=2, T=703 \mathrm{~K}\right){ }^{227} \mathrm{X}$-ray diffraction of ceria prior to and after exposing to HCl oxidation at variable $\mathrm{O}_{2}: \mathrm{HCl}$ feed conditions showed that $\mathrm{CeO}_{2}$ did not suffer from bulk chlorination in $\mathrm{O}_{2}$-rich feeds $\left(\mathrm{O}_{2}: \mathrm{HCl} \geq 0.75\right)$, while $\mathrm{CeCl}_{3}$ was detected in stoichiometric or sub-stoichiometric feeds $\left(\mathrm{O}_{2}: \mathrm{HCl} \leq 0.25\right.$; Figure 21c). It should be noted that although $\mathrm{CeO}_{2}$ transformed into bulk chloride in $\mathrm{O}_{2}$-lean conditions, the formed $\mathrm{CeCl}_{3}$ is stable at the reaction temperature of $703 \mathrm{~K}$, assuring no metal loss. Besides, it is shown that by increasing the oxygen content, full oxide phase can be recovered. ${ }^{227}$ 
This dynamic behavior of $\mathrm{CeO}_{2}$ and influence of the formation of bulk chloride phase on the catalytic activity were understood by operando PGAA studies (Figure 21e). ${ }^{229}$ Experiments under HCl-rich and $\mathrm{O}_{2}$-rich conditions evidenced that the degree of surface chlorination increased when the test was conducted at lower $\mathrm{O}_{2}: \mathrm{HCl}$ ratios, which also caused a loss in activity (Figure 21e, A,D). A subsequent increase of $\mathrm{O}_{2}: \mathrm{HCl}>2$ led to a rise of the catalyst activity, but was not able to remove the surface chlorine species fully (Figure 21e, B,C,E). The rise in the activity in this case was related to the positive dependence of reaction on the feed $\mathrm{O}_{2}$ content. ${ }^{227} \mathrm{In}$ fact, at $\mathrm{O}_{2}: \mathrm{HCl}=9$, a full activity was regained, but still the catalyst surface featured a high Cl:Ce ratio of 0.125 (Figure 21e, E). It was suggested, in view of mere surface $\mathrm{Cl}$ occupation leading to a $\mathrm{Cl}$ :Ce ratio of $\sim 0.01$, that the sample under all these conditions contains substantial $\mathrm{Cl}$ below the surface. Overall, the PGAA study suggested that: (i) chlorination at low oxygen over-stoichiometry indeed lead to deactivation, but (ii) reoxidation at high oxygen over-stoichiometry can regenerate the relevant surface sites without the necessity of removing all subsurface/bulk $\mathrm{Cl}$ from the material.

Mechanism of $\mathrm{HCl}$ oxidation on $\mathrm{CeO}_{2}$, studied by $\mathrm{DFT},{ }^{227}$ involved six main elementary steps (Eqs. 3-8, where Olat: lattice oxygen species, $\square$ : surface vacancy, *: surface site). Among all, the fourth step (Eq. 6) i.e. chlorine activation from vacancy position to surface site is the most energy-demanding, characterized by a $2.15 \mathrm{eV}$ energy barrier with the formation of an oxygen vacancy at a subsurface position. Still, it was suggested that the competition between chlorine and oxygen for available active sites may render reoxidation as the rate-limiting step on $\mathrm{CeO}_{2}$. It is important to note that, although the reaction scheme on $\mathrm{CeO}_{2}$ resembles that on $\mathrm{RuO}_{2},{ }^{227}$ some key differences can be pointed out. First, the reaction on $\mathrm{RuO}_{2}$ occurs at almost full coverage of the under-coordinated $\mathrm{Ru}_{\text {cus }}$ positions, as nearly all available sites are occupied by $\mathrm{Cl}^{235}$ For $\mathrm{CeO}_{2}$, under-coordinated cerium atoms only exist when oxygen vacancies are present in the surface or near-surface regions. As a consequence, the reaction profile for $\mathrm{CeO}_{2}$ is much more abrupt (involves higher energy requirements) than that of $\mathrm{RuO}_{2}$. This correlates with the higher temperatures needed to run the Deacon reaction on $\mathrm{CeO}_{2}$ (Figure 21a). 


$\begin{array}{lll}\mathrm{HCl}+\mathrm{O}_{\text {lat }}+\square & \leftrightarrow & \mathrm{O}_{\mathrm{lat}} \mathrm{H}+\mathrm{Cl} \square \\ \mathrm{HCl}+\mathrm{O}_{\mathrm{lat}} \mathrm{H}+* & \leftrightarrow & \mathrm{H}_{2} \mathrm{O}_{\text {lat }}+\mathrm{Cl} * \\ \mathrm{Cl}^{*}+\mathrm{H}_{2} \mathrm{O}_{\text {lat }} & \leftrightarrow & \mathrm{Cl} \square+\mathrm{H}_{2} \mathrm{O} \\ \mathrm{Cl} \square+* & \leftrightarrow & \square+\mathrm{Cl} * \\ \square+1 / 2 \mathrm{O}_{2} & \leftrightarrow & \mathrm{O}_{\text {lat }} \\ \mathrm{Cl} *+\mathrm{Cl} * & \leftrightarrow & \mathrm{Cl}_{2}+2 *\end{array}$

Owing to the remarkable performance of $\mathrm{CeO}_{2}$ in $\mathrm{HCl}$ oxidation, efforts were made to further boost the activity and stability by (i) synthesizing partially chlorinated phase (CeOCl), ${ }^{236}$ (ii) doping with several metal cations (such as La, Sm, Gd, Y, Hf, Zr, and Ti), ${ }^{237}$ (iii) synthesizing different nanostructures, and (iv) forming mixed oxides. ${ }^{224,238-240}$ Evaluation of $\mathrm{CeOCl}$ in $\mathrm{HCl}$ oxidation evidenced that it transformed into $\mathrm{CeO}_{2}$ during reaction, only after which a considerable $\mathrm{HCl}$ conversion was obtained. This suggests the necessity of cerium oxide phase to catalyze HCl oxidation. Doping of $\mathrm{CeO}_{2}$ revealed that the intrinsic reactivity of ceria in $\mathrm{HCl}$ oxidation can be significantly improved when doped with $\mathrm{Hf}$ and $\mathrm{Zr}$ in appropriate quantities, whereas trivalent dopants were found to be detrimental. ${ }^{237}$ This results also agree with a later study of Gd-doped $\mathrm{CeO}_{2}$, where the activity dropped with increasing Gd content. ${ }^{240}$ The promotional effects were attributed to the modification of vacancy formation energies, adsorption properties, and surface coverages by the dopants. ${ }^{237}$

Bulk ceria, calcined at $1173 \mathrm{~K}$, did not show any significant changes of morphology under standard Deacon conditions (vide supra). ${ }^{216}$ But this does not assure that the catalyst will be stable in long-term use, assessment of which is not always easy at the early stages of development program. Therefore, a strategy to shed light on the stability of $\mathrm{CeO}_{2}$ under mild and harsh $\mathrm{HCl}$ oxidation conditions is developed by Over et al. ${ }^{224,238}$ It includes (i) the synthesis of $\mathrm{CeO}_{2}$ and mixed $\mathrm{CeO}_{2}-\mathrm{ZrO}_{2}$ nanofibers (NFs) through an electrospinning method, leading to a well-defined cylindrical morphology, and (ii) evaluation of the morphological transformations of these microstructures upon Deacon reaction. The 
$\mathrm{CeO}_{2}$ NFs upon exposure to mild conditions $\left(\mathrm{O}_{2}: \mathrm{HCl}: \mathrm{Ar}=2: 1: 7\right)$ for $60 \mathrm{~h}$ mostly retained their morphology (Figures 22a,b), which is in line with the results reported on ceria powder with rounded nanoparticle morphology. ${ }^{216}$ However, an exposure of $\mathrm{CeO}_{2}$ NFs to HCl-rich conditions $\left(\mathrm{O}_{2}: \mathrm{HCl}: \mathrm{Ar}=2: 1: 7\right)$ for $60 \mathrm{~h}$ caused severe morphological alterations with the occurrence of hydrated cerium chloride phase (Figure 22c). Thus, these results suggest that $\mathrm{CeO}_{2}$ as such might not be stable in HCl-rich conditions in the long-term use, likely due to the formation of bulk chloride phase which is inactive in $\mathrm{HCl}$ oxidation. ${ }^{229}$ In fact, operando PGAA on $\mathrm{CeO}_{2}$ nanopowder supports these findings (Figure 21e). ${ }^{229}$ Interestingly, mixed oxide of $\mathrm{CeO}_{2}$ and $\mathrm{ZrO}_{2}\left(\mathrm{Zr}_{0.33} \mathrm{Ce}_{0.67} \mathrm{O}_{2}\right)$ preserved the morphology and suppressed the bulk chlorination after $\mathrm{HCl}$ oxidation in both mild and harsh reaction conditions, suggesting a positive role of $\mathrm{ZrO}_{2}$ on the stabilization of $\mathrm{CeO}_{2}$ (Figures 22d-f). ${ }^{224,238}$ Beside stability, the mixed oxide was also shown to be more active than $\mathrm{CeO}_{2}$, in line with the positive role of $\mathrm{Zr}$ doping on the performance of $\mathrm{CeO}_{2}{ }^{237}$ Based on these promising results, full series of $\mathrm{Zr}_{1-x} \mathrm{Ce}_{x} \mathrm{O}_{2}$ with $x=0-1$ was explored. ${ }^{238}$ It was found that pure $\mathrm{ZrO}_{2}$ is nearly inactive, while $30 \%$ Ce content leads to the same activity as the pure $\mathrm{CeO}_{2}$ sample. These results might serve as a promising basis for the design of a technical catalyst, where the content of ceria on a support should be kept as minimum as possible to obtain an economic catalyst (vide infra).

Since ceria is known to possess oxygen vacancies and in the oxidation catalysis its activity is generally correlated to its oxygen storage capacity (OSC), efforts were made to find the dependence of $\mathrm{HCl}$ oxidation activity on OSC. ${ }^{216,239,240}$ A quite reasonable correlation of Deacon activity with OSC was found on pure $\mathrm{CeO}_{2}$ nanoparticles, ${ }^{216}$ while no dependence of activity with OSC was observed over $\mathrm{Zr}_{1-x} \mathrm{Ce}_{x} \mathrm{O}_{2}$ or $\mathrm{Ce}_{1-x} \mathrm{Gd}_{x} \mathrm{O}_{2-\delta}$ nanofibers. ${ }^{239,240}$ It should be emphasized that the OSC in the above studies was measured on the as-prepared samples. It is understood from the above discussion that the surface structure of $\mathrm{CeO}_{2}$ will change according to the conditions applied, where chlorine atoms will also occupy some of the oxygen vacancy sites. Thus, values measured on the fresh samples or even ex situ might not be reasonable to explain the activity. This suggests that the properties of $\mathrm{CeO}_{2}$ need further study. 

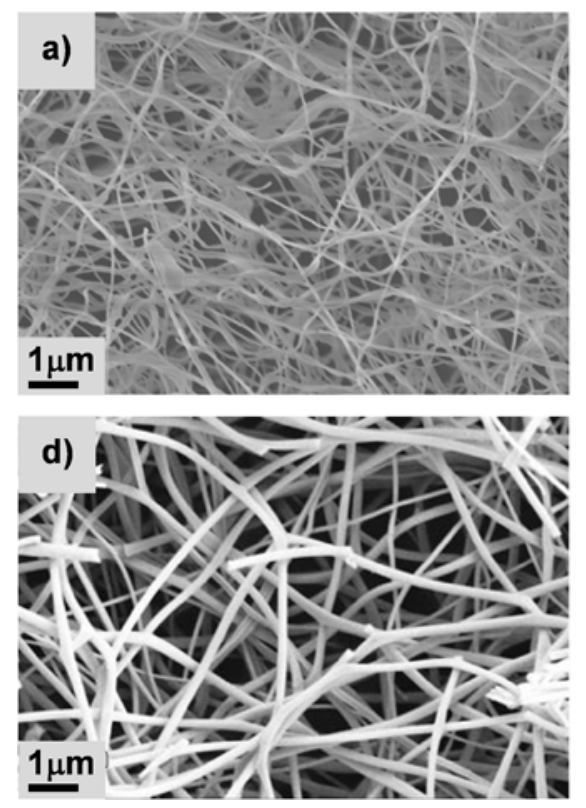
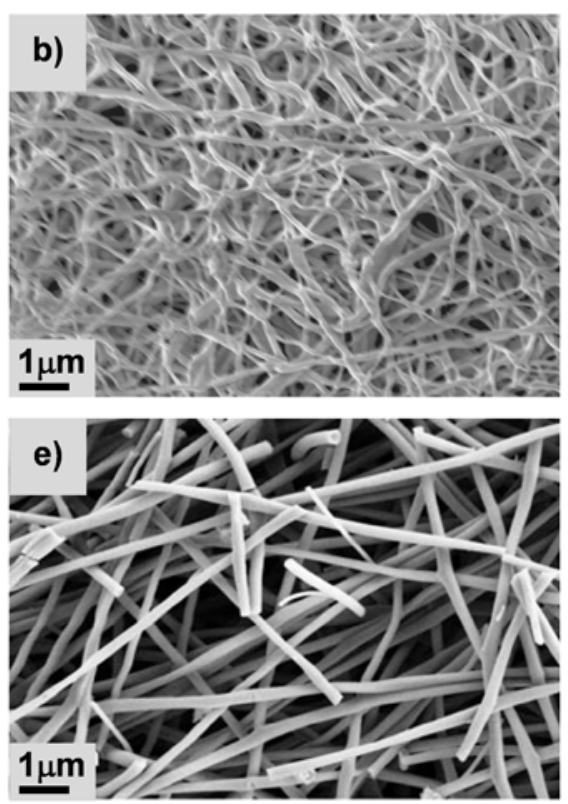
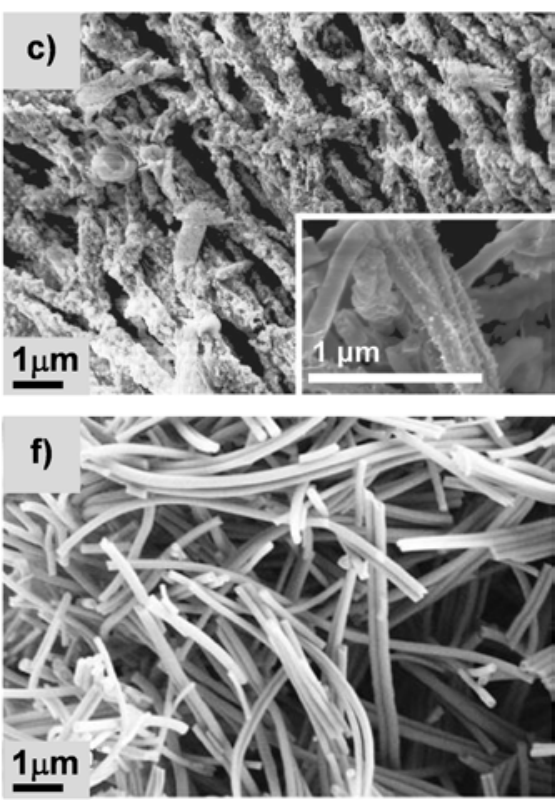

Figure 22. Scanning electron microscopic (SEM) images of a-c) $\mathrm{CeO}_{2}$ and $\mathbf{d - f}$ ) $\mathrm{Zr}_{0.33} \mathrm{Ce}_{0.67} \mathrm{O}_{2}$ nanofibers in as-prepared form (left column), after $60 \mathrm{~h}$ under mild conditions $\left(\mathrm{O}_{2}: \mathrm{HCl}: \mathrm{Ar}=2: 1: 7\right.$, middle column), and after $60 \mathrm{~h}$ under harsh conditions $\left(\mathrm{O}_{2}: \mathrm{HCl}: \mathrm{Ar}=2: 2: 6\right.$, right column). Other conditions: $W_{\text {cat }}=30 \mathrm{mg}, F=15 \mathrm{~cm}^{3} \mathrm{STP} \mathrm{min}^{-1}, T=703 \mathrm{~K}$. SEM images a-c and d-f are reproduced with permissions from refs 224 (Copyright 2013 Wiley-VCH) and 238 (Copyright 2013 Springer), respectively.

Toward Technical $\mathrm{CeO}_{2}$-Based Catalysts for Pilot Evaluation. Important steps taking $\mathrm{CeO}_{2}$ towards practical implementation comprised of a study of support effect and scaling up of catalyst for pilot evaluation. ${ }^{230}$ The choice of suitable carrier is crucial to attain high dispersion of the ceria phase and particularly to stabilize the latter. Supported ceria catalysts (3-20 wt.\% Ce) were prepared by impregnation of $\gamma-\mathrm{Al}_{2} \mathrm{O}_{3}$, anatase $\mathrm{TiO}_{2}$, and monoclinic $\mathrm{ZrO}_{2}$. The total surface area $\left(S_{\mathrm{BET}}\right)$ of the asreceived supports was 47, 111 , and $242 \mathrm{~m}^{2} \mathrm{~g}^{-1}$, respectively, for $\mathrm{ZrO}_{2}, \mathrm{TiO}_{2}$, and $\mathrm{Al}_{2} \mathrm{O}_{3}$. The original $S_{\text {BET }}$ of $\mathrm{ZrO}_{2}$ was retained upon $\mathrm{CeO}_{2}$ deposition $\left(42 \mathrm{~m}^{2} \mathrm{~g}^{-1}\right)$. On the contrary, it decreased to a significant extent for $\mathrm{Al}_{2} \mathrm{O}_{3}\left(165 \mathrm{~m}^{2} \mathrm{~g}^{-1}\right)$, and dramatically for $\mathrm{TiO}_{2}\left(8 \mathrm{~m}^{2} \mathrm{~g}^{-1}\right)$, suggesting particle sintering and/or pore blockage upon catalyst preparation.

Catalytic tests revealed the following activity order: $\mathrm{CeO}_{2} / \mathrm{ZrO}_{2}>\mathrm{CeO}_{2} / \mathrm{Al}_{2} \mathrm{O}_{3} \geq \mathrm{CeO}_{2} / \mathrm{TiO}_{2}$, suggesting that zirconia is a suitable support (Figure 21f). This is in line with a study on mixed $\mathrm{CeO}_{2-}$ $\mathrm{ZrO}_{2}$ systems (vide supra). ${ }^{238}$ The optimal Ce loading on $\mathrm{ZrO}_{2}$ was between 7 and 10 wt.\%, as a further 
increase in metal content did not lead to an enhanced activity. In the case of $\mathrm{CeO}_{2} / \mathrm{Al}_{2} \mathrm{O}_{3}$, the activity increased linearly with the Ce content up to $17 \mathrm{wt} . \%$, where it exhibited a comparable activity to that of the zirconia-supported samples. Still, zirconia was the preferred carrier not only in view of the beneficial effect on the specific catalytic activity but also due to the high density of the material. With an equal cerium loading, $\mathrm{CeO}_{2} / \mathrm{ZrO}_{2}$ requires a three times smaller bed volume than $\mathrm{CeO}_{2} / \mathrm{Al}_{2} \mathrm{O}_{3}$. This enables the use of a smaller reactor and thus a reduction of capital investment cost. ${ }^{8}$

$\mathrm{H}_{2}$-TPR analysis was conducted to explain the different $\mathrm{HCl}$ oxidation activity of the catalysts based on the size, chemical nature, and dispersion of the Ce-based structures stabilized by the supports. The superiority of the zirconia-supported samples was correlated to the presence of small nanostructures of $\mathrm{CeO}_{2}$ (based on reduction peak observed at $674 \mathrm{~K}$ ), ensuring high dispersion, and, possibly, of Ce- $\mathrm{Zr}$ mixed phases (reduction peak at $830 \mathrm{~K}$ ). ${ }^{241}$ Although the alumina supported ceria phase appeared to have a high dispersion (from reduction peaks below $1000 \mathrm{~K}$ ), its inferior performance was related to the absence of electronic effects induced by the support. The limited activity of $\mathrm{CeO}_{2} / \mathrm{TiO}_{2}$ was linked to the presence of $\mathrm{CeO}_{2}$ as particles of considerably large size i.e. to a low dispersion of ceria (intense reduction peaks at $1140 \mathrm{~K}$ ). These results are further supported by electron microscopy analyses of the supported catalysts (Figure 21g), showing that the Ce surface coverage on $\mathrm{Zr}$ was made of particles with different sizes (from clusters to nanoparticles) and intermixing of the ceria phase with $\mathrm{ZrO}_{2}$ to a certain extent. In contrast, $\mathrm{CeO}_{2} / \mathrm{Al}_{2} \mathrm{O}_{3}$ and $\mathrm{CeO}_{2} / \mathrm{TiO}_{2}$ were evidenced to be composed of nanoparticles of $c a$. 3-15 nm and 20-50 nm, respectively, explaining their inferior activity compared to $\mathrm{CeO}_{2} / \mathrm{ZrO}_{2}$.

As low surface chlorination is related to high activity as demonstrated for bulk $\mathrm{CeO}_{2}$ (vide supra, Figure 21e), operando PGAA was utilized to evaluate the effect of $\mathrm{Cl}$ uptake during $\mathrm{HCl}$ oxidation over $\mathrm{CeO}_{2} / \mathrm{ZrO}_{2}$ and $\mathrm{CeO}_{2} / \mathrm{Al}_{2} \mathrm{O}_{3}$ (Figure 21h). In agreement with its highest activity, the former exhibited the reduced $\mathrm{Cl}$ coverage at all $\mathrm{O}_{2}: \mathrm{HCl}$ ratios compared to the latter. This result further emphasizes the critical role of surface $\mathrm{Cl}$ poisoning on activity and suggests the suitability of $\mathrm{CeO}_{2} / \mathrm{ZrO}_{2}$ formulation for scaling up. Thus, $\mathrm{CeO}_{2} / \mathrm{ZrO}_{2}$ was shaped into a technical form. First, the cylindrical $\mathrm{ZrO}_{2}$ pellets (diameter $=3 \mathrm{~mm}$, length $=4 \mathrm{~mm}$ ) were prepared and then impregnated with cerium nitrate 
(9 wt.\% Ce). The shaped catalyst was tested in a pilot plant to assess its long-term stability. The $\mathrm{HCl}$ conversion levels were constant over $700 \mathrm{~h}$ on stream (Figure 21h, inset). On the basis of its remarkable activity and lifetime, $\mathrm{CeO}_{2} / \mathrm{ZrO}_{2}$ comprises a realistic alternative or complementary to $\mathrm{RuO}_{2}$-based catalysts for large-scale chlorine recycling.

Hybrid Fixed-Bed Reactors for Sustainable $\mathbf{C l}_{2}$ Production. $\mathrm{RuO}_{2}$-based catalysts are very sensitive to high reaction temperature under oxidative conditions. The high local temperature in the catalyst bed originated from hot spot formation leads to the over-oxidation of $\mathrm{RuO}_{2}$ generating volatile $\mathrm{RuO}_{4}$ species, thus deteriorating its activity. Therefore, the temperature rise for the $\mathrm{RuO}_{2}$-based process is determined by the maximum operation temperature ( $T_{1}$, Figure 23a), which necessitates the implementation of a large number of reactors, heat exchangers, and $\mathrm{HCl}$ side feeds, increasing the complexity and ultimately the capital investment. In order to use the heat of the reaction above $663 \mathrm{~K}$, a catalyst with different properties, including capability to withstand high temperatures, has to be implemented. ${ }^{242}$ The $\mathrm{CeO}_{2} / \mathrm{ZrO}_{2}$ system has been proposed to combine with $\mathrm{RuO}_{2}$-based catalysts for an adiabatic operation. ${ }^{243}$ The calculation showed that a staged bed of $\mathrm{RuO}_{2} / \mathrm{TiO}_{2}$ and $\mathrm{CeO}_{2} / \mathrm{ZrO}_{2}$ (Figure 23b) was able to reach the same chlorine production as the conventional cascade, while displaying more homogeneous temperature and conversion profiles (Figure 23c). HCl was first converted over a $\mathrm{RuO}_{2} / \mathrm{TiO}_{2}$ bed until reaching the temperature limit. At this point the $\mathrm{CeO}_{2} / \mathrm{ZrO}_{2}$ catalyst was used and the reaction progressed above $663 \mathrm{~K}$. The strategy to stage $\mathrm{RuO}_{2} / \mathrm{TiO}_{2}$ and $\mathrm{CeO}_{2} / \mathrm{ZrO}_{2}$ beds reduces the number of operation units by half, which led to a reduced cost of the capital investment, a major disadvantage of the conventional $\mathrm{RuO}_{2}$-based process. However, the size of the two single reactors would be 1.5 times larger than that of the conventional reactor cascade, because $50 \%$ more catalyst loading is required. Still, the catalyst cost was reduced by $54 \%$ due to the much lower price for cerium compared to ruthenium, firming the economic attractiveness of the staged bed process. $^{244}$ 

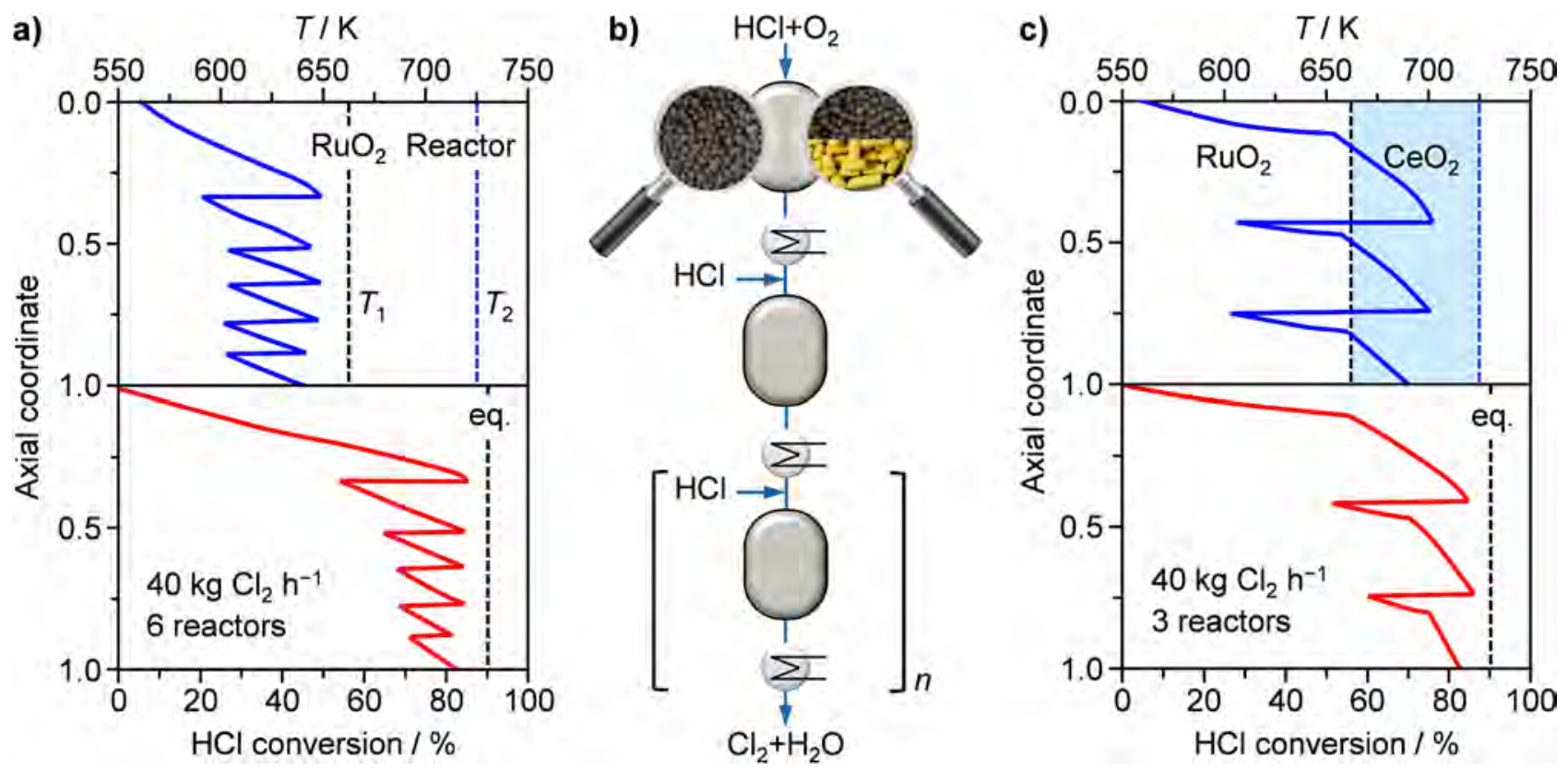

Figure 23. Axial coordinate versus temperature (top) and $\mathrm{HCl}$ conversion (bottom) of the adiabatic reactor cascade containing a) single $\mathrm{RuO}_{2} / \mathrm{TiO}_{2}$ (left inset in b) and c) a staged bed $\mathrm{RuO}_{2} / \mathrm{TiO}_{2}$ and $\mathrm{CeO}_{2} / \mathrm{ZrO}_{2}$ (right inset in b). The maximum operation temperature for the $\mathrm{RuO}_{2} / \mathrm{TiO}_{2}$ catalyst is indicated by $T_{1}$ while the reactor limit is shown by $T_{2}$. a and $\mathbf{c}$ were adapted from ref 244.

\section{HALOGEN-MEDIATED FUNCTIONALIZATION OF LIGHT HYDROCARBONS}

The chemical industry heavily relies on petroleum as its primary feedstock (Figure 24). Nowadays, the increasing scarceness of oil reserves provides a strong incentive to find new and viable raw materials to ensure the progress of our modern world. Albeit renewables are being considered as an alternative to fossils, bio-based feedstocks are not expected to sustain the total manufacture of chemicals and fuels, due to the insufficient projected availability and to the about halved carbon content compared to petrol on a weight basis. ${ }^{245}$ Furthermore, biomass exploitation is contingent upon the effective realization of industrially-viable conversion technologies in the next couple of decades. On the other hand, the recent discovery of substantial volumes of conventional and unconventional natural gas (shale gas, tight gas, and coalbed methane) has unlocked new expectations on them as a secure economic alternative to petroleum until viable renewable sources are developed. The primary constituent of natural gas is methane, accounting for 75-99 mol.\% of the overall composition, followed by ethane (1-15 mol.\%) and propane (1-10 mol.\%), ${ }^{70}$ which can serve as feedstocks for chemical and fuel manufacture, reducing our 
reliance on oil. According to BP statistical review of world energy, the proved reserves of natural gas have significantly increased over the last decades and estimates suggest that it would last for more than two centuries (Figure 24a). ${ }^{246}$ Both conventional and unconventional basins are widely located (Figure 24b). ${ }^{246,247}$ The basic difference between them is the geology of their reservoirs and therefore require different extraction techniques to acquire the commercial quantities (Figure 25). ${ }^{248}$ Conventional gas is usually found in porous rocks as relatively large reservoirs and can be extracted readily via vertical drilling. ${ }^{249,250}$ In contrast, unconventional gas is locked inside rocks such as shale and tight sands, having high porosity and low permeability, and is spread more diffusely throughout the rock
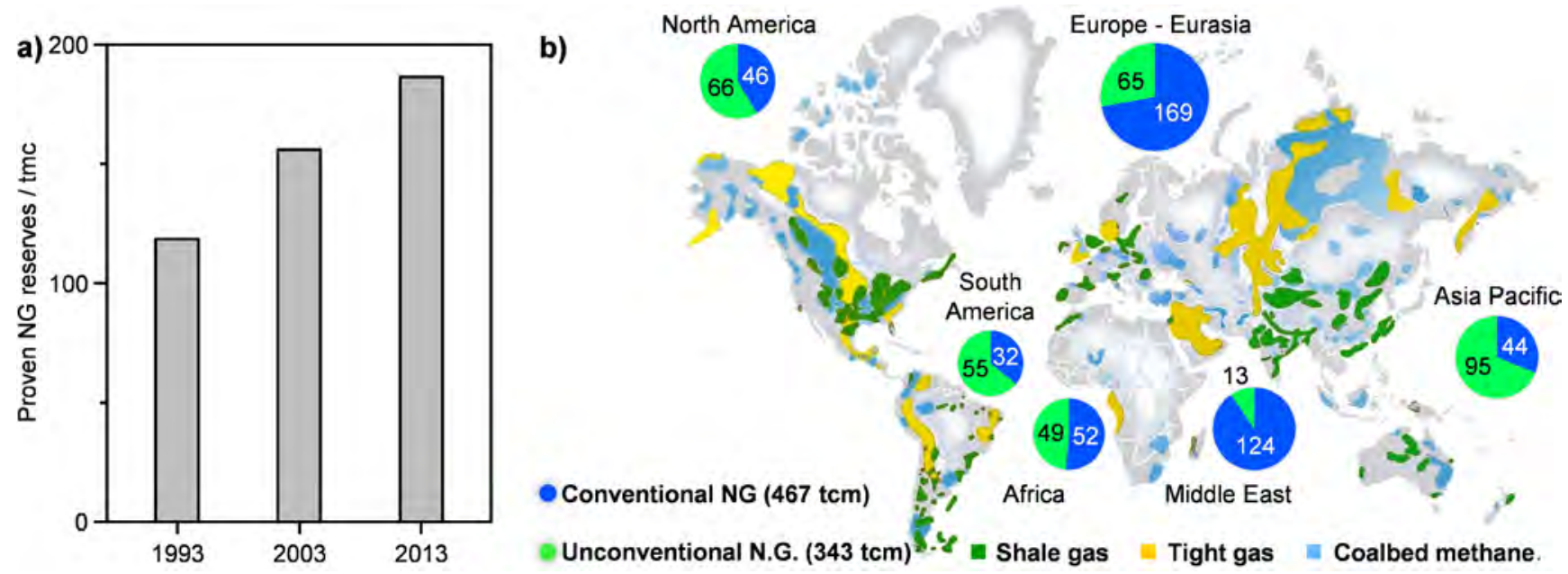

Figure 24. a) Proven natural gas reserves in trillion cubic meter (tcm). Data taken from ref 246. b) Global map of conventional and unconventional natural gas potential. Adapted with permission from ref 247. Copyright HIS.

substrates. $\stackrel{250,251}{2}$ This makes the recovery difficult and requires more specialized or unconventional extraction process, such as a combination of horizontal drilling and hydraulic fracturing, best known as fracking, to enable cost-effective production of natural gas from such reservoirs. ${ }^{4}$ Following the economic competitiveness of fracking technology, the U.S. has already commenced the production of natural gas from the unconventional sources and it is forecasted that shale gas will become the largest source of natural gas in the U.S. by $2040 .^{252}$ 


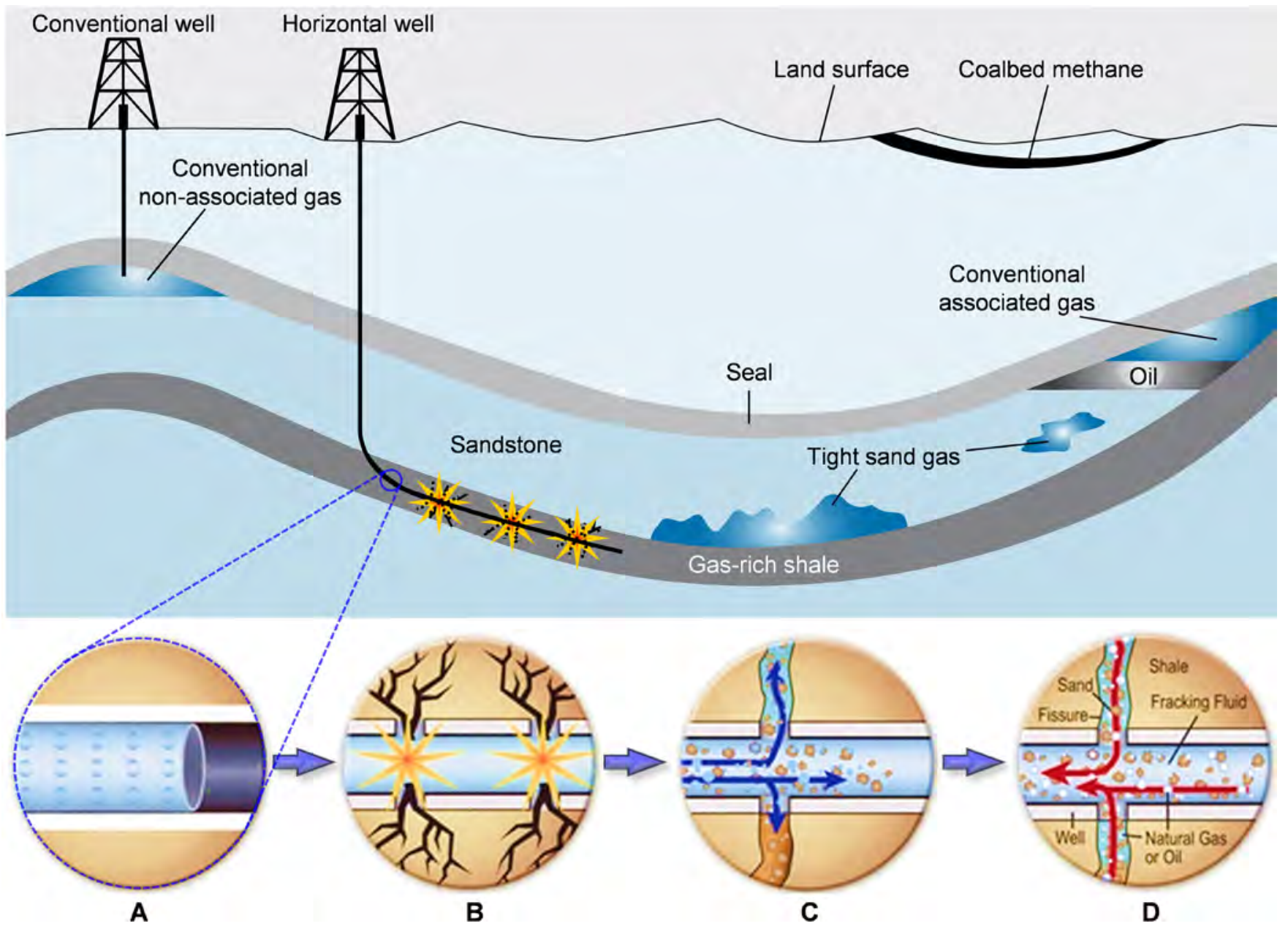

Figure 25. The geology of natural gas resources with extraction well. Conventional natural gas can be readily extracted by archetypical vertical well, however, unconventional gas is extracted by horizontal drilling coupled to high-volume hydraulic fracturing technology which make it economic and competitive with respect to conventional sources. Insets: A: Production casing inserted into borehole and surrounded with cement. B: Casing is perforated blasting small holes through pipe, cement as well as shale. C: Hydraulic fracturing of well using a mixture of water, sand, and chemicals (fracking fluid) at high pressure. D: Generation of numerous small fissures in the shale, freeing trapped oil and gas that flow back up the pipeline to the wellhead. The sand keeps the fissures open to increase the flow of oil and natural gas. Source: U.S. Energy Information Administration and U.S. Geological survey. ${ }^{248}$

Since the conversion of natural gas - especially of methane - to value-added products is demanding, most of the globally produced natural gas is burned for heating or electricity generation purposes $^{56,70}$ and about $4 \%$ is flared at oil fields and refineries due to the lack of infrastructure for transportation. ${ }^{253,254}$ Currently, only less than $10 \%$ of the annual production of natural gas is processed through energy-intensive steam reforming, forming syngas (a mixture of $\mathrm{CO}$ and $\mathrm{H}_{2}$ ) as an intermediate 
which is converted to liquid fuels by the Fischer-Tropsch process and to methanol. ${ }^{56}$ The latter route is highly endothermic and requires harsh conditions (>1073 K, 30-40 bar) to overcome the activation barrier, eventually resulting in energy- and capital-intensive processes. Alternatively, the idea of selective functionalization of a single $\mathrm{C}-\mathrm{H}$ bond instead of cleaving all of them homolytically is very attractive. Different routes studied for methane activation are outlined in Figure 26. The direct transformation of methane to methanol, sometimes referred as a “dream reaction', has attracted particular interest. Although excellent yields of methanol have been achieved over homogeneous metal complexes, ${ }^{255-257}$ harsh acidic conditions and difficulties in a subsequent catalyst separation hampered the practical implementation of this process. ${ }^{258}$ Oxidative coupling of methane (OCM) to ethylene is another route that has been studied intensively. ${ }^{259,260}$ In this reaction, methyl radicals, typically generated over a doped metal oxide above $1073 \mathrm{~K}$, react in the gas-phase to produce ethane as an intermediate, which undergoes dehydrogenation to ultimately form ethylene. Although the concept is elegant, three decades of research failed to produce a viable OCM catalyst achieving yields higher than 25\%, preventing the process from commercial applications. ${ }^{70,261,262}$ The high temperature and oxidative conditions required to achieve a reasonable conversion rate are also promoting the formation of undesired carbon oxides, which remains the main challenge for this reaction. ${ }^{259}$ Oxidative carbonylation and aromatization have also been considered. However, the use of trifluoroacetic acid as a solvent and

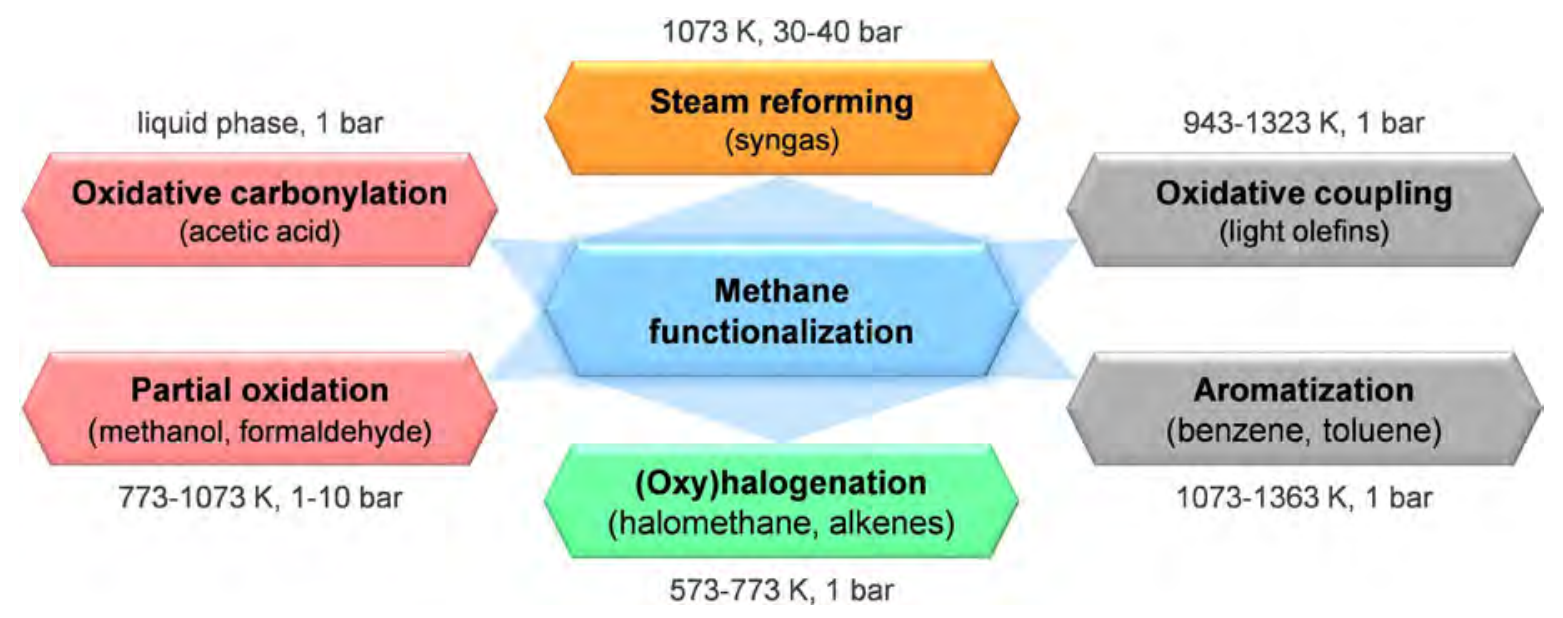

Figure 26. Widely investigated routes in the last decades for methane conversion to oxygenated products (red), syngas (orange), hydrocarbons (grey), and halogenated derivatives (green). Target products of each functionalization approach are mentioned in brackets. 
the severe thermodynamic limitations, respectively, impede their large-scale implementation. ${ }^{70}$ To overcome the above-mentioned drawbacks, it is imperative to develop different chemistry and processes, and to provide novel perspectives on the functionalization of low-cost hydrocarbon feedstocks.

Halogen-mediated functionalization of hydrocarbons, which has a long history in fine chemical synthesis, has emerged as a particularly attractive approach for the selective activation of light hydrocarbons under mild conditions (Figure 27). ${ }^{57,61,194,263,264}$ The direct halogenation of alkane produces alkyl halides that are deemed as versatile building blocks to synthesize a broad spectrum of commodities following an additional halide elimination step in which halogen atom is eliminated in the form of HX. ${ }^{61,194,264}$ Disadvantageously, the maximal halogen efficiency in halogenation is restricted to $50 \%$, with the rest of halogen ending up as HX. Thus, both the halogenation and subsequent transformation of alkyl halides release $\mathrm{HX}$, which has to be recycled in order to close the loop of

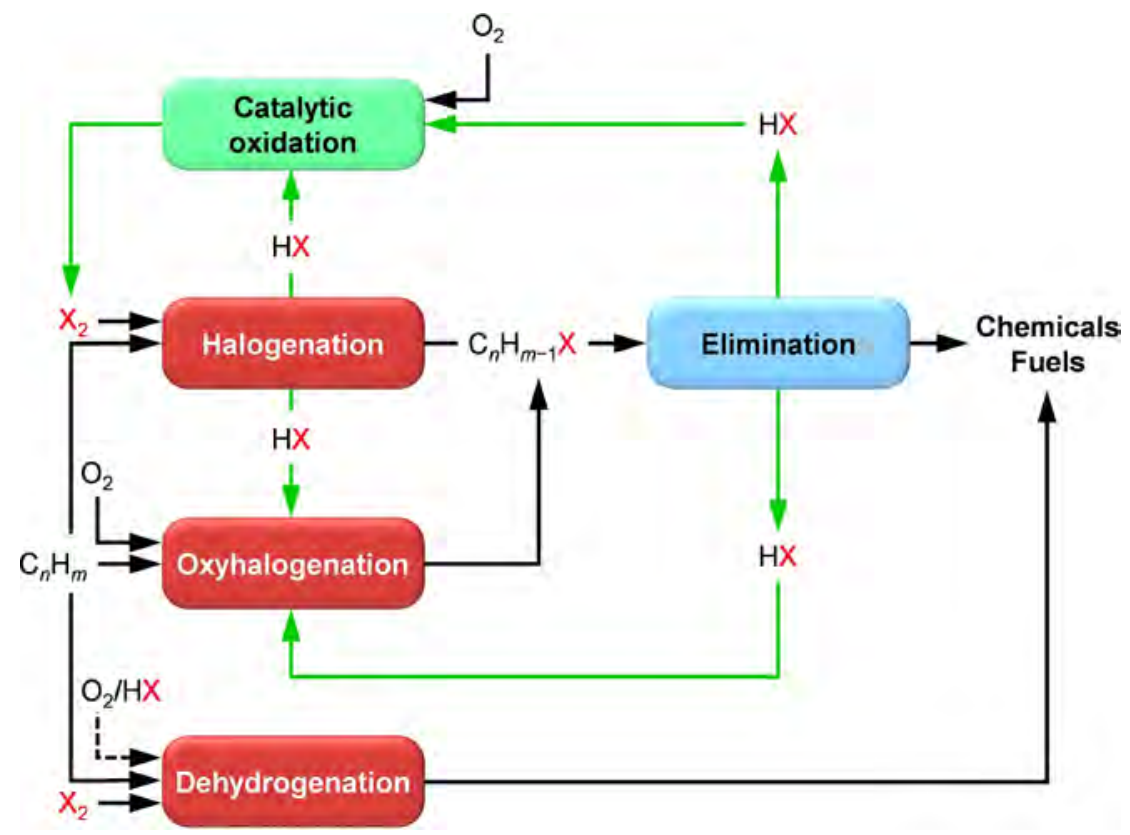

Figure 27. Halogen-mediated functionalization of hydrocarbons $\left(\mathrm{C}_{n} \mathrm{H}_{m}\right)$ by halogenation, oxyhalogenation, and dehydrogenation. The halide elimination step of alkyl halides leads to a variety of value-added chemicals and fuels. The hydrogen halide (HX) byproducts can be recycled by catalytic oxidation. Dehydrogenation occurs both in the absence and presence of oxygen (the dashed arrow denotes oxidative dehydrogenation), leading to respective olefins. $m=2 n$ or $2 n+2$. 
expensive halogens (Figure 27, top - green). A viable route to recover molecular halogen is by catalytic HX oxidation with molecular oxygen. Still, the oxyhalogenation reaction, in which an alkane is reacted with $\mathrm{HX}$ and $\mathrm{O}_{2}$, is conceptually a more advanced approach as it integrates alkane functionalization and halogen recovery in a single step (Figure 27, middle - red), enabling thus a highly desired process intensification. Alternatively, one-step dehydrogenation of higher alkanes to respective alkenes mediated by halogens can be applied both in the presence and absence of oxygen. ${ }^{46,265}$ Tremendous progresses have been achieved during the past decades, especially in novel halogenation processes and oxyhalogenation catalysts. In this context, we will examine in detail both the historical and newly developed concepts, processes, and catalysts for halogen-assisted functionalization technologies with three different categories of reactions i.e. halogenation, oxyhalogenation, and dehydrogenation, showing how the halogen chemistry evolved till the state-of-the-art in this field.

\subsection{Methane Halogenation}

The low-temperature activation of a highly symmetric methane molecule is thermodynamically favorable with molecular halogens such as chlorine and bromine. Nevertheless, the conventional gasphase halogenation reactions following a free-radical mechanism afford limited selectivity for the desired monosubstituted halomethanes $\left(\mathrm{CH}_{3} \mathrm{X}\right)$, as the formation of polyhalomethanes is even more favorable, particularly if highly reactive halogens (e.g., chlorine) are used. In the sections below, we will first briefly account the thermodynamics of methane halogenation reactions and then examine the newly developed chemistry, processes, and catalysts that can partly offset this constraint.

3.1.1. Free Radical Halogenation. Methane halogenation represents the classic example for the radical chain mechanism where the initiation is known as the activation of a molecular halogen by light or heat leading to the homolytic cleavage of the $X-X$ bond (Eqs. 9-13). This results in the formation of a species with an unpaired electron (the so-called radicals) that is extremely reactive and can readily abstract hydrogen from methane, giving methyl radicals and HX as the byproduct in the propagation step (Eqs. 10,11). The reaction terminates when all the remaining radicals combine to form $\mathrm{CH}_{3} \mathrm{X}$ or $\mathrm{X}_{2}$ 


$$
\begin{array}{ll}
\mathrm{X}_{2} \rightarrow 2 \mathrm{X}^{\cdot} & \text { Initiation } \\
\mathrm{CH}_{4}+\mathrm{X}^{\cdot} \rightarrow \mathrm{CH}_{3}{ }^{\cdot}+\mathrm{HX} & \text { Propagation } \\
\mathrm{CH}_{3}{ }^{\cdot}+\mathrm{X}_{2} \rightarrow \mathrm{CH}_{3} \mathrm{X}+\mathrm{X}^{\cdot} & \text { Propagation } \\
2 \mathrm{X}^{\cdot} \rightarrow \mathrm{X}_{2} & \text { Termination } \\
\mathrm{CH}_{3}{ }^{\cdot}+\mathrm{X}^{\cdot} \rightarrow \mathrm{CH}_{3} \mathrm{X} & \text { Termination }
\end{array}
$$

(Eqs. 12,13). However, these reactions do not necessarily stop after one halogen substitution. Instead, di-, tri-, and even tetra-halomethanes are commonly formed.

The reactivity varies greatly among different halogens in the free radical chain reactions. Thermodynamic analysis suggests that methane fluorination is a highly spontaneous and exothermic reaction which can result in an explosion if the reaction heat is not removed sufficiently fast. ${ }^{266,267}$ On the other hand, the iodination of methane is non-spontaneous and endothermic, and appreciable yields of $\mathrm{CH}_{3} \mathrm{I}$ can only be attained at high temperatures (873-1000 K). ${ }^{266-268}$ Chlorine and bromine are moderately reactive with much milder exothermicity compared to fluorine, but active enough compared to iodine. However, the chlorination leads to a mixture of polychlorinated products. The product distribution is less relevant to temperature, but solely determined by the $\mathrm{Cl}_{2}: \mathrm{CH}_{4}$ ratio (Figure 28a). ${ }^{269}$ Conversely, the bromination is more dependent on temperature and offers better control of selectivity (Figure 28b). ${ }^{270}$ This can be explained by the strengths of bonds being formed; the $\mathrm{H}-\mathrm{Cl}$ bond is $63 \mathrm{~kJ}$ mol $^{-1}$ stronger than the $\mathrm{H}-\mathrm{Br}$ bond, thus higher energy barriers must be overcome in the chainpropagation steps in methane bromination. The simulation based on a well-mixed reactor predicted that a high dibromomethane selectivity of $>90 \%$ can be attained accompanied with high methane conversions $\left(\mathrm{CH}_{4}: \mathrm{Br}=1: 3\right.$, residence time $\left.=3 \mathrm{~s}, T>593 \mathrm{~K}\right) .{ }^{266} \mathrm{~A}$ more recent study by Stucky et al. showed that the addition of a small amount of $I_{2}$ in this reaction can simultaneously increase the conversion of $\mathrm{CH}_{4}$ and selectivity to $\mathrm{CH}_{3} \mathrm{Br}$ (Figure 28c). ${ }^{270}$ The function of $\mathrm{I}_{2}$ was postulated to 

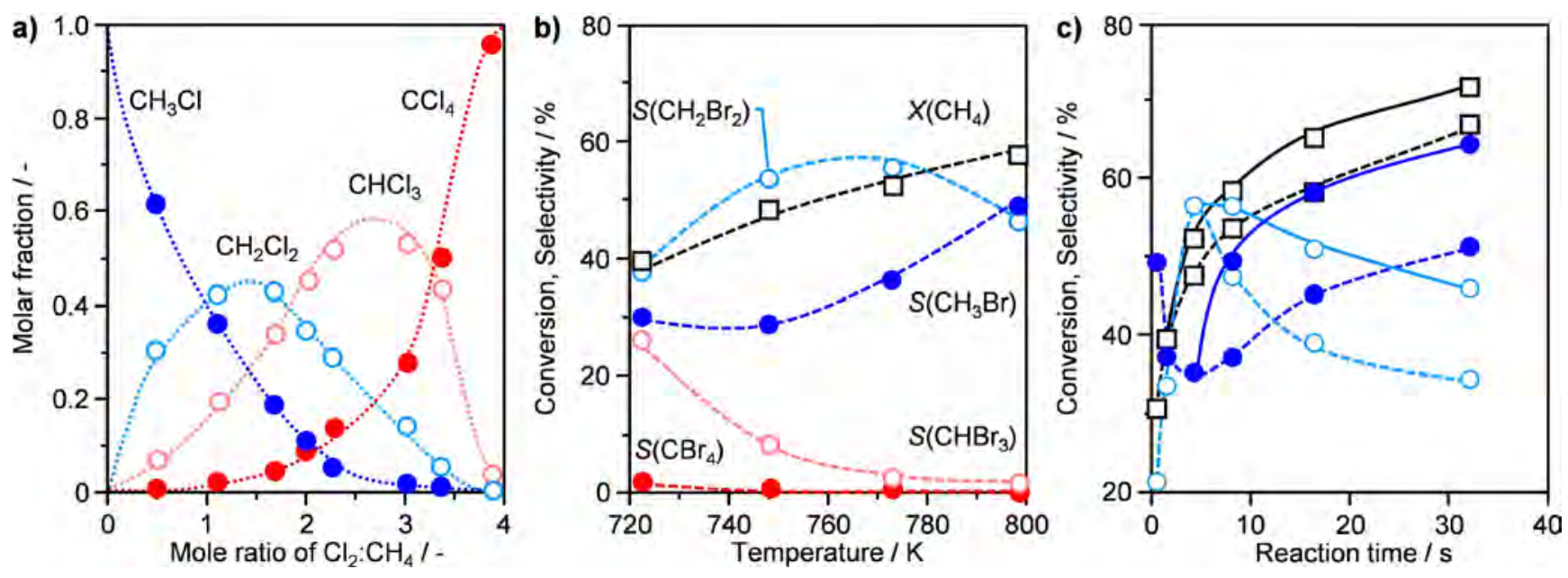

Figure 28. a) Effect of mole ratio of $\mathrm{Cl}_{2}: \mathrm{CH}_{4}$ on the product distribution at 713-733 K. Reproduced with permission from ref 269. Copyright 1942 American Chemical Society. Conversion and selectivity in methane bromination as a function of $\mathbf{b}$ ) temperature with a residence time of $8 \mathrm{~s}$, and $\mathbf{c}$ ) reaction time at 773 K. Reproduced with permission from ref 270. Copyright 2013 American Chemical Society. Conditions: $\mathrm{CH}_{4}: \mathrm{Br}_{2}: \mathrm{Ar}=1: 1: 2, \mathrm{I}_{2}: \mathrm{Br}_{2}=1: 9, \mathrm{CH}_{4}$ input was $8.2 \mathrm{mmol}$. The results with and without the presence of $\mathrm{I}_{2}$ are represented with solid and dashed lines, respectively. Legends in $\mathbf{b}$ are applicable in $\mathbf{c}$.

catalyze the reproportionation between $\mathrm{CH}_{2} \mathrm{Br}_{2}$ and $\mathrm{CH}_{4}$, driving the bromination reaction to equilibrium.

Lorkovic et al. established and compared energy diagrams based on bond strengths of $\mathrm{C}_{1}$ halomethanes for methane halogenation and halogen redistribution reactions (Figure 29). ${ }^{271}$ The chlorination is more favorable than chloromethane reproportionation (leading to high $\mathrm{CH}_{3} \mathrm{Cl}$ selectivity) thus the overall reaction is determined by kinetics. Contrarily, iodination is disadvantageous to iodomethane reproportionation, making thermodynamics crucial for the product distribution. The difference between methane bromination and reproportionation is relatively small $\left(\sim 25 \mathrm{~kJ} \mathrm{~mol}^{-1}\right)$, therefore, bromination is controlled by both kinetics and thermodynamics. Experimental results showed that a high $\mathrm{CH}_{3} \mathrm{Br}$ selectivity can be achieved, providing ample residence time for methane bromination $\left(X\left(\mathrm{CH}_{4}\right)=73 \%, S\left(\mathrm{CH}_{3} \mathrm{Br}\right)=69 \%, T=798 \mathrm{~K}\right) \cdot{ }^{271}$ It was speculated that the reactions proceeded in two phases, a rapid consumption of methane leading to kinetic product distribution and a slow reproportionation of polybromomethanes, yielding a high methane conversion and a high selectivity to $\mathrm{CH}_{3} \mathrm{Br}$. These findings suggest that bromine, with respect to better selectivity control, could be the most 

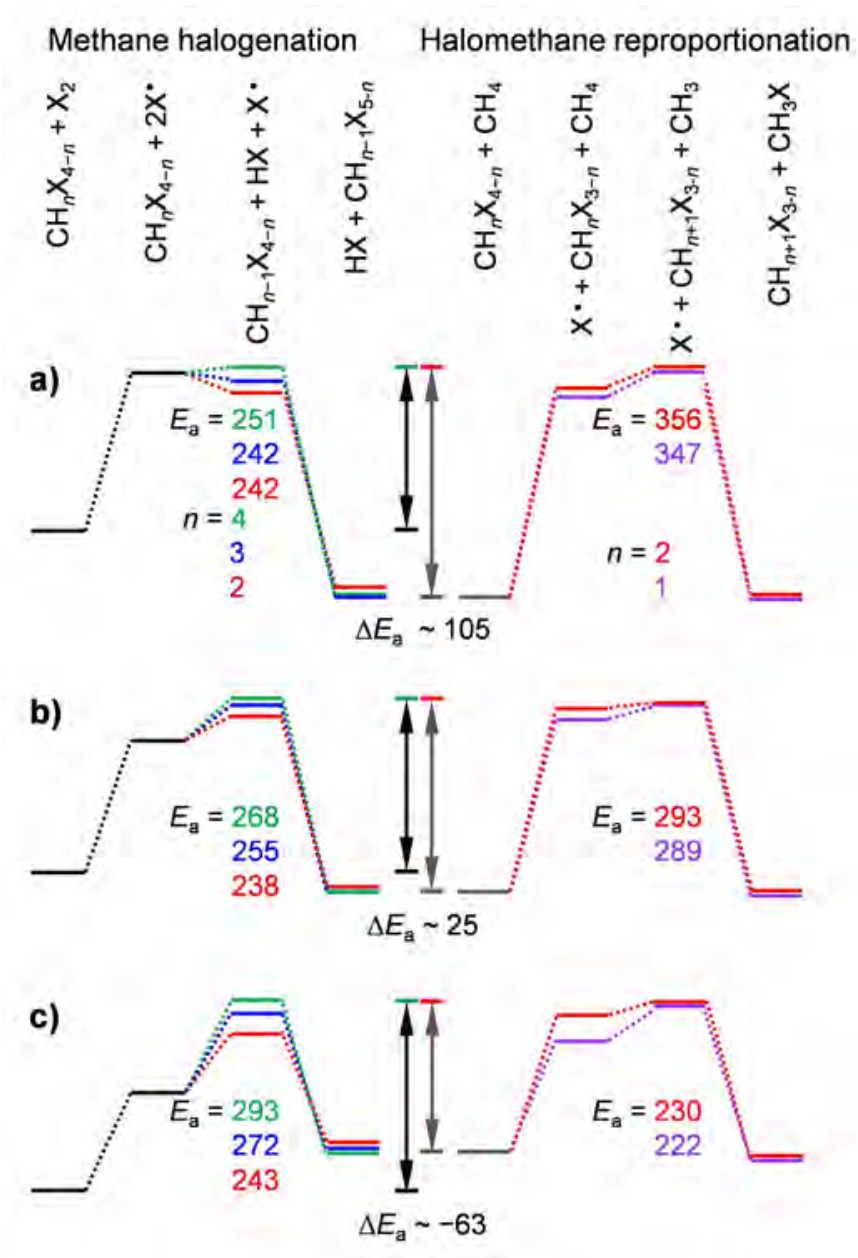

Figure 29. A comparison of energetic reaction profiles for methane halogenation and halomethane reproportionation: a) Chlorination, b) Bromination, and c) Iodination. The descriptions of each elemental steps and colored lines in a are applicable in $\mathbf{b}$ and $\mathbf{c}$. $\mathrm{X}=\mathrm{Cl}, \mathrm{Br}$, and I. Energies are in $\mathrm{kJ} \mathrm{mol}^{-1}$. Adapted with permission from ref 271. Copyright 2006 American Chemical Society.

promising candidate among halogens for methane functionization. However, the large availability of chlorine together with its cheap price makes it more attractive for large-scale application.

3.1.2. Electrophilic Halogenation. Electrophilic methane halogenation route, contrasting strongly with the radical halogenations, enables an extremely selective formation of methyl halides at low temperatures. These reactions are catalyzed by liquid or solid super acids. The general reaction pathways are depicted in Figure $30 .^{263}$ In this hypothesis, the halogen molecules are supposed to be polarized by super acids and methane halogenation subsequently occurs under ionic conditions with the formation of five-coordinated carbonium intermediates. Methyl halides are finally formed with an elimination step from the as-generated carbonium species. According to the mechanism, the high 


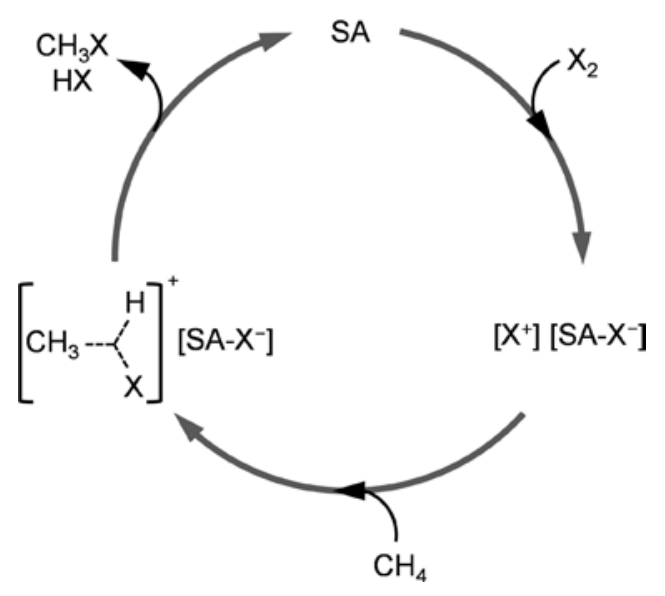

Figure 30. Electrophilic methane halogenation route over super acids (SA). ${ }^{263}$ Halogen molecules are first polarized by super acids to form a complex. It then acts as an electrophilic reagent reacting with methane in a typical electrophilic insertion reaction, forming five-coordinated carbonium ions. The cycle is completed with the release of $\mathrm{CH}_{3} \mathrm{X}$ and $\mathrm{HX}$ from these intermediates. $\mathrm{X}=\mathrm{Cl}$ or $\mathrm{Br}$.

selectivity to methyl halides can be explained by the preferential generation of monohalomethonium ion as compared to other higher halogenated intermediates where the halogen atoms increasingly dominate the donor ability of the $\sigma \mathrm{C}-\mathrm{H}$ bonds.

Olah et al. pioneered the concept of super acid-mediated transformation of methane to methyl halides in the 1970 s. ${ }^{272,273}$ It was observed that methane chlorination with superacid $\mathrm{SbF}_{5}-\mathrm{Cl}_{2}-\mathrm{SO}_{2} \mathrm{ClF}$ gave exclusively methyl chloride in the gas phase even at room temperature (dimethylchloronium ions were formed in the solution). The electrophilic halogenation was later extended to the heterogeneous gas-solid reactions over different types of catalysts (Table 4). A set of supported Lewis acid (oxy)halide catalysts including $\mathrm{FeOCl} / \mathrm{Al}_{2} \mathrm{O}_{3}, \mathrm{TaOF}_{3} / \mathrm{Al}_{2} \mathrm{O}_{3}, \mathrm{NbOF}_{3} / \mathrm{Al}_{2} \mathrm{O}_{3}, \mathrm{ZrOF}_{2} / \mathrm{Al}_{2} \mathrm{O}_{3}, \mathrm{SbF}_{5}$-graphite and $\mathrm{TaF}_{5-}$ Nafion have been proved to be extremely selective for the formation of methyl halides ( $S=82-99 \%$ at 453-473 K), with methylene dihalides as the main byproducts. ${ }^{263} \mathrm{Pt} / \mathrm{Al}_{2} \mathrm{O}_{3}$ and $\mathrm{Pd} / \mathrm{BaSO}_{4}$ were also demonstrated to be equally effective under similar reaction conditions. ${ }^{263}$ For all the above catalysts, the bromination reaction is superior to chlorination to achieve high methyl halide selectivity $\left(\mathrm{S}\left(\mathrm{CH}_{3} \mathrm{Br}\right)>99 \%\right)$. Since the 1990 s, the viable catalysts for selective methane halogenation have been further expanded to protonic and Na-exchanged zeolites (H-ZSM-5, H-MOR, Na-L, Na-X, and Na-Y), 
Table 4. Catalysts for Electrophilic Methane Halogenation

\begin{tabular}{|c|c|c|c|c|c|c|}
\hline \multirow{2}{*}{ catalyst } & \multicolumn{2}{|c|}{ reactivity $^{a}$} & \multicolumn{3}{|c|}{ conditions } & \multirow{2}{*}{ ref } \\
\hline & $X / \%$ & $S / \%$ & $\mathrm{GHSV}^{b}$ & $\mathrm{CH}_{4}: \mathrm{Cl}_{2}\left(\mathrm{Br}_{2}\right)$ & $T / \mathrm{K}$ & \\
\hline \multicolumn{7}{|l|}{ chlorination } \\
\hline SbF5-graphite $_{5}$ & 7 & 98 & 100 & $1: 2$ & 453 & 263 \\
\hline $\mathrm{NbOF}_{3} / \mathrm{Al}_{2} \mathrm{O}_{3}$ & 10 & 90 & 50 & $1: 3$ & 523 & 263 \\
\hline $\mathrm{TaOF}_{3} / \mathrm{Al}_{2} \mathrm{O}_{3}$ & 15 & 93 & 1400 & $1: 2$ & 508 & 263 \\
\hline $\mathrm{FeO}_{x} \mathrm{Cl}_{y} / \mathrm{Al}_{2} \mathrm{O}_{3}$ & 16 & 88 & 100 & $1: 2$ & 523 & 263 \\
\hline $\mathrm{GaO}_{x} \mathrm{Cl}_{y} / \mathrm{Al}_{2} \mathrm{O}_{3}$ & 26 & 90 & 100 & $1: 2$ & 523 & 263 \\
\hline $\mathrm{ZrOF}_{2} / \mathrm{Al}_{2} \mathrm{O}_{3}$ & 34 & 96 & 100 & $1: 4$ & 543 & 263 \\
\hline TaF5-Nafion & 11 & 97 & 100 & $1: 2$ & 473 & 263 \\
\hline Nafion-H & 18 & 88 & 100 & $1: 4$ & 458 & 263 \\
\hline $\mathrm{Pt} / \mathrm{Al}_{2} \mathrm{O}_{3}$ & 12 & 99 & 300 & $3: 1$ & 523 & 263 \\
\hline $\mathrm{Pd} / \mathrm{BaSO}_{4}$ & 15 & 99 & 600 & $2: 1$ & 473 & 263 \\
\hline $\mathrm{SO}_{4}{ }^{2-} / \mathrm{ZrO}_{2}$ & 6 & 91 & 1000 & $4: 1$ & 473 & 274 \\
\hline $\mathrm{Fe} / \mathrm{Mn} / \mathrm{SO}_{4}{ }^{2-} / \mathrm{ZrO}_{2}$ & 9 & 90 & 1000 & $4: 1$ & 508 & 274 \\
\hline $\mathrm{Pt} / \mathrm{SO}_{4}{ }^{2-} / \mathrm{ZrO}_{2}$ & 10 & 99 & 1000 & $4: 1$ & 508 & 274 \\
\hline H-MOR & 24 & 99 & 600 & $4: 1$ & 673 & 275 \\
\hline H-ZSM-5 & 26 & 87 & 600 & $4: 1$ & 673 & 275 \\
\hline Na-L & 24 & 86 & 600 & $4: 1$ & 673 & 275 \\
\hline Na-X & 25 & 87 & 600 & $4: 1$ & 673 & 275 \\
\hline $\mathrm{Na}-\mathrm{Y}$ & 26 & 98 & 600 & $4: 1$ & 673 & 275 \\
\hline \multicolumn{7}{|l|}{ bromination } \\
\hline $\mathrm{Pt} / \mathrm{Al}_{2} \mathrm{O}_{3}$ & 4 & 99 & 300 & $2: 1$ & 473 & 263 \\
\hline $\mathrm{TaOF}_{3} / \mathrm{Al}_{2} \mathrm{O}_{3}$ & 14 & 99 & 50 & $15: 1$ & 523 & 263 \\
\hline $\mathrm{SbOF}_{3} / \mathrm{Al}_{2} \mathrm{O}_{3}$ & 20 & 99 & 100 & $5: 1$ & 473 & 263 \\
\hline $\mathrm{SO}_{4}{ }^{2-} / \mathrm{ZrO}_{2} / \mathrm{SBA}-15$ & 69 & 99 & 3000 & $1: 10$ & 613 & 276 \\
\hline
\end{tabular}

${ }^{a} X$ and $S$ denote methane conversion and methyl halide selectivity, respectively. ${ }^{b}$ GHSV in $\mathrm{cm}^{3} \mathrm{STP} \mathrm{h}^{-1} \mathrm{gcat}^{-1}$. 
and sulfated metal oxides $\left(\mathrm{SO}_{4}{ }^{2-}-\mathrm{ZrO}_{2}, \mathrm{Pt} / \mathrm{SO}_{4}{ }^{2-}-\mathrm{ZrO}_{2}, \mathrm{Fe} / \mathrm{Mn} / \mathrm{SO}_{4}{ }^{2-} / \mathrm{ZrO}_{2}\right.$, and $\left.\mathrm{SO}_{4}{ }^{2-} / \mathrm{ZrO}_{2} / \mathrm{SBA}-15\right) .{ }^{274-}$ ${ }^{276}$ These catalysts are found to be sensitive to the reaction temperature. It has been reported that a free radical mechanism was dominant over zeolite-catalyzed methane chlorination at low temperatures (473$573 \mathrm{~K}$ ), giving a mixture of chlorinated products, however, selective monochlorination took place at 573-623 K. ${ }^{275}$ In contrast, for the sulfated catalysts, lower temperature was obviously more advantageous for a higher $\mathrm{CH}_{3} \mathrm{Cl}$ selectivity $(S>90 \%$ below $473 \mathrm{~K}){ }^{274}$

Albeit electrophilic halogenation reaction provides a very selective production of methyl halide, no practical implementation is reported to date. This might be related to the very low space velocity employed in these processes leading to inferior productivity. Besides, long-term stability could be another hurdle for the super acid-based catalysts, which has not been demonstrated. Further research on catalyst deactivation mechanism might lead to more robust catalysts and thus a practical process.

3.1.3. Halogenation Processes. Hoechst Process. The oldest halogenation process dates back to the 1920s when the Hoechst process was applied for the manufacture of chloromethanes $\left(71 \% \mathrm{CH}_{2} \mathrm{Cl}_{2}, 27 \%\right.$ $\mathrm{CHCl}_{3}$, and $\left.3 \% \mathrm{CCl}_{4}\right) .{ }^{32}$ In this route, a gas mixture of methane and chlorine reacts in a loop reactor with internal gas circulation at $623-723 \mathrm{~K}$. The $\mathrm{HCl}$ in the effluent is absorbed to prepare hydrochloric acid, $\mathrm{CH}_{3} \mathrm{Cl}$ and unreacted $\mathrm{CH}_{4}$ are cycled, and higher chlorinated products are separated by multiple distillation columns. Despite the disadvantage of producing a substantial amount of hydrochloric acid, this process continues essentially unchanged, apart from modifications reflecting the state-of-the-art technology. ${ }^{32}$

Miller Process. More advanced methane bromination processes have been developed in the past decades, taking into account (i) the selective formation of methyl bromide, (ii) subsequent transformation of the latter into valuable chemicals and fuels, and (iii) bromine recycling. $\mathrm{A} \mathrm{FeBr}_{3}-$ assisted bromination process from methane to methanol was developed by Miller in the 1990s (Figure 31). ${ }^{55}$ The centralized concept is taking advantage of the bromine released from the decomposition of $\mathrm{FeBr}_{3}$ to generate methyl bromide. By reacting with an aqueous solution of ferric 


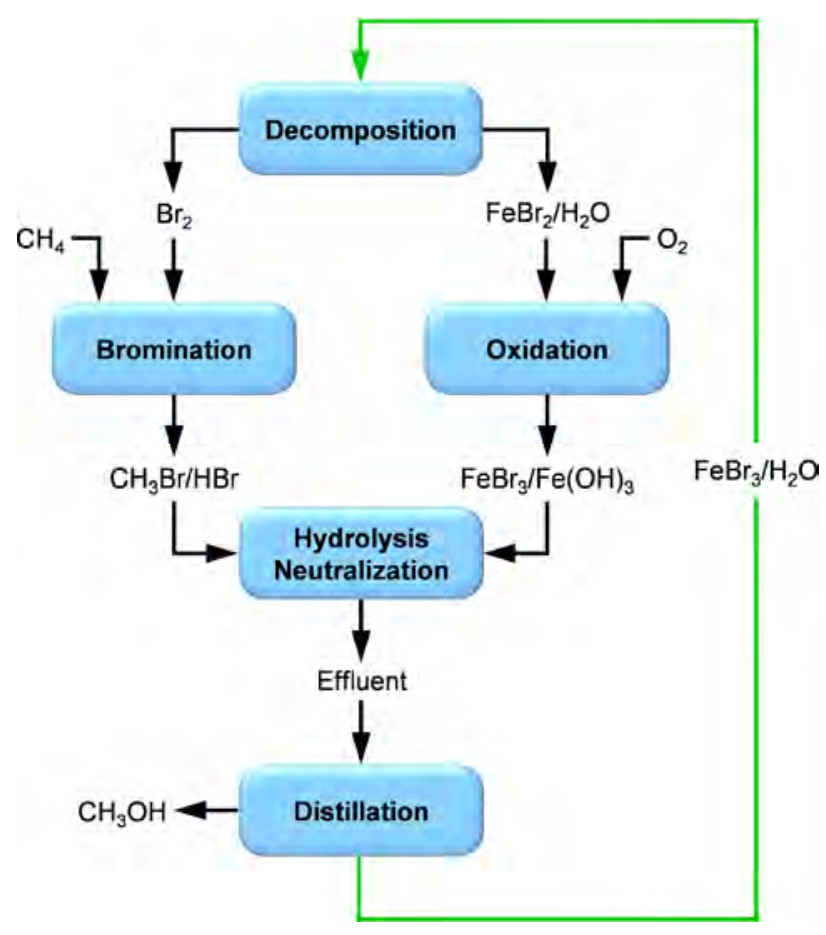

Figure 31. Miller process for methane conversion to methanol, comprising $\mathrm{FeBr}_{3}$ as the bromine mediator.

hydroxide in an absorber, this intermediate as well as the $\mathrm{HBr}$ byproduct from methane bromination can be readily transformed into $\mathrm{CH}_{3} \mathrm{OH}$ and $\mathrm{FeBr}_{3}$, respectively. The $\mathrm{FeBr}_{2}$ from the decomposition of $\mathrm{FeBr}_{3}$ can then be recovered by an oxidation reaction. Ideally, there is no net consumption of bromine, thus this route represents a closed-loop bromine-mediated process.

Bromine-Aided Multistep Methane to Oxygenates or Hydrocarbons. An integrated process for the functionalization of natural gas with bromine was proposed by McFarland and Stucky et al. in 2003. ${ }^{277-}$ ${ }^{280}$ A multiple-step conversion from methane to oxygenates (methanol and dimethyl ether - DME) was disclosed in the patent, comprising methane bromination and metal oxide-catalyzed hydrolysis of methyl bromide in separate reactors. ${ }^{277}$ Another process from natural gas to higher hydrocarbons was developed containing two tandem reactions in a dual-stage reactor (zone reactor). ${ }^{278}$ Firstly, an overstoichiometric feed $\left(\mathrm{CH}_{4}: \mathrm{Br}_{2}=10: 1\right)$ was used for methane bromination at $773 \mathrm{~K}$, in order to realize the total conversion of bromine and to maximize the selectivity of methyl bromide. The bromination effluent then passed over $\mathrm{CaO} / \mathrm{ZSM}-5$ catalyst bed at $673 \mathrm{~K}$ to produce $\mathrm{C}_{2}-\mathrm{C}_{5}$-rich hydrocarbons by 
$\mathrm{CH}_{3} \mathrm{Br}$ coupling and to eliminate $\mathrm{HBr}$. Disadvantageously, both of the above two processes require an additional step for bromine regeneration.

Bromine-Assisted Zone Reactor Technology. The full bromine utilization within the zone reactor can be realized by multiple stage catalyst packing. Figures 32a,b show two typical processes for natural gas to oxygenates and higher hydrocarbons without replenishing bromine. ${ }^{279,280}$ Conceptually, bromine was generated in situ by the oxidation of metal bromides packed in the first zone of the reactor. The asgenerated bromine then passed into the second zone where methane is introduced, forming methyl
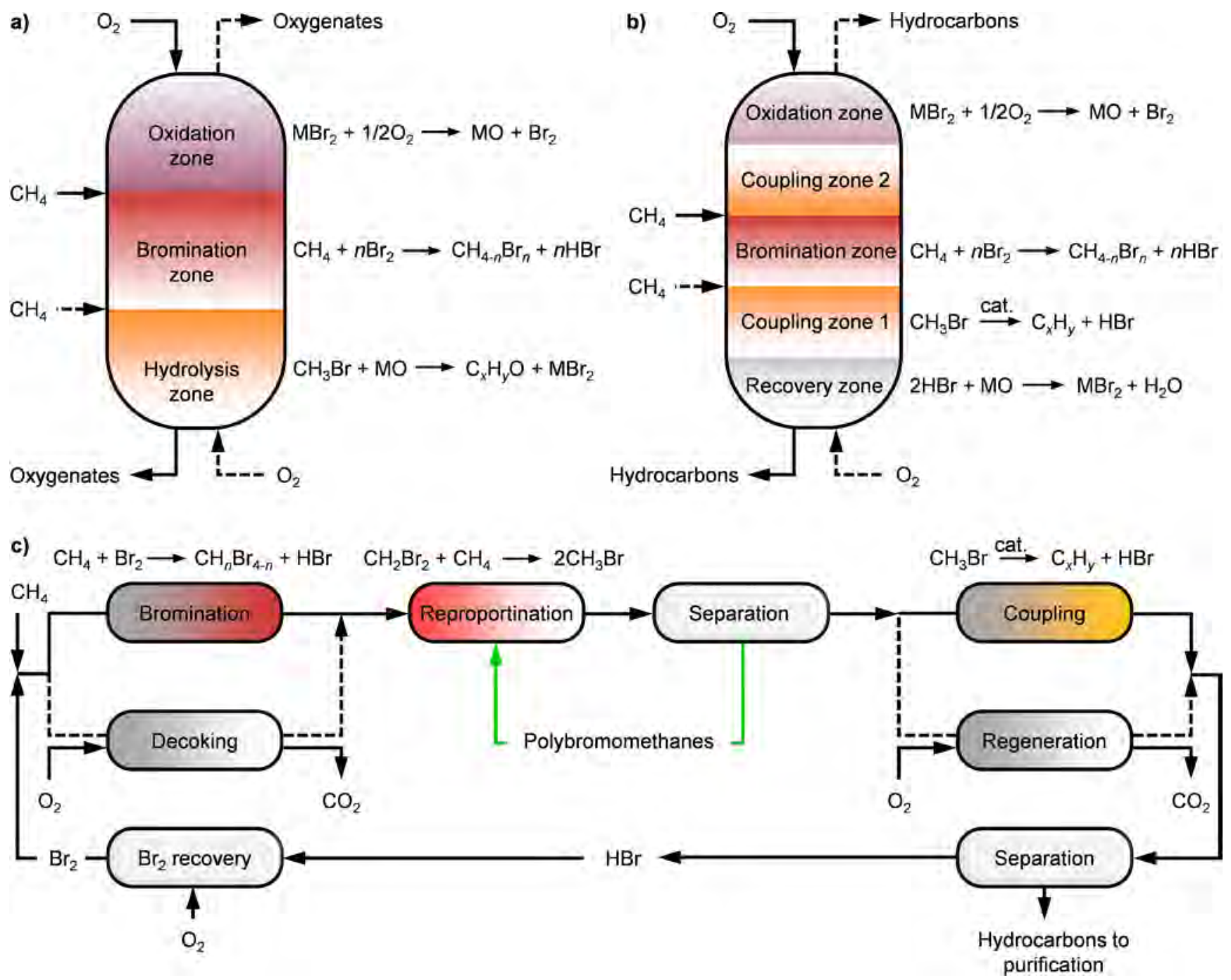

Figure 32. Bromine-assisted zone reactor technologies for methane conversions to a) oxygenates, ${ }^{279}$ and b) higher hydrocarbons. Adapted with permission from ref 280. Copyright 2004 Elsevier. The packed catalysts and possible reactions in each stage of the zone reactor are shown by the stacks. The dashed arrows indicate switch of feed directions. $\mathrm{M}$ denotes the metal components. c) Bromine-mediated gasto-liquids technology with separated reactors for process optimization. ${ }^{281}$ 
bromide, poly-bromomethanes, and $\mathrm{HBr}$. In the last step, the effluents were directed into the third zone of the reactor containing metal oxide catalysts, thus the intermediates were further transformed into corresponding alcohols and ethers by hydrolysis while bromine was stripped in the form of metal bromide by the metal oxide. In the case of methane-to-hydrocarbons route, a coupling catalyst bed was packed above the bromine recovery zone (Figure 32b). By optimizing the reaction conditions, the bromine can be retained within the zone reactor. It is claimed that these processes are also applicable to higher hydrocarbons such as ethane. ${ }^{279}$

The zone reactor technology has the biggest advantages of simplicity of equipment and no additional need for bromine regeneration, besides, in an ideal case, there is no direct contact of bromine out of the zone reactor. However, the disadvantages are apparent. Since the metathesis reactions between metal oxides and metal bromides are separated by two independent zones (usually at the inlet and outlet of the zone reactor), once the catalyst is fully transformed from oxide to bromide (per contra), a switch of feed direction is necessary (as indicated by the dashed arrows in Figures 32a,b) so as to operate in a continuous mode. The successful implementation of zone reactor technology is to some extent hindered by some problems, for instance, the long-term stability of the reported metal oxide catalysts $\left(\mathrm{CuO}-\mathrm{ZrO}_{2}, \mathrm{Co}_{3} \mathrm{O}_{4}-\mathrm{Sm}_{2} \mathrm{O}_{3}-\mathrm{ZrO}_{2}\right.$, and $\left.\mathrm{Co}_{3} \mathrm{O}_{4}-\mathrm{ZrO}_{2}\right)$ during massive bromination-oxidation cycles should be addressed. Alternatively, the recently developed catalysts for $\mathrm{HBr}$ oxidation, which have proved their excellent stability, might be implemented for the metathesis reactions. ${ }^{282-284}$ Heat management is another crucial issue. The oxidation zone is endothermic operating at 623-723 K, whereas the bromination and hydrolysis zones are generally exothermic. ${ }^{279}$ Since there is no sharp barrier to separate these zones, heat supply and removal of each zone are critical. It is claimed that the bromination and regeneration zones can be run adiabatically to minimize the need for temperature cycling. ${ }^{63}$ Furthermore, the oxygen feed to the oxidation zone should be strictly controlled, otherwise it will cause undesirable combustion in the downstream reactions and decrease the overall efficiency. Other practical problems like the recovery of bromine from $\mathrm{HBr}$ should deserve more attention (vide infra). 
One-Step Methane to Oxygenates. Another interesting one-step low-temperature route from methane to oxygenates, with the intention of restraining bromine within reactor, was reported by Li and Yuan. ${ }^{285}$ The reaction occurs on $\mathrm{MoO}_{2} \mathrm{Br}_{2}\left(\mathrm{H}_{2} \mathrm{O}\right)_{2} / \mathrm{Zn}-\mathrm{MCM}-48 \quad\left(X\left(\mathrm{CH}_{4}\right)<14 \%\right.$, and $\mathrm{S}\left(\mathrm{CH}_{3} \mathrm{OH}+\mathrm{CH}_{3} \mathrm{OCH}_{3}\right)=70-90 \%$ at $\left.493 \mathrm{~K}\right),{ }^{285}$ which is capable of bromine metathesis in the presence of oxygen. It was proposed that $\mathrm{Br}_{2}$ was released when $\mathrm{MoO}_{2} \mathrm{Br}_{2}$ reacted with $\mathrm{O}_{2}$, forming $\mathrm{MoO}_{3}$ that can scavenge the bromine atoms from $\mathrm{CH}_{3} \mathrm{Br}$ and $\mathrm{HBr}$ for the regeneration of $\mathrm{MoO}_{2} \mathrm{Br}_{2}$. Unfortunately, the catalyst deactivated rapidly due to the insufficient bromine-metathesis efficiency, as a large amount of bromine-containing compounds were detected in the reaction effluent in a few hours.

Shell Process. For the bromination technology, the poly-bromomethanes generated cannot be easily removed, which are prone to coke the catalysts in the MTH reaction. In this sense, separation of bromination and coupling reactors can offer the advantage of converting poly-bromomethanes (by reproportionation or hydrogenation) to useful $\mathrm{CH}_{3} \mathrm{Br}$, as well as enables the optimization of individual step. ${ }^{281,286,287}$ A proof-of-concept example, targeting the production of aromatics and $\mathrm{C}_{4+}$ non-aromatic hydrocarbons, has been disclosed by Shell (Figure 32c). ${ }^{281}$ In this process, the bromination effluent is directed to an adiabatic reproportination reactor where polybromomethanes react with unreacted $\mathrm{CH}_{4}$ to form $\mathrm{CH}_{3} \mathrm{Br}$. The remaining polybromomethanes are further separated by distillation and recycled to the reproportination reactor. Since most of the polybromomethanes have been converted, the feed to the coupling fixed-bed reactor is less prone to cause catalysts deactivation. Parallel reactor trains are installed for the bromination and coupling reactions. During operation, one reactor of each reaction is running for decoking or catalyst regeneration purpose. Additionally, a bromine regeneration reactor, comprising several shell/tube exchangers which are filled with copper oxide catalysts, is used to recover bromine from $\mathrm{HBr}$.

\subsubsection{Bromine Recycling via Catalyzed $\mathrm{HBr}$ Oxidation. The successful large-scale} implementation of the direct halogenation technology relies on the efficient recycling of bromine reduced as $\mathrm{HBr}$ in the bromination and elimination steps (Figure 27). Thus, the development of a robust and economic process to recover $\mathrm{Br}_{2}$ from $\mathrm{HBr}$ is essential to enable the sustainable bromine-mediated 
upgrading of alkanes. ${ }^{288}$ The catalyzed gas-phase oxidation of $\mathrm{HBr}$ with $\mathrm{O}_{2}$ or air (Eq. 14) is particularly attractive owing to its low energy requirement and the relative simplicity. The copper-based catalysts proposed in the Shell process for bromine recovery (vide supra) are prone to volatilization of copper phase and would need the replenishment/regeneration steps. ${ }^{191,288}$ Thus, new catalyst families that can withstand the $\mathrm{HBr}$ oxidation conditions are needed to achieve stable bromine recycling.

$$
2 \mathrm{HBr}+1 / 2 \mathrm{O}_{2} \rightarrow \mathrm{Br}_{2}+\mathrm{H}_{2} \mathrm{O} \quad \Delta H=-138 \mathrm{~kJ} \mathrm{~mol}^{-1}
$$

Analogies and Differences in $\mathrm{HBr}$ and $\mathrm{HCl}$ Oxidation. When targeting the discovery of active and stable $\mathrm{HBr}$ oxidation catalysts, it is important to understand its chemistry with respect to the analogous $\mathrm{HCl}$ oxidation (Section 2.5.3). Given the apparent chemical similarity of these reactions, an extrapolation of new generation of stable $\mathrm{HCl}$ oxidation catalysts appears to be straightforward. However, the intrinsic properties of $\mathrm{HBr}$ oxidation, such as higher exothermicity and more strong corrosiveness of $\mathrm{HBr}$, may render catalyst design critical. A highly advantageous difference between the two reactions is the absence of thermodynamic limitations in $\mathrm{HBr}$ oxidation, which a priori enables the complete recovery of bromine. Screening of representative $\mathrm{HCl}$ oxidation catalysts in $\mathrm{HBr}$ oxidation revealed that most of the catalysts exhibited significant $\mathrm{HBr}$ conversion in the range of $400-600 \mathrm{~K}$ (Figure 33a), which represents a decrease of 120-330 K in the operating temperature window relative to that required for $\mathrm{HCl}$ oxidation for the same conversion level (Section 2, Figure 21a). ${ }^{288}$ The case of $\mathrm{U}_{3} \mathrm{O}_{8} / \mathrm{ZrO}_{2}$, with a shift of approximately $330 \mathrm{~K}$, is exemplary. As a result, the $\mathrm{HBr}$ oxidation performance of $\mathrm{U}_{3} \mathrm{O}_{8} / \mathrm{ZrO}_{2}$ (the least active $\mathrm{HCl}$ oxidation catalyst) is comparable to that of the most active $\mathrm{HBr}$ oxidation catalyst, $\mathrm{RuO} / \mathrm{TiO}_{2}$. The $\mathrm{CeO}_{2} / \mathrm{ZrO}_{2}$ and $\mathrm{IrO}_{2} / \mathrm{TiO}_{2}$ were active at higher temperatures compared to $\mathrm{RuO}_{2-}$ and $\mathrm{U}_{3} \mathrm{O}_{8}$-based catalysts. Transition metal catalysts, $\mathrm{CuO} / \mathrm{SiO}_{2}$, $\mathrm{Cr}_{2} \mathrm{O}_{3} / \mathrm{SiO}_{2}$, and $\mathrm{Fe}_{2} \mathrm{O}_{3} / \mathrm{Al}_{2} \mathrm{O}_{3}$, evaluated in $\mathrm{HBr}$ oxidation were all unstable due to excessive volatilization of the active metal component and thus rapidly deactivated. ${ }^{244}$ Furthermore, catalytic evaluation of the bulk phases showed that $\mathrm{CeBr}_{3}, \mathrm{RuBr}_{3}$, and $\mathrm{IrBr}_{3}$ were inactive and displayed activity only when they transformed to their respective oxides during $\mathrm{HBr}$ oxidation. ${ }^{288}$ This suggests that bulk 
halides are inactive for $\mathrm{HBr}$ oxidation. Instead, the oxide phase is required to catalyze the reaction. However, this does not exclude the formation of surface oxybromide species under reaction conditions analogous to the case wherein an oxychloride phase was identified during $\mathrm{HCl}$ oxidation over $\mathrm{RuO}_{2}{ }^{288}$

$\mathrm{HBr}$ versus $\mathrm{HCl}$ Oxidation on Rutile Oxide Surfaces. Owing to the outstanding activity of $\mathrm{RuO}_{2}$, in-depth understanding of $\mathrm{HBr}$ oxidation was achieved over the rutile catalysts. The mechanism of $\mathrm{HBr}$ oxidation over $\mathrm{RuO}_{2}$, studied by DFT simulations and supported by TAP-2 experiments, was demonstrated to follow the same path as $\mathrm{HCl}$ oxidation with bromine evolution as the most energydemanding step. ${ }^{218,282,284}$ The activity in the two reaction was thus correlated to halogen desorption energy (Figure 33b). DFT simulation conducted on the $\mathrm{RuO}_{2}(110)$ stoichiometric surface estimated that $\mathrm{Cl}_{2}$ evolution requires $0.7 \mathrm{eV}$ more energy than that of $\mathrm{Br}_{2}$, justifying the lower operating temperature in $\mathrm{HBr}$ oxidation. ${ }^{38}$ To shed light on the influence of surface halogenation, comparative PGAA experiments were conducted over $\mathrm{RuO}_{2}$ (Figure 33c), which demonstrated extensive subsurface bromination, at lower $\mathrm{O}_{2}: \mathrm{HBr}$ ratios and temperature. ${ }^{38}$ Note that owing to the absence of change in the bulk, the bromine content determined herein by PGAA was ascribed to the surface and/or subsurface. On the other hand, the chlorination remained confined to the surface of $\mathrm{RuO}_{2}$ in $\mathrm{HCl}$ oxidation. This was further corroborated by HRTEM coupled to elemental mapping of the samples after exposure to $\mathrm{HBr}$ at $393 \mathrm{~K}$ or $\mathrm{HCl}$ at $543 \mathrm{~K}$, showing a much thicker layer for the former treatment than that of the latter (Figure 33d). This excessive bromination correlates with the slow deactivation (ca. $40 \%$ loss of initial activity) of $\mathrm{RuO}_{2} / \mathrm{TiO}_{2}$ during $30 \mathrm{~h}$ on stream, although $\mathrm{HBr}$ conversion seems to be stabilized after $30 \mathrm{~h}$ till $50 \mathrm{~h}$ on stream. ${ }^{244}$ In contrast, $\mathrm{U}_{3} \mathrm{O}_{8} / \mathrm{ZrO}_{2}$ remained stable in the above stability evaluation but the radioactive nature of uranium hampers the commercialization of this catalyst. Further search for better catalysts led to the discovery of $\mathrm{TiO}_{2}$ as a suitable $\mathrm{HBr}$ oxidation catalyst at $523-673 \mathrm{~K}$ (Figure 33a). This unprecedented performance of $\mathrm{TiO}_{2}$, exclusively used as a carrier in $\mathrm{HCl}$ oxidation due to its intrinsic inactivity and many other reactions in catalysis research, enables a cost-effective recovery of $\mathrm{HBr}$ waste in the chemical industry. Comparing its bromination behavior with $\mathrm{RuO}_{2}$, it 


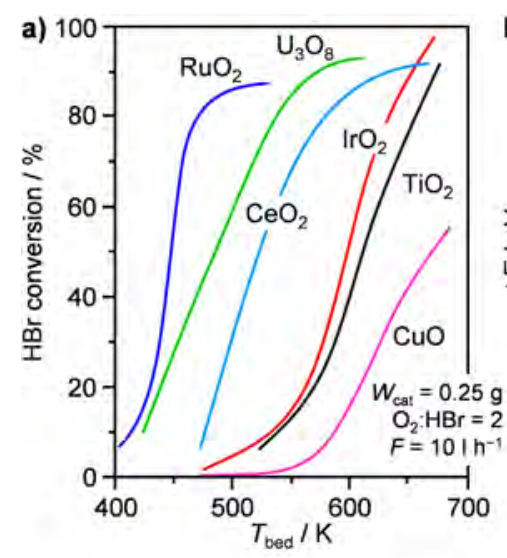

d)

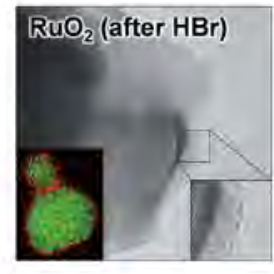

$\mathrm{TiO}_{2}$ (after $\mathrm{HBr}$ )
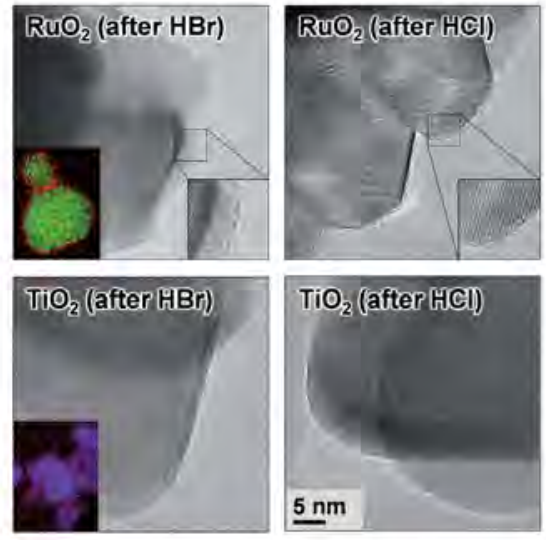

g)

Homogeneous $\left(\mathrm{Ce}_{0.75} \mathrm{Zr}_{0.25} \mathrm{O}_{2}-\mathrm{h}\right.$ )
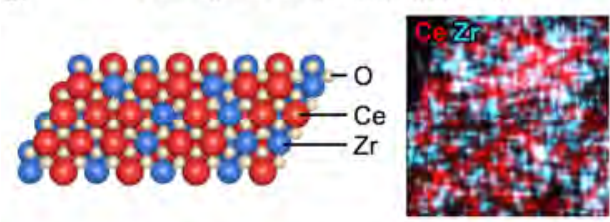

Nonhomogeneous $\left(\mathrm{Ce}_{0.75} \mathrm{Zr}_{0.25} \mathrm{O}_{2}\right.$-nh)

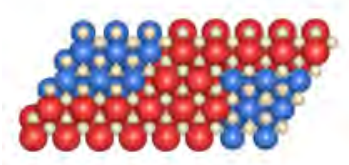

b)

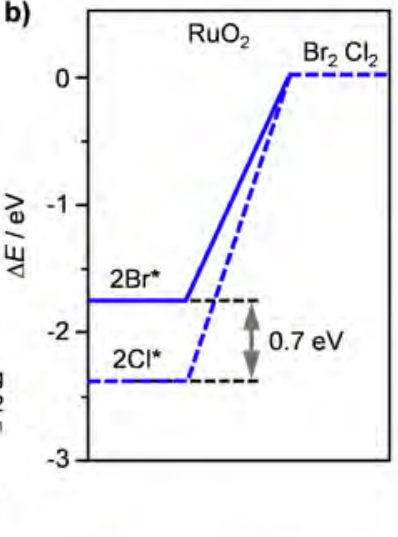

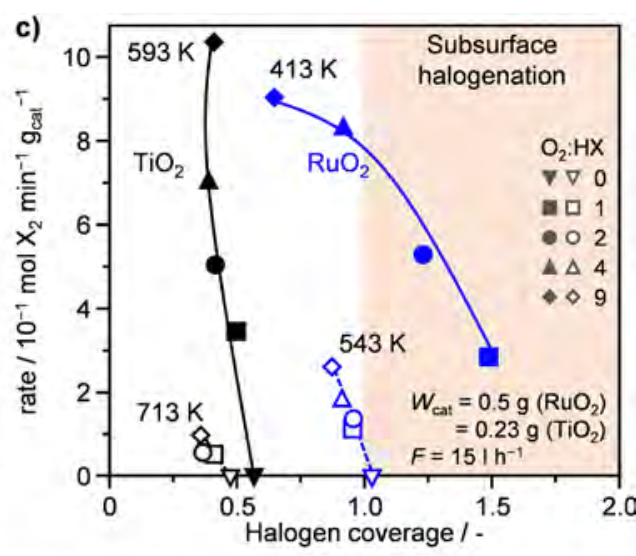
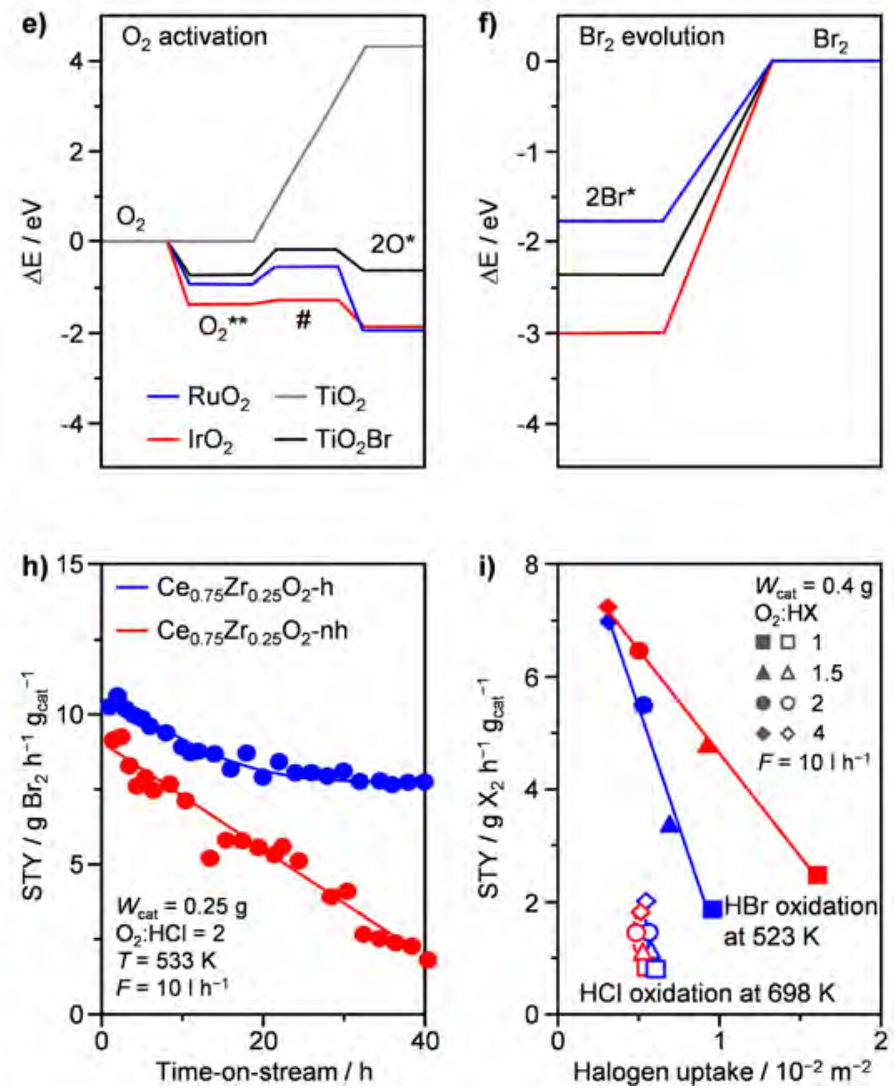

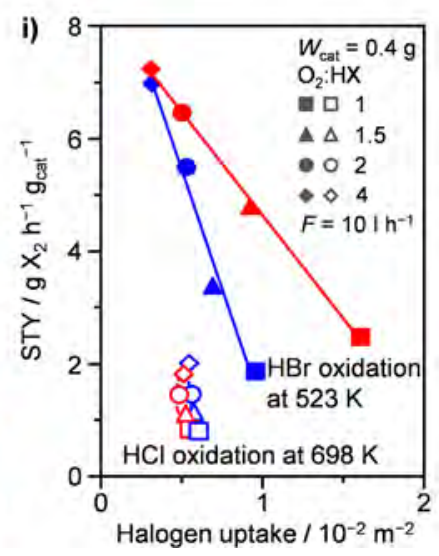

Figure 33. a) $\mathrm{HBr}$ oxidation over Deacon catalysts (supported systems, $\mathrm{RuO}_{2}$ and $\mathrm{IrO}_{2}$ supported on $\mathrm{TiO}_{2}$-rutile, $\mathrm{U}_{3} \mathrm{O}_{8}$ and $\mathrm{CeO}_{2}$ on $\mathrm{ZrO}_{2}$, and $\mathrm{CuO}$ on $\mathrm{SiO}_{2}$ ) (Adapted with permission from ref 288. Copyright 2013 Wiley-VCH) and $\mathrm{TiO}_{2}$-rutile ${ }^{284}$ b) Halogen desorption energy for $\mathrm{RuO}_{2}$ obtained by DFT calculation on the $\mathrm{RuO}_{2}(110)$ surface. c) Rate of halogen production versus surface halogen coverage, determined in PGAA experiments. d) HRTEM of $\mathrm{RuO}_{2}$ and $\mathrm{TiO}_{2}$ after treatments in $\mathrm{HBr}$ or $\mathrm{HCl}$. e) $\mathrm{O}_{2}$ activation and $\left.\mathbf{f}\right) \mathrm{Br}_{2}$ evolution energies over rutile surfaces. b-f, adapted with permission from ref 282. Copyright 2016 The Royal Society of Chemistry. g) Molecular model and elemental mapping showing homogeneous and nonhomogeneous $\mathrm{Ce}_{0.75} \mathrm{Zr}_{0.25} \mathrm{O}_{2}$. STY versus $\mathbf{h}$ ) time-on-stream and i) halogen uptake, in PGAA experiments, over mixed ceria-zirconia systems in HX oxidation. g-i, adapted with permission from ref 283. Copyright 2015 Elsevier. All experiments reported were performed at 1 bar. 
is clear that the bromination is limited to the surface as the $\mathrm{Br}$ coverage is in the range of $30-50 \%$ (Figure 33c), ensuring its long-term stability.

To shed light on the unusual activity of $\mathrm{TiO}_{2}$, XPS characterization was combined with DFT studies. ${ }^{284}$ It was found that $\mathrm{Ti}^{3+}$ sites are formed during $\mathrm{HBr}$ oxidation, ${ }^{284}$ which indicated the formation of surface defects. DFT calculations suggested the replacement of the bridge oxygen with a bromine atom in a self-doping mechanism that eventually enables the adsorption of molecular oxygen due to the smaller energy barrier to transfer the electrons from the bromide to the oxygen (Figure 33e). In contrast, the energy barrier of the chlorine doped surface is too large to enable the activation of molecular oxygen on the surface, thus supporting the inactivity of $\mathrm{TiO}_{2}$ in $\mathrm{HCl}$ oxidation. ${ }^{284} \mathrm{~A}$ DFT study further demonstrated that the reaction mechanism on $\mathrm{TiO}_{2}$ also follows the same path with bromine evolution as the rate limiting step. ${ }^{284}$ The calculations were corroborated by TAP-2 studies, which showed that the bromine evolution from the surface is impeded. Furthermore, the time delay between the $\mathrm{HBr}$ and $\mathrm{Br}_{2}$ pulses increased in the order: $\mathrm{RuO}_{2}<\mathrm{TiO}_{2}<\mathrm{IrO}_{2}$ which is in agreement with the increase in the calculated energy barriers (Figure 33f). ${ }^{282}$ This also supports the observed activity difference among these systems, where $\mathrm{RuO}_{2}$ is more active than $\mathrm{TiO}_{2}$ and $\mathrm{IrO}_{2}$.

HBr versus $\mathbf{H C l}$ Oxidation on $\mathbf{C e O}_{2}$-Based Catalysts. $\mathrm{CeO}_{2}$, which exhibits activity in between $\mathrm{RuO}_{2}$ and $\mathrm{TiO}_{2}$, can be anticipated to be even more prone to deeper bromination than $\mathrm{RuO}_{2}$ and thus preserving its degree of bromination is a key to consider this material as a suitable $\mathrm{HBr}$ oxidation catalyst. Based on the known influence of $\mathrm{ZrO}_{2}$ carrier to reduce the degree of chlorination (Section 2, Figure 18h), ${ }^{230}$ mixed $\mathrm{CeO}_{2}-\mathrm{ZrO}_{2}$ systems were investigated for $\mathrm{HBr}$ oxidation. ${ }^{283}$ Two samples having a Ce:Zr molar fraction of 0.75:0.25 were exclusively compared: (i) a homogeneous sample ( $\mathrm{Ce}_{0.75} \mathrm{Zr}_{0.25} \mathrm{O}_{2}$-h) obtained by co-precipitation of the precursor salts in the presence of $\mathrm{H}_{2} \mathrm{O}_{2}$ and (ii) a nonhomogeneous sample $\left(\mathrm{Ce}_{0.75} \mathrm{Zr}_{0.25} \mathrm{O}_{2}\right.$-nh) by thermal decomposition of the precursor salts. ${ }^{283}$ The degree of homogeneity of the obtained sample was confirmed by elemental mapping (Figure 33g). ${ }^{283}$ The catalyst evaluation in $\mathrm{HBr}$ oxidation evidenced a linear activity drop (ca. $80 \%$ of initial activity) during $40 \mathrm{~h}$ on steam over the nonhomogeneous sample (Figure 33h). ${ }^{283}$ Advantageously, the 
homogeneous mixed oxide showed only a little drop during the first $20 \mathrm{~h}$, after which it led to a stable $\mathrm{Br}_{2}$ production. This result suggests the beneficial role of $\mathrm{ZrO}_{2}$ on the stability of $\mathrm{CeO}_{2}$ when it is present as a homogenous phase with $\mathrm{CeO}_{2}$. Operando PGAA experiments were conducted to quantify the degree of halogenation (Figure 33i). ${ }^{283}$ The halogen uptake was essentially the same for $\mathrm{HCl}$ oxidation on both samples, however, it was first of all higher for both samples in $\mathrm{HBr}$ oxidation and secondly, the nonhomogeneous sample exhibited more extensive bromination than its homogeneous analogue. These results emphasize that preservation of degree of halogenation and confining it to the surface of the catalyst is the key to attain a stable $\mathrm{Br}_{2}$ production.

\subsection{Methane Oxyhalogenation}

In the oxyhalogenation reactions, methane is reacted with $\mathrm{HX}$ and $\mathrm{O}_{2}$ over a catalyst to produce halomethane and water. Although this route enables 100\% halogen atom efficiency (vide supra), the use of oxygen poses difficulties in terms of over-oxidation leading to the formation of unwanted carbon oxides. Thus, the catalyst design is highly demanding for methane oxyhalogenation. A realistic catalyst formulation should first meet the prerequisite of structural and chemical stabilities under the hightemperature and strongly corrosive reaction atmosphere. In an idealistic scenario, it should be capable of activating the three reactant molecules simultaneously, while preventing further halogenation as well as the oxidation of methyl halides. Further attention should be paid to the different reactivity of halogenated compounds in oxychlorination and oxybromination reactions, which requires systematic engineering of catalysts for respective reactions.

To date, numerous catalysts have been proposed for methane oxyhalogenation (Table 5). A careful survey of literature on this topic leads to clear categories of two-phase research interest. Briefly, the earlier focus of research was solely dedicated to oxychlorination of methane over Cu-based catalysts especially in the 1970-1980s. ${ }^{51,156,289}$ This is largely triggered by the successful utilization of copper chloride catalysts in ethylene oxychlorination within PVC manufacture. Since 2005, owing to the strong incentive of the discovery of large reserves of unconventional natural gas and the advances achieved in hydrogen halide recovery by catalytic oxidation, a renewed interest was witnessed in methane 
oxyhalogenation using both $\mathrm{HCl}$ and $\mathrm{HBr}$ as the halogenating agents over a wide range of catalysts such as precious metals, ${ }^{58,60,290,291}$ metal oxides/oxychlorides, ${ }^{188,194,264,292}$ and metal phosphate catalysts. ${ }^{61,293-}$ 296 The following discussions are split into two parts i.e. oxychlorination and oxybromination, as the chemistry involved between them is believed to be different. We will examine the structures, catalytic performance, characterizations, and mechanistic aspects for different catalysts and rationalize the structure-performance relationship.

Table 5. Catalysts for Methane Oxyhalogenation

\begin{tabular}{|c|c|c|c|c|c|c|}
\hline \multirow{2}{*}{ catalyst } & \multicolumn{2}{|r|}{ reactivity $^{a}$} & \multicolumn{2}{|c|}{ conditions } & \multirow{2}{*}{ redox pair } & \multirow{2}{*}{ ref } \\
\hline & $X / \%$ & $S / \%$ & $\mathrm{GHSV}^{b} / \mathrm{h}^{-1}$ & $T / \mathrm{K}$ & & \\
\hline \multicolumn{7}{|l|}{ oxychlorination } \\
\hline $\mathrm{CuLaCl}_{x} /$ pumice & 77 & $78\left(\mathrm{CCl}_{4}\right)$ & - & 723 & $\mathrm{Cu}^{2+} / \mathrm{Cu}^{+}$ & 289 \\
\hline $\mathrm{CuKLaCl}_{x} / \mathrm{SiO}_{2}$ & - & $\begin{array}{c}61 \\
\text { (chloromethanes) }^{c}\end{array}$ & $180-216$ & 509 & $\mathrm{Cu}^{2+} / \mathrm{Cu}^{+}$ & 156 \\
\hline $\mathrm{CuKLaCl}_{x} / \mathrm{SiO}_{2}$ & $18-43$ & $60-85\left(\mathrm{CH}_{3} \mathrm{Cl}\right)$ & $19-62$ & 603 & $\mathrm{Cu}^{2+} / \mathrm{Cu}^{+}$ & 51 \\
\hline $\mathrm{LaOCl} / \mathrm{LaCl}_{3}$ & $5-13$ & $63-84\left(\mathrm{CH}_{3} \mathrm{Cl}\right)$ & $2-5$ & 673 & $\mathrm{OCl}^{-} / \mathrm{Cl}^{-}$ & 193 \\
\hline $\mathrm{K}_{4} \mathrm{Ru}_{2} \mathrm{OCl}_{10} / \mathrm{TiO}_{2}$ & 15 & $75\left(\mathrm{CH}_{3} \mathrm{Cl}\right)$ & 1250 & 633 & - & 188 \\
\hline $\mathrm{FeO}_{x}-\mathrm{CeO}_{2}$ & 23 & $74\left(\mathrm{CH}_{3} \mathrm{Cl}\right)$ & 7344 & 753 & $\mathrm{Ce}^{4+} / \mathrm{Ce}^{3+}$ & 264 \\
\hline \multicolumn{7}{|l|}{ oxybromination } \\
\hline $\mathrm{Ru} / \mathrm{SiO}_{2}$ & 19 & $90\left(\mathrm{CH}_{3} \mathrm{Br}\right)$ & 400 & 803 & - & 58 \\
\hline $\mathrm{BaLaNiRuO}_{x} / \mathrm{SiO}_{2}$ & 70 & $90\left(\mathrm{CH}_{3} \mathrm{Br}+\mathrm{CO}\right)$ & 400 & 933 & - & 60 \\
\hline $\mathrm{Rh} / \mathrm{SiO}_{2}$ & 30 & $83\left(\mathrm{CH}_{3} \mathrm{Br}\right)$ & 1590 & 933 & $\mathrm{Rh}^{3+} / \mathrm{Rh}^{0}$ & 290 \\
\hline $\mathrm{Rh} / \beta-\mathrm{SiC}$ & 20 & $80\left(\mathrm{CH}_{3} \mathrm{Br}\right)$ & 1200 & 893 & $\mathrm{Rh}^{3+} / \mathrm{Rh}^{0}$ & 291 \\
\hline $\mathrm{BaO} / \mathrm{SiO}_{2}$ & 31 & $48\left(\mathrm{CH}_{3} \mathrm{Br}\right)$ & 800 & 923 & - & 292 \\
\hline $\mathrm{NiO}_{x}-\mathrm{CeO}_{2}$ & 22 & $82\left(\mathrm{CH}_{3} \mathrm{Br}\right)$ & 2300 & 873 & $\mathrm{Ce}^{4+} / \mathrm{Ce}^{3+}$ & 264 \\
\hline $\mathrm{FePO}_{4} / \mathrm{SiO}_{2}$ & 50 & $90\left(\mathrm{CH}_{3} \mathrm{Br}+\mathrm{CO}\right)$ & 400 & 843 & $\mathrm{Fe}^{3+} / \mathrm{Fe}^{2+}$ & 296 \\
\hline $\mathrm{FePO}_{4}-\mathrm{SBA}-15$ & 50 & $90\left(\mathrm{CH}_{3} \mathrm{Br}+\mathrm{CO}\right)$ & 400 & 863 & $\mathrm{Fe}^{3+} / \mathrm{Fe}^{2+}$ & 293 \\
\hline $\mathrm{Na}_{3} \mathrm{Fe}_{2}\left(\mathrm{PO}_{4}\right)_{3}$ & 45 & $88\left(\mathrm{CH}_{3} \mathrm{Br}+\mathrm{CO}\right)$ & 300 & 913 & $\mathrm{Fe}^{3+} / \mathrm{Fe}^{2+}$ & 295 \\
\hline $\mathrm{VOPO}_{4}$ & 25 & $64\left(\mathrm{CH}_{3} \mathrm{Br}\right)$ & 270 & 753 & - & 61 \\
\hline
\end{tabular}

${ }^{a}$ Methane conversion and product selectivity were denoted as $X$ and $S$, respectively. ${ }^{b} \mathrm{GHSV}$ was calculated based on methane. The voidage of catalyst bed was estimated as $50 \%$. ${ }^{c}$ Yield. 
3.2.1. Catalysts for Methane Oxychlorination. Copper Chloride-Based Catalysts. The successful application of copper chloride catalysts in ethylene oxychlorination has triggered research interest in extending the catalysts for methane oxychlorination. ${ }^{51,156,289}$ These catalysts are prepared by the impregnation method using silica or alumina as the supports, and can offer a methyl chloride selectivity of $60-85 \%$ at methane conversions of $18-78 \% .^{51}$ Due to the chemical inertness, methane molecules require much higher activation temperatures $(>673 \mathrm{~K}$ ) which is detrimental to the stability of copper catalyst. In contrast to the highly selective ethylene oxychlorination reaction, methane oxychlorination over copper chloride-based catalysts shows poorer product distribution. It is observed that a large quantity of higher chloromethanes can build up, especially for dichloromethane. ${ }^{51}$ An earlier patent shows that this reaction can be designed for the on-purpose production of $\mathrm{CCl}_{4}$ provided that a high $\mathrm{HCl}: \mathrm{CH}_{4}$ ratio of 3.2 was used in the feed, leading to $X\left(\mathrm{CH}_{4}\right)=77 \%$ and $S\left(\mathrm{CCl}_{4}\right)=78 \%$ at $723 \mathrm{~K}^{289} \mathrm{In}$ addition, high temperature usually resulted in the combustion of chlorinated compounds, yielding a large amount of deep oxidation products. Secondly, the intrinsic drawback of copper chloride catalysts is that they are very volatile at the high temperatures. The loss of copper leads to a rapid decline in catalyst activity and potential deposition of corrosive materials in the downstream parts of the process equipment. ${ }^{193}$ These issues can, to a certain extent, be eased with the addition of promoters. It has been reported that the addition of $\mathrm{KCl}$ can lower the melting point of copper chloride and promote the copper redox property, resulting in an enhanced stability. ${ }^{137,297,298}$ Moreover, $\mathrm{LaCl}_{3}$ as a second promoter has also been demonstrated to efficiently prevent melt segregation of copper and potassium chlorides at high reaction temperatures. ${ }^{299}$ The utilization of other promoters (Nd, Ce, Zr, and Pr) was also disclosed in the patent. ${ }^{300}$ Still, in general the promoters only partially improve the structural stability while they contribute little to the selective formation of methyl chloride. This can be related to the mechanism of methane oxychlorination over copper chlorides catalysts even though it has not been fully understood. Methane activation through liberation of molecular chlorine might be a possible route. Similar radical chlorination mechanism over copper chloride catalysts has already been proposed for the hightemperature ethylene oxychlorination reaction. ${ }^{145}$ Radical reactions could be more prominent in the case 
of methane activation regarding the even higher temperatures applied. The fact that a substantial portion of perchlorinated products, such as $\mathrm{CCl}_{4}$, was produced over these catalysts strongly evidences a radical chain mechanism. In short, the weaknesses of copper chloride catalysts, including poor $\mathrm{CH}_{3} \mathrm{Cl}$ selectivity and vulnerable chemical stability, render them less attractive in methane oxychlorination.

$\mathrm{LaOCl}_{\mathbf{L a C l}}$. Lanthanum components have been commonly used as promoters for copper chloride catalysts in oxychlorination reactions. Previous studies point out that the active catalyst for oxychlorination should contain at least a reducible metal. ${ }^{140,144,154,155}$ It is intriguing when researchers at the Dow Chemical Company first reported that a quasi-crystalline $\mathrm{LaOCl}$ with a porous structure was active and stable for methane oxychlorination at $673 \mathrm{~K}$, leading to $X\left(\mathrm{CH}_{4}\right)=5-13 \%$ and $S(\mathrm{CH} 3 \mathrm{Cl})=63$ 84\%. ${ }^{193} \mathrm{LaOCl}$ was thermally activated in a He flow at $823 \mathrm{~K}$ and subsequently converted in situ to $\mathrm{LaCl}_{3}$ by reacting with $\mathrm{HCl}$ at $673 \mathrm{~K} .{ }^{301}$ The working temperature of the catalyst was probed by temperature-programmed ramping experiments (Figure 34a). Increasing methane and HCl conversions, and $\mathrm{CH}_{3} \mathrm{Cl}$ yield were observed in the range of 723-833 K. A further increased temperature resulted in a decreased conversion of $\mathrm{HCl}$ accompanied with an abrupt increase in $\mathrm{CO}$ yield, which was attributed to the dechlorination from $\mathrm{LaCl}_{3}$ to $\mathrm{LaOCl}$ on the catalyst surface. ${ }^{302}$ The performance of this catalyst can be further manipulated by the addition of different dopants (Co, Ce, and $\mathrm{Ni}$ ). The presence of markedly redox-active dopants such as Ce and Co leads to a higher methane conversion rate, but a poorer selectivity to $\mathrm{CH}_{3} \mathrm{Cl}$, because of its strong adsorption on these catalysts promoting deep oxidation. ${ }^{302}$ In contrast, doping with $\mathrm{Ni}$ weakens the interaction and favors the desorption of $\mathrm{CH}_{3} \mathrm{Cl}$ from the catalyst and thus offers a higher selectivity (Figure 34b).

A systematic study on the possible reaction mechanism of lanthanum-based catalysts was carried out by Lercher et al. ${ }^{194,301}$ Gas-phase chlorination was first excluded since there is no correlation between the rate of chlorine incorporation into methane and chloromethanes and that of $\mathrm{Cl}_{2}$ evolution in the absence of methane at various conditions (Figure 34c). The results from activity tests and in situ Raman spectroscopic measurements showed that $\mathrm{LaOCl}, \mathrm{LaCl}_{3}$, and other lanthanum phases with a moderate extent of chlorination are all active for this reaction. Kinetic measurements demonstrated that 

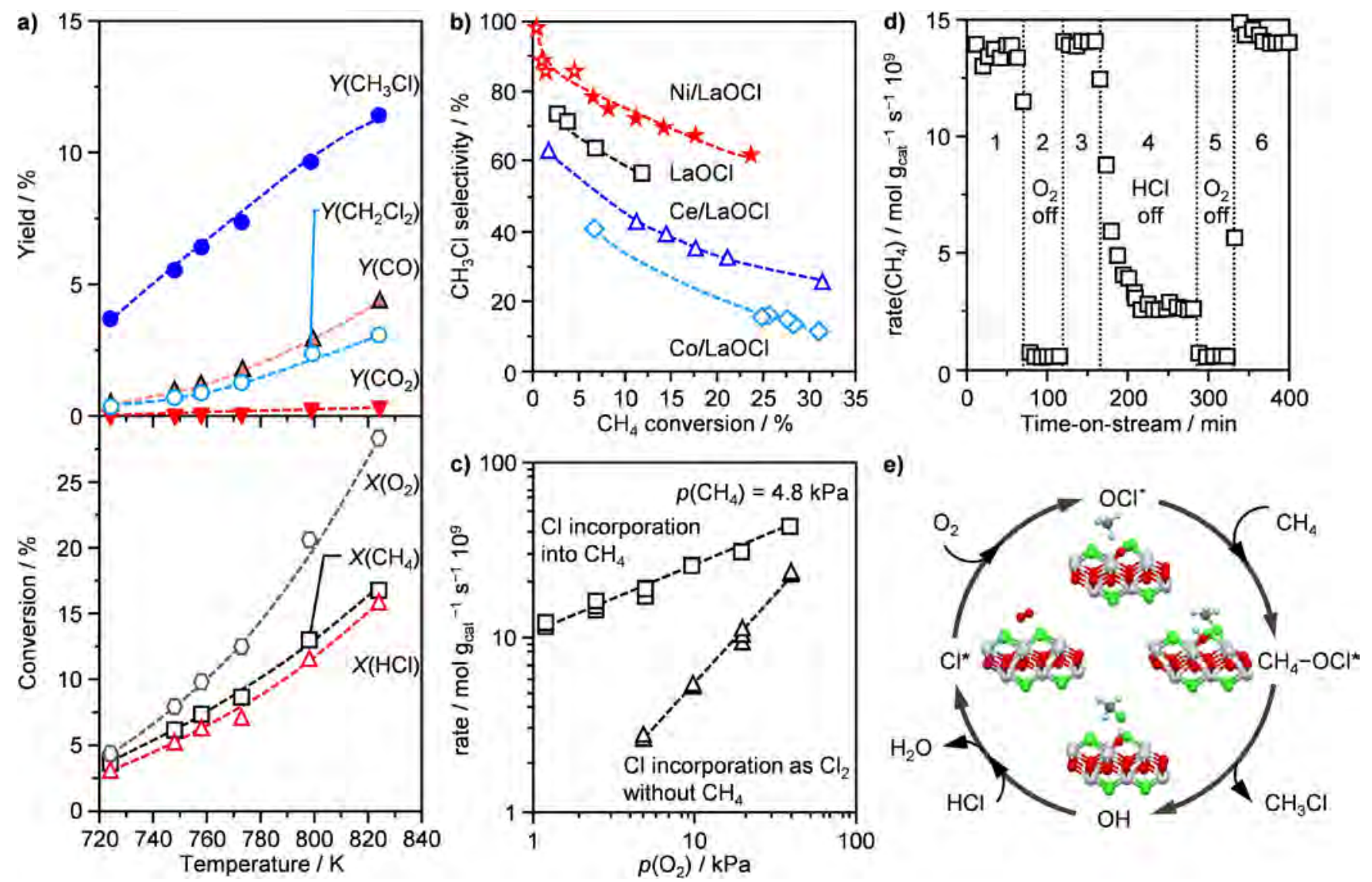

Figure 34. Methane oxychlorination over $\mathrm{LaOCl} / \mathrm{LaO}_{3}$ catalysts. a) Catalytic performance during temperature-programmed reaction $\left(1 \mathrm{~K} \mathrm{~min}^{-1}\right)$. Conditions: $\quad \mathrm{CH}_{4}: \mathrm{HCl}_{2} \mathrm{O}_{2}: \mathrm{He} \mathrm{N}_{2}=2: 2: 1: 4: 1$, $F=10 \mathrm{~cm}^{3}$ STP $\mathrm{min}^{-1}$. Reproduced with permission from ref 303. Copyright 2008 Elsevier. b) $\mathrm{CH}_{3} \mathrm{Cl}$ selectivity versus $\mathrm{CH}_{4}$ conversion over pristine and promoted catalysts. Conditions: $\mathrm{CH}_{4}: \mathrm{HCl}: \mathrm{O}_{2}: \mathrm{He}: \mathrm{N}_{2}=2: 2: 1: 4: 1, T=748 \mathrm{~K}$. Unfilled stars were collected at $853 \mathrm{~K}$. Reproduced with permission from ref 302. Copyright 2009 Springer. c) Comparison of reaction rates for $\mathrm{Cl}$ incorporation into methane and $\mathrm{Cl}$ evolution as $\mathrm{Cl}_{2}$ without methane in the feed. d) Effect of feed components on the reaction rate at $F=14 \mathrm{~cm}^{3} \mathrm{STP} \mathrm{min}{ }^{-1}$ containing 0.048 bar $\mathrm{CH}_{4}, 0.024$ bar $\mathrm{O}_{2}$, and 0.24 bar $\mathrm{HCl}$ with balance $\mathrm{He}$ and $T=675 \mathrm{~K}$. The reaction stops without gas-phase $\mathrm{O}_{2}$ (2 and 5) but can be sustained without $\mathrm{HCl}$ in the feed by $\mathrm{Cl}$ diffusion from the bulk onto the catalyst surface (4). e) Proposed reaction mechanism. Adapted with permission from ref 194. Copyright 2007 American Chemical Society.

methane activation proceeds on the surface of the catalyst rather than in the bulk. The presence of $\mathrm{HCl}$ was not required for activity, as indicated by the flow and pulse experiments, and its role appeared to only maintain the extent of catalyst chlorination, whereas, the presence of gas-phase oxygen was essential for the catalytic activity (Figure 34d). Based on these observations and DFT calculations, a three-step methane activation mechanism was proposed that involved: (i) activation of surface chlorine species by gaseous oxygen, forming $\mathrm{OCl}^{-}$surface species (Figure 34e), (ii) reaction of methane with 
$\mathrm{OCl}^{-}$by exchanging a proton for $\mathrm{Cl}^{+}$and by forming a hydroxyl group on the surface $\left(\mathrm{CH}_{4}+\mathrm{OCl}_{\text {sur }}^{-} \rightarrow \mathrm{CH}_{3} \mathrm{Cl}+\mathrm{OH}_{\text {sur }}^{-}\right.$, and (iii) replenishment of surface chlorine species by the reaction of gaseous $\mathrm{HCl}$ with surface hydroxyl group. ${ }^{194}$ The proposed mechanism, thus, involves changing of the formal oxidation state of surface chlorine from -1 to +1 without any changes in the oxidation state of the underlying metal. It is noteworthy that the concept of chloronium ion is based on the theoretical investigation.

$K_{4} \mathbf{R u}_{2} \mathrm{OCl}_{10} / \mathbf{T i O}_{2}$. Bal'zhinimaev et al. reported a $\mathrm{K}_{4} \mathrm{Ru}_{2} \mathrm{OCl}_{10} / \mathrm{TiO}_{2}$ catalyst that can catalyze methane oxychlorination at mild temperatures of 593-673 K (Figure 35a). ${ }^{188}$ The low temperature performance of the catalyst enabled a high selectivity to $\mathrm{CH}_{3} \mathrm{Cl}\left(\mathrm{S}>80 \%\right.$ at $X\left(\mathrm{CH}_{4}\right)=2-8 \%$ and $T<613 \mathrm{~K})$. Increasing the temperature up to $673 \mathrm{~K}$ caused a drop in selectivity to $66 \%$ with progressive $\mathrm{CO}_{2}$ production, because of the combustion of chlorinated products. The proposed reaction mechanism (Figure 35b) involves the electrophilic addition of oxygen to the methane molecules, and the formation of methoxy species as detected by in situ FTIR experiments. Methyl chloride was released with the insertion of $\mathrm{HCl}$ into the methoxy functionality. It is suggested that there was no valence change of $\mathrm{Ru}^{\mathrm{IV}}$ cations. However, unlike the lanthanum-based catalysts, $\mathrm{Cl}$ anions in $\mathrm{Cl}_{x} \mathrm{Ru}-\mathrm{O}$ were not oxidized in the catalytic cycle. Instead, the activation step is characterized by an insertion or oxidative addition of oxygen into the $\mathrm{C}-\mathrm{H}$ bond of methane with the simultaneous detachment of a proton by the basic sites. It should be noted that the ruthenium oxychloride catalyst is very similar to the robust $\mathrm{RuO}_{2} / \mathrm{TiO}_{2}$ catalyst well-known for Deacon reaction (473-653 K). ${ }^{208,304}$ It has been proposed that the active sites of bulk and supported $\mathrm{RuO}_{2}$ in the Deacon reaction correspond to $\mathrm{RuO}_{2-x} \mathrm{Cl}_{x_{\bullet}}{ }^{235,305}$ Bearing in mind the similarities of these catalysts and the potential connection between oxychlorination and Deacon reactions, comparative tests were conducted for methane oxychlorination over a $\mathrm{RuO}_{2} / \mathrm{TiO}_{2}$ catalyst. However, deep oxidation overwhelmed, restricting the selectivity to $\mathrm{CH}_{3} \mathrm{Cl}<20 \%{ }^{188}$ This huge difference in the methane oxychlorination performance of $\mathrm{RuO}_{2} / \mathrm{TiO}_{2}$ and $\mathrm{K}_{4} \mathrm{Ru}_{2} \mathrm{OCl}_{10} / \mathrm{TiO}_{2}$ might be determined by the compositions of the most outer-surface layers, whether $\mathrm{RuO}_{2}$ or $\mathrm{RuO}_{2-x} \mathrm{Cl}_{x}$, which are dependent on the reaction conditions (feed ratio and temperature). Therefore, the interpretation of the 

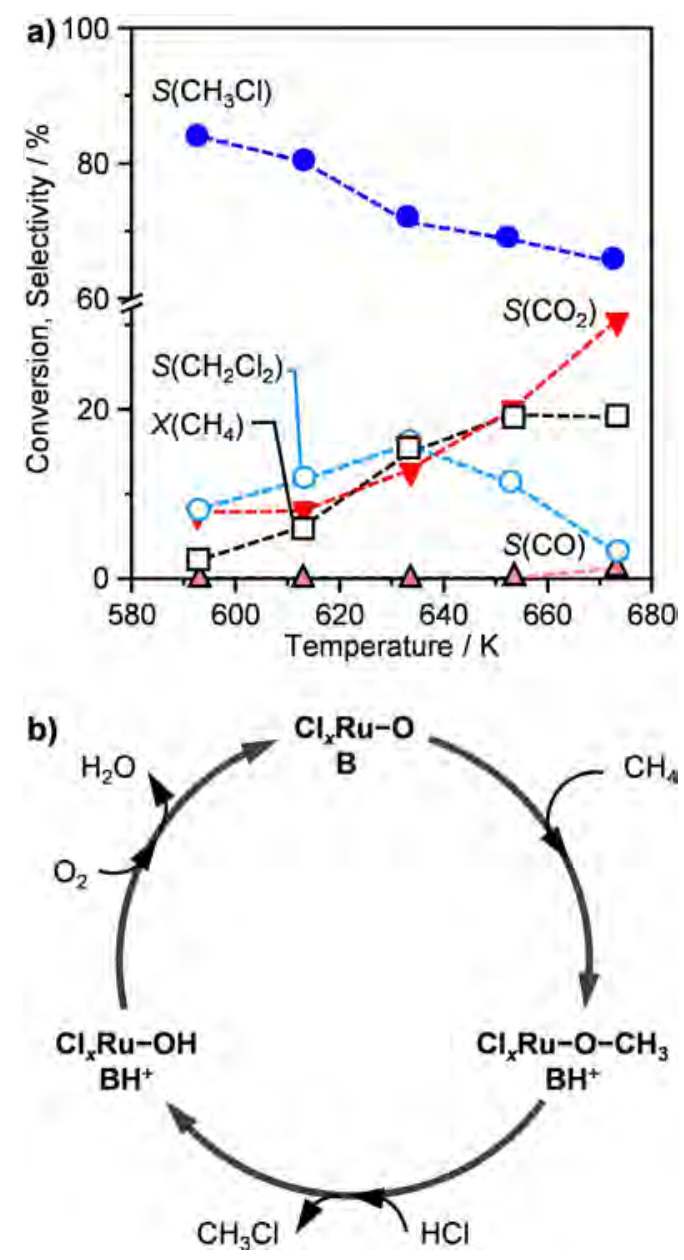

Figure 35. a) Methane conversion and product selectivity as a function of temperature in methane oxychlorination over $\mathrm{K}_{4} \mathrm{Ru}_{2} \mathrm{OCl}_{10} / \mathrm{TiO}_{2}$. Conditions: $\mathrm{CH}_{4}: \mathrm{HCl}: \mathrm{O}_{2}: \mathrm{Ar}=50: 20: 10: 20, \mathrm{GHSV}=2500 \mathrm{~h}^{-1}$. b) Proposed reaction mechanism. B denotes the basic oxygen species likely related to the potassium cations in the catalysts. Adapted with permission from ref 188. Copyright 2013 Springer.

structure-performance relationship would require more efforts in the preparation of materials with welldefined crystal structures and advanced operando characterizations.

$\mathrm{CeO}_{2}$-Based Catalysts. $\mathrm{CeO}_{2}$ with a fluorite structure has attracted much interest due to its tunable redox properties in processes such as the three-way catalysts for emissions control in petrol engines thanks to the generation of oxygen vacancies that facilitate activation and transport of oxygen species. ${ }^{306}$ It has also been recognized as a good catalyst in Deacon reaction. ${ }^{227}$ Recently, Wang et al. reported the catalytic application of bulk $\mathrm{CeO}_{2}$ for the oxychlorination of methane. ${ }^{264} \mathrm{CeO}_{2}$ nanocrystals with different morphologies (nanorod, nanocube, and nano-octahedron) were synthesized and evaluated. 

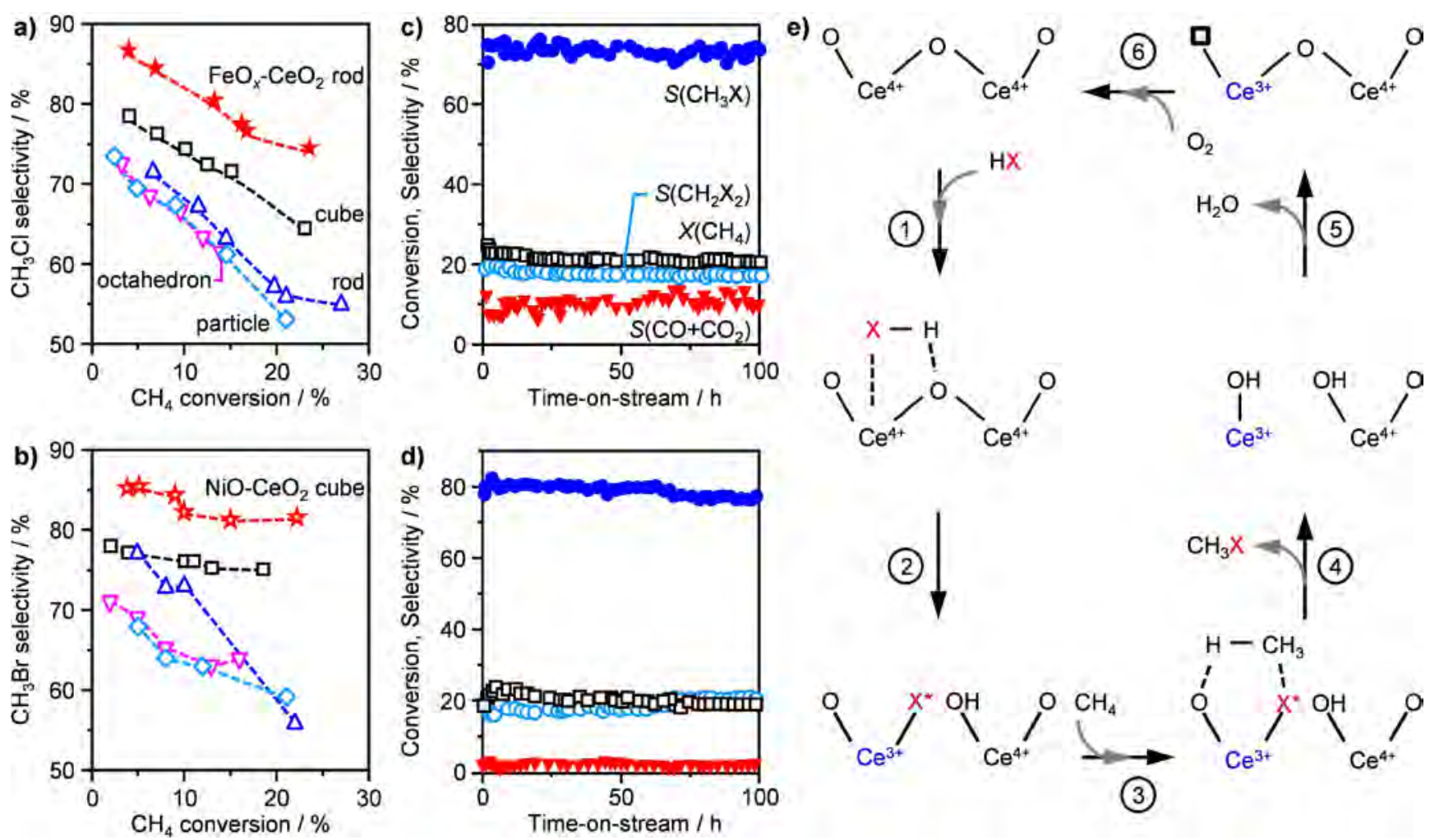

(3)

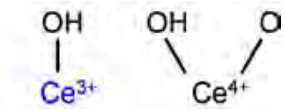

Figure 36. Methane oxyhalogenation over ceria-based catalysts. a) $\mathrm{CH}_{3} \mathrm{Cl}$ and b) $\mathrm{CH}_{3} \mathrm{Br}$ selectivity versus $\mathrm{CH}_{4}$ conversion in the oxychlorination and oxybromination of $\mathrm{CH}_{4}$ over $\mathrm{CeO}_{2}$ nanocrystals with different morphologies and the modified $\mathrm{CeO}_{2}$ nanocrystals. Conversion and selectivity versus time-onstream in c) $\mathrm{CH}_{4}$ oxychlorination over $15 \mathrm{wt} . \% \mathrm{FeO}_{x}-\mathrm{CeO}_{2}$ nanorods $(0.50 \mathrm{~g})$, and d) $\mathrm{CH}_{4}$ oxybromination over $10 \mathrm{wt} . \% \mathrm{NiO}-\mathrm{CeO}_{2}$ nanocubes $(1.0 \mathrm{~g})$. e) Proposed reaction mechanism for the oxyhalogenation over $\mathrm{CeO}_{2}$ catalysts. Conditions: a,c), $\mathrm{CH}_{4}: \mathrm{HCl}_{2}: \mathrm{O}_{2}: \mathrm{N}_{2}: \mathrm{He}=4: 2: 1: 1.5: 1.5$, $F=40 \mathrm{~cm}^{3}$ STP $\min ^{-1}, T=753 \mathrm{~K}$; b,d) $\mathrm{CH}_{4}: \mathrm{O}_{2}: \mathrm{N}_{2}=4: 1: 1, F=15 \mathrm{~cm}^{3} \mathrm{STP} \min ^{-1}, 40$ wt.\% $\mathrm{HBr}$ aqueous solution $4.0 \mathrm{~cm}^{3} \mathrm{~h}^{-1}, T=873 \mathrm{~K} . \mathrm{X}=\mathrm{Cl}$ or $\mathrm{Br}$. $\mathrm{X}^{*}$ are the active halogen species for methane activation. The legends in $\mathbf{a}$ and $\mathbf{c}$ are applicable to $\mathbf{b}$ and $\mathbf{d}$, respectively. Reproduced with permission from ref 264. Copyright 2012 Wiley-VCH.

Comparison of the catalytic performance reveals the structure sensitive nature of methane oxychlorination over $\mathrm{CeO}_{2}$, namely, nanorod (with preferential exposure of the (110) and (100) planes) showed the highest reactivity while nanocube that exposed the (100) planes was the most selective to $\mathrm{CH}_{3} \mathrm{Cl}$ (Figure 36a). The catalytic performance can be further enhanced by doping with additives. The $\mathrm{FeO}_{x}-\mathrm{CeO}_{2}$ nanorod (15 wt.\% $\mathrm{FeO}$ ) provided a $74 \% \mathrm{CH}_{3} \mathrm{Cl}$ selectivity with a $\mathrm{CH}_{4}$ conversion of $23 \%$ at $753 \mathrm{~K}$ during $100 \mathrm{~h}$ time-on-stream (Figure 36c). Concerning the very high selectivity to $\mathrm{CH}_{3} \mathrm{Cl}$, methane oxychlorination over $\mathrm{CeO}_{2}$-based catalysts is unlikely governed purely by radical reactions. A 
Mars-van Krevelen mechanism with the core idea of surface redox dynamic of $\mathrm{Ce}^{4+} / \mathrm{Ce}^{3+}$ was proposed to explain the catalytic cycle (Figure 36e). ${ }^{264}$ This mechanism was partially supported by the fact that the ease of reduction from $\mathrm{Ce}^{4+}$ to $\mathrm{Ce}^{3+}$ on various ceria oxides was in the order of nanorods $>$ nanocube $>$ nano-octahedra $>$ nanoparticles, in agreement with the intrinsic $\mathrm{CH}_{4}$ conversion rate over each catalyst.

The surface chemistry of $\mathrm{CeO}_{2}$ in the presence of $\mathrm{HCl}$ is a fascinating and challenging topic. In situ Raman spectroscopy was employed to provide evidence for the existence of $\mathrm{Ce}^{3+}\left(\mathrm{CeCl}_{3}\right.$ or $\left.\mathrm{CeOCl}\right)$ but only $\mathrm{CeO}_{2}$ was confirmed. These experiments suggested that the bulk of $\mathrm{CeO}_{2}$ remained unchanged under the oxychlorination reactions, but this cannot exclude the reduction of $\mathrm{CeO}_{2}$ on the surface since Raman spectroscopy is bulk-sensitive with a typical penetration depth of $1 \mu \mathrm{m} .{ }^{307}$ More fundamental studies should be directed to understand the surface chemistry of $\mathrm{CeO}_{2}$ which would help design a more efficient catalyst for $\mathrm{HCl}-$ involved reactions.

3.2.2. Catalysts for Methane Oxybromination. Zhou et al. first studied methane oxybromination using aqueous $\mathrm{HBr}$ solution over precious metal catalysts. ${ }^{58-60,290,308}$ From the economy viewpoint, the use of $\mathrm{HBr}$ is not so practical for the much higher cost of bromine compared with chlorine, not to mention the intensified corrosiveness of halogens in the presence of moisture. On the other hand, the utilization of $\mathrm{HBr}$ has its own advantages over $\mathrm{HCl}$, such as a possibility of offering a higher selectivity of methyl halide since bromination is more selective than chlorination. ${ }^{266}$ Another benefit results from the substantial amount of water in the feed that can vaporize and remove huge reaction heats associated with the intrinsic exothermic nature of the oxybromination reaction.

$\boldsymbol{R u}$ - and Rh-Based Catalysts. Methane oxybromination over Ru- and Rh-based catalysts was studied at $853-953 \mathrm{~K} \cdot{ }^{58,60,290}$ The product distribution was found to be influenced significantly by temperature over $\mathrm{BaLaNiRu} / \mathrm{SiO}_{2}$, but much milder over $\mathrm{Rh} / \mathrm{SiO}_{2}$ (Figures 37a,b). A high $\mathrm{CH}_{3} \mathrm{Br}$ selectivity of $90 \%$ can be achieved over both catalysts at $803-833 \mathrm{~K} .^{58,60}$ The stability of $\mathrm{Rh} / \mathrm{SiO}_{2}$, derived from a sol-gel method, was demonstrated via a $650 \mathrm{~h}$ on stream test, showing essentially a stable methane conversion, while $\mathrm{CH}_{3} \mathrm{Br}$ selectivity even witnessed a slight increase with reaction time 

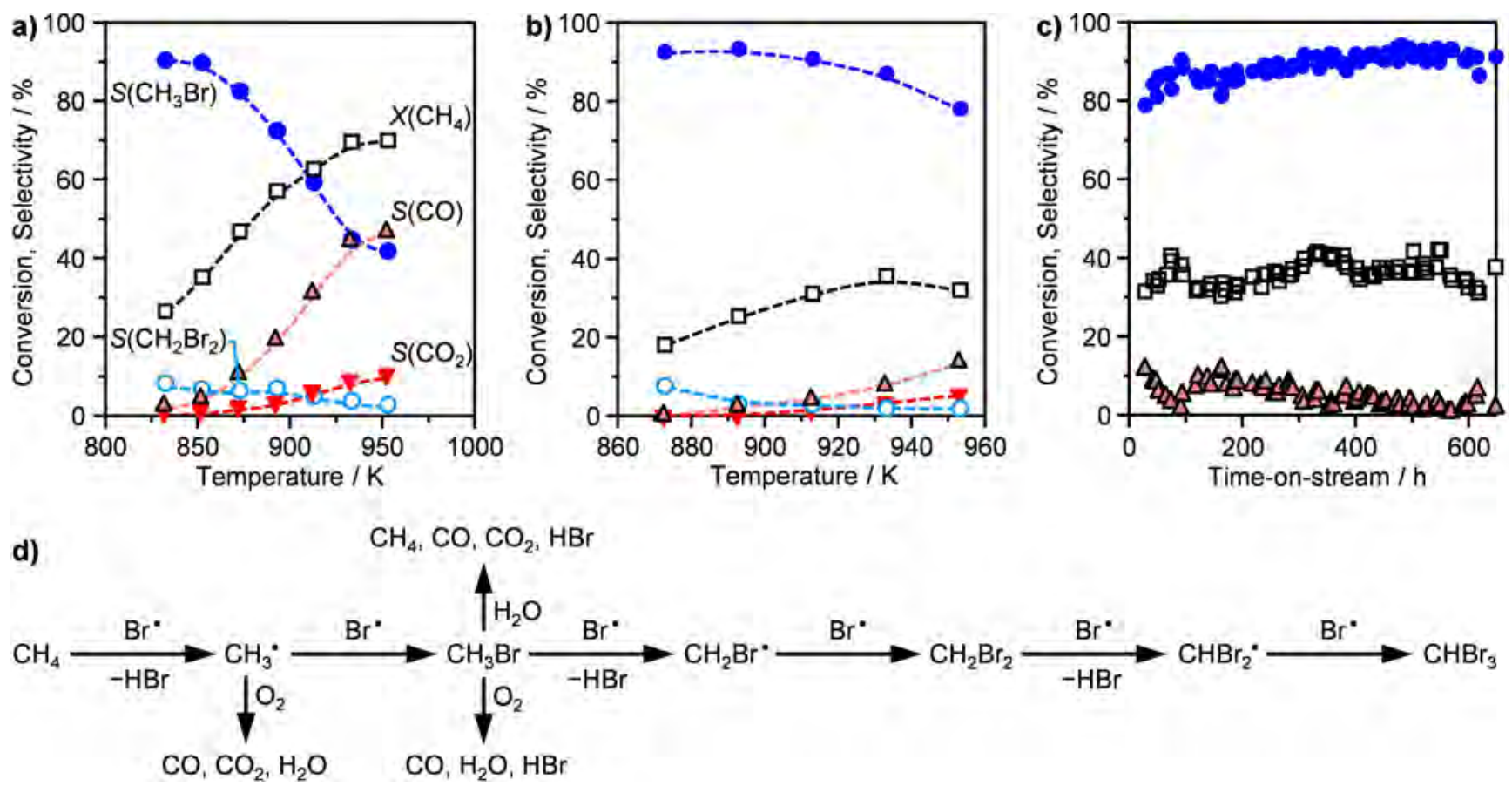

Figure 37. a) Methane oxybromination and d) the proposed radical chain-reaction mechanism over $\mathrm{BaLaNiRu} / \mathrm{SiO}_{2}$. Adapted with permission from ref 60. Copyright 2006 Elsevier. b) Methane oxybromination as a function of temperature and c) the stability evaluation at $933 \mathrm{~K}$ over $\mathrm{Rh} / \mathrm{SiO}_{2}$. Adapted with permission from ref 308. Copyright 2010 Elsevier. Conditions: a) $W_{\text {cat }}=1.0 \mathrm{~g}$,

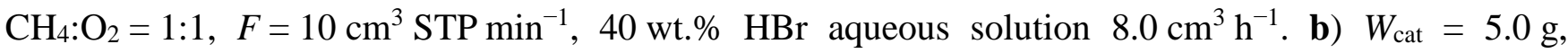
$\mathrm{CH}_{4}: \mathrm{O}_{2}: \mathrm{N}_{2}=4: 1: 1, F=30 \mathrm{~cm}^{3} \mathrm{STP} \mathrm{min}^{-1}, 48 \mathrm{wt} . \% \mathrm{HBr}$ aqueous solution $6.5 \mathrm{~cm}^{3} \mathrm{~h}^{-1}$. The legends in a are applicable to $\mathbf{b}$ and $\mathbf{c}$.

(Figure 37c). Elemental analysis revealed the severe Rh leaching from 0.41 to $0.15 \mathrm{wt} . \%$ after the evaluation. ${ }^{308}$ Besides, the selection of supports for Rh catalyst is crucial. It has been experimentally evidenced that the combustion products, $\mathrm{CO} / \mathrm{CO}_{2}$, were substantial for $\mathrm{ZrO}_{2}$ - and $\mathrm{TiO}_{2}$-supported $\mathrm{Rh}$ catalysts, whereas high $\mathrm{CH}_{3} \mathrm{Br}$ selectivity was only obtained for inert supports with preferably low surface areas such as $\mathrm{SiC}$ and $\mathrm{SiO}_{2} \cdot{ }^{291,308}$ The reaction route over these precious metal catalysts was suggested to follow gas-phase radical reactions (Figure 37d). Bromine radicals are proposed to be generated at the surface of solid catalysts rather than in the gas phase that would require much higher activation temperatures. Comparative experiments on Ru-based catalysts proved that carbon oxides were most likely originated from $\mathrm{CH}_{3} \mathrm{Br}$ by steam reforming or oxidation rather than from deep oxidation of methane. ${ }^{60}$ 
Non-Noble Metal Oxide Catalysts. A screening of various silica-supported non-precious metal oxides $\left(\mathrm{V}_{2} \mathrm{O}_{5}, \mathrm{CeO}_{2}, \mathrm{MoO}_{3}, \mathrm{BaO}\right.$, and $\left.\mathrm{WO}_{3}\right)$ was conducted, aiming at replacing noble metal-based catalysts with cheaper alternatives for methane oxybromination. ${ }^{292}$ Unfortunately, these catalysts generally led to a poor $\mathrm{CH}_{3} \mathrm{Br}$ selectivity and a significant $\mathrm{CO}$ production. A $\mathrm{CH}_{3} \mathrm{Br}$ selectivity of ca. $50 \%$ was obtained with above $40 \%$ conversion of $\mathrm{CH}_{4}$ at $893 \mathrm{~K}$ over $\mathrm{BaO} / \mathrm{SiO}_{2}$. The metathesis between $\mathrm{BaO}$ and $\mathrm{BaBr}_{2}$ was ascribed to be responsible for bromine formation. However, the leaching of a substantial amount of barium was observed during a $30 \mathrm{~h}$ test, rendering this catalyst less attractive. Bulk $\mathrm{CeO}_{2}$ with different morphologies was studied in the oxybromination of methane. ${ }^{264} \mathrm{The}^{\mathrm{CH}_{4}}$ conversion and $\mathrm{CH}_{3} \mathrm{Br}$ selectivity curves show that $\mathrm{CeO}_{2}$ nanocubes comprise the most selective morphology (Figure 36b). Besides, both the activity and $\mathrm{CH}_{3} \mathrm{Br}$ selectivity can be further enhanced by doping with $\mathrm{NiO}$. The stability of $\mathrm{NiO}-\mathrm{CeO}_{2}(10$ wt.\% NiO) was demonstrated during 100 h time-onstream (Figure 36d). Mars-van Krevelen mechanism was proposed to explain methane oxybromination on the $\mathrm{CeO}_{2}$-based catalyst (Figure 36e).

Iron Phosphates. Ding et al. studied methane oxybromination over a series of bulk and supported iron phosphates with the aim of achieving equimolar $\mathrm{CH}_{3} \mathrm{Br}$ plus $\mathrm{CO}$ (a presumed feedstock for acetic acid synthesis). ${ }^{291,293-296}$ A $10 \mathrm{wt} . \% \mathrm{FePO}_{4} / \mathrm{SiO}_{2}$ catalyst prepared by impregnation led to a methane conversion of $50 \%$ and a total selectivity of $96 \%$ for $\mathrm{CH}_{3} \mathrm{Br}$ and $\mathrm{CO}\left(\mathrm{CH}_{3} \mathrm{Br}: \mathrm{CO} \sim 1\right)$ at $843 \mathrm{~K} .{ }^{296} \mathrm{The}$ catalyst showed a relatively stable performance for $100 \mathrm{~h}$ on stream, but severe reduction in catalyst surface area (from 363 to $36 \mathrm{~m}^{2} \mathrm{~g}^{-1}$ ) and coke deposition were observed. ${ }^{294}$ This was claimed to be resulted from the accumulation of $\mathrm{CH}_{2} \mathrm{Br}_{2}$ which was identified as the predominant precursor of deposited coke in the $\mathrm{CH}_{3} \mathrm{Br}$-to-olefins transformation. ${ }^{309,310}$ Since iron phosphate is relatively stable in oxybromination ambience, a straightforward strategy to improve the catalyst stability was to find a coke-resistant support. FePO4-SBA-15, synthesized via a one-pot hydrothermal method by the same group, provided similar activity as $\mathrm{FePO}_{4} / \mathrm{SiO}_{2}$, but without any coke deposition for a duration of $1000 \mathrm{~h}$ (Figure 38a). ${ }^{293}$ Electron microscopy of the used catalyst confirmed that the ordered mesoporous structure of the catalyst was well kept, although the surface area was reduced to half. A slight leaching 
of Fe (3.36 to 3.04 wt.\%) and P (2.06 to 1.74 wt.\%) was revealed by elemental analysis. ${ }^{293}$ Several bulk iron phosphate catalysts have also been evaluated in the oxybromination reaction at higher temperatures, among which, $\mathrm{Na}_{3} \mathrm{Fe}_{2}\left(\mathrm{PO}_{4}\right)_{3}$ obtained via a fluoride route, was found to be even more active than bulk $\mathrm{FePO}_{4}\left(X\left(\mathrm{CH}_{4}\right)=49 \%, S\left(\mathrm{CH}_{3} \mathrm{Br}\right)=52 \%, T=913 \mathrm{~K}\right){ }^{295}$ Although all these iron phosphates have demonstrated their excellent stability and moderate activity toward oxybromination reaction, the selectivity to $\mathrm{CH}_{3} \mathrm{Br}$ is relatively low (around 50\% at appreciable methane conversions) compared with that over precious metal-based catalysts.
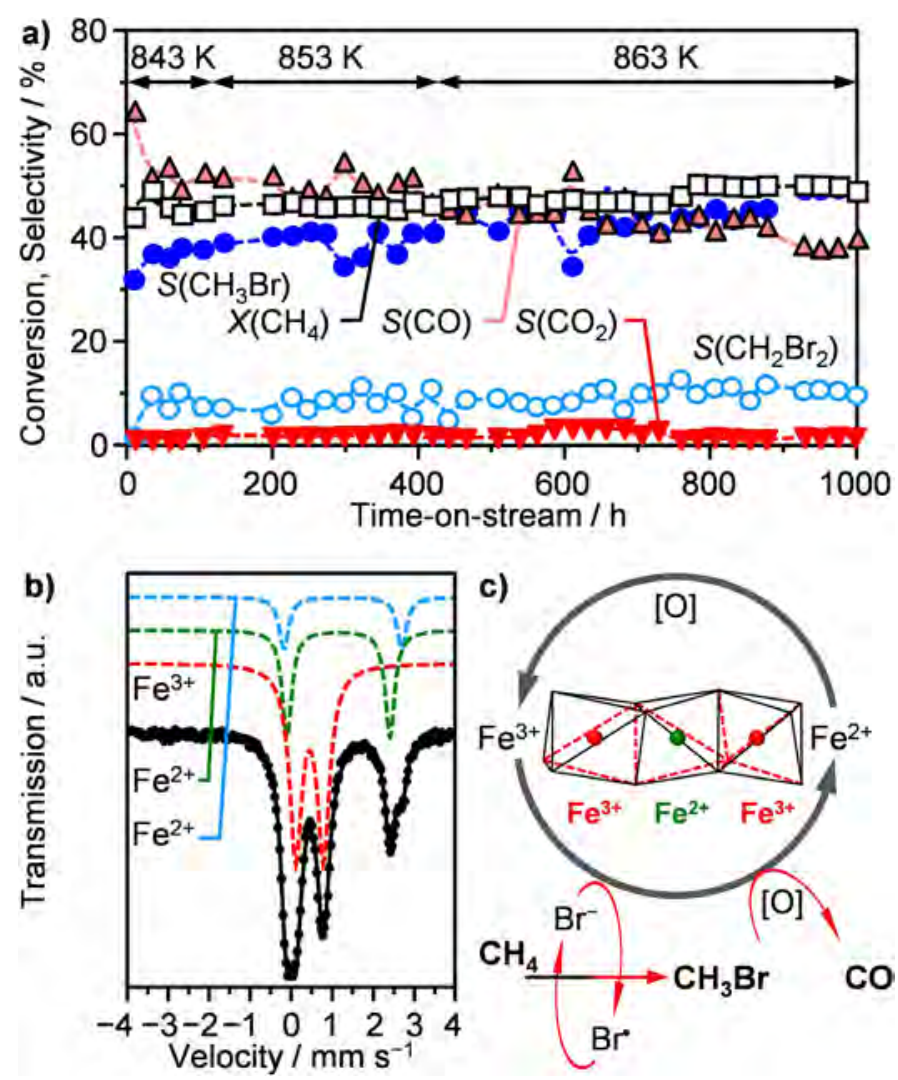

Figure 38. Methane oxybromination over supported iron phosphate catalysts. a) Stability of $\mathrm{FePO}_{4}$ SBA-15. Conditions: $W_{\text {cat }}=2.0$ g, $\mathrm{CH}_{4}: \mathrm{O}_{2}=2: 1, F=15 \mathrm{~cm}^{3}$ STP $\mathrm{min}^{-1}$, $40 \mathrm{wt} . \% \mathrm{HBr}$ aqueous solution $3.0 \mathrm{~cm}^{3} \mathrm{~h}^{-1}$. Reproduced with permission from ref 293. Copyright 2013 Elsevier. b) ${ }^{57} \mathrm{Fe}$ Mössbauer spectrum of the used catalysts, unambiguously demonstrating the coexistence of both ferric and ferrous ions. Black dot: experimental data; black lines: fitted spectra; color lines: least-square fits showing different iron components. c) A tentative redox route. The coordination of $\mathrm{Fe}_{3} \mathrm{O}_{12}$ in the presumed active phase of $\alpha-\mathrm{Fe}_{3}\left(\mathrm{P}_{2} \mathrm{O}_{7}\right)_{2}$ was shown by the inset, highlighting the similar locations of all iron cations in face-sharing octahedral sites. [O] could be gaseous or lattice oxygen. Adapted with permission from ref 296. Copyright 2010 Elsevier. 
The phase evolution of the iron phosphate catalyst was studied by combined characterization techniques. Time-dependent experiments on used $\mathrm{FePO}_{4} / \mathrm{SiO}_{2}$, examined by ${ }^{57} \mathrm{Fe}$ Mössbauer spectroscopy, convincingly revealed that both ferric and ferrous ions existed in the stable catalysts and at least two different routes were involved from the conversion of original $\mathrm{FePO}_{4}$ phase into both $\alpha$ $\mathrm{Fe}_{3}\left(\mathrm{P}_{2} \mathrm{O}_{7}\right)_{2}$ and $\mathrm{Fe}_{2} \mathrm{P}_{2} \mathrm{O}_{7}$ (Figure 38b). ${ }^{296}$ Quantitative analysis of the relative ratio of these two different phases from ${ }^{57} \mathrm{Fe}$ Mössbauer spectra showed a stable molar ratio of ca. 1:1 for $\alpha-\mathrm{Fe}_{3}\left(\mathrm{P}_{2} \mathrm{O}_{7}\right)_{2}: \mathrm{Fe}_{2} \mathrm{P}_{2} \mathrm{O}_{7}$ for all the used catalysts after an induction period. It is noted that $\alpha-\mathrm{Fe}_{3}\left(\mathrm{P}_{2} \mathrm{O}_{7}\right)_{2}$ contains both ferric and ferrous ions with an atomic ratio of 2:1. In a number of selective oxidation reactions based on bulk iron phosphate catalysts, $\alpha-\mathrm{Fe}_{3}\left(\mathrm{P}_{2} \mathrm{O}_{7}\right)_{2}$ has been recognized as the most active phase due to the unique configuration of three face-sharing $\mathrm{FeO}_{6}$ octahedra clusters (Figure 38c, inset). ${ }^{311,312}$ Theoretical studies using extended Hückel molecular orbital theory suggested an electron delocalization between the adjacent iron cations in the mixed-valence iron-oxygen trimer. ${ }^{313}$ Such a configuration may facilitate the generation of intervalence for the $\mathrm{Fe}^{3+} / \mathrm{Fe}^{2+}$ redox couple during catalytic reactions. ${ }^{311,314}$ Another phosphate containing mixed valence iron ions, $\mathrm{Fe}_{7}\left(\mathrm{PO}_{4}\right)_{6}$, was identified in the used $\mathrm{FePO}_{4}-\mathrm{SBA}-15$ catalyst. ${ }^{293}$ Similar results were also found on $\mathrm{Na}_{3} \mathrm{Fe}_{2}\left(\mathrm{PO}_{4}\right)_{3}$ which, after the reaction, was reduced to $\mathrm{Na}_{2} \mathrm{Fe}_{3}\left(\mathrm{PO}_{4}\right)_{3}$ with a lower ferric to ferrous ions atomic ratio of 1:2. ${ }^{295}$ The above findings seem to support that the oxybromination over iron phosphate catalysts proceeded in a redox mechanism wherein the redox pair of $\mathrm{Fe}^{3+} / \mathrm{Fe}^{2+}$ might play a crucial role in the catalytic process. In this sense, the development of controlled synthesis of iron phosphates with mixed iron valences and tailored structures might be an interesting direction to the discovery of superior oxybromination catalysts.

Vanadium Phosphates. Recent studies aiming to find improved catalysts for methane oxybromination have culminated in the discovery of vanadium phosphates, leading to an unprecedented selectivity to $\mathrm{CH}_{3} \mathrm{Br}$ compared to the previously reported catalysts. ${ }^{61}$ Interestingly, it is found that the operational window of all the active catalysts examined including $\mathrm{CeO}_{2}$ and $\mathrm{FePO}_{4}$ was advantageously shifted to lower temperatures at least by $100 \mathrm{~K}$ than those in the earlier literature. ${ }^{264,296}$ It is likely because this study ${ }^{61}$ was conducted using dry $\mathrm{HBr}$ where the water inhibition is anticipated to be 

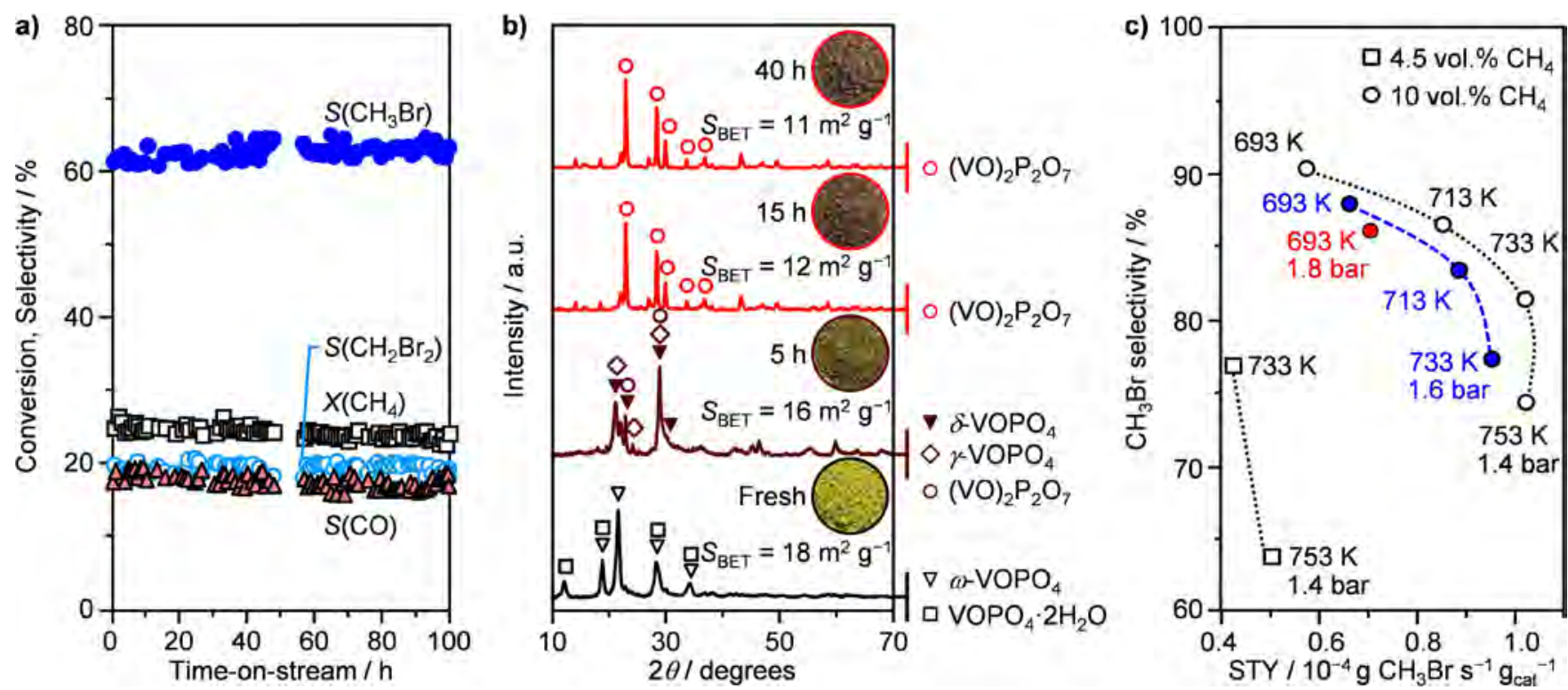

Figure 39. Methane oxybromination over vanadium phosphate catalysts. a) Stability. Conditions: $W_{\text {cat }}=1.0 \mathrm{~g}, \quad \mathrm{CH}_{4}: \mathrm{Br}_{2}: \mathrm{O}_{2}: \mathrm{Ar}: \mathrm{He}=4.5: 3: 1.5: 3: 88, \quad F=100 \mathrm{~cm}^{3} \mathrm{STP} \mathrm{min}^{-1}, \quad T=753 \mathrm{~K}, \quad P=1.4 \mathrm{bar}$. b) Characterizations of the fresh and used catalysts by $\mathrm{XRD}$ and $\mathrm{N}_{2}$-sorption. c) $\mathrm{CH}_{3} \mathrm{Br}$ selectivity versus STY of $\mathrm{CH}_{3} \mathrm{Br}$ production for two methane concentrations, total pressure, and temperature showed that an excess of methane in the feed was crucial to reach a high selectivity for $\mathrm{CH}_{3} \mathrm{Br}$. Reproduced with permission from ref 61. Copyright 2016 Macmillan Publishers Ltd.: Nature.

insignificant compared to that when wet $\mathrm{HBr}$ (40 wt.\% aqueous $\mathrm{HBr}$ solution) was used in other studies. ${ }^{264,296}$ The robustness of vanadium phosphate was demonstrated in a $100 \mathrm{~h}$ on stream test at 753 $\mathrm{K}$, showing stable catalyst performance $\left(X\left(\mathrm{CH}_{4}\right)=25 \%, S\left(\mathrm{CH}_{3} \mathrm{Br}\right)=64 \%\right.$, Figure 39a). Phase evolution of vanadium phosphates during the reaction was unfolded by combined characterization techniques (Figure 39b). The fresh catalysts prepared by the phosphation of $\mathrm{V}_{2} \mathrm{O}_{5}$ through a typical organic route comprised of mainly $\mathrm{VOPO}_{4}$. It transformed into a reduced (VO) ${ }_{2} \mathrm{P}_{2} \mathrm{O}_{7}$ form after $5 \mathrm{~h}$ treatment and equilibrium of the bulk-phase composition (mainly (VO) ${ }_{2} \mathrm{P}_{2} \mathrm{O}_{7}$ with a small amount of $\mathrm{V}^{5+}$ species) was reached within $15 \mathrm{~h}$.

The reaction mechanism of vanadium phosphates has been systematically studied based on a set of comparative experiments. ${ }^{61}$ Investigation of the gas-phase methane bromination and catalyzed oxybromination at similar reaction conditions revealed a similar onset temperature ( $\sim 675 \mathrm{~K})$ and the trends in methane conversion and product distribution of brominated products. The only difference originates from CO formation in the latter reaction. In another oxybromination experiment, the 
conversion of $\mathrm{HBr}$ and bromine yield were quantified as a function of temperature. Increasing productivity of the bromomethanes was observed to be accompanied by decreasing $\mathrm{HBr}$ conversion and bromine yield, with a rise of reaction temperature. The above results on vanadium phosphates evidenced the synergistic cooperation between the heterogeneously catalyzed $\mathrm{HBr}$ oxidation and gas-phase alkane bromination, mediated by radicals continuously supplied from the bromine pool that is, in turn, regenerated on the catalyst surface by molecular oxygen. The $\mathrm{C}-\mathrm{H}$ bond scission is therefore decoupled from the highly reactive oxygen species on the catalyst, which would generally promote the undesired deeper oxidation of alkane and brominated products. Thus, the outstanding performance of vanadium phosphate was rationalized by the high activity in $\mathrm{HBr}$ oxidation and low propensity for methane and bromomethane oxidation. ${ }^{61}$

The performance of vanadium phosphate was optimized towards high $\mathrm{CH}_{3} \mathrm{Br}$ yield by variation of reaction conditions (Figure 39c). Increasing the feed content of methane from 4.5 to 10 vol.\% led to a $10 \%$ increase in $\mathrm{CH}_{3} \mathrm{Br}$ selectivity with a doubled productivity at $753 \mathrm{~K}$. The selectivity was further boosted to $91 \%$ by decreasing the temperature to $693 \mathrm{~K}$ with a $10 \mathrm{vol} . \% \mathrm{CH}_{4}$ in the feed. An increase in the total pressure from 1.4 to 1.8 bar caused an increase in methane conversion with only a slight drop in selectivity $\left(\mathrm{S}\left(\mathrm{CH}_{3} \mathrm{Br}\right)>86 \%\right)$. The applicability of vanadium phosphates under realistic reactant-rich feed $\left(\mathrm{CH}_{4}\right.$ concentration up to 18 vol.\% while keeping the reactants molar ratio constant) has been tested. ${ }^{61}$ Small alterations in product distribution at similar methane conversions and a strong enhancement of the $\mathrm{CH}_{3} \mathrm{Br}$ productivity were observed, demonstrating the scalability of the catalyst performance.

\subsection{Oxyhalonation of Higher Hydrocarbons $\left(\mathrm{C}_{2}-\mathrm{C}_{4}\right)$}

Gas- and liquid-phase halogenation reactions hold significant importance in organic synthesis for the fine chemical industry since organic chlorides and bromides are widely used as synthetic precursors for various coupling reactions in organic and pharmaceutical synthesis. ${ }^{315}$ Conventional halogenation methods typically use toxic molecular halogens, which generate undesirable hydrohalic acid byproducts and inevitably reduce the halogen atom efficiency (a maximum of 50\%). Strategies using 
oxychlorination and oxybromination of higher hydrocarbons with $\mathrm{HCl} / \mathrm{HBr}$ over solid catalysts have been constantly explored, offering more sustainable approaches. ${ }^{316-318}$

3.3.1. Oxybromination of Ethane. Ethane oxybromination has been studied using $\mathrm{HBr}$ as the mediator both in anhydrous and in aqueous solution. ${ }^{61,62}$ Ethyl bromide and ethylene are the predominant products at 573-833 K, the rest being mainly other brominated hydrocarbons, together with $\mathrm{CH}_{4}$ and carbon oxides formed at higher temperatures. Zhou et al. reported a single pass ethane conversion of $34 \%$ with a maximal bromoethane selectivity of $87 \%$ at $653 \mathrm{~K}$ over $\mathrm{LaCl}_{3}-\mathrm{KCl}-$ $\mathrm{FeCl}_{3} / \mathrm{SiO}_{2}$ catalysts. ${ }^{62}$ A high $\mathrm{C}_{2} \mathrm{H}_{5} \mathrm{Br}$ selectivity was also observed over vanadium phosphates. ${ }^{61}$ In both studies, the temperature-dependent nature of product distribution was self-evident, which is in line with observations in ethane oxychlorination where increasing temperature usually resulted in selective formation of ethylene due to the sequential dehydrohalogenation of alkyl halides. ${ }^{27,178}$ These results might be indicative of similar reaction routes for both reactions. The advantages of ethane oxybromination over the oxychlorination route can be summarized as follows: (i) bromoethanes by themselves can be used as end products without further upgrading, e.g., ethyl bromide is widely used as a solvent or an anesthetic in medicine, and as an ethylating agent in the production of pharmaceuticals in organic synthesis industry; ${ }^{315}$ and (ii) the easy separation of bromoethanes from ethylene, due to the large differences in boiling points.

3.3.2. Oxyhalogenation of Propane/Propylene. Propane oxychlorination, though rarely targeted, has been disclosed in a few patents. ${ }^{319,320}$ An early study on copper chloride-based catalysts showed a spectrum of chloro-derivatives (tri-/tetra-chloroethylenes and tetrachloride) being the products. ${ }^{320}$ Thus, selectivity control presents a formidable challenge for this reaction. Recently, Schweizer et al. showed that propene and allyl chloride can be selectively produced by porous LaOCl-catalyzed oxychlorination of propane with low combustion $\left(X\left(\mathrm{C}_{3} \mathrm{H}_{8}\right)=51 \%, S\left(\mathrm{C}_{3} \mathrm{H}_{6}+\mathrm{C}_{3} \mathrm{H}_{5} \mathrm{Cl}\right)=75 \%, T=673 \mathrm{~K}\right){ }^{319}$ The high selectivity of $\mathrm{C}_{3} \mathrm{H}_{6}$ and $\mathrm{C}_{3} \mathrm{H}_{5} \mathrm{Cl}$ suggested that dehydrochlorination of both $\mathrm{C}_{3} \mathrm{H}_{7} \mathrm{Cl}_{\text {and }} \mathrm{C}_{3} \mathrm{H}_{6} \mathrm{Cl}_{2}$ occurred following sequential Cl-substitution of $\mathrm{C}_{3} \mathrm{H}_{8}$. This agrees well with another study by Testova et al. who found the predominating products shifted from chloropropanes to 
dehydrochlorination products in propane chlorination when the temperature was increased from 573 to $676 \mathrm{~K}^{321}$ Interestingly, propane oxybromination over vanadium phosphate gave prominent $\mathrm{C}_{2} \mathrm{H}_{5} \mathrm{Br}$ instead of $\mathrm{C}_{3} \mathrm{H}_{7} \mathrm{Br}$ in the low-temperature region, and the propylene selectivity increased rapidly at the compensation of $\mathrm{C}_{2} \mathrm{H}_{5} \mathrm{Br}$ with increasing temperature. ${ }^{61}$

The oxychlorination of propylene usually occurs in the temperature range of 473-623 K. ${ }^{317,322,323}$ It is of interest because, depending on the catalysts used and reaction conditions, the aimed products could be switched from 1,2-dichloropropane (addition product) to allyl chloride (substitution product). The latter, an important raw material for allyl alcohol, synthetic glycerol, and epoxy resin manufacture, is currently produced by high-temperature thermal chlorination (573-873 K), suffering from a low selectivity and coking. ${ }^{322,324,325}$

The catalyst plays a pivotal role in the oxychlorination of propylene. To date, metal chlorides are the most studied catalysts. The bond strength of $\mathrm{M}-\mathrm{Cl}$ ( $\mathrm{M}$ corresponds to metal in the catalysts) has been proposed as the descriptor for this reaction (Figure 40). For the metal chlorides with high binding energies, such as $\mathrm{FeCl}_{3}$ and $\mathrm{CoCl}_{2}$, the reactivity was low and $i$-propyl chloride was the main product. $\mathrm{CuCl}_{2}$ with moderate bond strength shows higher activity with the major product of 1,2dichloropropane. Noble metal chlorides like $\mathrm{PdCl}_{2}$ and $\mathrm{TeCl}_{4}$ with lower binding energies are the most active and selective catalysts for producing allyl chloride. Miyake and Hanaya speculated that the interaction between the metal chloride and propylene might be the key to distinguish the addition reaction from the substitution reaction. ${ }^{322}$ They assumed that there was a strong affinity for $\pi$-electrons on the double bond of propylene for $\mathrm{Cu}$, whereas a $\pi$-allyl type interaction prevailed for Pd and Te. The reaction mechanism of propylene oxychlorination over $\mathrm{PdCl}_{2}$ catalysts was proposed by Fujimoto et al., ${ }^{317,326}$ in which $\pi$-allylic intermediate was formed by the interaction between $\mathrm{Pd}^{0}$ and propylene (Eq. 15). With chloride substitution from $\mathrm{PdCl}_{2}$, allyl chloride was released while $\mathrm{Pd}^{2+}$ cations were reduced back to $\mathrm{Pd}^{0}$ (Eq. 16). This reaction route was partly supported by the observation that the optimal formation rate of allyl chloride was obtained over the catalysts only with the 

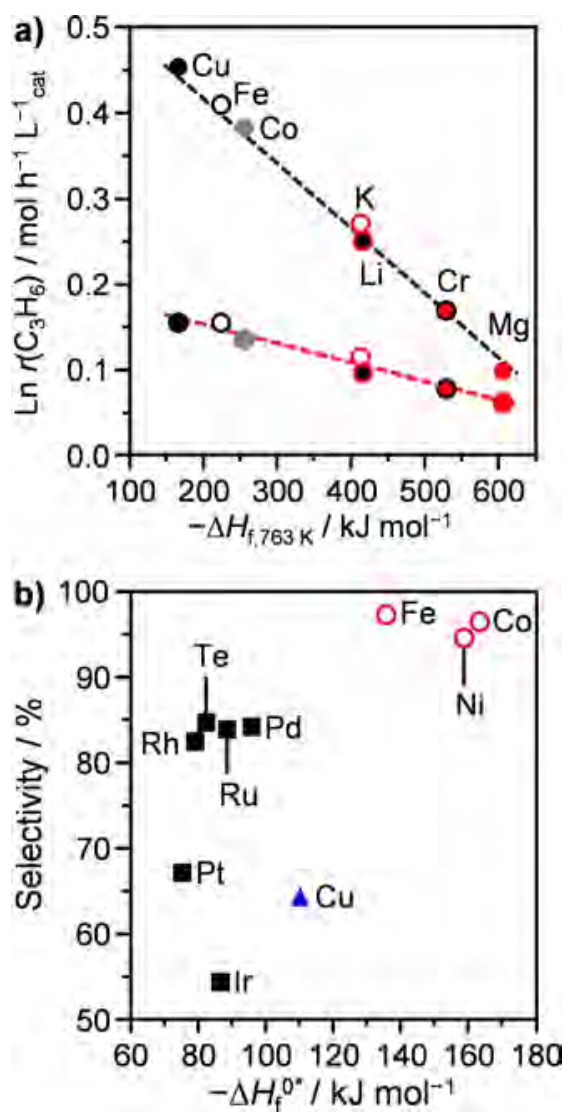

Figure 40. Oxychlorination of propylene over metal chloride catalysts. a) Correlations between the logarithm of reaction rate of propylene and the heat formation of the $\mathrm{M}-\mathrm{Cl}$ bond. Open circle, $733 \mathrm{~K}$; filled circle, 763 K. Reproduced with permission from ref 323. Copyright 1986 Springer. b) Selectivity of the main products as a function of the heat formation of metal chloride per chloride atom. Square, allyl chloride; triangle, dichloropropane; circle, isopropyl chloride. Data taken from refs 317,322.<smiles>[R]CCCCC=CC=[Pt]</smiles>

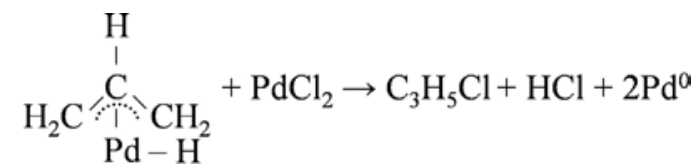

co-existence of $\mathrm{Pd}^{2+} / \mathrm{Pd}^{0}$. A radical reaction mechanism similar to that in ethylene oxychlorination was proposed for Cu-based catalysts, involving the redox cycle between $\mathrm{CuCl}_{2}$ and $\mathrm{CuCl}^{323}$ Although $\mathrm{TeCl}_{4}$-based catalysts showed promising behavior in the one-step production of allyl chloride from propylene, in-depth understanding on the reaction route is still lacking. Limited knowledge in this field can only be glimpsed from early scattered patents. ${ }^{327}$ 
A novel tandem process was reported by Stauffer for the synthesis of allyl chloride, comprising first the oxychlorination of perchloroethylene to hexachloroethane (Eq. 17) over copper chloride-based catalysts at 473-648 K preferably in a shell and tube reactor, and then a vapor-phase reaction with propylene at 673-973 K to produce allyl chloride (Eq. 18). ${ }^{328}$ Therefore, the net reaction (Eq. 19) of this tandem process is propylene oxychlorination to allyl chloride. The viability of this route should be further evaluated as no convincing reactivity results were disclosed in the patent.

$$
\begin{array}{lc}
\mathrm{C}_{2} \mathrm{Cl}_{4}+2 \mathrm{HCl}+1 / 2 \mathrm{O}_{2} \rightarrow \mathrm{C}_{2} \mathrm{Cl}_{6}+\mathrm{H}_{2} \mathrm{O} & \Delta H=-209 \mathrm{~kJ} \mathrm{~mol}^{-1} \\
\mathrm{C}_{2} \mathrm{Cl}_{6}+\mathrm{C}_{3} \mathrm{H}_{6} \rightarrow \mathrm{C}_{3} \mathrm{H}_{5} \mathrm{Cl}+\mathrm{C}_{2} \mathrm{Cl}_{4}+\mathrm{HCl} & \Delta H=67 \mathrm{~kJ} \mathrm{~mol}^{-1} \\
\mathrm{C}_{3} \mathrm{H}_{6}+\mathrm{HCl}+1 / 2 \mathrm{O}_{2} \rightarrow \mathrm{C}_{3} \mathrm{H}_{5} \mathrm{Cl}+\mathrm{H}_{2} \mathrm{O} & \Delta H=-142 \mathrm{~kJ} \mathrm{~mol}^{-1}
\end{array}
$$

3.3.3. Oxyhalogenation of Butane/Butadiene. Halogen functionality can be introduced into $\mathrm{C}_{4}$ aliphatic hydrocarbons by oxyhalogenation. The challenges with the activation of these long-chain molecules lie in achieving a high selectivity of the targeted product while maintaining reasonable conversion rates. Several organic intermediates can be prepared by these reactions. For instance, 1,1,4,4-tetrabromobutadiene was produced by the oxidative bromination of butane with oxygen and bromine in the presence of $\mathrm{CuBr}_{2}-\mathrm{KBr} / \gamma-\mathrm{Al}_{2} \mathrm{O}_{3}(90 \%$ selectivity at $523 \mathrm{~K}){ }^{329}$ 1,4-Dichlorobutadiene, a useful solvent and an intermediate for dyestuffs, can also be selectively synthesized by direct oxychlorination of straight chain $\mathrm{C}_{4}$ hydrocarbons (butane, butene, and/or butadiene) over $\mathrm{CuCl}_{2}-\mathrm{KCl} / \gamma$ $\mathrm{Al}_{2} \mathrm{O}_{3}(X=41-65 \%, S=57-92 \%$, at $563-593 \mathrm{~K}) .{ }^{330}$ There are several studies dealing with the catalyzed oxychlorination of butadiene to dichlorobutenes. ${ }^{331-335}$ Among the viable reactions including substitution, addition, cracking, and polymerization, it is of interest to promote only the addition of two chlorine atoms leading to a mixture of dichlorobutenes. A butadiene conversion of $65 \%$ with a total selectivity to dichlorobutenes of $71 \%$ was attained over $\mathrm{CuCl}_{2}-\mathrm{KCl} / \mathrm{SiO}_{2}$ promoted by didymium (a mixture of elements $\mathrm{Pr}$ and $\mathrm{Nd}$ ) at $553 \mathrm{~K} .{ }^{331}$ Todo and Hagiwara reported that $\mathrm{CuCl}_{2}-\mathrm{LiCl}_{-} \mathrm{H}_{3} \mathrm{PO}_{4}$ supported on sintered alumina-silica $\left(S_{\mathrm{BET}}<1 \mathrm{~m}^{2} \mathrm{~g}^{-1}\right)$, after modified with a trace amount of $\mathrm{Zr}$ (0.025 wt.\%), was extremely active and selective $(X=73 \%, S=96 \%) .{ }^{332-334}$ However, the promotional 


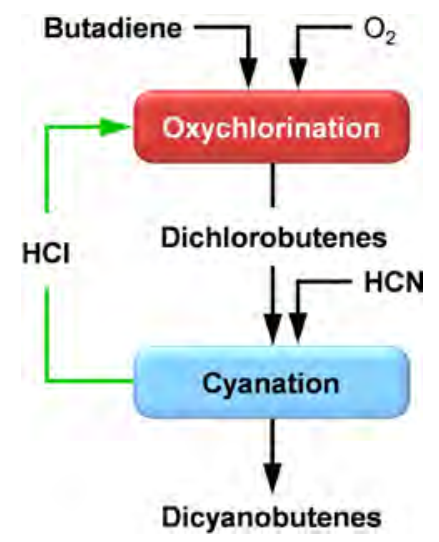

Figure 41. An integrated process from butadiene to dicyanobutenes, comprising butadiene oxychlorination to dichlorobutenes and the cyanation of the latter with HCN. The HCl produced by the second step can be recycled for oxychlorination to close the halogen loop. ${ }^{335}$

effect of $\mathrm{Zr}$ was not found when the support was replaced with $\mathrm{SiC}, 332$ suggesting the presence of interactions between $\mathrm{Zr}$ and the sintered alumina-silica support.

A novel process has been conceived for the synthesis of dicyanobutenes (Figure 41). ${ }^{335}$ In the first step, the oxychlorination of 1,3-butadiene over $\mathrm{CuCl}_{2} /$ pumice yielded $75 \%$ mixed dichlorobutenes at $543 \pm 10 \mathrm{~K}$. After separation, the dichlorobutenes were directed to a cyanation reactor with HCN, where substitution reaction occurred to produce dicyanobutenes. The liberated $\mathrm{HCl}$ can then be recycled back to the oxychlorination reactor. In this way the halogen loop is closed by recycling the stripped $\mathrm{HCl}$ to the oxychlorination reactions.

Indeed, oxyhalogenation of higher aliphatic hydrocarbons provides an alternative route for the synthesis of important halogenated organic compounds. Atom-economic process can be achieved when these reactions are appropriately coupled with sequential steps where hydrogen halides can be quantitatively extracted. On the other hand, the reaction network becomes even more complicated with the growth of carbon chain length, which represents a big challenge for the selective activation of certain functionalities. Besides, these reactions are exothermic and proceed so readily that avoidance of "hotspots" in catalyst bed and other problems related to adequate temperature control have been among the principal technical difficulties. ${ }^{330}$ 


\subsection{Halogen-Assisted Dehydrogenation of Alkanes ( $\left.\mathrm{C}_{2}-\mathrm{C}_{5}\right)$}

Olefins are extensively used as building blocks in the production of a vast array of chemicals, including polymers, oxygenates, and important chemical intermediates. The manufacture heavily relies on the steam cracking and fluid catalytic cracking of naphtha, light diesel, and other oil byproducts, especially for light olefins. ${ }^{336}$ These routes are energy-intensive and the selectivity towards particular olefins is low, not to mention the dwindling petroleum reserves and fluctuating oil price. Therefore, there has been much research interest devoted to finding an alternative dehydrogenation process suitable for producing paraffins. ${ }^{44-46,265,337-344}$ In this context, halogens play a unique role in the dehydrogenation of various alkanes, affording an exceptionally high selectivity to the respective alkenes (Table 6). Among the halogens, iodine is extremely effective. When used in conjunction with an alkaline acceptor to bind the iodide species, iodination of an alkane can give extensive dehydrogenation to olefins, diolefins, or aromatics. ${ }^{44-46,337-339}$ Depending on the forms how halogens are involved, these reactions can be classified into three groups: iodine-mediated dehydrogenation, molten salts (metal chlorides and iodides) catalyzed oxidative dehydrogenation, and bi-halogen-aided dehydrogenation.

3.4.1. Iodine-Mediated Dehydrogenation. The substitution of molecular iodine with various hydrocarbons has long been known, but it is generally recognized that iodine is poorly reactive toward saturated hydrocarbons. Raley et al. studied the high-temperature ( $T>673 \mathrm{~K}$ ) reactions between iodine and hydrocarbons, and demonstrated that a variety of paraffins can be dehydrogenated to corresponding monoolefins with the formation of stoichiometric HI. ${ }^{46,338,339}$ A quick quenching of reaction effluents was claimed to be indispensable, otherwise a substantial amount of organic iodides can be formed ${ }^{46}$ It seems that this reaction is more favorable for the dehydrogenation of low-chain hydrocarbons $\left(\mathrm{C}_{2}-\mathrm{C}_{3}\right)$ which gives much higher selectivity to the corresponding alkenes (Table 6). A free radical mechanism was also proposed for the stoichiometric iodination, consisting of successive hydrogen abstraction reactions involving both atomic and molecular iodine. ${ }^{46}$ Besides, high temperature reactions of iodine with long-chain hydrocarbons $\left(\mathrm{C}_{6+}\right)$ can lead to aromatization of higher aliphatic hydrocarbons, ${ }^{339}$ and 
Table 6. Halogen-Mediated Dehydrogenation Reactions of Various Alkanes

\begin{tabular}{|c|c|c|c|c|c|c|}
\hline \multirow{2}{*}{ reactant } & \multirow{2}{*}{ aimed product } & \multicolumn{2}{|c|}{ reactivity $^{a}$} & \multicolumn{2}{|c|}{ conditions } & \multirow{2}{*}{ ref } \\
\hline & & $X / \%$ & $S / \%$ & mediators & $T / \mathrm{K}$ & \\
\hline $\mathrm{C}_{2} \mathrm{H}_{6}$ & $\mathrm{C}_{2} \mathrm{H}_{4}$ & 53 & 90 & $\mathrm{LiCl}$ & 923 & 344 \\
\hline $\mathrm{C}_{2} \mathrm{H}_{6}$ & $\mathrm{C}_{2} \mathrm{H}_{4}$ & 28 & 97 & LiCl-KCl & 873 & 341 \\
\hline $\mathrm{C}_{2} \mathrm{H}_{6}$ & $\mathrm{C}_{2} \mathrm{H}_{4}$ & $24^{b}$ & $\sim 72$ & $\mathrm{I}_{2}$ & 958 & 46 \\
\hline $\mathrm{C}_{2} \mathrm{H}_{6}$ & $\mathrm{C}_{2} \mathrm{H}_{4}$ & 75 & 93 & $\mathrm{PbI}_{2}$ & 868 & 337 \\
\hline $\mathrm{C}_{2} \mathrm{H}_{6}$ & $\mathrm{C}_{2} \mathrm{H}_{4}$ & 78 & 96 & LiI & 810 & 44 \\
\hline $\mathrm{C}_{3} \mathrm{H}_{8}$ & $\mathrm{C}_{2} \mathrm{H}_{4}, \mathrm{C}_{3} \mathrm{H}_{6}$ & 60 & 78 & $\mathrm{LiCl}$ & 923 & 345 \\
\hline $\mathrm{C}_{3} \mathrm{H}_{8}$ & $\mathrm{C}_{3} \mathrm{H}_{6}$ & $68^{b}$ & 87 & $\mathrm{I}_{2}$ & 958 & 46 \\
\hline $\mathrm{C}_{3} \mathrm{H}_{8}$ & $\mathrm{C}_{3} \mathrm{H}_{6}$ & $50-64$ & $74-76$ & $\mathrm{LiOH} \cdot \mathrm{H}_{2} \mathrm{O} / \mathrm{LiI}$ & 873 & 346 \\
\hline $\mathrm{C}_{3} \mathrm{H}_{8}$ & $\mathrm{C}_{3} \mathrm{H}_{6}$ & 78 & 81 & $\mathrm{LiI} / \mathrm{LiOH}$ & 773 & 347 \\
\hline $\mathrm{C}_{3} \mathrm{H}_{8}$ & $\mathrm{C}_{3} \mathrm{H}_{6}$ & $60-79$ & $88-96$ & LiI & 727 & 44 \\
\hline $\mathrm{C}_{3} \mathrm{H}_{8}$ & $\mathrm{C}_{3} \mathrm{H}_{6}, \mathrm{C}_{3} \mathrm{H}_{7} \mathrm{Br}, \mathrm{C}_{3} \mathrm{H}_{7} \mathrm{I}$ & $54-96$ & $64-84$ & $\mathrm{I}_{2} / \mathrm{Br}_{2}$ & $580-800$ & 348 \\
\hline$n-\mathrm{C}_{4} \mathrm{H}_{10}$ & $\mathrm{C}_{2} \mathrm{H}_{4}, \mathrm{C}_{3} \mathrm{H}_{6}, \mathrm{C}_{4} \mathrm{H}_{8}$ & 68 & 83 & $\mathrm{LiCl}$ & 923 & 345 \\
\hline$n-\mathrm{C}_{4} \mathrm{H}_{10}$ & $\mathrm{C}_{4} \mathrm{H}_{8}$ & $52^{b}$ & 54 & $\mathrm{I}_{2}$ & 848 & 46 \\
\hline$n-\mathrm{C}_{4} \mathrm{H}_{10}$ & 1,3-butadiene & $75-92$ & $71-78$ & $\mathrm{LiI} / \mathrm{LiO}_{2}$ & 838 & 44 \\
\hline$i-\mathrm{C}_{4} \mathrm{H}_{10}$ & $\mathrm{C}_{4} \mathrm{H}_{8}$ & $63-75$ & $78-87$ & $\mathrm{LiI} / \mathrm{LiO}_{2}$ & 838 & 44 \\
\hline$i-\mathrm{C}_{4} \mathrm{H}_{10}$ & $p$-xylene & $33-43$ & $69-71$ & LiOH/LiI & 755-838 & 45 \\
\hline$n-\mathrm{C}_{5} \mathrm{H}_{12}$ & $n-\mathrm{C}_{5} \mathrm{H}_{10}$ & $77^{b}$ & 34 & $\mathrm{I}_{2}$ & 798 & 46 \\
\hline$i-\mathrm{C}_{5} \mathrm{H}_{12}$ & $i-\mathrm{C}_{5} \mathrm{H}_{10}$ & $75^{b}$ & 63 & $\mathrm{I}_{2}$ & 821 & 46 \\
\hline$i-\mathrm{C}_{5} \mathrm{H}_{12}$ & 2-methyl-1,3-butadiene & 71-95 & 58-92 & $\mathrm{LiI} / \mathrm{LiO}_{2}$ & 838 & 44 \\
\hline
\end{tabular}

${ }^{a}$ Hydrocarbon conversion and selectivity of aimed product were denoted as $X$ and $S$, respectively. ${ }^{b}$ Based on iodine.

the rearrangement of aliphatic free radicals (e.g., $\mathrm{CH}_{3} \mathrm{C}\left(\mathrm{CH}_{3}\right) \mathrm{R}_{1} \mathrm{CH}=\mathrm{CR}_{2} \mathrm{R}_{3} \quad \rightarrow$ $\mathrm{CH}_{3} \mathrm{CHR}_{1} \mathrm{CH}_{2} \mathrm{CH}=\mathrm{CR}_{2} \mathrm{R}_{3}, \mathrm{R}_{1}, \mathrm{R}_{2}, \mathrm{R}_{3}=\mathrm{H}$ or $\left.\mathrm{CH}_{3}\right){ }^{338}$

3.4.2. Alkali Metal Chloride-Catalyzed Oxidative Dehydrogenation. Supported alkali metal chloride catalysts have been demonstrated to be one of the most promising candidates for the oxidative dehydrogenation of light aliphatic alkanes $\left(\mathrm{C}_{2}-\mathrm{C}_{4}\right)$ to olefins. ${ }^{340}$ Activity and selectivity have been 
reported for the catalysts either with pure alkali metal chlorides or with several other divalent cations, such as $\mathrm{LiCl}, \mathrm{KCl}, \mathrm{Li}-\mathrm{K}-\mathrm{Cl}, \mathrm{Li}-\mathrm{Na}-\mathrm{Cl}, \mathrm{Li}-\mathrm{Sr}-\mathrm{Cl}$, and $\mathrm{Li}-\mathrm{Ba}-\mathrm{Cl}$, that are impregnated on various supports like (Dy2 $\mathrm{O}_{3}$-promoted) $\mathrm{MgO}^{265,341,342}$ and (metal oxide-promoted) sulfated-zirconia. ${ }^{343,344}$ The promotional effect of chlorides in these catalysts was reported by Lercher et al., who compared the oxidative dehydrogenation of ethane between $\mathrm{Li} / \mathrm{Dy}_{2} \mathrm{O}_{3}-\mathrm{MgO}$ and $\mathrm{LiCl} / \mathrm{Dy}_{2} \mathrm{O}_{3}-\mathrm{MgO}$, and found that the chloride-modified catalysts were ten times more active than the chloride-free ones (Figure 42a). ${ }^{349}$ It is speculated that a gas phase free radical reaction dominated over the latter, and the rate-determining step is the activation of ethane to form an alkyl radical over the presumed active site $\mathrm{Li}^{+} \mathrm{O}^{-}$. On the other hand, the intrinsic mechanism over chloride-promoted catalysts is still a matter of debate. For these catalysts, the interfaces generated by the introduction of molten salts under reaction conditions should play a crucial role in the observed performance. Instead of gas-solid two-phase reactions, those catalyzed by molten salts involve gas-melt-solid three-phase interactions because the reaction temperature is generally approaching or above the melting point of these chlorides. It has been reported that the maximum ethylene selectivity can be directly corelated with the melting point of the eutectic composition on the catalyst support (Figure 42b). ${ }^{342}$ A reverse Mars-van Krevelen mechanism was suggested for the activation of ethane over $\mathrm{KCl}-\mathrm{LiCl} / \mathrm{Dy}_{2} \mathrm{O}_{3}-\mathrm{MgO}$ (Figure 42c). In this mechanism, the activation of $\mathrm{O}_{2}$ and ethane were thought to occur at different interfaces (melt-solid and gas-melt, respectively). The active oxygen species, presumably $\mathrm{OCl}^{-}$, were formed at the oxygen vacancies on the support that diffused through the molten salt over-layer to the surface where ethane dehydrogenation happened. Theoretical study on a model $\mathrm{LiCl} / \mathrm{MgO}$ catalyst also showed that molecular adsorption of $\mathrm{O}_{2}$ at the $\mathrm{LiCl} / \mathrm{MgO}$ interface was the only possible process. ${ }^{350}$

3.4.3. Metal Iodide-Catalyzed Oxidative Dehydrogenation. Oxidative dehydrogenation of alkanes can also be catalyzed by iodide-based molten salts. The difference between iodide- and chloride-catalyzed dehydrogenation processes can be visualized from the reaction products: while iodine substitution products are commonly observed over iodide-based molten salts, no chlorinated compounds are formed over metal chloride catalysts. In fact, iodide-aided oxidative dehydrogenation 

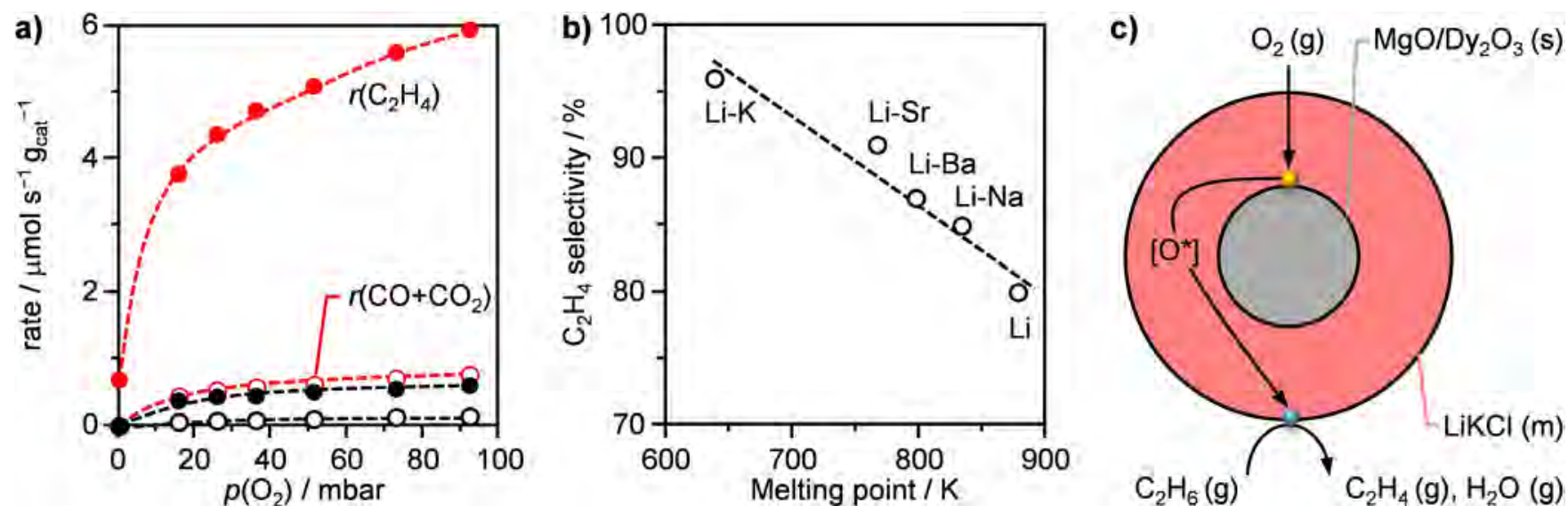

Figure 42. Ethane dehydrogenation over alkali metal chloride-based molten salt catalysts. a) Rate of product formation versus $\mathrm{O}_{2}$ partial pressure over chloride-free (black) and chloride-promoted (red) $\mathrm{Li} / \mathrm{Dy} / \mathrm{Mg} / \mathrm{O}$ catalysts. Conditions: GHSV $=6.1$ and $51.3 \mathrm{dm} \mathrm{STP} \mathrm{h}^{-1} \mathrm{~g}_{\mathrm{cat}}{ }^{-1}$ for the former and latter catalysts, respectively, $T=853 \mathrm{~K}, p\left(\mathrm{C}_{2} \mathrm{H}_{6}\right)=71$ mbar. Adapted with permission from ref 349. Copyright 2007 Springer. b) Correlation between the melting point of the eutectic melt and the maximum $\mathrm{C}_{2} \mathrm{H}_{4}$ selectivity derived from its curve leveled off with increasing reaction temperature. Conditions: $\mathrm{C}_{2} \mathrm{H}_{6}: \mathrm{O}_{2}: \mathrm{He}=8: 8: 84$, weight hourly space velocity (WHSV) $=0.8 \mathrm{~h}^{-1}, T=723-873 \mathrm{~K}$. Reproduced with permission from ref 342. Copyright 2007 Elsevier. c) Schematic representation of reaction pathways over $\mathrm{LiKCl} / \mathrm{MgO}-\mathrm{Dy}_{2} \mathrm{O}_{3}$ catalysts. The activation of $\mathrm{O}_{2}$ and $\mathrm{C}_{2} \mathrm{H}_{6}$ occurred at different interfaces, with the active sites highlighted by yellow and blue spheres, respectively. The spatial separation of these active sites, aided by the $\mathrm{LiKCl}$ melting layer (m), is concluded at least partially to be the origin of high olefin selectivity. Adapted with permission from ref 265. Copyright 2014 American Chemical Society.

was developed to overcome the drawbacks encountered in the direct iodination of hydrocarbons. Although far superior olefin yields can be obtained by iodine-based route compared to other conventional catalytic dehydrogenation methods, these iodination reactions are endothermic requiring large amount of energy, and the extent of dehydrogenation is intrinsically equilibrium limited. ${ }^{337,351}$ Among many approaches proposed to overcome these difficulties, oxidative dehydrogenation in the presence of molten salts (acting as hydrogen iodide acceptors) is an effective alternative. In this way, iodine acts as a real mediator and can be in situ generated by continuous oxidation of HI byproduct, shifting the equilibrium constrain. From the viewpoint of energy consumption, the overall reaction becomes more exothermic due to the participation of oxygen. Compared to the iodination reactions, the 
oxidative dehydrogenation usually shows higher alkane conversions and comparable/or even superior selectivity at much lower temperatures (Table 6).

The functions of metal iodides in the dehydrogenation have not been well-understood. The consensus is that they act as a mediator to adsorb and release $\mathrm{I}_{2}$. Constant-temperature ab initio molecular dynamics study of the reactions between $\mathrm{LiI}$ and gaseous molecules $\left(\mathrm{O}_{2}, \mathrm{H}_{2} \mathrm{O}\right.$, and $\left.\mathrm{I}_{2}\right)$ demonstrated that the most favorable process was the formation of gaseous $\mathrm{I}_{2}$, coproduced with $\mathrm{LiOH}$ or $\mathrm{Li}_{2} \mathrm{O}$. If the reaction in the presence of water (which is the case in the dehydrogenation reactions) was allowed to reach equilibrium, $\mathrm{I}_{2}$ (g) and $\mathrm{OH}^{-}$were the only species formed. ${ }^{351}$ Thus, the dehydrogenation reactions most likely occurred in the gas-phase. This is in agreement with a recent study on propane dehydrogenation which showed that the product distributions were quite similar under the same conditions when using either molecular iodine or $\mathrm{LiI} / \mathrm{LiOH}$ as the iodine source. ${ }^{347}$ Although the precise nature of the reactions involved in molten salt-mediated alkane dehydrogenation is not completely understood, the metathesis reactions between metal iodide and metal oxide can play a crucial role in the formation of iodine to initiate radical chain reactions and on the long-term stability. The promising catalysts to withstand these interlinked transformations should thus meet two prerequisites: (i) iodides are convertible at the dehydrogenation temperature to corresponding oxides by reacting with oxygen, and (ii) the oxides can be converted back to iodide by contacting iodine species. ${ }^{44}$ The effect of oxygen can also be multiple. On one hand, oxygen is indispensable for the generation of iodine radicals to trigger the chain reactions. On the other hand, an excess amount of oxygen can cause combustion of the desirable dehydrogenation products. Thus, an optimal oxygen content should be considered to modulate the above two reactions. ${ }^{347}$ Besides, Nager found that the presence of a very low concentration of hydrogen iodide in the iodine-mediated dehydrogenation reaction zone can substantially eliminate the necessity for a rapid quench of the reactor effluent as well as the recovery and recycling of large amount of iodine species normally required. ${ }^{44}$

An interesting oxidative dehydrogenation process for various hydrocarbons, based on metal iodides, was developed by Shell (Figure 43a). ${ }^{44,45}$ It is proposed that the dehydrogenation reactions occurred at 
698-863 K over molten metal iodides ( $\mathrm{LiI}, \mathrm{ZnI}_{2}, \mathrm{PbI}_{2}$ and $\mathrm{CdI}_{2}$ ). The reactor effluent was then sent to a phase separator, wherein the organic products were recovered. The remaining aqueous phase contains mainly water and a residual iodide species escaping from the molten salt reactor. This was further directed to an iodine scavenger, comprising reactive metals or metal oxides to remove substantially all of the iodine species by forming corresponding metal iodides. With another oxidation step, the iodine can be regenerated and recycled back to the dehydrogenation reactor. An additional benefit of using a molten metal iodide is related to its high heat capacity and high heat conductivity, refraining from the hot-spot formation. However, the effluent mixture still contains iodide species which causes undesirable reactions unless they are rapidly quenched with special handling techniques. ${ }^{44}$ Besides, the formation of carbon oxides was also observed due to the inevitable combustion of hydrocarbons, as well as floating coke on the surface of the melt possibly due to CO disproportionation reaction. ${ }^{347}$ Additionally, the presence of water with the molten salts is extremely corrosive and, thus, is intrinsically disadvantageous.

3.4.4. Bi-Halogens Interplay in Propane Dehydrogenation. Propane dehydrogenation to propylene has been extensively explored as an alternative approach to supplement the current propylene production based on steam cracking, fluidic catalytic cracking of naphtha and other hydrocarbons, and SAPO-34 catalyzed methanol to mixed olefins. ${ }^{336}$ Iodine-mediated dehydrogenation generally gives higher propylene yields compared to the conventional dehydrogenation routes. For propane iodination, the radial reactions mechanism is well established. ${ }^{46,337}$ It is demonstrated that iodine reacts selectively, but relatively slowly, with propane at low temperatures to form iodopropane and propylene (the latter formed via dehydroiodination of iodopropane). However, high propylene yields are only thermodynamically favorable at higher temperatures (Figure 43b). Oxidative iodination of propane over molten iodinated salts leads to better yields of propylene, but over-oxidation to carbon oxides lowers the feedstock utilization. ${ }^{44,346}$ Recently, Stucky et al. developed a low-temperature route for propane dehydrogenation by using bi-halogens $\left(\mathrm{Br}_{2}\right.$ and $\left.\mathrm{I}_{2}\right)$ as the mediators. ${ }^{348}$ Adding a little amount of bromine in the iodination reaction can significantly promote $\mathrm{C}_{3} \mathrm{H}_{8}$ conversion and the selectivity of the 

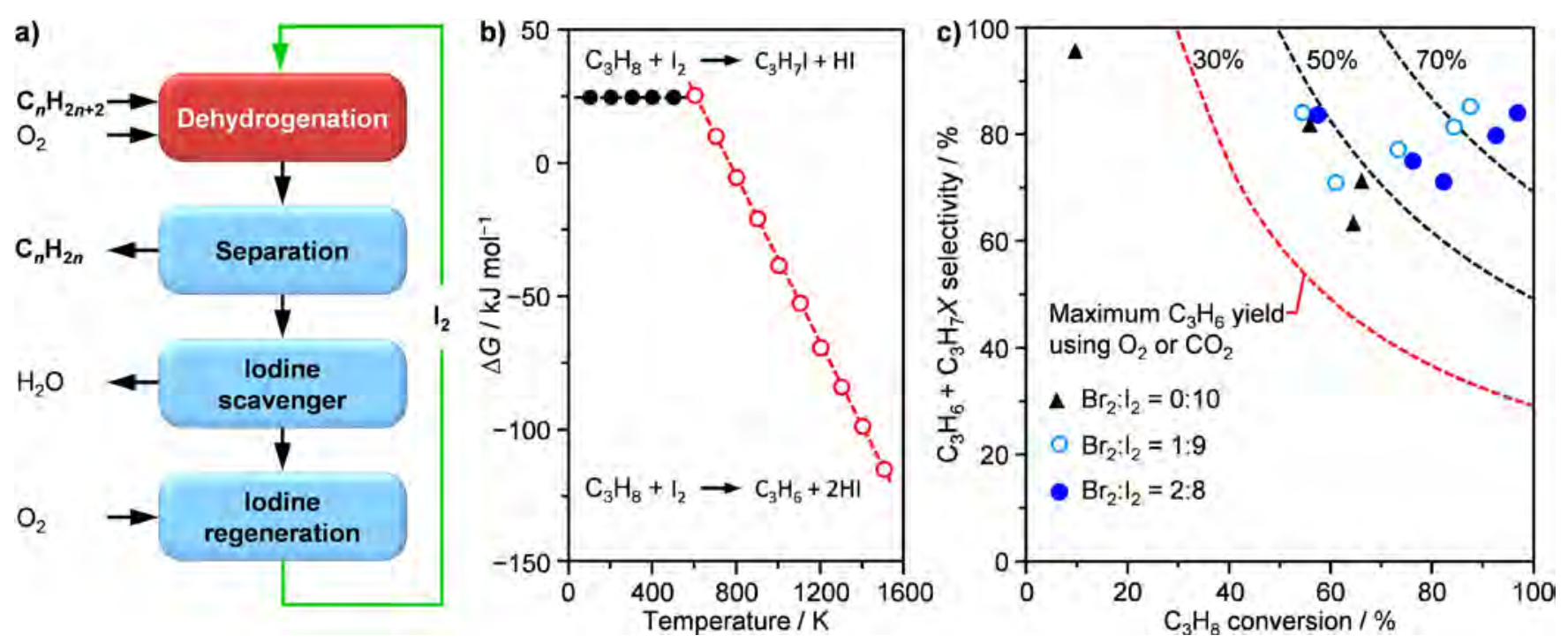

Figure 43. a) A simplified process for oxidative dehydrogenation of different hydrocarbons based on iodide-related molten salts catalysts, adapted from ref 44 . b) Thermodynamics of iodine-aided dehydrogenation of propane. c) Conversion versus selectivity curves for $\mathrm{C}_{3} \mathrm{H}_{8} / \mathrm{Br}_{2} / \mathrm{I}_{2}$ system, showing the promotional effect of bi-halogens in $\mathrm{C}_{3} \mathrm{H}_{8}$ dehydrogenation. Conditions: residence time $=8 \mathrm{~s}$, $\mathrm{C}_{3} \mathrm{H}_{8}: \mathrm{Br}_{2}: \mathrm{Ar}=7: 7: 47, \mathrm{C}_{3} \mathrm{H}_{8}$ input $=7.9 \mathrm{mmol}$, and $T=500-800 \mathrm{~K}$, Reproduced with permission from ref 348. Copyright 2013 Wiley-VCH.

desired products (Figure 43c). A high yield of $\mathrm{C}_{3} \mathrm{H}_{6}+\mathrm{C}_{3} \mathrm{H}_{7} \mathrm{X}(\mathrm{X}=\mathrm{Br}$ and I) up to $80 \%$ was attained at moderate reaction temperatures below $800 \mathrm{~K}$. The interplay between $\mathrm{Br}_{2}$ and $\mathrm{I}_{2}$ was believed to be crucial, combining the high reactivity of bromine and high selectivity of iodine. A comparative experiment showed that the direct bromination of $\mathrm{C}_{3} \mathrm{H}_{8}$ involved a batch of sequential substitution reactions, leading to inferior selectivity of desired product. The addition of iodine into the bromination process accelerated the formation of $\mathrm{C}_{3} \mathrm{H}_{6}$ by reducing the main side-reaction from $2-\mathrm{C}_{3} \mathrm{H}_{7} \mathrm{Br}$ to $2,2-$ $\mathrm{C}_{3} \mathrm{H}_{6} \mathrm{Br}_{2}$.

\section{TRANSFORMATION OF ALKYL HALIDES TO CHEMICALS AND FUELS}

In the modern chemical industry, alcohols, especially methanol, are important platform molecules, which can be transformed into a spectrum of valuable chemicals such as aldehydes, acetates, olefins, aromatics, etc. Likewise, haloalkanes can also be viewed as alternative building blocks for a broad range of specialty chemicals. Thus, efficient transformation of haloalkanes to valuable chemicals and fuels is as important as their synthesis from alkanes (via the (oxy)halogenation chemistry (Sections 3.1-3.3)) in 
the halogen-mediated alkane upgrading chain. Different technologies for alkyl halides conversion have been discovered (Figure 44). Among them, high-temperature pyrolysis represents one of the oldest routes from alkyl halides to different hydrocarbons, including olefins, VCM, and aromatics. . $2,352,353^{\text {The }}$ developed processes based on pyrolysis are all non-catalytic, yielding a broad range of products, which leads to cost-intensive separation steps. Besides, it suffers from carbonaceous deposits in the pyrolysis reaction. A more advanced technology of methyl halides coupling over aluminosilicate molecular sieves was discovered by the Mobil scientists. ${ }^{50}$ These reactions occur in a low temperature range of 553$753 \mathrm{~K}$, operating both in batch and continuous modes. ${ }^{50,310,354}$ By tuning the topology and acidity of various zeolites, this route can be designed for the on-purpose production of gasolines, olefins, and aromatics. $^{355-358}$ Additionally, alkyl halides can be converted to oxygenates by hydrolysis or carbonylation. ${ }^{54,60,263,359}$ In this section, the above-mentioned technologies for alkyl halides conversion will be reviewed, with the emphasis on the recent advances on methyl halides transformation and the differences with respect to the MTH route. The toxicity and safe handling of halogenated compounds will also be discussed.

\subsection{Methyl Halides to Hydrocarbons}

Catalytic coupling of methyl halides to various hydrocarbon products signifies one of the most promising technologies for the upgrading of halogenated methane. Zeolite materials hold utmost importance in these transformations. In the sections below, the major factors influencing the catalytic performance and the proposed reaction mechanisms of respective zeolites will be discussed.

4.1.1. Zeolite Catalysts. Catalytic conversion of methyl halides to higher hydrocarbons via coupling over different zeolites has been extensively studied. The performance with respect to activity, product distribution, catalyst lifetime, and coke deposition is closely associated with the properties of a catalyst, of which the topology and acidity have been revealed to be highly relevant. However, it should be stressed that for zeolites with different compositions, the influence of topology and acidity are interconnected which makes it even difficult to determine the specific role of each factor. In addition, the feed impurities as well as reaction conditions exert an impact on the catalyst performance. 


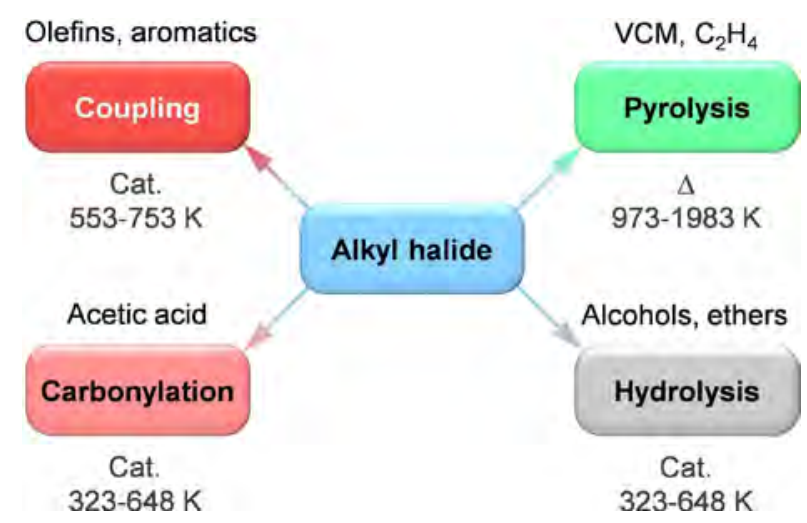

Figure 44. Investigated routes for alkyl halide conversion to several classes of chemicals through coupling (red), pyrolysis (green), carbonylation (pink), and hydrolysis (grey) processes. Target products (top) and conditions (bottom) are mentioned for each process.

Impact of Topology. The topology impact of various protonic zeolites on the methyl chloride coupling reaction have been studied by different groups, regardless of the potential influence of different acidity arising from the coordination and Si/Al ratio. ${ }^{362-364}$ Juamain and Su compared the catalytic performance of Y, Beta, and ZSM-5 catalysts, and revealed that the pore size of the zeolites was decisive to the reaction. ${ }^{364}$ While large pore zeolites (Y and Beta) showed appreciable conversions, carbonaceous deposits were severe due to the relatively large cages or channels of zeolites. ZSM-5 with medium pore size, on the other hand, demonstrated high $\mathrm{CH}_{3} \mathrm{Cl}$ conversion rate and more distinctively prolonged stability with strong reduction in coke formation. These findings agree with the study by Liu et al. who reported a more general comparison of the performance for the chloromethane conversion over 8 different types of zeolites. ${ }^{363}$ They concluded that gasoline-rich products predominated over silica-alumina zeolites while SAPOs molecular sieves showed higher selectivity to light olefins, especially for the SAPO-34 upon which the total selectivity of $\mathrm{C}_{2} \mathrm{H}_{4}$ plus $\mathrm{C}_{3} \mathrm{H}_{6}$ exceeded 56\% (Table 7). Generally, the apparent differences in the selectivity and coke deposition of different zeolites can be partly interpreted by steric effect of cavities. As is well known that the coupling reaction intermediates can be formed and even captured in these motifs which might serve as the precursors to the releasing products or coke. For instance, Shen et al. demonstrated that at the initial stage of the reaction long chain alkanes were the main carbon species trapped in ZSM-22 while polymethylated benzenes and 
Table 7. Catalytic Performance of Various Protonic Zeolites for Methyl Chloride-to-Hydrocarbons Conversion $^{a}$

\begin{tabular}{|c|c|c|c|c|c|c|c|c|c|}
\hline Zeolite & & $\mathrm{H}-\mathrm{Y}$ & H-Beta & H-ZSM-5 & H-MCM-22 & $\begin{array}{c}\text { H-ZSM- } \\
35\end{array}$ & $\begin{array}{c}\text { H-ZSM- } \\
34\end{array}$ & $\begin{array}{c}\text { H- } \\
\text { SAPO-5 }\end{array}$ & $\begin{array}{c}\text { H-SAPO- } \\
34\end{array}$ \\
\hline$T / \mathrm{K}$ & & 673 & 673 & 673 & 673 & 673 & 673 & 723 & 723 \\
\hline$X / \%$ & & 44.8 & 50.6 & 99.9 & 54.3 & 45.0 & 81.4 & 20.2 & 50.6 \\
\hline \multicolumn{10}{|l|}{$S / \%$} \\
\hline $\mathrm{CH}_{4}$ & & 1.5 & 4.7 & 0.7 & 1.9 & 0.6 & 2.1 & 3.2 & 1.9 \\
\hline $\mathrm{C}_{2} \mathrm{H}_{4}$ & & 13.2 & 7.0 & 1.5 & 4.5 & 12.1 & 7.6 & 9.1 & 24.7 \\
\hline $\mathrm{C}_{2} \mathrm{H}_{6}$ & & 0.4 & 1.7 & 0.7 & 1.0 & 0.2 & 1.2 & 0.2 & 0.4 \\
\hline $\mathrm{C}_{3} \mathrm{H}_{6}$ & & 3.5 & 0.7 & 1.7 & 1.3 & 14.1 & 5.5 & 31.5 & 31.4 \\
\hline $\mathrm{C}_{3} \mathrm{H}_{8}$ & & 9.2 & 40.6 & 24.8 & 25.3 & 3.5 & 56.1 & 3.7 & 4.1 \\
\hline $\mathrm{C}_{4} \mathrm{H}_{8}$ & & 0.9 & 0.0 & 0.9 & 0.5 & 19.2 & 2.8 & 14.0 & 15.1 \\
\hline $\mathrm{C}_{4} \mathrm{H}_{10}$ & & 25.3 & 34.2 & 19.4 & 36.2 & 4.8 & 14.8 & 6.5 & 0.6 \\
\hline $\mathrm{C}_{5+}{ }^{b}$ & & 25.0 & 11.2 & 23.9 & 17.5 & 32.8 & 8.3 & 30.7 & 21.6 \\
\hline $\mathrm{C}_{6} \mathrm{H}_{6}$ & & - & - & 2.3 & - & 1.9 & - & 0.3 & 0.3 \\
\hline $\mathrm{C}_{7} \mathrm{H}_{8}$ & & 19.7 & - & 9.5 & 11.8 & 8.7 & 0.2 & 0.4 & - \\
\hline $\mathrm{C}_{8} \mathrm{H}_{10}$ & & 1.2 & - & 14.5 & 1.0 & 2.1 & 1.1 & 0.6 & - \\
\hline $\begin{array}{l}\text { Coke } \\
\text { wt.\% }\end{array}$ & & 10.5 & 8.8 & 1.6 & 7.3 & 4.0 & 10.0 & 0.6 & 3.3 \\
\hline
\end{tabular}

${ }^{a}$ Conditions: WHSV $\left(\mathrm{CH}_{3} \mathrm{Cl}\right)=3.17 \mathrm{~h}^{-1}, p\left(\mathrm{CH}_{3} \mathrm{Cl}\right)=0.5$ bar. ${ }^{b} \mathrm{BTX}$ (a mixture of benzene, toluene, and the three xylene isomers) not included. Reproduced with permission from ref 363. Copyright 2006 Springer.

methylnaphthalene overwhelmed in SAPO-34. ${ }^{362}$ This is interpreted by the bigger interior diameter of the CHA cage in SAPO-34 $(c a .12 .7 \times 0.94 \mathrm{~nm})$ than in ZSM-22 $(0.46 \times 0.57 \mathrm{~nm})$. Experimental results revealed that SAPO-34 surpassed ZSM-22 with a higher activity and total selectivity to light olefins, but was more prone to coking under equivalent conditions. However, it is difficult to draw any conclusion about the effect of topology at this stage since the influence of other factors has not been excluded. Building the correlation between the zeolite topology structure and the performance (especially 
selectivity and coking), though challenging, will be an important step toward rational catalyst design in this field.

Impact of Acidity. Zeolitic materials are rich in acid chemistry which in turn could exert a great impact on the catalytic performance. Both Brønsted and Lewis acid sites can act as the active centers in $\mathrm{CH}_{3} \mathrm{X}$ coupling. Thus, the manipulation of the acidity of zeolites has been used as one of the most effective methods to improve the catalyst performance.

Si/Al Ratio. The acid properties (types, strength, and total amount) can be well tuned by varying the $\mathrm{Si} / \mathrm{Al}$ ratio during the synthesis with intended feeding or occasionally by dealuminization or desilication with the introduction of different anions. It has been revealed that increase in the $\mathrm{Si} / \mathrm{Al}$ ratio in $\mathrm{H}-\mathrm{ZSM}$ 5 and Mg-ZSM-5 leads to decrease in the total acidity, as measured by NH3-TPD (Figures 45a-c). ${ }^{355,365}$ The number of weak acid sites apparently decreased with the decreasing acidity, as revealed by deconvolution of the desorption profiles. ${ }^{365}$ Pyridine FTIR further demonstrated the decreasing Brønsted/Lewis site ratio with increasing Si/Al ratio in protonic zeolite. ${ }^{355}$ Consequently, the catalyst performance in $\mathrm{CH}_{3} \mathrm{Cl}$ coupling showed decreased activity with the increase in $\mathrm{Si} / \mathrm{Al}$ ratio, whereas the selectivity to light olefins (especially propene) was enhanced (Figure 45e). ${ }^{355,366}$ However, Mg-ZSM-5 with a high $\mathrm{Si} / \mathrm{Al}$ ratio of 360 showed superior stability in $\mathrm{CH}_{3} \mathrm{Br}$ coupling reaction compared with those with low ratios (Figure 45d). Anions modification of ZSM-5 could also be used to improve the catalyst performance, especially for increasing the selectivity of light olefins. For instance, introducing P on MgZSM-5 led to an increased $\mathrm{C}_{3} \mathrm{H}_{6}$ selectivity (60\% versus $\left.50 \%\right)$ and improved stability. ${ }^{367}{ }^{27} \mathrm{Al}$ nuclear magnetic resonance (NMR) study indicated that the dealuminization in the zeolites framework due to the modification of $\mathrm{P}$ reduced the strong Brønsted acid sites, which should be responsible for the relatively high $\mathrm{C}_{3} \mathrm{H}_{6}$ selectivity. Recently, Wang et al. reported a fluoride-treated HZSM-5 as highly selective catalysts for $\mathrm{C}_{3} \mathrm{H}_{6}$ production. Instead of incorporation into the zeolite framework, the fluoride ions caused desilication of the zeolite (presumably defective Si). ${ }^{358}$ It was concluded that fluoride treatments led to weaker acidity and enlarged micropores $(0.73-0.78 \mathrm{~nm})$, the latter being beneficial for the formation of penta- and hexa-methylbenzenes, the presumed precursors for $\mathrm{C}_{3} \mathrm{H}_{6}$ generation in 

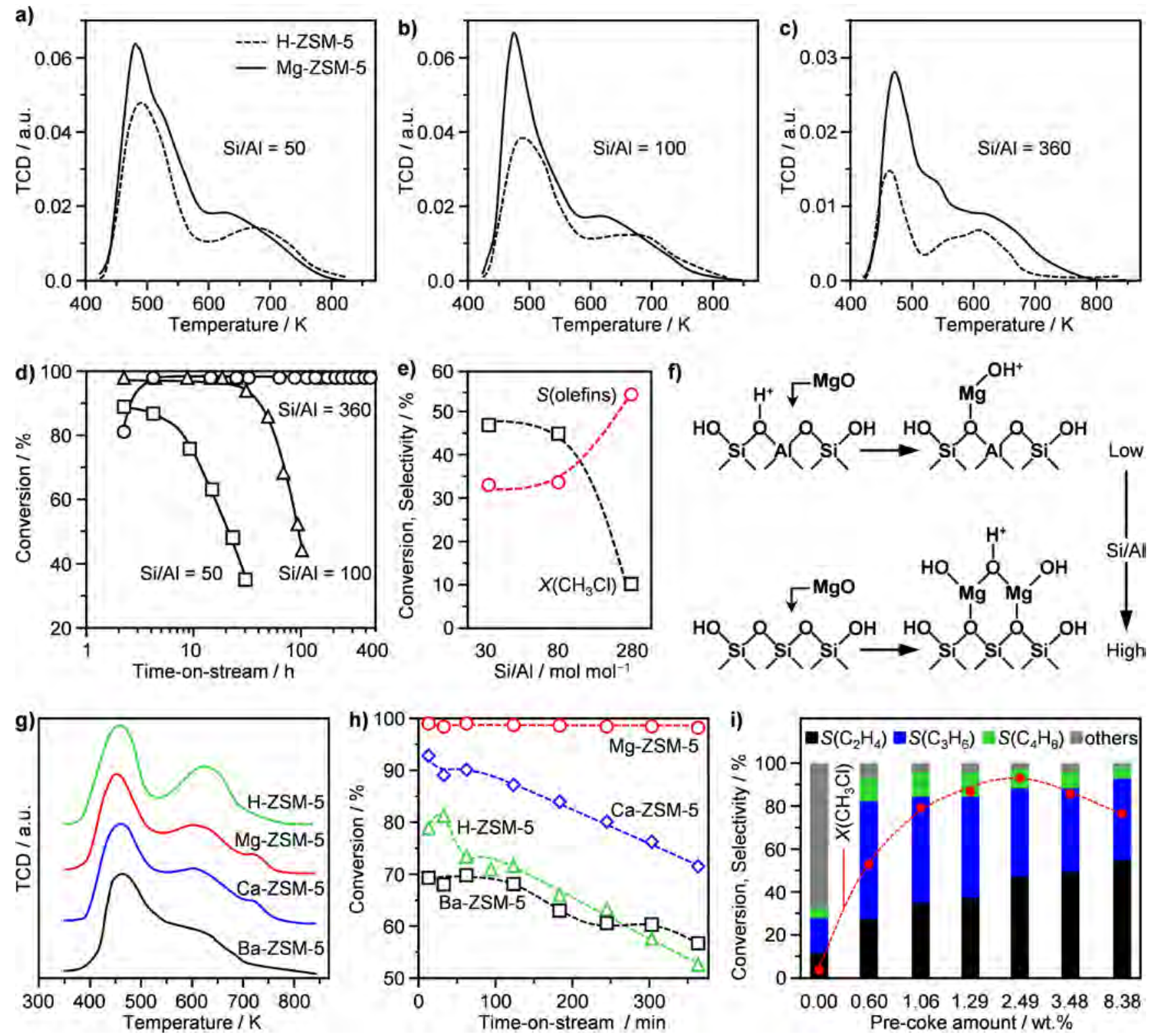

Figure 45. $\mathrm{NH}_{3}-\mathrm{TPD}$ of H-ZSM-5 and MgO impregnated ZSM-5 with $\mathrm{Si} / \mathrm{Al}$ of a) 50 , b) 100 , and c) 360. d) Conversion versus time-on-stream in $\mathrm{CH}_{3} \mathrm{Br}$ coupling over MgO impregnated ZSM-5. Conditions: $\mathrm{WHSV}\left(\mathrm{CH}_{3} \mathrm{Br}\right)=0.6 \mathrm{~h}^{-1}, T=553 \mathrm{~K}, p\left(\mathrm{CH}_{3} \mathrm{Br}\right)=0.8$ bar. f) $\mathrm{Si} / \mathrm{Al}$ dependency of $\mathrm{MgO}$ interactions with the zeolite framework. a-d and f, reproduced with permission from ref 365 . Copyright 2014 Springer. e) Conversion and selectivity versus $\mathrm{Si} / \mathrm{Al}$ ratio in $\mathrm{CH}_{3} \mathrm{Cl}$ coupling over ZSM-5. Data taken from ref 355. Conditions: space time $=5.89$ gcat h mol $\left.\left(\mathrm{CH}_{3} \mathrm{Cl}\right)^{-1}, T=623 \mathrm{~K} . \mathbf{g}\right) \mathrm{NH}_{3}-\mathrm{TPD}$ of alkali earth metal-exchanged ZSM-5 and H-ZSM-5. h) Conversion versus time-on-stream in $\mathrm{CH}_{3} \mathrm{Cl}$ coupling over alkali earth metal-exchanged ZSM-5 and H-ZSM-5. Conditions: $\mathrm{WHSV}\left(\mathrm{CH}_{3} \mathrm{Cl}\right)=3 \mathrm{~h}^{-1}$, $T=698 \mathrm{~K}, p\left(\mathrm{CH}_{3} \mathrm{Cl}\right)=0.17$ bar. Reproduced with permission from ref 361. Copyright 1991 Elsevier. i) Conversion and selectivity versus pre-coke in $\mathrm{CH}_{3} \mathrm{Cl}$ coupling over H-SAPO-34. Conditions: $T=723 \mathrm{~K}, 0.28 \mathrm{mg}\left(\mathrm{CH}_{3} \mathrm{Cl}\right) /$ pulse, $t=2.4 \mathrm{~ms}$. Adapted with permission from ref 368. Copyright 2009 The Royal Society of Chemistry. 
“hydrocarbon pool” mechanism.

Metal Cation Incorporation. Modification of H-type ZSM-5 or SAPO zeolites with mono-, di- and trivalent cations can strongly influence the catalytic performance (activity, selectivity, and lifetime) in methyl halide coupling reactions. ${ }^{357,361,369-371}$ Results from alkali metal-modified ZSM-5 showed that the reactivity decreased in the order of Li-ZSM-5 > Na-ZSM-5 > K-ZSM-5 > Cs-ZSM-5, indicating that a high Lewis acidity of the counter ion might be beneficial for the reaction. ${ }^{369}$ A comparative study between various transition and alkaline earth metal-exchanged ZSM-5 revealed that the transition metal ( $\mathrm{Mn}, \mathrm{Fe}$, and $\mathrm{Co}$ ) exchanged zeolites showed higher activity and relatively high selectivity to olefins $\left(X\left(\mathrm{CH}_{3} \mathrm{Cl}\right)>90 \%, S\right.$ (olefins) $\left.>30 \%, T=698 \mathrm{~K}\right)$, while Mg-exchanged catalyst exhibited the best stability-among the alkaline metal-exchanged catalysts, with a total conversion under the same reaction conditions (Figure 45h). ${ }^{361}$ Compared to the other catalysts, the Mg-modified zeolite showed the lowest amount of $\mathrm{C}_{9+}$ aromatics which was speculated to affect the catalyst lifetime. The influence on acidity due to the cation modification was probed with $\mathrm{NH}_{3}$-TPD (Figure 45g). Compared to H-ZSM-5, the strong acid sites featured by the desorption centered at $c a .610 \mathrm{~K}$ decreased for alkaline cation-modified zeolites, while the weak acid sites remained stable. Additional strong acid sites, likely of Lewis type, were created after the treatment. Sun et al. indicated that the incorporated $\mathrm{Mg}$ might exist as $\mathrm{Mg}^{2+}$ and/or $\mathrm{Mg}(\mathrm{OH})^{+}$, serving as new active sites for $\mathrm{CH}_{3} \mathrm{Cl}$ conversion. ${ }^{367}$ Zhou et al. further proposed that the interactions between $\mathrm{Mg}^{2+}$ and the zeolite framework might be dependent on the $\mathrm{Si} / \mathrm{Al}$ ratio (Figure 45f). ${ }^{365}$ Namely, $\mathrm{Mg}^{2+}$ preferentially interacted with the acidic bridging hydroxyl groups in ZSM-5 with a low Si/Al ratio, forming $\mathrm{Mg}(\mathrm{OH})^{+}$, and in high silica zeolite the acidity may come from the surface $\mathrm{OH}$ groups of $\mathrm{Mg}-\mathrm{OH}$.

Incorporation of transition or alkaline earth metals has also been used in the modification of SAPO34 catalysts. ${ }^{357,370-372}$ Liu et al. reported a general improvement in the catalyst stability and selectivity to light olefins over Mn-, Fe-, and Co-modified systems. ${ }^{357,370}$ Similar effects were also confirmed for MgSAPO-34, upon which $\mathrm{C}_{2} \mathrm{H}_{4}$ and $\mathrm{C}_{3} \mathrm{H}_{6}$ was the main products (a total selectivity of $c a$. $80 \%$ ). ${ }^{371}$ It was concluded that the doping of molecular sieve with these cations can facilitate the formation of Si 
islands, decreasing the acidity on one hand, and slowing down hydrogen transfer reaction on the other hand, both of which contribute to the improved catalytic performance.

Impact of Feed Impurities. The methane (oxy)halogenation reactions produce appreciable amount of over-halogenated byproducts, especially the di-halogenated compounds. From the viewpoint of an industrial process from methane to hydrocarbons, it is of interest to elucidate the possibility of cofeeding the byproducts into a coupling reactor. This can greatly simplify the process by eliminating the tedious separation and purification of halogenated compounds. Theoretically, the addition of higher halogenated methane $(\mathrm{H}: \mathrm{C} \leq 2)$ will lead to an increasing propensity for the formation of aromatics. This is understandable considering that the $\mathrm{H}: \mathrm{C}$ ratio in the products is shifted below 2 when all the halogens end up as hydrogen halides. Lorkovic et al. observed a significant buildup of adsorbed carbons and aromatics over CaO/ZSM-5 when the effluent of the gas-phase bromination reaction was fed into a second cascade catalyst bed. ${ }^{278}$ It was hypothesized that the adsorbed carbons were formed predominantly by $\mathrm{CH}_{2} \mathrm{Br}_{2}$ condensation while cross coupling between $\mathrm{CH}_{3} \mathrm{Br}$ and $\mathrm{CH}_{2} \mathrm{Br}_{2}$ led to higher selectivity of aromatics. The detrimental effect of $\mathrm{CH}_{2} \mathrm{Cl}_{2}$ on $\mathrm{CH}_{3} \mathrm{Cl}$ coupling reaction over SAPO-34 crystals has been reported by Olsbye et al. ${ }^{373}$ Like in the case of bromomethanes coupling reactions, the addition of $\mathrm{CH}_{2} \mathrm{Cl}_{2}$ promoted the formation of aromatics and caused rapid catalyst deactivation due to coke deposition. Isotopic labeling experiments showed that $\mathrm{CH}_{2} \mathrm{Cl}_{2}$ can be incorporated into methylbenzene reaction intermediates and form the gas phase products via the hydrocarbon pool mechanism. These results suggest that separation of (oxy)halogenation products is indispensable for the zeolite-based upgrading route.

Impact of Coke. Coke deposition over zeolites is commonly observed in the coupling of methyl halides. It is generally acknowledged that heavy coking will affect mass transfer by blocking the pores or poison the active sites, thus is responsible for catalyst deactivation. However, the intrinsic impact of coking might be more complex considering the facts: (i) there is an induction period when activity buildup and product variation are observed with fast coke deposition, ${ }^{355,360}$ and (ii) stable catalyst performance of several to hundreds of hours have been reported for zeolites with heavy coke 
depositions. ${ }^{355,365}$ A study of $\mathrm{CH}_{3} \mathrm{Cl}$ coupling by pulse experiments on pre-coked SAPO-34 zeolites revealed that the fresh catalyst was least active and selective, and the best performed catalyst seemed to have a maximal coke amount of 2.49 wt.\% (Figure 45i). ${ }^{368}$ Analyzing the trapped carbonaceous species in the zeolites points to the accumulation of multi-methyl substituted benzene and naphthalene with highly coking catalysts, in line with the steady-state results. ${ }^{365,368}$ As proposed by different research groups, both gaseous products and cokes are formed from these trapped species. ${ }^{360,368,373}$ In this sense, a highly active catalyst could be unfortunately most prone to deactivation. As a matter of fact, the commercial methanol-to-olefins (MTO) reactions are conducted over catalysts with an optimal operation window of coke content of $c a .8 \% .{ }^{374}$ Therefore, instead of avoiding the coke deposition on zeolites, much effort on methyl halide coupling should be directed on process and operational aspects such as fluidized-bed reactor technologies and continuous catalyst regeneration.

Methyl Halides versus Methanol. Methyl halide has a similar chemical structure as methanol. Results from coupling reactions of these methylating agents demonstrated similar reaction patterns in terms of product distribution (Figure 46). ${ }^{60,354,359}$ However, the different functional groups bring diversities in terms of reactivity, nature of the leaving group, and toxicity. All these aspects have to be considered at the microlevel (catalyst design), mesolevel (reactor modeling), and macrolevel (process considerations). As shown in Table 8 , cleaving a $\mathrm{C}-\mathrm{X}(\mathrm{X}=\mathrm{Cl}$ or $\mathrm{Br})$ bond is thermodynamically more favorable than in the case of $\mathrm{C}-\mathrm{OH}$, reflecting the higher stability of the leaving group. However, Olsbye et al. found that the reactivity of these chemical species over H-SAPO-34 to follow quite an opposite trend with methanol being the most reactive and methyl bromide the least, in agreement with previous studies (Figure 46). ${ }^{354}$ They claim that this is due to the lower proton affinity of the methyl halide molecules with respect to methanol $\left(647 \mathrm{~kJ} \mathrm{~mol}^{-1}\right.$ for $\mathrm{CH}_{3} \mathrm{Cl}$ versus $754 \mathrm{~kJ} \mathrm{~mol}^{-1}$ for $\left.\mathrm{CH}_{3} \mathrm{OH}\right)$, leading to a lower coverage of the active sites. ${ }^{356}$ In addition, the presence of $\mathrm{HX}$ represents a net difference with respect to the MTH process, where water is the main byproduct. The alteration of the catalyst structure has been observed in different zeolite materials exposed to $\mathrm{HCl}$. During methyl chloride conversion over H-SAPO-34, Su et al. confirmed that $\mathrm{HCl}$ can strongly interact with the 


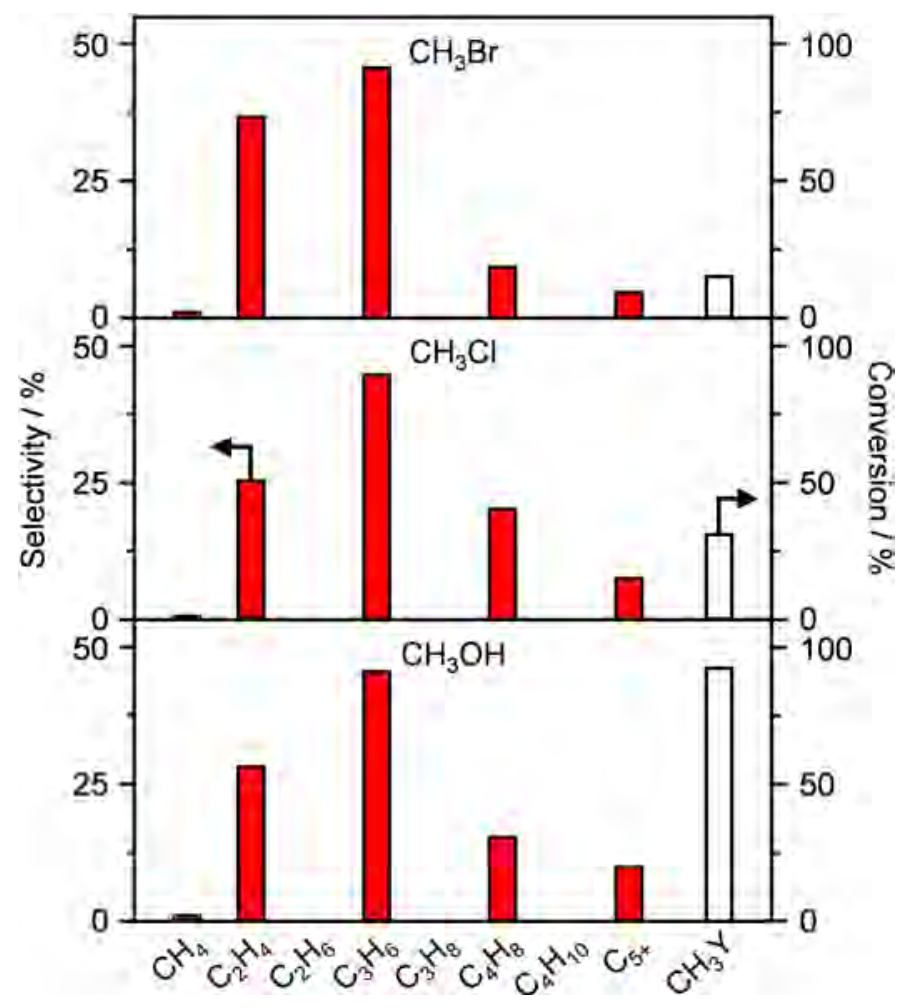

Figure 46. Product selectivity for methanol and methyl halides $\left(\mathrm{CH}_{3} \mathrm{Y}, \mathrm{Y}=\mathrm{OH}, \mathrm{Cl}, \mathrm{Br}\right)$ conversion over H-SAPO-34. Conditions: $F=100 \mathrm{~cm}^{3} \mathrm{STP} \min ^{-1}, T=623 \mathrm{~K}, p\left(\mathrm{CH}_{3} \mathrm{Y}\right)=0.1$ bar. Data taken from ref 354. Copyright 2006 Elsevier.

Table 8. Bond Length and Energies for Methane, Methanol, and Methyl Halides

\begin{tabular}{lcc}
\hline bond & length / pm & energy / kJ mol \\
\hline $\mathrm{C}-\mathrm{H}$ & 109 & 440 \\
$\mathrm{C}-\mathrm{OH}$ & 142 & 381 \\
$\mathrm{C}-\mathrm{Cl}$ & 178 & 355 \\
$\mathrm{C}-\mathrm{Br}$ & 193 & 309 \\
\hline
\end{tabular}

catalyst and cause the reversible rupture of $\mathrm{Si}-\mathrm{O}-\mathrm{Al}$ and $\mathrm{Al}-\mathrm{O}-\mathrm{P}$ bonds. ${ }^{357}$ Castaño et al. studied methyl chloride conversion over H-ZSM-5, and concluded that the presence of $\mathrm{HCl}$ in the reaction medium led to the irreversible dealumination of the zeolite and the formation of extra-framework $\mathrm{AlCl}_{3 .}{ }^{360}$ Lersch and Bandermann demonstrated that $\mathrm{Fe}$ and $\mathrm{Cu}$ exchanged ZSM-5 suffered from leaching due to the formation of volatile metal (oxy)chlorides. ${ }^{361}$ The above examples ambiguously point to the different chemistry involved between the transformations of methanol and methyl halides. 
Undoubtedly, the presence of halides in the upgrading technologies poses new challenges regarding catalyst, reactor, and process design.

4.1.2. Reaction Mechanism. The reaction mechanism of methyl halides/methanol coupling over zeolites has not been well-understood. ${ }^{68,375}$ Based on the analogous molecular structures between methyl halides and $\mathrm{CH}_{3} \mathrm{OH}$, and similar reaction patterns (especially the product distribution), the general reaction steps for the coupling of methyl halides were suggested to follow the same route as that of $\mathrm{CH}_{3} \mathrm{OH}$ conversion. ${ }^{367,376,377}$ Light olefins are suggested to be the primary products that underdo oligomerization to form higher alkenes. Further steps by hydrogen transfer or cracking lead to a spectrum of products such as parafins, olefins, and aromatics. Of particular importance in these steps is the formation of the first $\mathrm{C}-\mathrm{C}$ bond, for which various mechanisms have been proposed, such as carbene, carbocationic, free radical, hydrocarbon pool, and oxonium ylide. ${ }^{357,367,377-380}$ Nevertheless, considering the different leaving groups between methyl halide and $\mathrm{CH}_{3} \mathrm{OH}$, some of the developed reaction mechanism involving the formation of methoxy functionalities might not be directly applicable to the transformation of methyl halides.

Mechanistic study on methyl halide coupling is mainly centered at $\mathrm{CH}_{3} \mathrm{Cl}$ and different reaction mechanisms have been proposed with the aids of in situ NMR or FTIR techniques. The first C-C linking via an alkoxy-ylide route (Figure 47a) has been proposed by Haw et al. based on the NMR study of Cs-X. ${ }^{377}$ In this mechanism, a framework-bound methoxy intermediate was formed by the nucleophilic attack of Brønsted acid sites in the first step. The methoxy species were assumed to be sufficiently acidic to deprotonation, forming a sort of ylide stabilized by the framework. After methylation with a second methyl halide molecule, framework-bound ethoxy intermediates were formed. An elimination step of a $\mathrm{C}_{2} \mathrm{H}_{4}$ molecule from ethoxy groups would regenerate the Brønsted acid sites. Cserényi et al. studied the adsorption of $\mathrm{CH}_{3} \mathrm{Cl}$ on ZSM-5 and $\mathrm{Mo}_{2} \mathrm{C} / \mathrm{ZSM}-5$ by temperatureprogrammed desorption and FTIR techniques and came up with a carbene route. ${ }^{380}$ In this mechanism, they proposed that carbene species can be released from and inserted into the surface-bound methoxy groups to initiate the carbon chain propagation. These reaction mechanisms do not specify the role of a 
metal cation, but they are at least partially supported by the fact that the framework-bound methoxy species have been frequently detected on the zeolites saturated with $\mathrm{CH}_{3} \mathrm{Cl}^{369,380}$

As it has been discussed above, the reactivity of methyl halide coupling can be strongly influenced by the modification with different metal cations. This indicates that the dopants should participate in the activation of the reactants. Elaboration of the previous alkoxy-ylide route with the explicit roles of metal cations in the key steps of hydrocarbon synthesis is presented in Figure $47 \mathrm{~b} .^{381}$ In the first step, $\mathrm{CH}_{3} \mathrm{X}$ was activated by Lewis acid sites of a metal cation, forming a framework-bound methoxy species. Instead of releasing free carbene species, a negatively charged $\mathrm{CH}_{2}$ species was generated by the deprotonation of methoxy groups and stabilized by the framework and metal cation ions. The first C-C linkage was completed by the attack of $\mathrm{CH}_{3} \mathrm{X}$ on the framework-bound $\mathrm{CH}_{2}$ species (variously described as a stabilized carbene or carbanion). According to the mechanism, species derived from the cations act both as a Lewis acid in the elimination of the halide leaving groups and as a base in the formation of stabilized carbene species. The Lewis acidity of metal cations is generally accepted to play a role in $\mathrm{CH}_{3} \mathrm{X}$ coupling. However, there is no evidence demonstrating the formation of frameworkbound species. Therefore, the initial carbon chain growth step is highly controversial. Sun et al. argued that the first $\mathrm{C}-\mathrm{C}$ bond was derived from the addition of carbene species to a surface methoxy group, ${ }^{367}$ while Jaumain and Su debated that a carbene transfer between neighboring methoxy groups might be responsible for the first $\mathrm{C}-\mathrm{C}$ linkage. ${ }^{364,369}$

“Hydrocarbon pool” concept was initially proposed to explain the phenomenon observed in the MTO reaction where the other reaction mechanisms failed to elucidate the chain growth of products. ${ }^{382}$ The hydrocarbon pool can be described as a catalytic scaffold, constituted by large organics adsorbed in the zeolite, to which methanol is added and olefins are eliminated in a closed catalytic cycle. ${ }^{383}$ Liu et al. suggested that the transformation of $\mathrm{CH}_{3} \mathrm{Cl}$ to hydrocarbons upon SAPO-34 crystals followed this pattern. ${ }^{357,384}$ Based on in situ infrared spectroscopic studies, four different surface adsorbed species, as shown in Figure 47c, have been identified. A surface-bound ethoxy group (adsorption III) was suggested to be formed by the interactions between adsorbed $\mathrm{HCl}$ (adsorption II) and 
a)

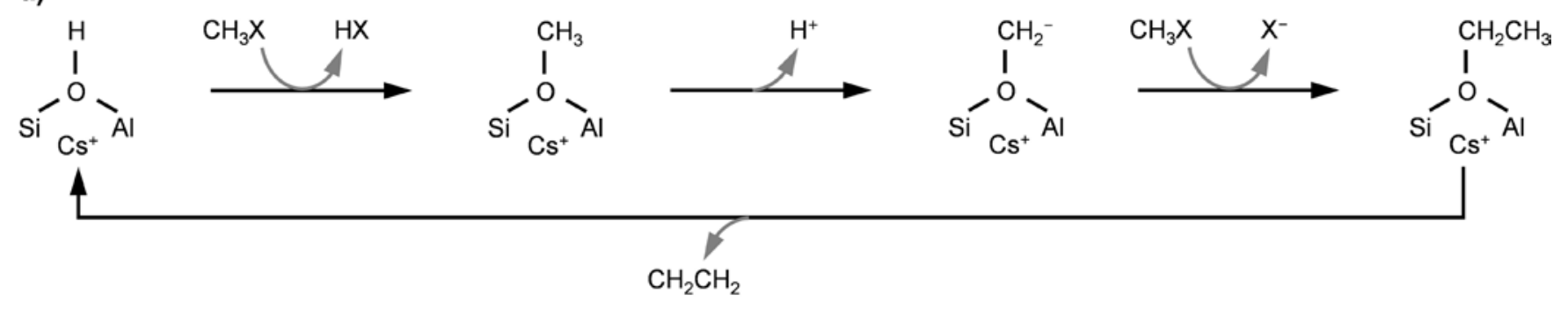

b)

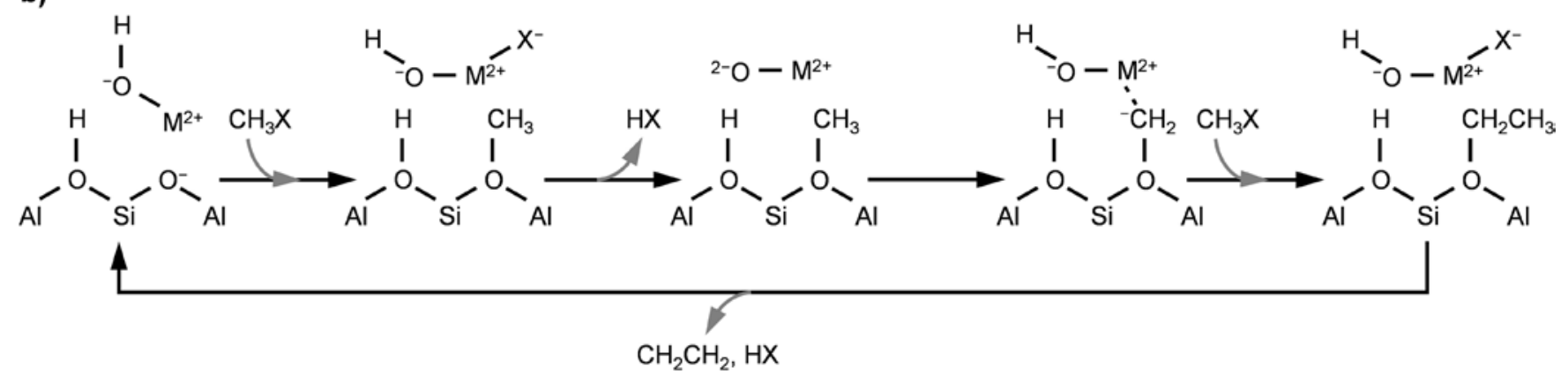

c)

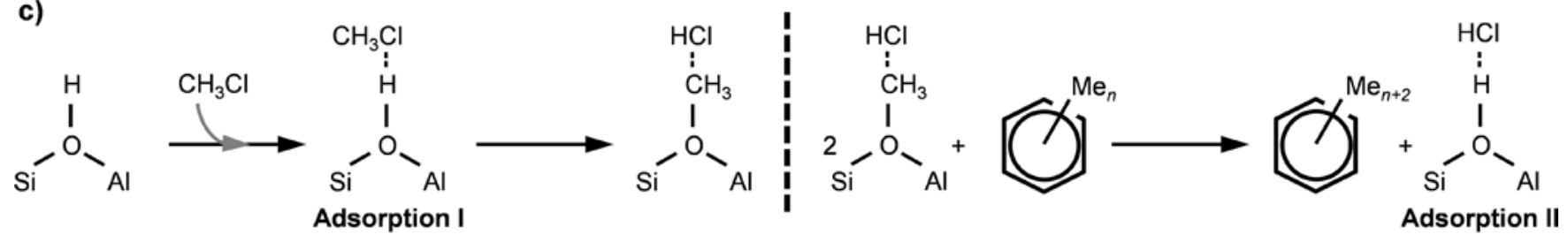

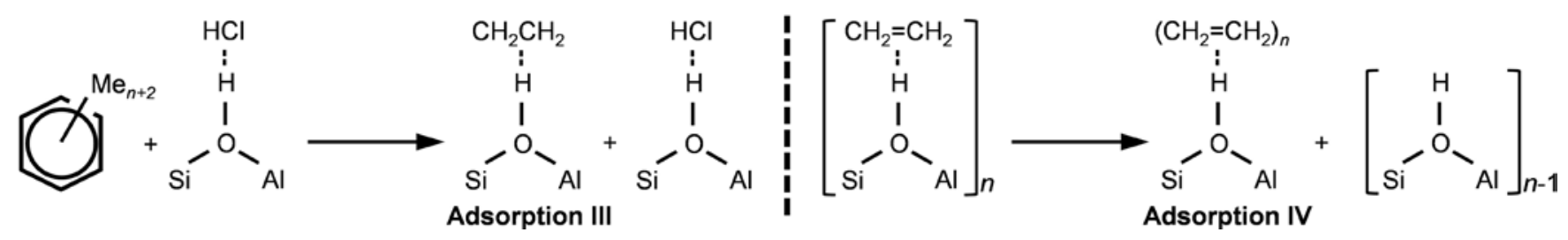

Figure 47. Schematic representation of the methyl halides coupling mechanism over different zeolite catalysts. Alkoxy-ylide routes over cation modified zeolites, emphasizing the crucial role of frameworkbound alkoxy species during $\mathrm{C}-\mathrm{C}$ bond formation: a) $\mathrm{Cs}-\mathrm{X}$, without the specific role of cations, and b) X, Y, and ZSM-5 zeolites, with the explicit role of metal in the key steps of olefin synthesis. Adapted with permissions from refs 377,381. Copyright 1993 and 1994 American Chemical Society. c) "Hydrocarbon pool” mechanism and four possible adsorption sites over SAPO-34 molecular sieves. Polymethylbenzenes are formed during the reaction and confined in the small cavity of the zeolites. The formation of the first $\mathrm{C}-\mathrm{C}$ bond is believed to be related to these aromatics. $\mathrm{X}=\mathrm{Cl}, \mathrm{Br}$, and I. Adapted with permission from ref 357. Copyright 2006 Elsevier.

polymethylbenzenes in the cage, albeit how the migration occurs is rather unclear. In addition, surfacebound polymerized alkene species (adsorption IV) were detected on the zeolite with a high coverage of the reactant, which might be responsible for the formation of higher olefins or cokes. 


\subsection{Methyl Halides to Oxygenates}

The conversion of methyl halides to oxygenates offers another attractive route for methyl halide upgrading. It is of interest because the aimed-products are of high values and can be easily transported. The major transformation technologies are based on catalyzed hydrolysis or carbonylation reactions.

4.2.1. Hydrolysis. Methyl halides can be further converted to valuable oxygenates such as methanol and dimethyl ether by hydrolysis. Olah et al. first reported the catalytic hydrolysis of methyl chloride/bromide with steam in a continuous flow reactor over $\gamma-\mathrm{Al}_{2} \mathrm{O}_{3}$. Methanol and dimethyl ether were the only products at $13-23 \%$ conversions at $648 \mathrm{~K} .{ }^{54,263}$ An effort was made to improve catalyst activity by modifying $\gamma-\mathrm{Al}_{2} \mathrm{O}_{3}$ with different metal oxides and metal hydroxides. Only moderate effect was observed, with the highest conversion of $25 \%$ obtained upon $\mathrm{ZnO} / \mathrm{Al}(\mathrm{OH})_{3} / \gamma-\mathrm{Al}_{2} \mathrm{O}_{3} .{ }^{263}$ In addition, catalyst deactivation and leaching of metal components occurred in the course of the reaction because of the formation of metal halides on the catalyst surface. More efficient catalysts have been discovered in the last decade, operating in a batch reactor. ${ }^{59,385,386}$ Zhou et al. reported the hydrolysis of $\mathrm{CH}_{3} \mathrm{Br}$ to methanol and DME over a homogeneous $\mathrm{RuCl}_{3}$ catalyst $\left(X\left(\mathrm{CH}_{3} \mathrm{Br}\right)=66-98 \%, 423-453 \mathrm{~K}\right) .{ }^{59}$ Increasing reaction time favors DME yield arising from the dehydration of methanol. Disadvantageously, water was used as the solvent in this reaction and thus the separation of the catalyst from reaction products could be problematic. An even more robust heterogeneous catalyst, poly(4-vinylpyridine) (PVP), was shown to catalyze the hydrolysis of $\mathrm{CH}_{3} \mathrm{Br}$ to a mixture of $\mathrm{CH}_{3} \mathrm{OH}$ and $\mathrm{DME}$ at low temperatures of 323-398 $\mathrm{K}\left(X\left(\mathrm{CH}_{3} \mathrm{Br}\right)=52-89 \%\right)$, using water as the solvent. ${ }^{385}$ Notably, the catalyst can be easily separated, and recycled after simply washing with dichloromethane and water. No obvious drop in catalyst performance was observed in five consecutive cycles. Furthermore, when replacing the water solvent with $\mathrm{CH}_{3} \mathrm{OH}$, DME was the only hydrolysis product $\left(X\left(\mathrm{CH}_{3} \mathrm{Br}\right)=24-35 \%, T=373-398 \mathrm{~K}\right){ }^{386}$

4.2.2. Carbonylation. Carbonylation of methyl halides with $\mathrm{CO}$ over $\mathrm{RhCl}_{3}$-based homogeneous catalysts produces acetyl halides that can readily undergo hydrolysis in the presence of water, leading to the formation of acetic acid exclusively. ${ }^{60,359}$ Zhou et al. studied the carbonylation of $\mathrm{CH}_{3} \mathrm{Br}$ to acetic acid over $\mathrm{RhCl}_{3}-\mathrm{PPh}_{3}-\mathrm{KI}\left(\mathrm{PPh}_{3}\right.$, triphenylphosphine) catalysts (yield $>99 \%, T=423 \mathrm{~K}, P=26$ bar), 
well known for the homogeneous methanol carbonylation reaction. ${ }^{60}$ Using the same catalyst recipe, Bao et al. confirmed the feasibility of $\mathrm{CH}_{3} \mathrm{Cl}$ carbonylation to acetic acid under similar conditions. ${ }^{359}$ The role of promoters is crucial for these reactions, and the highest activity was only obtained in the presence of co-catalysts $\mathrm{PPh}_{3}$ and KI. These observations are in line with the findings in $\mathrm{Rh}$-catalyzed methanol carbonylation, revealing that the rate-determining step in the carbonylation cycle is the oxidative addition of $\mathrm{CH}_{3} \mathrm{I}$ to $\left[\mathrm{Rh}(\mathrm{CO})_{2} \mathrm{I}_{2}\right]^{-1}$ to a rhodium-methyl complex which can be accelerated by increasing the electron density at the Rh center by coordination of phosphine ligands. ${ }^{387}$ Likewise, it is reasonable to speculate that the carbonylation of methyl halides over Rh catalysts followed a similar mechanism with the methanol carbonylation reaction. However, $\mathrm{CH}_{3} \mathrm{Br}$ showed much superior carbonylation reactivity to $\mathrm{CH}_{3} \mathrm{Cl}$ (TOF of $1.1 \times 10^{-3} \mathrm{~s}^{-1}$ for $\mathrm{CH}_{3} \mathrm{Cl}$ and $12.7 \times 10^{-3} \mathrm{~s}^{-1}$ for $\mathrm{CH}_{3} \mathrm{Br}$ ), ${ }^{60,359}$ which can be explained by the difference of $\mathrm{C}-\mathrm{X}$ bond energy in $\mathrm{CH}_{3} \mathrm{X}$ (Table 8).

\subsection{Transformation of Other Haloalkanes}

Due to the lack of selectivity, a spectrum of haloalkanes can be produced during the (oxy)halogenation of a hydrocarbon compound. Most of these side products, however, do not have a stable market. With an additional process, the alkyl halides can be transformed into value-added commodities.

4.3.1. Polyhalomethanes. Polyhalomethanes are formed in a substantial amount in methane halogenation reactions. It is of interest to develop new catalysts and routes to further convert them into useful chemicals. A novel process was discovered by Stauffer for the direct production of VCM via coactivation of $\mathrm{CH}_{3} \mathrm{Cl}$ and $\mathrm{CH}_{2} \mathrm{Cl}_{2}$ (Eq. 20). ${ }^{173}$ This endothermic reaction is thermodynamically favorable and essentially goes to completion at relevant temperatures (573-773 K) over a catalyst such as $\mathrm{ZnCl}_{2}$ supported on alumina or zeolites. More recently, Rabiu and Yusuf conceived a new process for olefinsrich hydrocarbon synthesis from di- and tri-chloromethanes over an iron-based Fisher-Tropsch catalyst, $\mathrm{Fe} / \mathrm{Al}_{2} \mathrm{O}_{3} / \mathrm{Cu}$, operating in a moving bed reactor under the industrially relevant conditions. ${ }^{388}$ However, no experimental details were disclosed regarding the activity and selectivity. Besides, the catalysts used were rather fragile in the presence of chlorine-rich environment. Phase transformation of reduced Fe 
crystallites into iron chlorides and probably $\mathrm{FeOCl}$ is inevitable and calls for an additional catalyst regeneration step.

$$
\mathrm{CH}_{3} \mathrm{Cl}+\mathrm{CH}_{2} \mathrm{Cl}_{2} \rightarrow \mathrm{C}_{2} \mathrm{H}_{3} \mathrm{Cl}+2 \mathrm{HCl} \quad \Delta H=59 \mathrm{~kJ} \mathrm{~mol}^{-1}
$$

Methylene bromide is the primary side product in the gas-phase methane bromination reaction. Several novel routes have been developed concerning the transformation of $\mathrm{CH}_{2} \mathrm{Br}_{2}$ into useful commodities. For instance, Prakash et al. demonstrated that $\mathrm{CH}_{2} \mathrm{Br}_{2}$, when hydrolyzed in the presence of methanol, can be efficiently and selectively converted to dimethoxymethane (DMM), over a basic solid catalyst, poly(4-vinylpyridine), under mild conditions $\left(X\left(\mathrm{CH}_{2} \mathrm{Br}_{2}\right)=58 \%, S(\mathrm{DMM})=100 \%\right.$, $398 \mathrm{~K}){ }^{386}$ Stucky et al. reported several catalytic systems for the hydrodebromination and oligomerization of $\mathrm{CH}_{2} \mathrm{Br}_{2} .{ }^{389}$ Among the catalysts screened, $\mathrm{Pd}_{6} \mathrm{C} / \mathrm{SiO}_{2}$ showed a high selectivity for the conversion of $\mathrm{CH}_{2} \mathrm{Br}_{2}$ to higher hydrocarbons rich in light olefins, and $\mathrm{Ru} / \mathrm{SiO}_{2}$ gave the highest selectivity to $\mathrm{CH}_{3} \mathrm{Br}$ (Figures 48a-c). Besides, co-feeding of $\mathrm{HBr}$ with $\mathrm{CH}_{2} \mathrm{Br}_{2} / \mathrm{H}_{2}$ over Ru-based catalysts showed promotional effect on the enhanced selectivity of $\mathrm{CH}_{3} \mathrm{Br}$ (96\%), whereas $\mathrm{CH}_{4}, \mathrm{C}_{2+}$, and coke formations were all suppressed. Thus, this can be a promising step to consume the $\mathrm{CH}_{2} \mathrm{Br}_{2}$ produced in methane bromination routes. Another method was demonstrated by the same authors via an iodine-catalyzed gas phase reaction between propane and $\mathrm{CH}_{2} \mathrm{Br}_{2}$ in the presence of a substantial amount of $\mathrm{HBr}$ to produce $\mathrm{C}_{3} \mathrm{H}_{6}$ and $\mathrm{CH}_{3} \mathrm{Br} .{ }^{390}$ By optimizing the reaction parameters, a high singlepass yield of " $\mathrm{C}_{3} \mathrm{H}_{6}+\mathrm{C}_{3} \mathrm{H}_{7} \mathrm{Br}+\mathrm{C}_{3} \mathrm{H}_{7} \mathrm{I}$ " and $\mathrm{CH}_{3} \mathrm{Br}$ up to $80 \%$ and $74 \%$, respectively, was achieved simultaneously with a residence time of $16 \mathrm{~s}$ at $798 \mathrm{~K}$ (Figure 48d). It is noteworthy that the conversions of both $\mathrm{CH}_{2} \mathrm{Br}_{2}$ and $\mathrm{C}_{3} \mathrm{H}_{8}$ are highly dependent on the addition of iodine. A reaction route was proposed wherein iodine mainly abstracts bromine out of $\mathrm{CH}_{2} \mathrm{Br}_{2}$, while bromine radicals contribute to the activation of $\mathrm{C}_{3} \mathrm{H}_{8}$ in dehydrogenation (Figure 48e). Albeit the novelty and high efficiency in the coactivation of $\mathrm{CH}_{2} \mathrm{Br}_{2}$ and $\mathrm{C}_{3} \mathrm{H}_{8}$, the elemental iodine employed cannot be retained in the reactor and a recovery process might be required. 
4.3.2. Ethyl Halides. Ethyl halides are formed as the primary products in the ethane oxyhalogenation reactions, although they can be instantaneously converted to VCM or $\mathrm{C}_{2} \mathrm{H}_{4}$ at elevated temperatures (vide supra). Several novel routes have been developed regarding the further upgrading of ethyl halides. Among them, dehydrohalogenation has been found to be an effective way to prepare
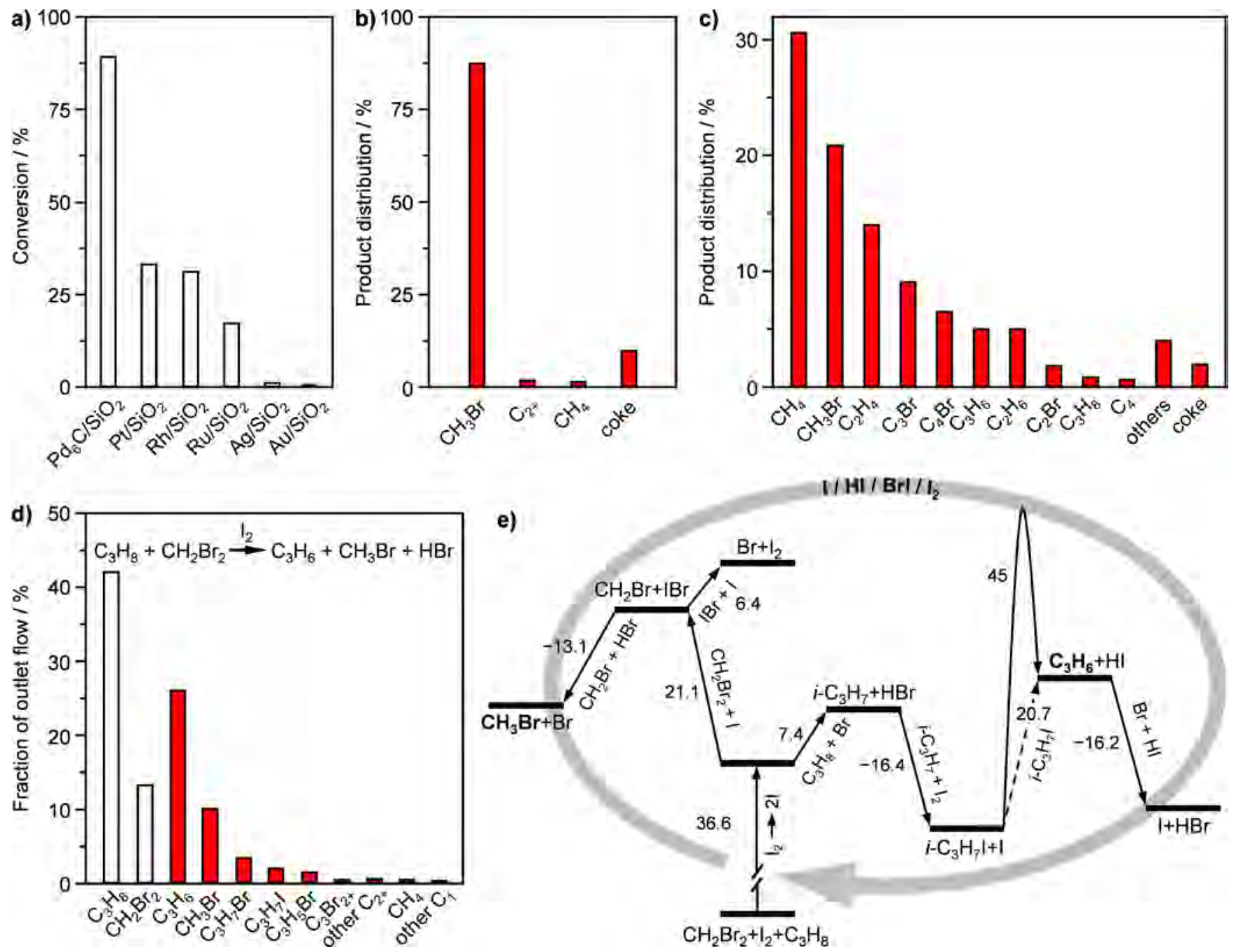

Figure 48. a) Dibromomethane conversion in hydrogenation process over several noble metal-based catalysts. Conditions: $\mathrm{CH}_{2} \mathrm{Br}_{2}: \mathrm{H}_{2}=0.5$, residence time $=2 \mathrm{~s}, T=623 \mathrm{~K}$. Product distribution of dibromomethane hydrogenation over b) $\mathrm{Ru} / \mathrm{SiO}_{2}$ and c) $\mathrm{Pd}_{6} \mathrm{C} / \mathrm{SiO}_{2}$ at comparable conditions. ${ }^{389}$ d) Conversion and selectivity for the iodine-catalyzed gas-phase propane oxidative dehydrogenation using dibromomethane as oxidizing agent. Conditions: $\mathrm{C}_{3} \mathrm{H}_{8}: \mathrm{CH}_{2} \mathrm{Br}_{2}=1, \mathrm{I}_{2}:\left(\mathrm{CH}_{2} \mathrm{Br}_{2}+\mathrm{I}_{2}\right)=0.05$, residence time $=8 \mathrm{~s}, T=773 \mathrm{~K}$. e) The proposed mechanism for this reaction is herein schematized together with energies profiles in $\mathrm{kcal} \mathrm{mol}^{-1}$. The activation of dibromomethane and propane are highlighted towards $\mathrm{CH}_{3} \mathrm{Br}$ and $\mathrm{C}_{3} \mathrm{H}_{6}$ (both in bold). ${ }^{390}$ Adapted with permissions from refs 389,390. Copyright 2012 American Chemical Society. 
ethylene. For instance, dehydrochlorination of ethyl chloride over a sulfated fiber glass-supported platinum catalyst $\left(0.02 \% \mathrm{Pt}-\mathrm{SO}_{4} / \mathrm{Zr}-\mathrm{Si}\right)$ showed a $\mathrm{C}_{2} \mathrm{H}_{4}$ selectivity of $94 \%$ at a $\mathrm{C}_{2} \mathrm{H}_{5} \mathrm{Cl}$ conversion of $25 \%$ at $723 \mathrm{~K}^{188}$ Dehydrobromination of ethyl bromide can occur even more readily. The $12 \% \mathrm{ZnO}_{2}$ $\mathrm{SiO}_{2}$ catalyst prepared by the sol-gel method showed $70-100 \%$ conversion, with ethylene as the only product at $473-573 \mathrm{~K} .{ }^{62}$ Alternatively, hydrolysis can be applied to the transformation of ethyl bromide into oxygenates. In an integrated process for ethane bromination, McFarland et al. directed the bromination effluents comprising mainly of ethyl bromide together with dibromoethane into different mixed metal oxide catalysts. ${ }^{57}$ Valuable products such as ethanol and diethyl ether with a total selectivity of $65 \%$ were obtained over a $\mathrm{Co}_{3} \mathrm{O}_{4}-\mathrm{Sm}_{2} \mathrm{O}_{3}-\mathrm{ZrO}_{2}$ catalyst at $473 \mathrm{~K}$.

\subsection{Toxicity and Safe Handling of Halogen-Containing Compounds}

Halogens have been extensively employed in numerous important industrial processes, such as chloroform $^{37}$ and polymer ${ }^{72}$ manufactures, and they are expected to play a bigger role in the future for the development of the modern chemical society. As it has been mentioned in previous sections, this topic is gaining increasing attention since the last decade because of the great potential for the valorization of light hydrocarbons. ${ }^{69}$ However, the R\&D in academia are still relatively skeptical likely due to the notorious reputation of halogenated chemicals and the lack of knowledge on safe handling. Thus, it is highly desirable to well understand the potential harms of related reaction intermediates/byproducts and elaborate precautions in order to maintain environmental and personnel safety. Halocarbons are diverse in their properties and the reaction intermediates differ from one reaction to another, making generalization difficult. In the sections below, a general discussion on safety issues will be presented from the aspects of corrosiveness, flammability, and toxicity. The potential harms of halogen-containing compounds of relevant interest in this review are summarized in Table 9.

4.4.1. Inorganic Halides. Hydrogen halides, both reactants and byproducts in (oxy)halogenation reactions, are among the most common chemicals encountered in halogen chemistry. They may be used as gases or aqueous solutions. In both cases they should be handled with great care. The gaseous 
Table 9. Summary of Potential Harms of Halogen-Containing Compounds

\begin{tabular}{|c|c|c|c|c|c|c|c|c|c|c|}
\hline \multirow{2}{*}{$\begin{array}{l}\text { halogenated } \\
\text { compound }\end{array}$} & \multicolumn{3}{|c|}{ main hazards } & \multicolumn{7}{|c|}{$\mathrm{GHS}_{\text {pictograms }}{ }^{c}$} \\
\hline & flammability $^{a}$ & corrosiveness & carcinogenicity $^{b}$ & 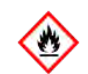 & $\Leftrightarrow$ & $\Leftrightarrow$ & 队 & $\langle!$ & 8 & 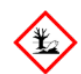 \\
\hline hydrogen chloride & none & strong & group 3 & - & yes & yes & yes & - & - & - \\
\hline hydrogen bromide & none & strong & - & - & yes & yes & - & yes & - & - \\
\hline hydrogen iodine & none & strong & - & - & yes & yes & - & - & - & - \\
\hline chlorine & none & strong & - & yes & yes & yes & yes & - & - & yes \\
\hline bromine & none & strong & - & - & - & yes & yes & - & - & yes \\
\hline iodine & none & strong & - & - & - & yes & yes & yes & - & yes \\
\hline carbonyl chloride & none & strong & group $\mathrm{D}^{d}$ & - & yes & yes & yes & - & - & - \\
\hline methyl chloride & $253 \mathrm{~K}$ & weak & group 3 & yes & yes & - & - & - & yes & - \\
\hline dichloromethane & none & weak & group 2A & - & yes & - & - & - & yes & - \\
\hline trichloromethane & none & weak & group 2B & - & yes & - & - & - & yes & - \\
\hline tetrachloromethane & none & weak & group $2 \mathrm{~B}$ & - & - & - & yes & - & yes & - \\
\hline methane bromide & $243 \mathrm{~K}$ & weak & group 3 & yes & - & - & yes & & yes & yes \\
\hline dibromomethane & None & weak & - & - & yes & - & - & - & yes & - \\
\hline chloroethane & $223 \mathrm{~K}$ & weak & group 3 & yes & yes & - & - & - & yes & - \\
\hline bromoethane & $250 \mathrm{~K}$ & weak & group 3 & yes & - & - & - & yes & yes & - \\
\hline vinyl chloride & $195 \mathrm{~K}$ & weak & group 1 & yes & - & - & - & - & yes & - \\
\hline 1,2-dichloroethane & $286 \mathrm{~K}$ & weak & group 2B & yes & - & - & yes & yes & yes & - \\
\hline 1,1-dichloroethane & $256 \mathrm{~K}$ & weak & group $\mathrm{C}^{d}$ & yes & - & - & - & yes & - & - \\
\hline 1,1,2-trichloroethane & - & weak & group 3 & - & - & - & yes & yes & yes & - \\
\hline
\end{tabular}




\begin{tabular}{|c|c|c|c|c|c|c|c|c|c|c|}
\hline tetrachloroethylene & - & weak & group 2A & - & - & - & - & yes & yes & yes \\
\hline hexachloroethane & - & weak & group 2B & - & - & - & - & yes & yes & yes \\
\hline allyl chloride & $241 \mathrm{~K}$ & weak & group 3 & yes & - & - & - & yes & yes & yes \\
\hline 1-iodopropane & $317 \mathrm{~K}$ & weak & - & - & - & - & - & - & - & - \\
\hline 1,2-dichloropropane & $289 \mathrm{~K}$ & weak & group 1 & yes & - & - & - & yes & - & - \\
\hline
\end{tabular}

${ }^{a}$ Temperature listed below corresponds to the flash point of respective compounds. ${ }^{b}$ Toxicity level is classified according to International Agency for Research on Cancer: Group 1, carcinogenic to humans; Group 2A, probably carcinogenic to humans, Group 2B, possibly carcinogenic to humans, Group 3, not classifiable as to its carcinogenicity to humans. ${ }^{391}{ }^{c} \mathrm{GHS}$ pictograms indicate vividly several serious hazards of chemicals; the meanings of each can be referred to ref 392. ${ }^{d}$ Toxicity level is classified according to United States Environmental Protection Agency: Group C, possible human carcinogen; Group D, not classifiable as to human carcinogenicity. 
hydrogen halides are not combustible, but toxic if inhaled, and might cause respiratory irritation. When dissolved in water, they are known as hydrohalic acids. All these acids are dangerous and belong to strong chemical acids except HF. Being extremely corrosive, direct skin contact will cause severe skin burns and eye damage, thus should be strictly avoided. Halogens are generally toxic or even lethal to biological organisms in their elemental forms, and they tend to decrease in toxicity towards the heavier halogens. Chlorine gas is highly toxic, while bromine and iodine are somewhat toxic, being able to irritate the lungs and eyes. They are not classifiable as a human carcinogen. However, all routes of exposure by means of inhalation, skin, and eye contact should be refrained. Chronic exposure could cause serious respiratory effects such as eye and throat irritation and airflow obstruction. Phosgene, in contrast to the irritant halogens, is an insidious poison because the odor may not be noticed and symptoms may be slow to appear. ${ }^{393}$ However, it is extremely toxic by acute inhalation exposure. Furthermore, as a strong electrophilic reactant, phosgene can react easily with water to produce highly corrosive HCl.

4.4.2. Halocarbons. Halocarbons occur in nature as well as are synthesized in the laboratory. They generally resemble the parent alkanes in being colorless, relatively odorless, and hydrophobic. Their boiling points are higher than the corresponding alkanes and scale with the atomic weight and number of halides. They are used as flame retardants, fire extinguisher, refrigerants, propellants, solvents, and pharmaceuticals. ${ }^{394}$ Subsequent to the widespread use in commerce, many halocarbons have also been shown to be serious pollutants and toxins. Haloalkanes are generally insoluble in water and regarded as much less corrosive when compared with inorganic hydrohalic acids. However, water-incompatible halogen-containing compounds such as acetyl halides are highly corrosive, and hydrolysis reaction can occur readily with the formation of hydrohalic acids. ${ }^{60}$ Flammability is another big issue for haloalkanes. It is inappropriate to consider that all alkyl halides are nonflammable. In fact, most of them have relatively low flash points, and some intermediates, e.g., VCM, are extremely flammable. Noncombustible alkyl halides are only restricted to polyhalogenated compounds with substitution of multiple halogens such as $\mathrm{CH}_{2} \mathrm{Cl}_{2}, \mathrm{CHCl}_{3}, \mathrm{CCl}_{4}$ and $\mathrm{CH}_{2} \mathrm{Br}_{2}$. The biggest concern for these alkyl halides 
is their toxicity. Some problematic aspects include carcinogenicity and liver damage. Under certain conditions phosgene can be formed by combustion of certain intermediates (e.g., VCM, 1,1dichloroethane, etc.) which is highly toxic. Although few alkyl halides are acutely toxic, many pose risks from prolonged exposure. Among these some have been identified as carcinogen (e.g., VCM and 1,2-dichlopropane) while most of the others are classified as possibly carcinogenic due to inadequate evidence in humans $\left(\mathrm{CH}_{2} \mathrm{Cl}_{2}, \mathrm{CHCl}_{3}, \mathrm{CCl}_{4}, \mathrm{C}_{2} \mathrm{Cl}_{4}, \mathrm{C}_{2} \mathrm{Cl}_{6}, \mathrm{EDC}\right.$, etc.). Therefore, inhalation should be avoided as much as possible in all circumstances.

4.4.3. Safe Handling. Smooth operations of halogenation reactions in a laboratory scale should emphasize strict operation procedures, sufficient personal safety protections, and proper waste treatments. Experience from our lab encourages conducting these experiments in fume hoods with good air ventilation and with installation of gas alarms equipped with a halogen gas detector in case of any emergent leakage of toxic gases. The reactor in lab is usually made of quartz to withstand hightemperature and severe corrosion ambiences. For those reactions with the formation of water, Teflon pipes are recommended for the downstream of the reactor, as even a trace of moisture will aggressively accelerate corrosion and increase susceptibility to stress corrosion cracking of pipelines. The staffs should always wear safety goggles and anti-acid gloves when running the reactions. In case of emergency situations, gas masks will help protect from irritations by inhalation. Last but not least, the chemical wastes are generally highly acidic and rich in halogens, a neutralization step with a diluted basic solution should be performed before dumping. The experience accumulated in a lab might be cautiously extrapolated to the large-scale productions in industry where the potential harms of haloalkanes should be foreseen and guarded with contingency plan.

4.4.4. Materials of Construction. In chemical industry, corrosion is a major issue, quite often leading to shutdowns of plants and high maintenance costs. Whilst internal corrosion results in contamination of products and process streams, external corrosion leaks compromise safety causing undesirable personnel and environmental risks. Therefore, the successful development of a process, especially when halogens are involved, depends on finding suitable materials of construction. Today, 
owing to a tremendous progress in metallurgy and corrosion science, different materials, including metals, alloys, ceramics, graphite, silicon carbide, glasses, polymers, etc, have been widely used for the construction of reactors, vessels, columns, heat exchangers, pumps, and piping under various conditions to handle corrosive halogens.

Knowledge accumulated from theoretical study and industrial practice is rich on the corrosion behaviors of metals/alloys and protections from chlorine/chloride attacks. Equipment fabricated from iron, steel, nickel, copper, and lead can be safely used to handle dry chlorine (gaseous and liquid). ${ }^{395,396}$ However, the corrosion rate can be accelerated at elevated temperatures. For instance, carbon steel should not be used when operation temperature reaches above $390 \mathrm{~K} \cdot{ }^{396}$ Under more demanding conditions, nickel and high nickel alloys are the better choices when higher temperatures are required (up to $813 \mathrm{~K}) .{ }^{397}$ Titanium, which reacts violently with dry chlorine, should never be used in any circumstances. Dry chlorine has an extremely high affinity for moisture, whose presence will rapidly increase the corrosion rate for common metals of construction. In this case, platinum and tantalum are some of the metals resistant to moist chlorine. Titanium can also be used because the strongly oxidizing nature of moist chlorine results in passivation of the metal. The performance of metal/alloys in dry $\mathrm{HCl}$ is somewhat analogous to their behaviors in dry chlorine. Wet hydrogen chloride at temperatures below the dew point behaves the same as concentrated hydrochloric acid, and Hastelloy $\mathrm{C}$ is the most resistant nickel alloy. The effect of moisture in $\mathrm{HCl}$ at elevated temperatures has been reported for a number of materials such as carbon steel, nickel, Hastelloy B, and the results showed that a moisture content of 0.25\% did not significantly alter the corrosion rate. ${ }^{397}$ For a chemical process, the presence of halogens poses a big challenge to reactor design in order to meet stringent requirements induced by high temperatures and pressures, as well as complicated chemical reactions. Thus, material selection as the first step is vital. Experience from PVC manufacture shows that (i) carbon steel is adequate for lowtemperature ethylene chlorination $(T<373 \mathrm{~K})$ though nickel-based nonferrous alloys are often preferred, ${ }^{398}$ (ii) stainless steel vessels are more frequently used in both high-temperature ethylene 
chlorination and acetylene hydrochlorination, and (iii) stainless steel and tantalum are suitable construction materials for ethylene oxychlorination reactor. ${ }^{399}$

Like chlorine, bromine attacks many of the metals and alloys commonly used as materials of construction, which is strongly dependent on the conditions of service including temperature, pressure, and moisture content. Nickel, lead, and alloys such as Monel and Hastelloy can be used for handling dry bromine. $^{400}$ These materials, however, are all susceptible to severe attack in the presence of moisture. Tantalum is rather resistant to wet bromine ( $>30 \mathrm{ppm}_{2} \mathrm{O}$ ) and is often used for heat exchange surface. In contrast, Hastelloy and Monel can be used if the bromine contains less than 30 ppm water, and Inconel can be used when bromine is essentially dry $\left(<1 \mathrm{ppm} \mathrm{H}_{2} \mathrm{O}\right) \cdot{ }^{401}$ Early patents revealed that reactors constructed with refractory or zirconia lining are suitable for $\mathrm{HBr}$ oxidation, ${ }^{402}$ and a refractory alumina lining reactor can withstand gas-phase bromination up to $1173 \mathrm{~K}$ without significant corrosion. ${ }^{403}$ Besides, non-metallic glass and plastics are usable in a wide range of conditions. Glasslined reactors are frequently used for brominations, given that the operating pressure is limited to 10 bar. $^{401}$ Low price plastic materials such as polyvinylidene fluoride (PVDF) have now become available and in many cases can be readily used to replace expensive lead-lined pipes and tanks. ${ }^{404}$

Construction of equipment and piping by common metals such as nickel, copper, alumina, magnesium, Monel, and even steel can be used to handle successfully fluorine. ${ }^{405}$ Among these materials, nickel and Monel are equally resistant and outperform the others. Nickel, copper, and Monel also show good resistance to anhydrous HF even at elevated concentrations and temperatures. It is claimed that the presence of steam did not accelerate the corrosion rate at 773-873 K. ${ }^{405}$ Steel equipment might be suitable for handling HF under relatively anhydrous conditions considering that they are satisfactorily applied in the production of $\mathrm{HF}$ from fluorspar at ca. $450 \mathrm{~K} .^{406}$ With respect to hydrofluoric acid, Monel is more universally applicable over a wide range of temperatures. Lead is also widely employed for the preparation and commercial handling of hydrofluoric acid up to 60\% strength whereas it fails rapidly at higher concentrations and at elevated temperatures. ${ }^{407}$ 
The corrosion data of materials attacked by iodine is limited compared to those of other halogens. Hastelloy B and C-276 have been demonstrated to be resistant to corrosion in an $\mathrm{HI} / \mathrm{I}_{2}$ environment in the absence of moisture. ${ }^{408}$ A number of engineering alloys and corrosion resistant materials have been screened in a $\mathrm{HI} / \mathrm{I}_{2} / \mathrm{H}_{2} \mathrm{O}$ environment at $473-673 \mathrm{~K}$. It is found that tantalum, zirconium, titanium, SiC, and SiN showed very low corrosion rates at all temperatures. ${ }^{409}$ On the other hand, tantalum, niobium, molybdenum, zirconium, SiC, and carbon-based materials have the best prospect in lower temperatures $(T<473 \mathrm{~K}){ }^{410}$

\section{CONCLUSIONS AND OUTLOOK}

Halogen-mediated processes have emerged as very prominent technologies in the chemical industry for the production of polymers and have been showing a great potential to revolutionize the chemical value chain by capitalizing on the abundant natural gas reserves. The key aspect of halogens making them effective mediators under mild conditions is their high electron affinities for the hydrogen abstraction from a hydrocarbon molecule that weakens in the order of $\mathrm{Cl}>\mathrm{F}>\mathrm{Br}>\mathrm{I}$. The past decades have witnessed the renaissance of halogen chemistry. Promising catalytic technologies have been conceived for the utilization of low-cost hydrocarbon feedstocks for the production of polymers, chemicals, and fuels. However, pertaining challenges remain to be solved regarding the design of more selective and stable catalysts, the construction of suitable reactors with well heat, and corrosion managements, and process engineering. Herein, in-depth analysis of the fundamental understanding and applied relevance of halogen chemistry in polymer industry and in the valorization of light hydrocarbons to chemicals and fuels is conducted.

The modern VCM manufacture technologies heavily rely on the $\mathrm{HgCl}_{2}$-catalyzed acetylene hydrochlorination and ethylene-based two-step routes. These industrially applied processes are suboptimal due to the use of relatively expensive feedstocks, metal leaching, and pollution problems of the catalysts. Gold-based catalysts have demonstrated to be promising to replace the oldest recipe for the hydrochlorination. Reducing the gold loading to an economical level while keeping an appreciable 
productivity on long-term is a challenging next step. Even more intriguing is to find new catalysts based on cheaper and non-toxic metals which not only will enable the expansion, but also will reduce the environmental impact of this process. Direct oxychlorination of $\mathrm{C}_{2} \mathrm{H}_{4} / \mathrm{C}_{2} \mathrm{H}_{6}$ to $\mathrm{VCM}$ is a promising technology to intensify the PVC production. Ethane oxychlorination is especially demanding, and the main obstacle comes from selective VCM formation. Design of multifunctional materials featuring optimal balance between redox and acid properties can be anticipated to address this issue.

Selective activation of light alkanes, particularly of methane, still comprises of one of the most complex challenge to the catalysis community. Single-step methane halogenation is impracticable either because of the poor selectivity of the gas-phase reaction or the insufficient stability of the super acid catalysts. The drawbacks can be overcome by feeding over stoichiometric $\mathrm{CH}_{4}: \mathrm{X}_{2}$ with the recycle of unreacted methane. Even so, this process should always be integrated with a halogen recovery unit, such as HX oxidation over novel Deacon catalysts to recycle HX released in the halogenation and subsequent elimination steps. Alternatively, catalyzed oxyhalogenation processes are more advanced as the hydrocarbon activation and HX recovery can be integrated in one step, with sufficiently high selectivity to methyl halides. However, the presence of oxygen can lead to over-oxidation, forming undesired carbon oxides. Several metal oxides and phosphate catalysts have demonstrated to be sufficiently durable and active in these reactions. The rich phosphate chemistry with numerous compositions and phases provides huge opportunities to further explore more active components in this group of materials. Unprecedented selectivity to light alkenes can be achieved by halogen-aided dehydrogenation of corresponding alkanes. The corrosion and recovery of halogens require sophisticated process and reactor engineering, especially when iodine and water are present in the system.

The conversion of haloalkanes, produced via (oxy)halogenation of alkanes, into high value-added commodities is the most important second step in halogen-mediated alkane upgrading technology. Zeolitic materials are the prime candidates studied extensively to catalyze methyl halide coupling to gasolines or light olefins. Compared with the MTH reaction, methyl halides coupling shows inferior activity and stability due to the different leaving groups $\left(\mathrm{X}^{-}\right.$versus $\left.\mathrm{OH}^{-}\right)$. These reactions are strongly 
influenced by the topology and acidity of the catalysts. Therefore, zeolite engineering by turning the topology and composition or by doping strategy is imperative to develop efficient and stable coupling catalysts. Future research should also tackle the impact of halides on the catalyst performance and the structural alteration.

In general, to deal with the above mentioned hurdles in different halogen-mediated technologies, scientists should devote more efforts to the development of sufficiently active and durable catalysts, suitable reactors, and integrated processes. Catalyst design at a molecular level based on deeper understanding of the structure-performance relationship is the key. To achieve this elegant goal, the selection of a suitable catalyst should take into account of different hydrocarbon molecules, the applied halogens, as well as the potential impact of halogen on the catalyst structure. Operando techniques enabling in situ detection of reaction intermediate species and structural variation of catalytic materials can provide in-depth understanding of the reaction path. However, these techniques are scarcely applied in halogen-mediated reactions because of the extremely corrosive nature of HX. Micro-kinetic analysis coupled with DFT studies can be expected to complement this and provide more mechanistic insights.

Reactor engineering should tackle the issues of exothermicity and corrosion. The reaction heat is particularly prominent in the oxyhalogenation reactions. Strategies for the fixed-bed technologies including catalyst grading or staging of feed in reactor cascades offer better temperature control. In addition, fluidized-bed reactor generally has good heat removal capacity and thus can ease the hot spot effect. But in this case, new difficulties arise from the fluidization technology and catalyst stickiness. Materials of construction are demanding for a halogen-mediated process. As susceptibility of materials to attack by halogens is strongly dependent on working conditions, possible candidates selected therefore should be tested under the actual conditions of use. Albeit there have been some demonstrations on halogen-mediated processes in a pilot scale, limited information on metallurgy of reactor materials, their long-term durability, as well as the impact on catalysts, makes it difficult to draw any realistic conclusions for the time being. 
Providing an integrated process by coupling halogen-related reactions is of vital importance, which represents a giant step towards the commercialization of the developing technologies. This is based on the following considerations: (i) hydrocarbon activation with halogens generally yields alkyl halides instead of ultimate bulk chemicals, thus, a sequential upgrading step is required; (ii) the recovery of halogens is imperative in order to keep the process competitive and sustainable; and (iii) offering a package of technologies enables a reliable assessment of a chemical process. In view of process integration, numerous innovative concepts have been developed. The "balanced process” in ethylene-toVCM is intrinsically the combination of ethylene chlorination and oxychlorination, the latter being able to consume the byproduct $\mathrm{HCl}$ produced from the former. "Zone reactor" concept, with different functional catalysts packed in cascades within one reactor, has also been conceived for the one-step transformation of light alkanes to oxygenates or gasolines using bromine as the meditator. These innovative strategies as discussed along the review can provide hints to improve the developing and existing halogen-mediated routes. Thus, joint efforts between the chemists and chemical engineers, as well as collaborations between academia and industry, can be anticipated to greatly accelerate the commercialization and intensification of the halogen-mediated hydrocarbon transformations.

\section{ACKNOWLEDGEMENTS}

This work was funded by the Swiss National Science Foundation (project no. 20021-156107) and by ETH (research grant ETH-04-16-1). V. Paunović and G. Zichittella are thanked for their input on illustrations in Sections 3 and 4 of the manuscript.

\section{LIST OF ABBREVIATIONS AND TECHNIQUES}

AC

${ }^{27}$ Al MAS NMR

\author{
activated carbon
}

${ }^{27} \mathrm{Al}$ magic angle spinning nuclear magnetic resonance (a spectroscopic technique to assess the coordination environment of aluminum species in 
solids ${ }^{411}$ )

BMS

BTX

$\mathrm{C}_{60}$

cat

$\mathrm{C}_{2} \mathrm{H}_{l}$

$\mathrm{C}_{n} \mathrm{H}_{m}$

$\mathrm{C}_{2} \mathrm{H}_{6-n} \mathrm{Cl}_{n}$

$\mathrm{C}_{2} \mathrm{H}_{4-n} \mathrm{Cl}_{n}$

$\mathrm{CH}_{3} \mathrm{X}$

$\mathrm{CH}_{2} \mathrm{X}_{2}$

$\mathrm{CO}_{x}$

$\mathrm{C}_{4444} \mathrm{P}^{+} \mathrm{Cl}^{-}$

D

DFT

DME

DMM

E

$E_{\mathrm{a}}$

EC

EDC

E-R

$F$

${ }^{57} \mathrm{Fe}$
Bayer MaterialScience

a mixture of benzene, toluene, and xylene

fullerene

catalyst

hydrocarbons with two carbon atoms, $l=4$ or 6

hydrocarbons, where $m=2 n$ or $2 n+2$

Cl-containing saturated hydrocarbons, where $n=0-6$

Cl-containing unsaturated hydrocarbons, where $n=0-4$

methyl halides

methylene dihalides

carbon oxides

tetrabutylphosphonium chlorides

dispersion

density functional theory (a computational quantum mechanical modeling method to study the properties of molecules and materials ${ }^{412}$ )

dimethyl ether (methoxymethane)

dimethoxymethane

photon energy

activation energy

ethyl chloride (chloroethane)

ethylene dichloride (1,2-dichloroethane)

Eley-Rideal

flow rate

a spectroscopic technique based on the Mössbauer effect to examine the 

functional groups on solids or the interactions between probe molecules and solids ${ }^{414}$ )

G

\section{GHS}

GHSV

$\Delta H$

$\Delta H_{\mathrm{f}}$

Hastelloy B

Hastelloy C

Hastelloy C-276

HOMO

HRTEM

$\mathrm{H}_{2}$-TPR

HX

IR

L-H

LUMO

MDA

MDI
Gibbs energy

globally harmonized system of classification and labeling of chemicals

gas hourly space velocity

enthalpy of reaction

standard enthalpy of formation

an alloy composed of nickel and molybdenum

an alloy composed of nickel, molybdenum, chromium, and iron

a nickel-molybdenum-chromium alloy with the addition of tungsten

highest occupied molecular orbital

high resolution transmission electron microscopy (a technique to observe the morphological and crystal features of materials in an atomic scale ${ }^{415}$ )

temperature-programmed reduction with hydrogen (a technique to analyze the redox property of a solid catalyst ${ }^{416}$ )

hydrogen halides

infrared (a spectroscopic technique to distinguish different functional groups on solids or to study the interactions between probe molecules and solids ${ }^{414}$ )

\section{Langmuir-Hinshelwood}

lowest unoccupied molecular orbital

methylenedianiline (4-[(4-aminophenyl)methyl]aniline)

methylene diphenyl diisocyanate

(1-isocyanato-4-[(4- 
isocyanatophenyl)methyl]benzene)

$\mathrm{Me}$

Monel

MTH

MTO

N-AC

$\mathrm{NH}_{3}-\mathrm{TPD}$

NFs

NMR

$\mathrm{N}_{2}$-sorption

[O]

$\mathrm{O}_{\text {ads }}$

$\mathrm{O}_{\text {lat }}$

OCM

ODC

OSC

$p$

$P$

PAN-ACF methyl

a group of nickel alloys, primarily composed of nickel (up to 67\%) and copper, with small amounts of iron, manganese, carbon, and silicon

methanol-to-hydrocarbons

methanol-to-olefins

N-doped coconut activated carbon

temperature-programmed desorption of ammonia (a chemisorption technique to determine the acidic property of a solid catalyst using $\mathrm{NH}_{3}$ as probe molecule ${ }^{417}$ )

nanofibers

nuclear magnetic resonance spectroscopy (an spectroscopic technique to determine the content and purity of a sample as well as its molecular structure $^{418}$ )

a physisorption technique to determine the porous properties and surface area of solids using $\mathrm{N}_{2}$ as probe molecule $\mathrm{e}^{419}$

gaseous or lattice oxygen species

adsorbed oxygen species

lattice oxygen species

oxidative coupling of methane

oxygen depolarized cathode

oxygen storage capacity

partial pressure

total pressure

polyacrylonitrile-based active carbon fiber 
prompt gamma activation analysis (a nondestructive, neutron-based

$\mathrm{PPh}_{3}$

ppm

PU

PVC

PVDF

PVP

r

S

$S_{\text {BET }}$

SA

SEM

STP

STY

$t$

$T$

$T_{\text {bed }}$

TAP-2

TCD

TCE spectroscopic method to measure elemental composition of a solid ${ }^{229}$ )

triphenylphosphine (triphenylphosphane)

parts per million

polyurethanes

polyvinyl chloride

polyvinylidene fluoride

poly(4-vinylpyridine)

reaction rate

selectivity

total surface area determined by applying the Brunauer-Emmett-Teller method super acids

scanning electron microscopy (a technique to observe the surface topography

of samples ${ }^{415}$ )

standard temperature and pressure

space time yield

time

temperature

temperature of catalyst bed

temporal analysis of products (a pulse-response technique to study the kinetics of physicochemical interactions between gases and solids, and to derive mechanistic hints for a catalytic process ${ }^{420}$ )

thermal conductivity detector

1,1,2-trichloroethane 
tcm trillion cubic meter

TDA toluenediamine (4-methylbenzene-1,3-diamine)

TDI toluene diisocyanate (2,4-diisocyanato-1-methylbenzene)

TEM transmission electron microscopy (a technique to observe the morphological and crystal features of materials in an atomic scale ${ }^{415}$ )

TGA-DTA thermogravimetric and differential thermal analysis (a technique to evaluate thermal stability of a material by measuring weight changes as a function of temperature $^{421}$ )

TOF

turnover frequency

UHV

ultra-high vacuum

UV-Vis-NIR

ultraviolet-visible-near infrared spectroscopy (a technique for quantitative analysis of different analytes and to study interactions of different molecules ${ }^{422}$ )

VCM vinyl chloride monomer

vol.\% volume percentage

$W_{\text {cat }} \quad$ catalyst weight

WHSV weight hourly space velocity

wt.\% weight percentage

X halogen atoms

$\mathrm{X}^{*} \quad$ active halogen species

$\mathrm{X}^{\bullet} \quad$ halogen radicals

$\mathrm{X}_{2} \quad$ elemental halogens

$X$

conversion

XANES X-ray absorption near edge structure (a spectroscopic technique to distinguish the valence state, energy bandwidth, and the bond angle of an element in 
condensed matters ${ }^{423}$ )

XPS

X-ray photoelectron spectroscopy (a technique to examine the chemical state

of an element in the outer surface levels ${ }^{424}$ )

XRD

X-ray diffraction (a spectroscopic technique to study the structure of crystalline solids ${ }^{425}$ ) 


\section{REFERENCES}

(1) National Research Council. Sustainability in the Chemical Industry: Grand Challenges and Research Needs - A Workshop Report; The National Academies Press: Washington, DC, 2005.

(2) New Energy Sources: Possibilities and Prospects, http://www.theenergycollective.com/mark-ecaine/173971/new-energy-sources-possibilities-and-prospects, (accessed Aug 8, 2016).

(3) BP Energy Outlook 2035, http://www.bp.com/content/dam/bp/pdf/energy-economics/energyoutlook-2015/bp-energy-outlook-2035-booklet.pdf, (accessed Aug 8, 2016).

(4) Malakoff, D. The Gas Surge. Science 2014, 344, 1464-1467.

(5) The Chlorine Tree, http://www.eurochlor.org/the-chlorine-universe/what-is-chlorine-usedfor/the-chlorine-tree.aspx, (accessed, Aug 10, 2016).

(6) World Chlorine Council, http://www.worldchlorine.org/products/index.html, (accessed Mar 14, 2014).

(7) Herrera-Rodriguez, L. N.; Khan, F.; Robins, K. T.; Meyer, H. P. Perspectives on Biotechnological Halogenation Part I: Halogenated Products and Enzymatic Halogenation. Chim. Oggi-Chem. Today 2011, 29, 31-33.

(8) Pérez-Ramírez, J.; Mondelli, C.; Schmidt, T.; Schlüter, O. F. K.; Wolf, A.; Mleczko, L.; Dreier, T. Sustainable Chlorine Recycling via Catalysed HCl Oxidation: From Fundamentals to Implementation. Energ. Environ. Sci. 2011, 4, 4786-4799.

(9) Amrute, A. P. Deacon Chemistry Revisited: New Catalysts for Chlorine Recycling. Ph.D. Dissertation, ETH Zurich, 2013.

(10) Chlorine, http://www.essentialchemicalindustry.org/chemicals/chlorine.html, (accessed Jul 17, 2016).

(11) Bromine, http://www.essentialchemicalindustry.org/chemicals/bromine.html, (accessed Jul 17, 2016).

(12) Jaccaud, M.; Faron, R.; Devilliers, D.; Romano, R. Fluorine. In Ullmann's Encyclopedia of Industrial Chemistry; Bellussi, G.; Bohnet, M.; Bus, J.; Drauz. K.; Faulhammer, H.; Greim, H.; 
Karst, U.; Kleemann, A.; Kutscher, B.; Meier, W.; et al., Ed.; Wiley-VCH Verlag GmbH \& Co. KGaA: Weinheim, 2012; p 392.

(13) Iodine, http://www.essentialchemicalindustry.org/chemicals/iodine.html, (accessed Jul 17, 2016).

(14) Berry, R. S.; Reimann, C. W. Absorption Spectrum of Gaseous F- and Electron Affinities of Halogen Atoms. J. Chem. Phys. 1963, 38, 1540-1543.

(15) Chlorine, http://www.rsc.org/periodic-table/element/17/chlorine, (accessed Aug 8, 2016).

(16) Deacon, H. U.S. Patent 85,370, 1868.

(17) Busca, G. Heterogeneous Catalytic Materials: Solid State Chemistry, Surface Chemistry and Catalytic Behavior; Elsevier: Amsterdam, 2014; p 409.

(18) Nilsson, L.; Persson, P. O.; Rydén, L.; Darozhka, S.; Zaliauskiene, A. Cleaner Production: Technologies and Tools for Resource Efficient Production; The Baltic University Press: Uppsala, 2007; p 236.

(19) Iodine, http://www.rsc.org/periodic-table/element/53/iodine, (accessed Aug 8, 2016).

(20) Bromine, http://www.rsc.org/periodic-table/element/35/bromine, (accessed Aug 8, 2016).

(21) Fluorine, http://www.rsc.org/periodic-table/element/9/fluorine, (accessed Aug 8, 2016).

(22) Nicolas Leblanc, http://www.encyclopedia.com/topic/Nicolas_Leblanc.aspx, (accessed Jul 17, 2016).

(23) Baumann, E. Ann. Chem. Pharm. 1872, 163, 308-322.

(24) Patrick, S.G. Practical Guide to Polyvinyl Chloride; Rapra Technology Limited: Shropshire, 2005; p 2.

(25) Dingerdissen, U.; Martin, A.; Herein, D.; Wernicke, H. J. The Development of Industrial Heterogenous Catalysis. In Handbook of Heterogeneous Catalysis; Ertl, G.; Knözinger, H.; Schüth, F.; Weitkamp, J., Ed.; John Wiley and Sons, Inc. 2014; p 45.

(26) Leach, B. E. Applied Industrial Catalysis; Academic Press, Inc.: New York, 1983; p 241.

(27) Carroll, R. T.; De Witt, E. W.; Trapasso, L. E. U.S. Patent 3,173,962, 1965. 
(28) Croce, L. J.; Bajars, L.; Gabliks, M. U.S. Patent 4,025,461, 1975.

(29) Wittcoff, H. A.; Reuben, B. G.; Plotkin, J. S. Industrial Organic Chemicals; 3rd edition; John Wiley \& Sons, Inc.: Hoboken, New Jersey, 2013; p 220.

(30) Brunelle, D. J.; Smigelski, P. M.; Boden, E. P. Evolution of Polycarbonate Process Technologies. In Advances in Polycarbonates; ACS Symposium Series; Amercian Chemical Society: Washinton, DC, 2005, 898, 8-21.

(31) Sharmin, E.; Zafar, F. Polyurethne; InTech Open Access Publisher, 2012; p 3.

(32) Rossberg, M.; Lendle, W.; Pfleiderer, G.; Tögel, A.; Dreher, E.; Langer, E.; Rassaerts, H.; Kleinschmidt, P.; Strack, H.; Cook, R.; et al. Chlorinated Hydrocarbons. In Ullmann's Encyclopedia of Industrial Chemistry; Bellussi, G.; Bohnet, M.; Bus, J.; Drauz. K.; Faulhammer, H.; Greim, H.; Karst, U.; Kleemann, A.; Kutscher, B.; Meier, W.; et al., Ed.; Wiley-VCH Verlag GmbH \& Co. KGaA: Weinheim, 2006; p 4.

(33) Dumas, J. Ueber die Einwirkung des Chlors auf den aus essigsauren Salzen entstehenden Kohlenwasserstoff. Liebigs Ann. 1840, 33, 187-189.

(34) Bucsi, I.; Olah, G. Selective Monochlorination of Methane Over Solid Acid and Zeolite Catalysts. Catal. Lett. 1992, 16, 27-38.

(35) Lacy, B. S. U.S. Patent 1,111,842, 1914.

(36) Ernst, O.; Pfaffendorf, W.; Wulff, O. D.E. Patent 362,142, 1922.

(37) Rossberg, M.; Lendle, W.; Pfleiderer, G.; Tögel, A.; Torkelson, T. R.; Beutel, K. K. Chloromethanes. In Ullmann's Encyclopedia of Industrial Chemistry; Bellussi, G.; Bohnet, M.;

Bus, J.; Drauz. K.; Faulhammer, H.; Greim, H.; Karst, U.; Kleemann, A.; Kutscher, B.; Meier, W.; et al., Ed.; Wiley-VCH Verlag GmbH \& Co. KGaA: Weinheim, 2012; p 39.

(38) Gorin, E.; Fontana, C. M.; Kidder, G. A. Chlorination of Methane with Copper Chloride Melts: Rate of Chlorination. Ind. Eng. Chem. 1948, 40, 2128-2134.

(39) Krause, E.; Roka, K. U.S. Patent 7,1789,124, 1928.

(40) Ernst, O.; Wahl, H. D.E. Patent 486,952, 1929. 
(41) Tizard, H. T.; Chapman, D. L.; Taylor, R. G.B. Patent 214,293, 1924.

(42) Gorin, E. U.S. Patent 2,407,828, 1946.

(43) Fontana, C. M.; Gorin, E.; Kidder, G. A.; Meredith, C. S. Chlorination of Methane with Copper Chloride Melts: Ternary System Cuprous Chloride Cupric Chloride Potassium Chloride and Its Equilibrium Chlorine Pressures. Ind. Eng. Chem. 1952, 44, 363-368.

(44) Nager, M. U.S. Patent 3,080,435, 1963.

(45) Nager, M. U.S. Patent 3,168,584, 1965.

(46) Raley, J. H.; Bittner, C. W.; Mullineaux, R. D. High Temperature Reactions of Iodine With Hydrocarbons. 1. Dehydrogenation. J. Am. Chem. Soc. 1963, 85, 3174-3178.

(47) Popov, A. I.; Deskin, W. An Observation on Chlorination of Normal Hexane with Iodine Monochloride. J. Organ. Chem. 1957, 22, 1732-1733.

(48) Kelly, C. C.; Yu, W. H. S.; Wijnen, M. H. J. Competitive Chlorination Reaction with ICl. II. $\mathrm{CH}_{4}, \mathrm{C}_{2} \mathrm{H}_{6}, \mathrm{C}_{3} \mathrm{H}_{8}$, and $\mathrm{C}_{2} \mathrm{H}_{5} \mathrm{Cl}$. Can. J. Chem. 1970, 48, 603-606.

(49) Evans, B. S.; Whittle, E. The Kinetics of the Reactions of Methyl Radicals with $\mathrm{Br}_{2}, \mathrm{Cl}_{2}$, and BrCl. Int. J. Chem. Kinet. 1978, 10, 745-757.

(50) Butter, S. A.; Jurewicz, A. T.; W., Kaeding. W. U.S. Patent 3,894,107, 1975.

(51) Taylor, C. E.; Noceti, R. P.; Schehl, R. R. Direct Conversion of Methane to Liquid Hydrocarbons Through Chlorocarbon Intermediates. Stud. Surf. Sci. Catal. 1988, 36, 483-489.

(52) Marquaire, P. M.; Kazzaz, M. A. Mechanism of "Chloro-Pyrolysis" of Methane. Stud. Surf. Sci. Catal. 1998, 119, 269-274.

(53) Olah, G. A.; Gupta, B.; Felberg, J. D.; Ip, W. M.; Husain, A.; Karpeles, R.; Lammertsma, K.; Melhotra, A. K.; Trivedi, N. J. Electrophilic Reactions at Single Bonds. 20. Selective Monohalogenation of Methane over Supported Acidic or Platinum Metal Catalysts and Hydrolysis of Methyl Halides over Gamma-Alumina-Supported Metal Oxide/Hydroxide Catalysts. A Feasible Path for the Oxidative Conversion of Methane into Methyl Alcohol/Dimethyl Ether. J. Am. Chem. Soc. 1985, 107, 7097-7105. 
(54) Olah, G. A. Electrophilic Methane Conversion. Acc. Chem. Res. 1987, 20, 422-428.

(55) Miller, J. U.S. Patent 5,998,679, 1999.

(56) McFarland, E. Unconventional Chemistry for Unconventional Natural Gas. Science 2012, 338, 340-342.

(57) Zhou, X. P.; Yilmaz, A.; Yilmaz, G. A.; Lorkovic, I. M.; Laverman, L. E.; Weiss, M.; Sherman, J. H.; McFarland, E. W.; Stucky, G. D.; Ford, P. C. An Integrated Process for Partial Oxidation of Alkanes. Chem. Commun. 2003, 2294-2295.

(58) Wang, K. X.; Xu, H. F.; Li, W. S.; Zhou, X. P. Acetic Acid Synthesis from Methane by NonSynthesis Gas Process. J. Mol. Catal. A 2005, 225, 65-69.

(59) Xu, H. F.; Wang, K. X.; Li, W. S.; Zhou, X. P. Dimethyl Ether Synthesis from Methane by Non Syngas Process. Catal. Lett. 2005, 100, 53-57.

(60) Wang, K. X.; Xu, H. F.; Li, W. S.; Au, C. T.; Zhou, X. P. The Synthesis of Acetic Acid from Methane via Oxidative Bromination, Carbonylation, and Hydrolysis. Appl. Catal. A 2006, 304, 168-177.

(61) Paunović, V.; Zichittella, G.; Moser, M.; Amrute, A. P.; Pérez-Ramírez, J. Catalyst Design for Natural Gas Upgrading via Oxybromination Chemistry. Nat. Chem. 2016, 8, 803-809.

(62) Wang, H. T.; Lin, D. M.; Zhou, X. P. Ethylene Synthesis from the Oxidative Bromination of Ethane. Appl. Catal. A 2009, 364, 130-136.

(63) Breed, A.; Doherty, M. F.; Gadewar, S.; Grosso, P.; Lorkovic, I. M.; McFarland, E. W.; Weiss, M. J. Natural Gas Conversion to Liquid Fuels in a Zone Reactor. Catal. Today 2005, 106, 301-304.

(64) IRPC'15: New Gas-to-Aromatics Technology Offers Huge Potential - GTC, http://www.hydrocarbonprocessing.com/Article/3459075/IRPC-15-New-gas-to-aromaticstechnology-offers-huge-potentialGTC.html, (accessed Jul 17, 2016).

(65) Egloff, G.; Schaad, R. E.; Lowry, C. D. The Halogenation of the Paraffin Hydrocarbons. Chem. Rev. 1931, 8, 1-80. 
(66) Treger, Y. A.; Rozanov, V. N.; Flid, M. R.; Kartashov, L. M. Oxidative Chlorination of Aliphatic Hydrocarbons and Their Chloro-derivatives. Russ. Chem. Rev. 1988, 57, 326-335.

(67) Over, H. Surface Chemistry of Ruthenium Dioxide in Heterogeneous Catalysis and Electrocatalysis: From Fundamental to Applied Research. Chem. Rev. 2012, 112, 3356-3426.

(68) Olsbye, U.; Svelle, S.; Bjorgen, M.; Beato, P.; Janssens, T. V. W.; Joensen, F.; Bordiga, S.; Lillerud, K. P. Conversion of Methanol to Hydrocarbons: How Zeolite Cavity and Pore Size Controls Product Selectivity. Angew. Chem. Int. Ed. 2012, 51, 5810-5831.

(69) Guo, Z.; Liu, B.; Zhang, Q.; Deng, W.; Wang, Y.; Yang, Y. Recent Advances in Heterogeneous Selective Oxidation Catalysis for Sustainable Chemistry. Chem. Soc. Rev. 2014, 43, 3480-3524.

(70) Horn, R.; Schlögl, R. Methane Activation by Heterogeneous Catalysis. Catal. Lett. 2015, 145, 23-39.

(71) Olivos-Suarez, A. I.; Szécsényi, À.; Hensen, E. J. M.; Ruiz-Martinez, J.; Pidko, E. A.; Gascon, J. Strategies for the Direct Catalytic Valorization of Methane Using Heterogeneous Catalysis: Challenges and Opportunities. ACS Catal. 2016, 6, 2965-2981.

(72) Everything About PVC from Manufacturing to Recycling, www.renolit.com (accessed Jul 6, 2016).

(73) Study: Global PVC Demand to Grow 3.2\% Annually Through 2021, http://www.plasticstoday.com/study-global-pvc-demand-grow-32-annually-through2021/196257501821043 (accessed Jun 8, 2016).

(74) Global Polyurethane Market is Estimated to Grow with the Rate of 6.3\% CAGR by 2021, http://beforeitsnews.com/business/2016/02/global-polyurethane-market-is-estimated-to-growwith-the-rate-of-6-3-cagr-by-2021-2819460.html (accessed Aug 1, 2016).

(75) Global Polycarbonate Market to be Worth US\$19.6 bn by 2020 due to Rising Demand in $\begin{array}{lll}\text { Automotive, } & \text { Consumer } & \text { Electronics }\end{array}$ http://www.transparencymarketresearch.com/pressrelease/polycarbonate-market.htm (accessed Aug 1, 2016). 
(76) Klatte, F. Ger. Patent. 281,687, 1912.

(77) Barton, D. H. R.; Mugdan, M. The Synthesis of Vinyl Chloride from Acetylene and Hydrogen Chloride. J. Soc. Chem. Ind. 1950, 69, 75-79.

(78) Skaperdas, G. T.; Meadows, F.; Schreiner, W. C.; Kurzius, S. C. U.S. Patent 3,159,455, 1964.

(79) Legrand, D. G.; Bendler, J. T. Handbook of Polycarbonate Science and Technology; Marcel Dekker, Inc.: New York, 2000; p 3.

(80) R\&D Progress of and Feasibility Study Report on Mercury-free Catalyst in China, released by Foreign Economic Cooperation Office, Ministry of Environmental Protection of the People’s Republic of China, 2011.

(81) Zhang, H.; Li, W.; Jin, Y.; Sheng, W.; Hui, M.; Wang, X.; Zhang, J. Ru-Co(III)-Cu(II)/SAC Catalyst for Acetylene Hydrochlorination. Appl. Catal. B 2016, 189, 56-64.

(82) Li, G.; Li, W.; Zhang, H.; Pu, Y.; Sun, M.; Zhang, J. Non-Mercury Catalytic Acetylene Hydrochlorination over Ru Catalysts Enhanced by Carbon Nanotubes. RSC Adv. 2015, 5, 90029008.

(83) Zhao, J.; Cheng, X.; Wang, L.; Ren, R.; Zeng, J.; Yang, H.; Shen, B. Free-Mercury Catalytic Acetylene Hydrochlorination Over Bimetallic $\mathrm{Au}-\mathrm{Bi} / \gamma-\mathrm{Al}_{2} \mathrm{O}_{3}$ : A Low Gold Content Catalyst. Catal. Lett. 2014, 144, 2191-2197.

(84) Li, X.; Pan, X.; Yu, L.; Ren, P.; Wu, X.; Sun, L.; Jiao, F.; Bao, X. Silicon Carbide-Derived Carbon Nanocomposite as a Substitute for Mercury in the Catalytic Hydrochlorination of Acetylene. Nat. Commun. 2014, 5.

(85) Nkosi, B.; Adams, M. D.; Coville, N. J.; Hutchings, G. J. Hydrochlorination of Acetylene Using Carbon-Supported Gold Catalysts: A Study of Catalyst Regeneration. J. Catal. 1991, 128, 378386.

(86) Johnston, P.; Carthey, N.; Hutchings, G. J. Discovery, Development, and Commercialization of Gold Catalysts for Acetylene Hydrochlorination. J. Am. Chem. Soc. 2015, 137, 14548-14557. 
Zhu, M.; Wang, Q.; Chen, K.; Wang, Y.; Huang, C.; Dai, H.; Yu, F.; Kang, L.; Dai, B.

Development of a Heterogeneous Non-Mercury Catalyst for Acetylene Hydrochlorination. ACS Catal. 2015, 5, 5306-5316.

(88) Angew, J. B.; Shankar, H. S. Catalyst Deactivation in Acetylene Hydrochlorination. Ind. Eng. Chem. Process Des. Dev. 1986, 25, 19-22.

(89) Prokudina, N. A.; Chesnokov, V. V.; Zolotolvskii, B. P.; Yelesina, L. N.; Yenakaeva, V. G.; Tarasov, V. F. Catalyst for Vinyl Chloride Synthesis. Stud. Surf. Sci. Catal. 1993, 75, 24512454.

(90) Wesselhoft, R. D.; Woods, J. M.; Smith, J. M. Vinyl Chloride from Acetylene and Hydrogen Chloride: Catalytic Rate Studies. AIChE J. 1959, 5, 361-366.

(91) Shankar, H. S.; Agnew, J. B. Kinetics of Acetylene Hydrochlorination. Ind. Eng. Chem. Process Des. Dev. 1980, 19, 232-237.

(92) Dan, N.; Trung, T. Q. Kinetics of Gas-Phase Hydrochlorination of Acetylene over a Mercury Catalyst. React. Kinet. Catal. Lett. 1981, 17, 423-426.

(93) Bremer, H.; Lieske, H. Kinetics of the Hydrochlorination of Acetylene on $\mathrm{HgCl}_{2}$ on Active Carbon Catalysts. Appl. Catal. 1985, 18, 191-203.

(94) Ghosh, A. K.; Agnew, J. B. Kinetics and Mechanism of the Catalytic Hydrochlorination of Acetylene to Vinyl Chloride by Use of a Transient-Response Technique. Ind. Eng. Chem. Process Des. Dev. 1985, 24, 152-159.

(95) Zhou, K.; Wang, W.; Zhao, Z.; Luo, G.; Miller, J. T.; Wong, M. S.; Wei, F. Synergistic Gold Bismuth Catalysis for Non-Mercury Hydrochlorination of Acetylene to Vinyl Chloride Monomer. ACS Catal. 2014, 4, 3112-3116.

(96) Wang, X. X.; Wu, G. W.; Wu, H.; Shi, C. C.; Li, W. W.; Wu, X. X. Kinetic Study of Hydrochlorination of Acetylene on Low-Mercury Catalyst. Ind. Catal. (Gongye Cuihua) 2014, 22, 392-396. 
(97) Smith, D. M.; Walsh, P. M.; Slager, T. L. Studies of Silica-Supported Metal Chloride Catalysts for Vapor-Phase Hydrochlorination of Acetylene. J. Catal. 1968, 11, 113-130.

(98) Shinoda, K. The Vapor-Phase Hydrochlorination of Acetylene over Metal Chlorides Supported on Activated Carbon. Chem. Lett. 1975, 4, 219-220.

(99) Hutchings, G. J. Vapor Phase hydrochlorination of Acetylene: Correlation of Catalytic Activity of Supported Metal Chloride Catalysts. J. Catal. 1985, 96, 292-295.

(100) Nkosi, B.; Coville, N. J.; Hutchings, G. J. Vapour Phase Hydrochlorination of Acetylene with Group VIII and IB Metal Chloride Catalysts. Appl. Catal. 1988, 43, 33-39.

(101) Conte, M.; Carley, A.; Heirene, C.; Willock, D.; Johnston, P.; Herzing, A.; Kiely, C.; Hutchings, G. Hydrochlorination of Acetylene Using a Supported Gold Catalyst: A Study of the Reaction Mechanism. J. Catal. 2007, 250, 231-239.

(102) Wang, Y.; Zhu, M.; Kang, L.; Dai, B. Neutral Aun $(n=3-10)$ Clusters Catalyze Acetylene Hydrochlorination: A Density Functional Theory Study. RSC Adv. 2014, 4, 38466-38473.

(103) Nkosi, B.; Coville, N. J.; Hutchings, G. J.; Adams, M. D.; Friedl, J.; Wagner, F. E. Hydrochlorination of Acetylene Using Gold Catalysts: A Study of Catalyst Deactivation. J. Catal. 1991, 128, 366-377.

(104) Duan, X.; Tian, X.; Ke, J.; Yin, Y.; Zheng, J.; Chen, J.; Cao, Z.; Xie, Z.; Yuan, Y. Size Controllable Redispersion of Sintered Au Nanoparticles by Using Iodohydrocarbon and Its Implications. Chem. Sci. 2016, 7, 3181-3187.

(105) Zhou, K.; Jia, J.; Li, C.; Xu, H.; Zhou, J.; Luo, G.; Wei, F. A Low Content Au-Based Catalyst for Hydrochlorination of $\mathrm{C}_{2} \mathrm{H}_{2}$ and Its Industrial Scale-Up for Future PVC Processes. Green Chem. 2015, 17, 356-364.

(106) Zhang, H.; Dai, B.; Wang, X.; Li, W.; Han, Y.; Gu, J.; Zhang, J. Non-Mercury Catalytic Acetylene Hydrochlorination over Bimetallic Au-Co(III)/SAC Catalysts for Vinyl Chloride Monomer Production. Green Chem. 2013, 15, 829-836.

(107) Carthey, N. A.; Johnston, P.; Smidt, M. L. WO 2010/055341A3, 2010. 
(108) Conte, M.; Carley, A. F.; Hutchings, G. J. Reactivation of a Carbon-Supported Gold Catalyst for the Hydrochlorination of Acetylene. Catal. Lett. 2008, 124, 165-167.

(109) Bishop, P. T.; Carthey, N. A.; Johnston, P. WO 2013/008004A3, 2013.

(110) Li, X.; Zhu, M.; Dai, B. $\mathrm{AuCl}_{3}$ on Polypyrrole-Modified Carbon Nanotubes as Acetylene Hydrochlorination Catalysts. Appl. Catal. B 2013, 142, 234-240.

(111) Zhao, J.; Xu, J.; Xu, J.; Zhang, T.; Di, X.; Ni, J.; Li, X. Enhancement of Au/AC Acetylene Hydrochlorination Catalyst Activity and Stability via Nitrogen-Modified Activated Carbon Support. Chem. Eng. J. 2015, 262, 1152-1160.

(112) Wang, B.; Yu, L.; Zhang, J.; Pu, Y.; Zhang, H.; Li, W. Phosphorus-Doped Carbon Supports Enhance Gold-Based Catalysts for Acetylene Hydrochlorination Dagger. RSC Adv. 2014, 4, 15877-15885.

(113) Xu, H.; Zhou, K.; Si, J.; Li, C.; Luo, G. A Ligand Coordination Approach for High Reaction Stability of an Au-Cu Bimetallic Carbon-Based Catalyst in the Acetylene Hydrochlorination Process. Catal. Sci. Technol. 2016, 6, 1357-1366.

(114) Conte, M.; Carley, A.; Attard, G.; Herzing, A.; Kiely, C.; Hutchings, G. Hydrochlorination of Acetylene Using Supported Bimetallic Au-Based Catalysts. J. Catal. 2008, 257, 190-198.

(115) Li, G.; Li, W.; Zhang, J. Non-Mercury Catalytic Acetylene Hydrochlorination over Activated Carbon-Supported Au Catalysts Promoted by CeO2. Catal. Sci. Technol. 2016, 6, 1821-1828.

(116) Dong, Y.; Zhang, H.; Li, W.; Sun, M.; Guo, C.; Zhang, J. Bimetallic Au-Sn/AC Catalysts for Acetylene Hydrochlorination. J. Ind. Eng. Chem. 2016, 35, 177-184.

(117) Zhang, H.; Li, W.; Li, X.; Zhao, W.; Gu, J.; Qi, X.; Dong, Y.; Dai, B.; Zhang, J. Non-Mercury Catalytic Acetylene Hydrochlorination over Bimetallic $\mathrm{Au}-\mathrm{Ba}(\mathrm{II}) / \mathrm{AC}$ Catalysts. Catal. Sci. Technol. 2015, 5, 1870-1877.

(118) Zhang, H.; Dai, B.; Li, W.; Wang, X.; Zhang, J.; Zhu, M.; Gu, J. Non-Mercury Catalytic Acetylene Hydrochlorination over Spherical Activated-Carbon-Supported Au-Co(III)-Cu(II) Catalysts. J. Catal. 2014, 316, 141-148. 
(119) Jin, Y.; Li, G.; Zhang, J.; Pu, Y.; Li, W. Effects of Potassium Additive on the Activity of Ru Catalyst for Acetylene Hydrochlorination. RSC Adv. 2015, 5, 37774-37779.

(120) Zhang, J.; Sheng, W.; Guo, C.; Li, W. Acetylene Hydrochlorination over Bimetallic Ru-Based Catalysts. RSC Adv. 2013, 3, 21062-21068.

(121) Xu, J.; Zhao, J.; Zhang, T.; Di, X.; Gu, S.; Ni, J.; Li, X. Ultra-Low Ru-Promoted $\mathrm{CuCl}_{2}$ as Highly Active Catalyst for the Hydrochlorination of Acetylene. RSC Adv. 2015, 5, 38159-38163.

(122) Zhou, K.; Jia, J.; Li, X.; Pang, X.; Li, C.; Zhou, J.; Luo, G.; Wei, F. Continuous Vinyl Chloride Monomer Production by Acetylene Hydrochlorination on Hg-Free Bismuth Catalyst: From LabScale Catalyst Characterization, Catalytic Evaluation to a Pilot-Scale Trial by Circulating Regeneration in Coupled Fluidized Beds. Fuel Process. Technol. 2013, 108, 12-18.

(123) Dreher, E. L.; Torkelson, T. R.; Beutel, K. K. Chloroethanes and Chloroethylenes. In Ullmann's Encyclopedia of Industrial Chemistry; Bellussi, G.; Bohnet, M.; Bus, J.; Drauz. K.; Faulhammer, H.; Greim, H.; Karst, U.; Kleemann, A.; Kutscher, B.; Meier, W.; et al., Ed.; Wiley-VCH Verlag GmbH \& Co. KGaA: Weinheim, 2012; p 750.

(124) Campbell, R. G. U.S. Patent 4,347,391, 1982.

(125) Vinyl Chloride and Polyvinyl Chloride, http://www.thyssenkrupp-industrialsolutions.com/fileadmin/documents/brochures/uhde_brochures_pdf_en_8.pdf, (accessed Jun 25, 2016).

(126) Jaqueau, D.; Piester, L. W.; Bohl, L. E.; Knoop, J. F. Oxychlorination. Chem. Ing. Tech. 1971, 43, 184-187.

(127) Baker, R. W.; McCarthy, J. H.; Place, H. G.; Wikman, A. O. U.S. Patent 3,468,968, 1969.

(128) Daumas, J. U.S. Patent 4,058,574, 1977.

(129) Wakiyama, Y.; Uchida, K. U.S. Patent 3,624,170, 1971.

(130) Dugan, J. J. U.S. Patent 3,670,037, 1972.

(131) Lemanski, M. F.; Leitert, F. C.; Vinson, C. G. U.S. Patent 4,115,323, 1978.

(132) Jones, M. E.; Olken, M. M.; Hickman, D. A. U.S. Patent 6,909,024, 2005. 
(133) Scharfe, M.; Lira-Parada, P. A.; Paunović, V.; Moser, M.; Amrute, A. P.; Pérez-Ramírez, J. Oxychlorination-Dehydrochlorination Chemistry on Bifunctional Ceria Catalysts for Intensified Vinyl Chloride Production. Angew. Chem. Int. Ed. 2016, 55, 3068-3072.

(134) Fortini, E. M.; Garcia, C. L.; Resasco, D. E. Stabilization of the Active Phase by Interaction with the Support in $\mathrm{CuCl}_{2}$ Oxychlorination Catalysts. J. Catal. 1986, 99, 12-18.

(135) Conner, W. C.; Pieters, W. J. M.; Gates, W.; Wilkalis, J. E. The Oxychlorination of Methane on Fumed Silica-Based Cu, K, La Catalysts 2. Gas-Phase Stoichiometry. Appl. Catal. 1984, 11, 4958.

(136) Morterra, C.; Magnacca, G. A Case Study: Surface Chemistry and Surface Structure of Catalytic Aluminas, as Studied by Vibrational Spectroscopy of Adsorbed Species. Catal. Today 1996, 27, 497-532.

(137) Rouco, A. J. Low-Temperature Ethylene Oxyhydrochlorination: Effects of Supports and Promoters on the Mobilities of Active Species in $\mathrm{CuCl}_{2}$ Catallysts. J. Catal. 1995, 157, 380-387.

(138) Leofanti, G.; Padovan, M.; Garilli, M.; Carmello, D.; Zecchina, A.; Spoto, G.; Bordiga, S.; Palomino, G. T.; Lamberti, C. Alumina-Supported Copper Chloride 1. Characterization of Freshly Prepared Catalyst. J. Catal. 2000, 189, 91-104.

(139) Leofanti, G.; Padovan, M.; Garilli, M.; Carmello, D.; Marra, G. L.; Zecchina, A.; Spoto, G.; Bordiga, S.; Lamberti, C. Alumina-Supported Copper Chloride 2. Effect of Aging and Thermal Treatments. J. Catal. 2000, 189, 105-116.

(140) Gianolio, D.; Muddada, N. B.; Olsbye, U.; Lamberti, C. Doped-CuCl $2 / \mathrm{Al}_{2} \mathrm{O}_{3}$ Catalysts for Ethylene Oxychlorination: Influence of Additives on the Nature of Active Phase and Reducibility. Nucl. Instrum. Meth. B 2012, 284, 53-57.

(141) Neurock, M.; Zhang, X. Y.; Olken, M.; Jones, M.; Hickman, D.; Calverley, T.; Gulotty, R. A First-Principle Analysis of Ethylene Chemisorption on Copper Chloride Clusters. J. Phys. Chem. B 2001, 105, 1562-1572. 
(142) Prasad, P. S. S.; Prasad, K. B. S.; Rao, P. K.; Kaushik, V. K. Redistribution of Copper in KClPromoted $\mathrm{CuCl}_{2} / \gamma-\mathrm{Al}_{2} \mathrm{O}_{3}$ Catalyst During Oxychlorination of Ethylene. J. Mater. Sci. 1997, 32, 1479-1482.

(143) Leofanti, G.; Marsella, A.; Cremaschi, B.; Garilli, M.; Zecchina, A.; Spoto, G.; Bordiga, S.; Fisicaro, P.; Berlier, G.; Prestipino, C.et al. Alumina-Supported Copper Chloride 3. Effect of Exposure to Ethylene. J. Catal. 2001, 202, 279-295.

(144) Lamberti, C.; Prestipino, C.; Bonino, F.; Capello, L.; Bordiga, S.; Spoto, G.; Zecchina, A.; Moreno, S. D.; Cremaschi, B.; Garilli, M.et al. The Chemistry of the Oxychlorination Catalyst: an In Situ, Time-Resolved XANES Study. Angew. Chem. Int. Ed. 2002, 41, 2341-2344.

(145) Carrubba, R. V.; Spencer, J. L. Kinetic of Oxychlorination of Ethylene Ind. Eng. Chem. Process Des. Dev. 1970, 9, 414-419.

(146) Leofanti, G.; Marsella, A.; Cremaschi, B.; Garilli, M.; Zecchina, A.; Spoto, G.; Bordiga, S.; Fisicaro, P.; Prestipino, C.; Villain, F.et al. Alumina-Supported Copper Chloride 4. Effect of Exposure to $\mathrm{O}_{2}$ and HCl. J. Catal. 2002, 205, 375-381.

(147) Finocchio, E.; Rossi, N.; Busca, G.; Padovan, M.; Leofanti, G.; Cremaschi, B.; Marsella, A.; Carmello, D. Characterization and Catalytic Activity of $\mathrm{CuCl}_{2}-\mathrm{Al}_{2} \mathrm{O}_{3}$ Ethylene Oxychlorination Catalysts. J. Catal. 1998, 179, 606-618.

(148) Shalygin, A. S.; Malysheva, L. V.; Paukshtis, E. A. Mechanism of 1,2-Dichloroethane Dehydrochlorination on the Acid Sites of Oxide Catalysts as Studied by IR Spectroscopy. Kinet. Catal. 2011, 52, 305-315.

(149) Muddada, N. B.; Olsbye, U.; Fuglerud, T.; Vidotto, S.; Marsella, A.; Bordiga, S.; Gianolio, D.; Leofanti, G.; Lamberti, C. The Role of Chlorine and Additives on the Density and Strength of Lewis and Bronsted Acidic Sites of $\gamma-\mathrm{Al}_{2} \mathrm{O}_{3}$ Support Used in Oxychlorination Catalysis: A FTIR Study. J. Catal. 2011, 284, 236-246. 
(150) Muddada, N. B.; Fuglerud, T.; Lamberti, C.; Olsbye, U. Tuning the Activity and Selectivity of $\mathrm{CuCl}_{2} / \gamma-\mathrm{Al}_{2} \mathrm{O}_{3}$ Ethene Oxychlorination Catalyst by Selective Promotion. Top. Catal. 2014, 57, 741-756.

(151) Feijen-Jeurissen, M. M. R.; Jorna, J. J.; Nieuwenhuys, B. E.; Sinquin, G.; Petit, C.; Hindermann, J. P. Mechanism of Catalytic Destruction of 1,2-Dichloroethane and Trichloroethylene over $\gamma$ $\mathrm{Al}_{2} \mathrm{O}_{3}$ and $\gamma-\mathrm{Al}_{2} \mathrm{O}_{3}$ Supported Chromium and Palladium Catalysts. Catal. Today 1999, 54, 65-79.

(152) Xie, Y.; Zhang, H.; Wang, R. Kinetic Behavier and Mechanism of Oxychlorination Catalyst. Sci. China Math. 1980, 23, 979-991.

(153) Takamitsu, Y.; Yoshida, S.; Kobayashi, W.; Ogawa, H.; Sano, T. Combustion of Volatile Organic Compounds over Composite Catalyst of $\mathrm{Pt} / \gamma-\mathrm{Al}_{2} \mathrm{O}_{3}$ and Beta Zeolite. J. Environ. Sci. Health Part A-Toxic/Hazard. Subst. Environ. Eng. 2013, 48, 667-674.

(154) Muddada, N. B.; Olsbye, U.; Leofanti, G.; Gianolio, D.; Bonino, F.; Bordiga, S.; Fuglerud, T.; Vidotto, S.; Marsella, A.; Lamberti, C. Quantification of Copper Phases, Their Reducibility and Dispersion in Doped-CuCl $2 / \mathrm{Al}_{2} \mathrm{O}_{3}$ Catalysts for Ethylene Oxychlorination. Dalton Trans. 2010, 39, 8437-8449.

(155) Muddada, N. B.; Olsbye, U.; Caccialupi, L.; Cavani, F.; Leofanti, G.; Gianolio, D.; Bordiga, S.; Lamberti, C. Influence of Additives in Defining the Active Phase of the Ethylene Oxychlorination Catalyst. Phys. Chem. Chem. Phys. 2010, 12, 5605-5618.

(156) Pieters, W. J. M.; Conner, W. C.; Carlson, E. J. The Oxychlorination of Methane on Fumed Silica-based $\mathrm{Cu}^{+1}$, K, La Catalysts: 1. Catalysts Synthesis. Appl. Catal. 1984, 11, 35-48.

(157) Eden, J. S. U.S. Patent 4,446,249, 1984.

(158) Mochida, I.; Yasumoto, Y.; Watanabe, Y.; Fujitsu, H.; Kojima, Y.; Morita, M. Catalytic Dehydrochlorination of 1,2-Dichloroethane into Vinyl Chloride over Polyacrylonitrile-Based Active Carbon Fiber (PAN-ACF). Chem. Lett. 1994, 197-200. 
(159) Zhao, W.; Sun, M.; Zhang, H.; Dong, Y.; Li, X.; Li, W.; Zhang, J. Catalytic Dehydrochlorination of 1,2-Dichloroethane to Produce Vinyl Chloride over N-Doped Coconut Activated Carbon. RSC Adv. 2015, 5, 104071-104078.

(160) Uvarova, E. B.; Kustov, L. M.; Lishchiner, II; Malova, O. V.; Kazansky, V. B. Vinyl Chloride Synthesis on Zeolite Catalysts: The Role of Strong Lewis Acid-Base Pair Sites. Stud. Surf. Sci. Catal. 1997, 105, 1243-1250.

(161) Baran, R.; Srebowata, A.; Kaminska, I. I.; Lomot, D.; Dzwigaj, S. Catalytic Activity of HAlBEA and NixHAlBEA Zeolites in Hydrogen-Assisted Dehydrochlorination of 1,2-Dichloroethane into Vinyl Chloride Monomer. Microporous Mesoporous Mater. 2013, 180, 209-218.

(162) Sotowa, C.; Watanabe, Y.; Yatsunami, S.; Korai, Y.; Mochida, I. Catalytic Dehydrochlorination of 1,2-Dichloroethane into Vinyl Chloride over Polyacrylonitrile-Based Active Carbon Fiber. Appl. Catal. A 1999, 180, 317-323.

(163) Boudewijns, T.; Piccinini, M.; Degraeve, P.; Liebens, A.; De Vos, D. Pathway to Vinyl Chloride Production via Dehydrochlorination of 1,2-Dichloroethane in Ionic Liquid Media. ACS Catal. 2015, 5, 4043-4047.

(164) Jiang, B.; Zhong, J. U.S. Patent 2013/0204052 A1, 2013.

(165) Zhao, W.; Li, W.; Zhang, J. Ru/N-AC Catalyst to Produce Vinyl Chloride from Acetylene and 1,2-Dichloroethane. Catal. Sci. Technol. 2016, 6, 1402-1409.

(166) Van Rooijen, F. E.; De Bruijn, A.; Nieuwland, J. J. U.S. Patent 2009/0054708, 2009.

(167) Rubini, C.; Malentacchi, M. E.P. Patent 1,020,222, 2004.

(168) Campbell, R. G.; Doane, E. P.; Heines, M. H.; Naworski, J. S.; Vogt, H. J. U.S. Patent 4,123,467, 1978.

(169) Marsella, A.; Fatutto, P.; Carmello, D. U.S. Patent 6,465,701, 2002.

(170) Hatch, L.S.; Matar, S. Chemistry of Petrochemical Processes; Butterworth-Heinemann: Woburn, 2001; p 169.

(171) Kroenke, W. J.; Nicholas, P. P. U.S. Patent 4,375,569, 1983. 
(172) Clegg, I. M.; Hardman, R. U.S. Patent 572,905, 1998.

(173) Stauffer, J. U.S. Patent 7,253,328, 2007.

(174) Xueju, L.; Jie, L.; Guangdong, Z.; Kaiji, Z.; Wenxing, L.; Tiexin, C. 'Ethane Oxychlorination' over $\gamma-\mathrm{Al}_{2} \mathrm{O}_{3}$ Supported $\mathrm{CuCl}_{2}-\mathrm{KCl}_{-} \mathrm{LaCl}_{3}$. Catal. Lett. 2005, 100, 153-159.

(175) Liu, J.; Lue, X.; Zhou, G.; Zhen, K.; Zhang, W.; Cheng, T. Effect of $\mathrm{KCl}$ on $\mathrm{CuCl}_{2} / \gamma-\mathrm{Al}_{2} \mathrm{O}_{3}$ Catalyst for Oxychlorination of Ethane. React. Kinet. Catal. Lett. 2006, 88, 315-323.

(176) Li, C.; Zhou, G. D.; Wang, L. P.; Dong, S. L.; Li, J.; Cheng, T. X. Effect of Ceria on the MgO- $\gamma-$ $\mathrm{Al}_{2} \mathrm{O}_{3}$ Supported $\mathrm{CeO}_{2} / \mathrm{CuCl}_{2} / \mathrm{KCl}$ Catalysts for Ethane Oxychlorination. Appl. Catal. A 2011, 400, 104-110.

(177) Li, C.; Zhou, G. D.; Wang, L. P.; Li, Z.; Xue, Y. X.; Cheng, T. X. Effect of Impregnation Procedure of $\mathrm{La}_{2} \mathrm{O}_{3}$ Precursor on Copper-Based Catalysts for Ethane Oxychlorination. Catal. Commun. 2011, 13, 22-25.

(178) Li, Z.; Zhou, G.; Li, C.; Cheng, T. Effect of Pr on Copper-Based Catalysts for Ethane Oxychlorination. Catal. Commun. 2013, 40, 42-46.

(179) Hickman, D. A.; Jones, M. E.; Jovanovic, Z. R.; Olken, M. M.; Podkolzin, S. G.; Stangland, E. E.; Thompson, R. K. Reactor Scale-Up for Fluidized Bed Conversion of Ethane to Vinyl Chloride. Ind. Eng. Chem. Res. 2010, 49, 10674-10681.

(180) Flid, M. R.; Kurlyandskaya, I. I.; Treger, Y. A.; Guzhnovskaya, T. D. The Ethane Oxidative Chlorination Process and Efficient Catalyst for It. Stud. Surf. Sci. Catal. 1997, 110, 305-313.

(181) Shi, D.; Hu, R.; Zhou, Q.; Li, C. Effect of Cr-Doping on $\mathrm{CuCl}_{2}-\mathrm{KCl}-\mathrm{CeO}_{2} / \gamma-\mathrm{Al}_{2} \mathrm{O}_{3}$ Catalysts for Ethane Oxychlorination. Appl. Catal. A 2015, 506, 91-99.

(182) Barclay, J. L. U.K. Patent 1,492,945, 1977.

(183) Shi, D.; Hu, R.; Zhou, Q.; Yang, L. Catalytic Activities of Supported Perovskite Promoter Catalysts $\mathrm{La}_{2} \mathrm{NiMnO}_{6}-\mathrm{CuCl}_{2} / \gamma-\mathrm{Al}_{2} \mathrm{O}_{3}$ and $\mathrm{La}_{1.7} \mathrm{~K}_{0.3} \mathrm{NiMnO}_{6}-\mathrm{CuCl}_{2} / \gamma-\mathrm{Al}_{2} \mathrm{O}_{3}$ for Ethane Oxychlorination. Chem. Eng. J. 2016, 288, 588-595. 
(185) Henley, J. P.; Jones, M. E.; Hickman, D. A.; Marshall, K. A.; Reed, D. J.; Clarke, W. D.; Olken, M. M.; Walko, L. E. U.S. Patent 6,933,417, 2005.

(186) Princeton Chemical Research Inc. U.K. Patent 1,039,369, 1966.

(187) Yu, F. C.; Wu, X. J.; Zhang, Q. H.; Wang, Y. Oxidative Dehydrogenation of Ethane to Ethylene in the Presence of $\mathrm{HCl}$ over $\mathrm{CeO}_{2}$-Based Catalysts. Chin. J. Catal. 2014, 35, 1260-1266.

(188) Shalygin, A.; Paukshtis, E.; Kovalyov, E.; Bal'zhinimaev, B. Light Olefins Synthesis from $\mathrm{C}_{1}-\mathrm{C}_{2}$ Paraffins via Oxychlorination Processes. Front. Chem. Sci. Eng. 2013, 7, 279-288.

(189) Riegel, H. U.S. Patent 3,879,482, 1975.

(190) Clegg, I. M.; Hardman, R. E.P. Patent 667,844, 1998.

(191) Amrute, A. P.; Mondelli, C.; Hevia, M. A. G.; Pérez-Ramírez, J. Temporal Analysis of Products Study of HCl Oxidation on Copper- and Ruthenium-Based Catalysts. J. Phys. Chem. C 2011, 115, 1056-1063.

(192) Kroenke, W. J.; Carroll, R. T.; Magistro, A. J. U.S. Patent 4,159,968, 1979.

(193) Schweizer, A. E.; Jones, M. E.; Hickman, D. A. U.S. Patent 6,452,058, 2002.

(194) Podkolzin, S. G.; Stangland, E. E.; Jones, M. E.; Peringer, E.; Lercher, J. A. Methyl Chloride Production from Methane over Lanthanum-Based Catalysts. J. Am. Chem. Soc. 2007, 129, 25692576.

(195) Sze, M. C.; Riegel, H. U.S. Patent 3,879,481, 1975.

(196) Clegg, I. M.; Hardman, R. C.N. Patent 1,115,574, 1996.

(197) Clegg, I. M.; Hardman, R. U.S. Patent 5,663,465, 1997.

(198) Harth, K.; Schindler, G.; Walsdorff, C.; Simon, F. U.S. Patent 6,900,363, 2005.

(199) Vinyl Chloride Monomer (VCM) Production and Manufacturing Process, http://www.icis.com/resources/news/2007/11/07/9076569/vinyl-chloride-monomer-vcmproduction-and-manufacturing-process/ (accessed Mar 21, 2016). 
(200) Schneider1, W.; Diller, W. Phosgene. In Ullmann's Encyclopedia of Industrial Chemistry; Bellussi, G.; Bohnet, M.; Bus, J.; Drauz. K.; Faulhammer, H.; Greim, H.; Karst, U.; Kleemann, A.; Kutscher, B.; Meier, W.; et al., Ed.; Wiley-VCH Verlag GmbH \& Co. KGaA: Weinheim, 2012; p 623.

(201) Cotarca, L.; Eckert, H. Phosgenations - A Handbook; Wiley-VCH Verlag GmbH \& Co. KGaA, 2003; p 44.

(202) Abrams, L.; Cicha, W. V.; Manzer, L. E.; Subramoney, S. A New Catalyst for an Old Process Driven by Environmental Issues. Stud. Surf. Sci. Catal. 2000, 130, 455-460.

(203) Gupta, N. K.; Pashigreva, A.; Pidko, E. A.; Hensen, E. J. M.; Mleczko, L.; Roggan, S.; Ember, E. E.; Lercher, J. A. Bent Carbon Surface Moieties as Active Sites on Carbon Catalysts for Phosgene Synthesis. Angew. Chem. Int. Ed. 2016, 55, 1728-1732.

(204) Mitchell, C. J.; van der Borden, W.; van der Velde, K.; Smit, M.; Scheringa, R.; Ahrika, K.; Jones, D. H. Selection of Carbon Catalysts for the Industrial Manufacture of Phosgene. Catal. Sci. Technol. 2012, 2, 2109.

(205) Shapatina, E. N.; Kuchaev, V. L.; Penkovoi, B. E.; Temkin, M. I. Kinetics of Catalytic Synthesis of Phosgene. Kinet. Catal. 1976, 17, 559-566.

(206) Moussallem, I.; Jorissen, J.; Kunz, U.; Pinnow, S.; Turek, T. Chlor-Alkali Electrolysis With Oxygen Depolarized Cathodes: History, Present Status and Future Prospects. J. Appl. Electrochem. 2008, 38, 1177-1194.

(207) Weber, R.; Kintrup, J.; Bulan, A.; Kamper, F. U.S. Patent 20080029404, 2008.

(208) Seki, K. Development of $\mathrm{RuO}_{2} /$ Rutile- $\mathrm{TiO}_{2}$ Catalyst for Industrial $\mathrm{HCl}$ Oxidation Process. Catal. Surv. Asia 2010, 14, 168-175.

(209) Nieken, U.; Watzenberger, O. Periodic Operation of the Deacon Process. Chem. Eng. Sci. 1999, 54, 2619-2626.

(210) Pan, H. Y.; Minet, R. G.; Benson, S. W.; Tsotsis, T. T. Procee for Converting Hydrogen Chloride to Chlorine. Ind. Eng. Chem. Res. 1994, 33, 2996-3003. 
(211) Johnson, A. J.; Cherniavsky, A. J. U.S. Patent 2,542,961, 1951.

(212) Wattimena, F.; Sachtler, W. M. H. In Studies in Surface Science and Catalysis; Seiyama, T.;Tanabe, K., Eds.; Elsevier, 1981; Volume 7, Part B.

(213) Kiyoura, T.; Kogure, Y.; Nagayama, T.; Kanaya, K. U.S. Patent 4,822,589, 1989.

(214) Itoh, H.; Kono, Y.; Ajioka, M.; Takenaka, S.; Kataita, M. U.S. Patent 4,803,065, 1989.

(215) Feng, K. K.; Li, C. W.; Guo, Y. L.; Zhan, W. C.; Ma, B. Q.; Chen, B. W.; Yuan, M. Q.; Lu, G. Z. Effect of $\mathrm{KCl}$ on the Performance of $\mathrm{Cu}-\mathrm{K}-\mathrm{La} / \gamma-\mathrm{Al}_{2} \mathrm{O}_{3}$ Catalyst for $\mathrm{HCl}$ Oxidation. Chin. J. Catal. 2014, 35, 1359-1363.

(216) Amrute, A. P.; Mondelli, C.; Pérez-Ramírez, J. Kinetic Aspects and Deactivation Behaviour of Chromia-Based Catalysts in Hydrogen Chloride Oxidation. Catal. Sci. Technol. 2012, 2, 20572065.

(217) Teschner, D.; Novell-Leruth, G.; Farra, R.; Knop-Gericke, A.; Schlögl, R.; Szentmiklosi, L.; Hevia, M. G.; Soerijanto, H.; Schomäcker, R.; Pérez-Ramírez, J. et al. In Situ Surface Coverage Analysis of $\mathrm{RuO}_{2}$-Catalysed $\mathrm{HCl}$ Oxidation Reveals the Entropic Origin of Compensation in Heterogeneous Catalysis. Nat. Chem. 2012, 4, 739-745.

(218) López, N.; Gómez-Segura, J.; Marín, R. P.; Pérez-Ramírez, J. Mechanism of HCl Oxidation (Deacon Process) over $\mathrm{RuO}_{2}$. J. Catal. 2008, 255, 29-39.

(219) Heemskerk, J.; Stuiver, J. C. M. G. B. Patent 1,046,313, 1964.

(220) Mondelli, C.; Amrute, A. P.; Krumeich, F.; Schmidt, T.; Pérez-Ramírez, J. Shaped RuO $2 / \mathrm{SnO}_{2}-$ $\mathrm{Al}_{2} \mathrm{O}_{3}$ Catalyst for Large-Scale Stable $\mathrm{Cl}_{2}$ Production by $\mathrm{HCl}$ Oxidation. ChemCatChem 2011, 3, 657-660.

(221) Wolf, A.; Mleczko, L.; Schlueter, O. F.; Schubert, S. E.P. Patent 2,026,905, 2006.

(222) Teschner, D.; Farra, R.; Yao, L. D.; Schlögl, R.; Soerijanto, H.; Schomäcker, R.; Schmidt, T.; Szentmiklósi, L.; Amrute, A. P.; Mondelli, C.et al. An Integrated Approach to Deacon Chemistry on $\mathrm{RuO}_{2}$-Based Catalysts. J. Catal. 2012, 285, 273-284. 
(223) Xiang, G. L.; Shi, X. J.; Wu, Y. L.; Zhuang, J.; Wang, X. Size Effects in Atomic-Level Epitaxial Redistribution Process of $\mathrm{RuO}_{2}$ over $\mathrm{TiO}_{2}$. Sci. Rep. 2012, 2, 1-6.

(224) Kanzler, C. H.; Urban, S.; Zalewska-Wierzbicka, K.; Hess, F.; Rohrlack, S. F.; Wessel, C.; Ostermann, R.; Hofmann, J. P.; Smarsly, B. M.; Oven, H. Electrospun Metal Oxide Nanofibres for the Assessment of Catalyst Morphological Stability under Harsh Reaction Conditions. ChemCatChem 2013, 5, 2621-2626.

(225) Amrute, A. P.; Krumeich, F.; Mondelli, C.; Pérez-Ramírez, J. Depleted Uranium Catalysts for Chlorine Production. Chem. Sci. 2013, 4, 2209-2217.

(226) Moser, M.; Mondelli, C.; Amrute, A. P.; Tazawa, A.; Teschner, D.; Schuster, M. E.; Klein-

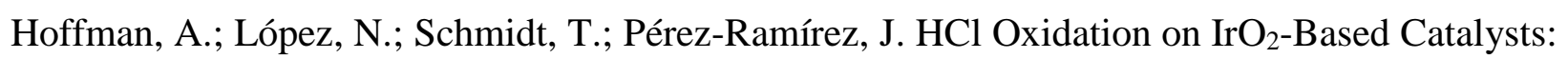
From Fundamentals to Scale-Up. ACS Catal. 2013, 3, 2813-2822.

(227) Amrute, A. P.; Mondelli, C.; Moser, M.; Novell-Leruth, G.; López, N.; Rosenthal, D.; Farra, R.; Schuster, M. E.; Teschner, D.; Schmidt, T. et al. Performance, Structure, and Mechanism of $\mathrm{CeO}_{2}$ in $\mathrm{HCl}$ Oxidation to $\mathrm{Cl}_{2}$. J. Catal. 2012, 286, 287-297.

(228) Amrute, A. P.; Mondelli, C.; Schmidt, T.; Hauert, R.; Pérez-Ramírez, J. Industrial RuO2-Based Deacon Catalysts: Carrier Stabilization and Active Phase Content Optimization. ChemCatChem 2013, 5, 748-756.

(229) Farra, R.; Eichelbaum, M.; Schlögl, R.; Szentmiklósi, L.; Schmidt, T.; Amrute, A. P.; Mondelli, C.; Pérez-Ramírez, J.; Teschner, D. Do Observations on Surface Coverage-Reactivity Correlations Always Describe the True Catalytic Process? A Case Study on Ceria. J. Catal. 2013, 297, 119-127.

(230) Moser, M.; Mondelli, C.; Schmidt, T.; Girgsdies, F.; Schuster, M. E.; Farra, R.; Szentmiklósi, L.; Teschner, D.; Pérez-Ramírez, J. Supported $\mathrm{CeO}_{2}$ Catalysts in Technical Form for Sustainable Chlorine Production. Appl. Catal. B 2013, 132, 123-131. 
(231) Toftelund, A.; Man, I. C.; Hansen, H. A.; Abild-Pedersen, F.; Bligaard, T.; Rossmeisl, J.; Studt, F. Volcano Relations for Oxidation of Hydrogen Halides over Rutile Oxide Surfaces. ChemCatChem 2012, 4, 1856-1861.

(232) Hammes, M.; Soerijanto, H.; Schomäcker, R.; Valtchev, M.; Stoewe, K.; Maier, W. F. Niobium: Activator and Stabilizer for a Copper-Based Deacon Catalyst. ChemCatChem 2014, 6, 245-254.

(233) Amrute, A. P.; Larrazábal, G. O.; Mondelli, C.; Pérez-Ramírez, J. CuCrO 2 Delafossite: A Stable Copper Catalyst for Chlorine Production. Angew. Chem. Int. Ed. 2013, 52, 9772-9775.

(234) Over, H.; Schomäcker, R. What Makes a Good Catalyst for the Deacon Process? ACS Catal. 2013, 3, 1034-1046.

(235) Hevia, M. A. G.; Amrute, A. P.; Schmidt, T.; Pérez-Ramírez, J. Transient Mechanistic Study of the Gas-Phase $\mathrm{HCl}$ Oxidation to $\mathrm{Cl}_{2}$ on Bulk and Supported $\mathrm{RuO}_{2}$ Catalysts. J. Catal. 2010, 276, 141-151.

(236) Farra, R.; Girgsdies, F.; Frandsen, W.; Hashagen, M.; Schlög, R.; Teschner, D. Synthesis and Catalytic Performance of CeOCl in Deacon Reaction. Catal. Lett. 2013, 143, 1012-1017.

(237) Farra, R.; Garcia-Melchor, M.; Eichelbaum, M.; Hashagen, M.; Frandsen, W.; Allan, J.; Girgsdies, F.; Szentmiklósi, L.; López, N.; Teschner, D. Promoted Ceria: A Structural, Catalytic, and Computational Study. ACS Catal. 2013, 3, 2256-2268.

(238) Urban, S.; Tarabanko, N.; Kanzler, C. H.; Zalewska-Wierzbicka, K.; Ellinghaus, R.; Rohrlack, S. F.; Chen, L.; Klar, P. J.; Smarsly, B. M.; Over, H. Stable and Active Mixed Zr-Ce Oxides for Catalyzing the Gas Phase Oxidation of HCl. Catal. Lett. 2013, 143, 1362-1367.

(239) Möller, M.; Over, H.; Smarsly, B.; Tarabanko, N.; Urban, S. Electrospun Ceria-Based Nanofibers for the Facile Assessment of Catalyst Morphological Stability under Harsh $\mathrm{HCl}$ Oxidation Reaction Conditions. Catal. Today 2015, 253, 207-218.

(240) Möller, M.; Urban, S.; Cop, P.; Weller, T.; Ellinghaus, R.; Kleine-Boymann, M.; Fiedler, C.; Sann, J.; Janek, J.; Chen, L. M.et al. Synthesis and Physicochemical Characterization of Ce 1 - 
${ }_{x} \mathrm{Gd}_{x} \mathrm{O}_{2-\delta}$ : A Case Study on the Impact of the Oxygen Storage Capacity on the HCl Oxidation Reaction. ChemCatChem 2015, 7, 3738-3747.

(241) Trovarelli, A. Catalytic Properties of Ceria and $\mathrm{CeO}_{2}-$ Containing Materials. Catal. Rev. Sci. Eng. 1996, 38, 439-520.

(242) Moser, M.; Rodríguez-García, L.; Pérez-Ramírez, J. Catalyst Distribution Strategies in FixedBed Reactors for Bromine Production. Ind. Eng. Chem. Res. 2014, 53, 9067-9075.

(243) Schmidt, T.; Moser, M.; Mueller, W. WO Patent 2013/060628 A1, 2013.

(244) Moser, M. Bridging $\mathrm{HCl}$ and $\mathrm{HBr}$ Oxidation over Heterogeneous Catalysts for Halogen Production. Ph.D. Dissertation, ETH Zurich, Zurich, 2016.

(245) Bardhan, S. K.; Gupta, S.; Gorman, M. E.; Haider, M. A. Biorenewable Chemicals: Feedstocks, Technologies and the Conflict with Food Production. Renew. Sustain. Energy Rev. 2015, 51, 506-520.

(246) Global Natural Gas Reserves (Conventional and Unconventional), http://www.gasinfocus.com/en/downloads/ (May 12, 2016).

(247) Shale/Unconventional Resources, http://pacwestcp.com/education/shaleunconventionalresources/ (accessed May 12, 2016).

(248) What Next for the Oil and Industry? https://www.chathamhouse.org/sites/files/chathamhouse/public/Research/Energy,\%20Environm ent\%20and\%20Development/1012pr_oilgas.pdf, (accessed Aug 8, 2016).

(249) Torres, L.; Yadav, O. P.; Khan, E. A Review on Risk Assessment Techniques for Hydraulic Fracturing Water and Produced Water Management Implemented in Onshore Unconventional Oil and Gas Production. Sci. Total Environ. 2016, 539, 478-493.

(250) Vidic, R. D.; Brantley, S. L.; Vandenbossche, J. M.; Yoxtheimer, D.; Abad, J. D. Impact of Shale Gas Development on Regional Water Quality. Science 2013, 340.

(251) Kerr, R. A. Natural Gas From Shale Bursts Onto the Scene. Science 2010, 328, 1624-1626. 
(252) Annual Energy Outlook 2013, http://www.eia.gov/forecasts/aeo/pdf/0383\%282013\%29.pdf (accessed Jul 14, 2015).

(253) Tollefson, J. 'Flaring' Wastes 3.5\% of World's Natural Gas. Nature, DOI:10.1038/nature.2016.19141.

(254) Global Flaring Visualization, http://skytruth.org/viirs/ (accessed May 4, 2016).

(255) Periana, R. A.; Taube, D. J.; Evitt, E. R.; Loffler, D. G.; Wentrcek, P. R.; Voss, G.; Masuda, T. A Mercury- Catalyzed, High-Yield System for the Oxidation of Methane to Methanol. Science 1993, 259, 340-343.

(256) Periana, R. A.; Taube, D. J.; Gamble, S.; Taube, H.; Satoh, T.; Fujii, H. Platinum Catalysts for the High-Yield Oxidation of Methane to a Methanol Derivative. Science 1998, 280, 560-564.

(257) Caballero, A.; Perez, P. J. Methane as Raw Material in Synthetic Chemistry: The Final Frontier. Chem. Soc. Rev. 2013, 42, 8809-8820.

(258) Alayon, E. M.; Nachtegaal, M.; Ranocchiari, M.; van Bokhoven, J. A. Catalytic Conversion of Methane to Methanol over Cu-Mordenite. Chem. Commun. 2012, 48, 404-406.

(259) Lunsford, J. H. The Catalytic Oxidative Coupling of Methane. Angew. Chem. Int. Ed. 1995, 34, 970-980.

(260) Takanabe, K.; Iglesia, E. Rate and Selectivity Enhancements Mediated by OH Radicals in the Oxidative Coupling of Methane Catalyzed by $\mathrm{Mn} / \mathrm{Na}_{2} \mathrm{WO}_{4} / \mathrm{SiO}_{2}$. Angew. Chem. Int. Ed. 2008, 47, 7689-7693.

(261) Hammond, C.; Conrad, S.; Hermans, I. Oxidative Methane Upgrading. ChemSusChem 2012, 5, 1668-1686.

(262) Kevin, B. Chasing the Dream of Half-Price Gasoline from Natural Gas. MIT Technology Review, https://www.technologyreview.com/s/523146/chasing-the-dream-of-half-pricegasoline-from-natural-gas/ (accessed May 11, 2016).

(263) Olah, G. A.; Gupta, B.; Farina, M.; Felberg, J. F.; Ip, W. M.; Husain, A.; Karpeles, R.; Lammertsma, K.; Melhotra, A. K.; Trivedi, N. J. Selective Monohalogenation of Methane over 
Supported Acid or Platinum Metal Catalysts and Hydrolysis of Methyl Halides over $\gamma$-Alumina-

Supported Metal Oxide/Hydroxide Catalysts. A Feasible Path for the Oxidative Conversion of Methane into Methyl Alcohol/Dimethyl Ether. J. Am. Chem. Soc. 1985, 107, 7097-7105.

(264) He, J. L.; Xu, T.; Wang, Z. H.; Zhang, Q. H.; Deng, W. P.; Wang, Y. Transformation of Methane to Propylene: A Two-Step Reaction Route Catalyzed by Modified $\mathrm{CeO}_{2}$ Nanocrystals and Zeolites. Angew. Chem. Int. Ed. 2012, 51, 2438-2442.

(265) Gaertner, C. A.; van Veen, A. C.; Lercher, J. A. Oxidative Dehydrogenation of Ethane on Dynamically Rearranging Supported Chloride Catalysts. J. Am. Chem. Soc. 2014, 136, 1269112701.

(266) Degirmenci, V.; Uner, D.; Yilmaz, A. Methane to Higher Hydrocarbons via Halogenation. Catal. Today 2005, 106, 252-255.

(267) Fettis, G. C.; Knox, J. H.; Trotman-Dickenson, A. F. The Transfer Reactions of Halogen Atoms. Can. J. Chem. 1960, 38, 1643-1647.

(268) Larsen, P.; Ulin, J.; Dahlstrøm, K.; Jensen, M. Synthesis of $\left[{ }^{11} \mathrm{C}\right]$ Iodomethane by Iodination of $\left[{ }^{11} \mathrm{C}\right]$ Methane. Appl. Radiat. Isot. 1997, 48, 153-157.

(269) McBee, E. T.; Hass, H. B.; Neher, C. M.; Strickland, H. Chlorination of Methane. Ind. Eng. Chem. 1942, 34, 296-300.

(270) Ding, K. L.; Metiu, H.; Stucky, G. D. The Selective High-Yield Conversion of Methane Using Iodine-Catalyzed Methane Bromination. ACS Catal. 2013, 3, 474-477.

(271) Lorkovic, I. M.; Sun, S. L.; Gadewar, S.; Breed, A.; Macala, G. S.; Sardar, A.; Cross, S. E.; Sherman, J. H.; Stucky, G. D.; Ford, P. C. Alkane Bromination Revisited: "Reproportionation" in Gas-Phase Methane Bromination Leads to Higher Selectivity for $\mathrm{CH}_{3} \mathrm{Br}$ at Moderate Temperatures. J. Phys. Chem. A 2006, 110, 8695-8700.

(272) Olah, G. A.; Mo, Y. K. Electrophilic Reaction at Single Bonds. XIII. Chlorination and Chlorolysis of Alkanes in $\mathrm{SbF}_{5}-\mathrm{Cl}_{2}-\mathrm{SO}_{2} \mathrm{ClF}$ Solution at Low Temperature. J. Am. Chem. Soc. 1972, 94, 6864-6865. 
(273) Olah, G. A.; Renner, R.; Schillin.P; Mo, Y. K. Electrophilic Reaction at Single Bonds. XVII. $\mathrm{SbF}_{5}, \mathrm{AlCl}_{3}$, and $\mathrm{AgSbF}_{6}$ Catalyzed Chlorination and Chlorolysis of Alkanes and Cycloalkanes. J. Am. Chem. Soc. 1973, 95, 7686-7692.

(274) Batamack, P.; Bucsi, I.; Molnar, A.; Olah, G. A. Electrophilic Chlorination of Methane over Superacidic Sulfated Zirconia. Catal. Lett. 1994, 25, 11-19.

(275) Bucsi, I.; Olah, G. A. Selective Monochlorination of Methane Over Solid Acid and Zeolite Catalysts. Catal. Lett. 1992, 16, 27-38.

(276) Degirmenci, V.; Yilmaz, A.; Uner, D. Selective Methane Bromination over Sulfated Zirconia in SBA-15 Catalysts. Catal. Today 2009, 142, 30-33.

(277) Yilmaz, A.; Yilmaz, G. A.; Lorkovic, I. M.; Stucky, G. D.; Ford, P. C.; McFarland, E.; Sherman, J. H. U.S. Patent 6,713,655, 2004.

(278) Lorkovic, I.; Noy, M.; Weiss, M.; Sherman, J.; McFarland, E.; Stucky, G. D.; Ford, P. C. C 1 Coupling via Bromine Activation and Tandem Catalytic Condensation and Neutralization over CaO/Zeolite Composites. Chem. Commun. 2004, 566-567.

(279) Grosso, P. U.S. Patent 6,525,230, 2003.

(280) Lorkovic, I. M.; Noy, M. L.; Schenck, W. A.; Belon, C.; Weiss, M.; Sun, S.; Sherman, J. H.; McFarland, E. W.; Stucky, G. D.; Ford, P. C. C1 Oxidative Coupling via Bromine Activation and Tandem Catalytic Condensation and Neutralization over CaO/Zeolite Composites II. Product Distribution Variation and Full Bromine Confinement. Catal. Today 2004, 98, 589-594.

(281) Evans, W. E.; Komplin, G. C.; Muthusamy, D. U.S. Patent 8,536,393, 2013.

(282) Moser, M.; Paunović, V.; Guo, Z.; Szentmiklósi, L.; Hevia, M. G.; Higham, M.; López, N.; Teschner, D.; Pérez-Ramírez, J. Interplay Between Surface Chemistry and Performance of Rutile-Type Catalysts for Halogen Production. Chem. Sci. 2016, 7, 2996-3005.

(283) Moser, M.; Vilé, G.; Colussi, S.; Krumeich, F.; Teschner, D.; Szentmiklósi, L.; Trovarelli, A.; Pérez-Ramírez, J. Structure and Reactivity of Ceria-Zirconia Catalysts for Bromine and Chlorine Production via the Oxidation of Hydrogen Halides. J. Catal. 2015, 331, 128-137. 
(284) Moser, M.; Czekaj, I.; López, N.; Pérez-Ramírez, J. The Virtue of Defects: Stable Bromine Production by Catalytic Oxidation of Hydrogen Bromide on Titanium Oxide. Angew. Chem. Int. Ed. 2014, 53, 8628-8633.

(285) Li, F. B.; Yuan, G. Q. Hydrated Dibromodioxomolybdenum(VI) Supported on Zn-MCM-48 for Facile Oxidation of Methane. Angew. Chem. Int. Ed. 2006, 45, 6541-6544.

(286) Maycuilis, J. J. U.S. Patent 7,244,867, 2007.

(287) Brichek, R. T.; Lisewsky, G. A.; Waycuilis, J .J.; York, S. D. U.S. Patent 8,642,822, 2014.

(288) Moser, M.; Rodríguez-García, L.; Amrute, A. P.; Pérez-Ramírez, J. Catalytic Bromine Recovery: An Enabling Technology for Emerging Alkane Functionalization Processes. ChemCatChem 2013, 5, 3520-3523.

(289) Ukaji, R.; Maruo, K.; Misaki, S.; Ogawa, S. U.S. Patent 3,267,161, 1966.

(290) Liu, Z.; Huang, L.; Li, W. S.; Yang, F.; Au, C. T.; Zhou, X. P. Higher Hydrocarbons from Methane Condensation Mediated by HBr. J. Mol. Catal. A 2007, 273, 14-20.

(291) Lin, R.; Ding, Y.; Gong, L.; Li, J.; Chen, W.; Yan, L.; Lue, Y. Different Carriers-Supported RhBased Catalysts for Oxidative Bromination of Methane. Chin. J. Catal. 2010, 31, 213-217.

(292) Lin, R.; Ding, Y.; Gong, L.; Li, J.; Chen, W.; Yan, L.; Lu, Y. Oxidative Bromination of Methane on Silica-Supported Non-Noble Metal Oxide Catalysts. Appl. Catal. A 2009, 353, 87-92.

(293) Wang, R.; Lin, R.; Ding, Y.; Liu, J.; Wang, J.; Zhang, T. Structure and Phase Analysis of Onepot Hydrothermally Synthesized $\mathrm{FePO}_{4}$-SBA-15 as an Extremely Stable Catalyst for Harsh Oxybromination of Methane. Appl. Catal. A 2013, 453, 235-243.

(294) Lin, R.; Ding, Y.; Gong, L.; Dong, W.; Chen, W.; Lu, Y. Studies on Oxy-bromination of Methane and Coke Deposition over $\mathrm{FePO}_{4} / \mathrm{SiO}_{2}$ Catalysts. Catal. Today 2011, 164, 34-39.

(295) Wang, R.; Lin, R.; Ding, Y.; Liu, J. Model Iron Phosphate Catalysts for the Oxy-bromination of Methane. Catal. Lett. 2014, 144, 1384-1392. 
(296) Lin, R.; Ding, Y.; Gong, L.; Dong, W.; Wang, J.; Zhang, T. Efficient and Stable SilicaSupported Iron Phosphate Catalysts for Oxidative Bromination of Methane. J. Catal. 2010, 272, 65-73.

(297) Kenney, C. N. Molten-Salt Catalyst of Gas Reactions. Catal. Rev. Sci. Eng. 1975, 11, 197-224.

(298) Garcia, C. L.; Resasco, D. E. Effect of the Support and the Addition of a Second Promoter on Potassium Chloride-Copper(II) Chloride Catalysts Used in the Oxychlorination of Methane. Appl. Catal. 1989, 46, 251-267.

(299) Garcia, C. L.; Resasco, D. E. High-Temperature Oxychlorination Catalysts: Role of LaCL $\mathrm{L}_{3}$ as an Inhibitor of the Segregation of Active Species During Heating-Cooling Cycles. J. Catal. 1990, 122, 151-165.

(300) Berkowitz, S.; Park, H.; Meadow, M. U.S. Patent 3,496,242, 1970.

(301) Peringer, E.; Podkolzin, S. G.; Jones, M. E.; Olindo, R.; Lercher, J. A. LaCl 3 -Based Catalysts for Oxidative Chlorination of $\mathrm{CH}_{4}$. Top. Catal. 2006, 38, 211-220.

(302) Peringer, E.; Salzinger, M.; Hutt, M.; Lemonidou, A. A.; Lercher, J. A. Modified Lanthanum Catalysts for Oxidative Chlorination of Methane. Top. Catal. 2009, 52, 1220-1231.

(303) Peringer, E.; Tejuja, C.; Salzinger, M.; Lemonidou, A. A.; Lercher, J. A. On the Synthesis of $\mathrm{LaCl}_{3}$ Catalysts for Oxidative Chlorination of Methane. Appl. Catal. A 2008, 350, 178-185.

(304) Hibi, T.; Nishida, H.; ZAbekawa, H. U.S. Patent 5,871,707, 1999.

(305) Crihan, D.; Knapp, M.; Zweidingey, S.; Lundgren, E.; Weststrate, C. J.; Andersen, J. N.; Seitsonen, A. P.; Over, H. Stable Deacon Process for $\mathrm{HCl}$ Oxidation over $\mathrm{RuO}_{2}$. Angew. Chem. Int. Ed. 2008, 47, 2131-2134.

(306) Wang, J.; Chen, H.; Hu, Z.; Yao, M.; Li, Y. A Review on the Pd-Based Three-Way Catalyst. Catal. Rev. Sci. Eng. 2015, 57, 79-144.

(307) Wachs, I. E.; Jehng, J. M.; Deo, G.; Weckhuysen, B. M.; Guliants, V. V.; Benziger, J. B. In Situ Raman Spectroscopy Studies of Bulk and Surface Metal Oxide Phases During Oxidation Reactions. Catal. Today 1996, 32, 47-55. 
(308) Liu, Z.; Li, W.; Zhou, X. Product Oriented Oxidative Bromination of Methane over Rh/SiO 2 Catalysts. J. Nat. Gas. Chem. 2010, 19, 522-529.

(309) Lorkovic, I. M.; Yilmaz, A.; Yilmaz, G. A.; Zhou, X. P.; Laverman, L. E.; Sun, S. L.; Schaefer, D. J.; Weiss, M.; Noy, M. L.; Cutler, C. I. et al. A Novel Integrated Process for the Functionalization of Methane and Ethane: Bromine as Mediator. Catal. Today 2004, 98, 317322.

(310) Osterwalder, N.; Stark, W. J. Direct Coupling of Bromine-Mediated Methane Activation and Carbon-Deposit Gasification. ChemPhysChem 2007, 8, 297-303.

(311) Grasselli, R. K.; Burrington, J. D. Selective Oxidation and Ammoxidation of Propylene by Heterogeneous Catalysts. Adv. Catal. 1981, 30, 133-163.

(312) Millet, J. M. M. FePO Catalysts for the Selective Oxidative Dehydrogenation of Isobutyric Acid into Methacrylic Acid. Catal. Rev. Sci. Eng. 1998, 40, 1-38.

(313) Robert, V.; Borshch, S. A.; Bigot, B. Molecular Orbital Model of Electron Delocalization in Mixed-Valence Trimeric Clusters. J. Phys. Chem. 1996, 100, 580-584.

(314) Védrine, J. C.; Coudurier, G.; Ouqour, A.; de Oliveira, P. G. P.; Volta, J. C. Niobium Oxide Based Materials as Catalysts for Acidic and Partial Oxidation Type Reactions. Catal. Today 1996, 28, 3-15.

(315) Wang, Y. J.; Zhang, M. Synthesis and Analysis of Ethylene Glycol Methyl Ethyl Ether. Adv. Mater. Res. 2013, 608-609, 1395-1398.

(316) Allen, J. A.; Clark, A. J. Oxychlorination Catalysts. Rev. Pure Appl. Chem. 1971, 21, 145-166.

(317) Fujimoto, K.; Takashima, H.; Kunugi, T. Oxychlorination of Propylene on Supported Palladium and Other Platium Group Metal Catalysts J. Catal. 1976, 43, 234-242.

(318) Mallikarjunan, M. M.; Hussain, S. Z. Oxychlorination of Some Lower Aliphatic-Hydrocarbons. J. Sci. Ind. Res. 1983, 42, 209-229.

(319) Schweizer, A. E.; Jones, M. E.; Hickman, D. A. U.S. Patent 6,984,763, 2006.

(320) Trebillon, E.; Wetroff, G. Fr. Patent 1,498,462, 1967. 
(321) Testova, N. V.; Shalygin, A. S.; Maksimov, G. M.; Paukshtis, E. A.; Parmon, V. N. Propane Chlorination over Ruthenium Oxychloride Catalysts. Kinet. Catal. 2015, 56, 428-433.

(322) Miyake, T.; Hanaya, M. Screening of Metal Chloride Catalysts for Oxychlorination of Propene. Appl. Catal. A 1995, 121, L13-L17.

(323) Potapov, A. M.; Rafikov, S. R. Some Mechanisms of Catalytic Direct and Oxidative Chlorination of Propylene. Russ. Chem. Bull. 1986, 35, 2252-2256.

(324) Turja, A.; Demichela, M. In Icheap-10: 10th International Conference on Chemical and Process Engineering, Pts 1-3; Pierucci, S., Ed., 2011; Vol. 24.

(325) Turja, A.; Demichela, M. Risk Based Design of Allyl Chloride Production Plant. Chem. Eng. Trans. 2011, 24, 1087-1092.

(326) Takashima, H.; Fujimoto, K.; Kunugi, T. Oxychlorination of Propylene over Platium Group Metal Catalyst. Nippon Kagaku Kaishi 1972, 12, 2297-2302.

(327) Hanatani, M.; Miyake, T. Jap. Patent 5,163,176, 1993.

(328) Stauffer, J. E. U.S. Patent 4,899,000, 1990.

(329) Uriarte, A. K. U.S. Patent 4,039,598, 1977.

(330) Liu, A. T. G.B. Patent 1,146,493, 1969.

(331) G.B. Patent 1,007,077, 1965.

(332) Hagiwara, H.; Todo, N. Promoting Effect of Zirconium Compound on Catalytic Activity for Oxychlorination of Butadiene. Bull. Chem. Soc. Jpn. 1972, 46, 1944.

(333) Hagiwara, H.; Todo, N. Studies on Oxychlorination Catalysts of 1,3-Butadiene. 1. Effects of Additive on Activities of Supported Copper(II) Chloride Catalysts for Oxychlorination of 1,3Butadiene. Nippon Kagaku Kaishi 1974, 2260-2266.

(334) Hagiwara, H.; Todo, N. Studies on Oxychlorination Catalysts of 1,3-Butadiene. 2. Carrier Effects on Supported $\mathrm{CuCl}_{2}-\mathrm{H}_{3} \mathrm{PO}_{4}$-LICl Catalysts for Oxychlorination of 1,3-Butadiene. Nippon Kagaku Kaishi 1974, 2267-2271.

(335) Lambert, A.; Makinson, G. K. G.B. Patent 1,139,516, 1969. 
(336) Sattler, J. J. H. B.; Ruiz-Martinez, J.; Santillan-Jimenez, E.; Weckhuysen, B. M. Catalytic Dehydrogenation of Light Alkanes on Metals and Metal Oxides. Chem. Rev. 2014, 114, 1061310653.

(337) Adams, C. T.; Brandenberger, S. G.; Dubois, J. B.; Mill, G. S.; Nager, M.; Richardson, D. B. Dehydrogenation and Coupling Reactions in the Presence of Iodine and Molten-Salt Hydrogen Iodide Acceptors. J. Org. Chem. 1977, 42, 1-6.

(338) Slaugh, L. H.; Raley, J. H.; Mullineaux, R. D. High Temperature Reactions of Iodine With Hydrocarbons. 3. Rearrangement of Aliphatic Free Radicals. J. Am. Chem. Soc. 1963, 85, 31803183.

(339) Mullineaux, R. D.; Raley, J. H. High Temperature Reactions of Iodine With Hydrocarbons. 2. Aromatization. J. Am. Chem. Soc. 1963, 85, 3178-3180.

(340) Gaertner, C. A.; van Veen, A. C.; Lercher, J. A. Oxidative Dehydrogenation of Ethane: Common Principles and Mechanistic Aspects. ChemCatChem 2013, 5, 3196-3217.

(341) Gartner, C. A.; van Veen, A. C.; Lercher, J. A. Highly Selective Supported Alkali Chloride Catalysts for the Oxidative Dehydrogenation of Ethane. Top. Catal. 2014, 57, 1236-1247.

(342) Tope, B.; Zhu, Y.; Lercher, J. A. Oxidative Dehydrogenation of Ethane over $\mathrm{Dy}_{2} \mathrm{O}_{3} / \mathrm{MgO}^{\circ}$ Supported LiCl Containing Eutectic Chloride Catalysts. Catal. Today 2007, 123, 113-121.

(343) Wang, S.; Murata, K.; Hayakawa, T.; Hamakawa, S.; Suzuki, K. Lithium-Chloride-Promoted Sulfated Zirconia Catalysts for the Oxidative Dehydrogenation of Ethane. Catal. Lett. 1999, 59, 173-178.

(344) Wang, S. B.; Murata, K.; Hayakawa, T.; Hamakawa, S.; Suzuki, K. Performance of MetalOxide-Promoted LiCl/Sulfated-Zirconia Catalysts in the Ethane Oxidative Dehydrogenation into Ethene. Catal. Lett. 1999, 62, 191-195.

(345) Leveles, L.; Fuchs, S.; Seshan, K.; Lercher, J. A.; Lefferts, L. Oxidative Conversion of Light Alkanes to Olefins over Alkali Promoted Oxide Catalysts. Appl. Catal. A 2002, 227, 287-297. 
(346) Dahl, I. M.; Grande, K.; Jens, K. J.; Rytter, E.; Slagtern, A. Oxidative Dehydrogenation of Propane in Lithium Hydroxide/Lithium Iodide Melts. Appl. Catal. 1991, 77, 163-174.

(347) Upham, D. C.; Gordon, M. J.; Metiu, H.; McFarland, E. W. Halogen-Mediated Oxidative Dehydrogenation of Propane Using Iodine or Molten Lithium Iodide. Catal. Lett. 2016, 146, 744-754.

(348) Ding, K. L.; Metiu, H.; Stucky, G. D. Interplay Between Bromine and Iodine in Oxidative Dehydrogenation. ChemCatChem 2013, 5, 1906-1910.

(349) Gaab, S.; Find, J.; Muller, T. E.; Lercher, J. A. Kinetics and Mechanism of the Oxidative Dehydrogenation of Ethane over Li/Dy/Mg/O/(Cl) Mixed Oxide Catalysts. Top. Catal. 2007, 46, 101-110.

(350) Kristoffersen, H. H.; Metiu, H. Molten LiCl Layer Supported on MgO: Its Possible Role in Enhancing the Oxidative Dehydrogenation of Ethane. J. Phys. Chem. C 2015, 119, 8681-8691.

(351) Huang, C.; Kristoffersen, H. H.; Gong, X. Q.; Metiu, H. Reactions of Molten LiI with $\mathrm{I}_{2}, \mathrm{H}_{2} \mathrm{O}$, and $\mathrm{O}_{2}$ Relevant to Halogen-Mediated Oxidative Dehydrogenation of Alkanes. J. Phy. Chem. C 2016, 120, 4931-4936.

(352) Gorin, E.; Ted, D. U.S. Patent 2,320,274, 1943.

(353) Benson, S. W. U.S. Patent 4,199,533, 1980.

(354) Svelle, S.; Aravinthan, S.; Bjorgen, M.; Lillerud, K.; Kolboe, S.; Dahl, I.; Olsbye, U. The Methyl Halide to Hydrocarbon Reaction over H-SAPO-34. J. Catal. 2006, 241, 243-254.

(355) Gamero, M.; Aguayo, A. T.; Ateka, A.; Perez-Uriarte, P.; Gayubo, A. G.; Bilbao, J. Role of Shape Selectivity and Catalyst Acidity in the Transformation of Chloromethane into Light Olefins. Ind. Eng. Chem. Res. 2015, 54, 7822-7832.

(356) Olsbye, U.; Saure, O. V.; Muddada, N. B.; Bordiga, S.; Lamberti, C.; Nilsen, M. H.; Lillerud, K. P.; Svelle, S. Methane Conversion to Light Olefins-How Does the Methyl Halide Route Differ from the Methanol to Olefins (MTO) Route? Catal. Today 2011, 171, 211-220. 
(357) Wei, Y. X.; Zhang, D. Z.; Liu, Z. M.; Su, B. L. Highly Efficient Catalytic Conversion of Chloromethane to Light Olefins over HSAPO-34 as Studied by Catalytic Testing and In Situ FTIR. J. Catal. 2006, 238, 46-57.

(358) Xu, T.; Zhang, Q.; Song, H.; Wang, Y. Fluoride-Treated H-ZSM-5 as a Highly Selective and Stable Catalyst for the Production of Propylene from Methyl Halides. J. Catal. 2012, 295, 232241.

(359) Fan, Y.; Ma, D.; Bao, X. Acetic Acid from the Carbonylation of Chloride Methane Over Rhodium Based Catalysts. Catal. Lett. 2009, 130, 286-290.

(360) Ibáñez, M.; Gamero, M.; Ruiz-Martínez, J.; Weckhuysen, B. M.; Aguayo, A. T.; Bilbao, J.; Castaño, P. Simultaneous Coking and Dealumination of Zeolite H-ZSM-5 During the Transformation of Chloromethane into Olefins. Catal. Sci. Technol. 2016, 6, 296-306.

(361) Lersch, P.; Bandermann, F. Conversion of Chloromethane Over Metal-Exchanged ZSM-5 to Higher Hydrocarbons. Appl. Catal. 1991, 75, 133-152.

(362) Kong, L. T.; Shen, B. X.; Zhao, J. G.; Liu, J. C. Comparative Study on the Chloromethane to Olefins Reaction over SAPO-34 and HZSM-22. Ind. Eng. Chem. Res. 2014, 53, 16324-16331.

(363) Zhang, D. H.; Wei, Y. X.; Xu, L.; Du, A. P.; Chang, F. X.; Su, B. L.; Liu, Z. M. Chloromethane Conversion to Higher Hydrocarbons over Zeolites and SAPOs. Catal. Lett. 2006, 109, 97-101.

(364) Juamain, D.; Su, B. L. Monitoring the Bronsted Acidity of Zeolites by Means of In Situ FT-IR and Catalytic Testing Using Chloromethane as Probe Molecule. Catal. Today 2002, 73, 187-196.

(365) Liu, Z.; Zhang, Z.; Xing, W.; Komarneni, S.; Yan, Z.; Gao, X.; Zhou, X. Tailoring Acidity of HZSM-5 Nanoparticles for Methyl Bromide Dehydrobromination by Al and Mg Incorporation. Nanoscale Res. Lett. 2014, 9, 1-12.

(366) Noronha, L. A.; Souza-Aguiar, E. F.; Mota, C. J. A. Conversion of Chloromethane to Light Olefins Catalyzed by ZSM-5 Zeolites. Catal. Today 2005, 101, 9-13. 
(367) Sun, Y.; Campbell, S. M.; Lunsford, J. H.; Lewis, G. E.; Palke, D.; Tau, L. M. The Catalytic Conversion of Methyl Chloride to Ethylene and Propylene Over Phosphorous-Modified ZSM-5 Zeolites J. Catal. 1993, 143, 32-44.

(368) Wei, Y.; Zhang, D.; Chang, F.; Xia, Q.; Su, B. L.; Liu, Z. Ultra-Short Contact Time Conversion of Chloromethane to Olefins over Pre-coked SAPO-34: Direct Insight into the Primary Conversion with Coke Deposition. Chem. Commun. 2009, 5999-6001.

(369) Jaumain, D.; Su, B. L. Direct Catalytic Conversion of Chloromethane to Higher Hydrocarbons over a Series of ZSM-5 Zeolites Exchanged with Alkali Cations. J. Mol. Catal. A 2003, 197, 263-273.

(370) Wei, Y. X.; Zhang, D. Z.; Xu, L.; Chang, F. X.; He, Y. L.; Meng, S. H.; Su, B. L.; Liu, Z. M. Synthesis, Characterization and Catalytic Performance of Metal-Incorporated SAPO-34 for Chloromethane Transformation to Light Olefins. Catal. Today 2008, 131, 262-269.

(371) Zhang, D. Z.; Wei, Y. X.; Xu, L.; Chang, F. X.; Liu, Z. Y.; Meng, S. H.; Su, B. L.; Liu, Z. M. MgAPSO-34 Molecular Sieves with Various Mg Stoichiometries: Synthesis, Characterization and Catalytic Behavior in the Direct Transformation of Chloromethane into Light Olefins. Microporous Mesoporous Mater. 2008, 116, 684-692.

(372) Jiang, Z.; Shen, B. X.; Zhao, J. G.; Wang, L.; Kong, L. T.; Xiao, W. G. Enhancement of Catalytic Performances for the Conversion of Chloromethane to Light Olefins over SAPO-34 by Modification with Metal Chloride. Ind. Eng. Chem. Res. 2015, 54, 12293-12302.

(373) Nilsen, M. H.; Svelle, S.; Aravinthan, S.; Olsbye, U. The Conversion of Chloromethane to Light Olefins over SAPO-34: The Influence of Dichloromethane Addition. Appl. Catal. A 2009, 367, 23-31.

(374) Tian, P.; Wei, Y.; Ye, M.; Liu, Z. Methanol to Olefins (MTO): From Fundamentals to Commercialization. ACS Catal. 2015, 5, 1922-1938. 
(375) Hemelsoet, K.; Van der Mynsbrugge, J.; De Wispelaere, K.; Waroquier, M.; Van Speybroeck, V. Unraveling the Reaction Mechanisms Governing Methanol-to-Olefins Catalysis by Theory and Experiment. ChemPhysChem 2013, 14, 1526-1545.

(376) Taylor, C. E. Conversion of Substituted Methane Over ZSM-Catalysts. Stud. Surf. Sci. Catal. 2000, 130, 3633-3638.

(377) Murray, D. K.; Chang, J. W.; Haw, J. F. Conversion of Methyl Halides to Hydrocarbons on Basic Zeolites-A Discovery by In Situ NMR. J. Am. Chem. Soc. 1993, 115, 4732-4741.

(378) Haw, J. F.; Song, W. G.; Marcus, D. M.; Nicholas, J. B. The Mechanism of Methanol to Hydrocarbon Catalysis. Acc. Chem. Res. 2003, 36, 317-326.

(379) McCann, D. M.; Lesthaeghe, D.; Kletnieks, P. W.; Guenther, D. R.; Hayman, M. J.; van Speybroeck, V.; Waroquier, M.; Haw, J. F. A Complete Catalytic Cycle for Supramolecular Methanol-to-Olefins Conversion by Linking Theory with Experiment. Angew. Chem. Int. Ed. 2008, 47, 5179-5182.

(380) Cserényi, J.; Óvári, L.; Bánsági, T.; Solymosi, F. Adsorption and Reactions of $\mathrm{CH}_{3} \mathrm{Cl}$ on $\mathrm{Mo}_{2} \mathrm{C}$ Based Catalyst. J. Mol. Catal. A 2000, 162, 335-352.

(381) Murray, D. K.; Howard, T.; Goguen, P. W.; Krawietz, T. R.; Haw, J. F. Methyl Halide Reactions on Mutifunctional Metal-Exchanged Zoelite Catalysts. J. Am. Chem. Soc. 1994, 116, 6354-6360.

(382) Dahl, I. M.; Kolboe, S. On the Reaction-Mechanism for Propene Formation in the MTO Reaction over SAPO-34 Catal. Lett. 1993, 20, 329-336.

(383) Svelle, S.; Joensen, F.; Nerlov, J.; Olsbye, U.; Lillerud, K.-P.; Kolboe, S.; Bjorgen, M. Conversion of Methanol into Hydrocarbons over Zeolite H-ZSM-5: Ethene Formation is Mechanistically Separated From the Formation of Higher Alkenes. J. Am. Chem. Soc. 2006, 128, $14770-14771$.

(384) Wei, Y.; Zhang, D.; Liu, Z.; Su, B. L. Mechanistic Elucidation of Chloromethane Transformation over SAPO-34 Using Deuterated Probe Molecule: A FTIR Study on the Surface Evolution of Catalyst. Chem. Phys. Lett. 2007, 444, 197-201. 
(385) Prakash, G. K. S.; Colmenares, J. C.; Batamack, P. T.; Mathew, T.; Olah, G. A. Poly(4vinylpyridine) Catalyzed Hydrolysis of Methyl Bromide to Methanol and Dimethyl Ether. $J$. Mol. Catal. A 2009, 310, 180-183.

(386) Prakash, G. K. S.; Colmenares, J. C.; Batamack, P. T.; Mathew, T.; Olah, G. A. Poly(4vinylpyridine) Catalyzed Selective Methanolysis of Methyl and Methylene Bromides. Tetrahedron Lett. 2009, 50, 6016-6018.

(387) Thomas, C. M.; Suss-Fink, G. Ligand Effects in the Rhodium-Catalyzed Carbonylation of Methanol. Coord. Chem. Rev. 2003, 243, 125-142.

(388) Rabiu, A. M.; Yusuf, I. M. Industrial Feasiblity of Direct Methane Conversion to Hydrocarbons over Fe-Based Fischer Tropsch Catalyst. J. Power Energy Eng. 2013, 1, 41-46.

(389) Ding, K. L.; Derk, A. R.; Zhang, A. H.; Hu, Z. P.; Stoimenov, P.; Stucky, G. D.; Metiu, H.; McFarland, E. W. Hydrodebromination and Oligomerization of Dibromomethane. ACS Catal. 2012, 2, 479-486.

(390) Ding, K. L.; Zhang, A.; Stucky, G. D. Iodine Catalyzed Propane Oxidative Dehydrogenation Using Dibromomethane as an Oxidant. ACS Catal. 2012, 2, 1049-1056.

(391) IARC Monographs on the Evaluation of Carcinogenic Risks to Humans, http://monographs.iarc.fr/ENG/Classification/index.php (accessed Mar 21, 2016).

(392) GHS Pictograms with Their GHS Number, Signal Words and Meaning, http://www.reachcompliance.ch/ghsclp/ghspictograms/index.html (accessed Mar 21, 2016).

(393) Borak, J.; Diller, W. F. Phosgene Exposure: Mechanisms of Injury and Treatment Strategies. J. Occup. Env. Med. 2001, 43, 110-119.

(394) Khan, M. A. Q.; Stanton, R. H. Toxicology of Halogenated Hydrocarbons Health and Ecological Effects; Pergamon Press Inc.: New York, Oxford, Toronto, Sydney, Paris, Frankfurt, 1981; p 3.

(395) Chawla, S. L.; Gupta, R. K. Materials Selection for Corrosion Control; ASM International: Materials Park, 1993; p 146. 
http://www.oxy.com/ourbusinesses/chemicals/products/documents/chlorine/chlorhb1.pdf (accessed Nov 10, 2016).

(397) Resistance of Nickel and High Nickel Alloys to Corrosion by Hydrochloric Acid, Hydrogen Chloride and Chlorine, https://www.nickelinstitute.org/ /media/Files/TechnicalLiterature/ResistanceofNickelandHigh_ NickelAlloystoCorrosionbyHydrochloricAcid_HydrogenChlorideandChlorine_279_.ashx (accessed Nov 10, 2016).

(398) McKetta, J. J. Chemical Processing Handbook; Marcel Dekker, Inc.: New York, 1993; p 329.

(399) Suzuki, Y.; Takenoue, A.; Kojima, H. U.S. Patent 3,699,178, 1972.

(400) McKetta, J. J.; Cunningham, W. A. Encyclopedia of Chemical Processing and Design; Marcel Dekker, Inc.: New York, 1977; p 80.

(401) Kurukchi, S. A.; Moodley, A.; Liu, Y. J.; Gondolfe, J. M.; Waycuilis, J. J. U.S. Patent 2013/0178675, 2013.

(402) Hall, T. J.; Mckinnie, B. G. WO Patent 2008106318, 2008.

(403) Gradishar, F. J.; Del, W. U.S. Patent 2,875,254, 1959.

(404) Technical Polymer: CPI Spotlight, http://asia.kynar.com/export/sites/kynarasia/.content/medias/downloads/literature/pulp-and-paper-kynar-pipes-and-vessels.pdf (accessed Nov 10, 2016).

(405) Landau, R. Corrosion by Fluorine and Fluorine Compounds. Corrosion 1952, 8, 283-288.

(406) Yacoe, J. C. U.S. Patent 2,846,290, 1958.

(407) Whitaker, G. C. Corrosion of Metal in Fluorine and Hydrofluoric Acid. Corrosion 1950, 7, 283285.

(408) Trester, P. W.; Staley, H. G. Assessment and Investigation of Containment Materials for the Sulfur-Iodine Thermochemical Water-Splitting Process for Hydrogen Production. Gas Research Institute Report 80/0081, 1981. 
(409) Onuki, K.; Ioka, I.; Futakawa, H.; Shimizu, S.; Tayama, I. Screening Tests on Materials of Construction for the Thermochemical IS Process. Corros. Eng. (Zairyo To Kankyo) 1977, 46, 141-149.

(410) Wong, B.; Trester, P. W. Materials Development for Sulfur-Iodine Thermochemical Hydrogen Production. In Materials for the Hydrogen Economy; Jones, R. H.; Thomas, G. J., Ed.; CRC Press: Boca Raton, 2008; p 81.

(411) Kao, H. M.; Chen, Y. C. ${ }^{27} \mathrm{Al}$ and ${ }^{19} \mathrm{~F}$ Solid-State NMR Studies of Zeolite H- $\beta$ Dealuminated with Ammonium Hexafluorosilicate. J. Phys. Chem. B 2003, 107, 3367-3375.

(412) Geerlings, P.; De Proft, F.; Langenaeker, W. Conceptual Density Functional Theory. Chem. Rev. 2003, 103, 1793-1873.

(413) Liu, K.; Rykov, A. I.; Wang, J. H.; Zhang, T. Recent Advances in the Application of Mößbauer Spectroscopy in Heterogeneous Catalysis. Adv. Catal. 2015, 58, 1-142.

(414) Czarnecki, M. A.; Morisawa, Y.; Futami, Y.; Ozaki, Y. Advances in Molecular Structure and Interaction Studies Using Near-Infrared Spectroscopy. Chem. Rev. 2015, 115, 9707-9744.

(415) Su, D. S.; Zhang, B. S.; Schlögl, R. Electron Microscopy of Solid Catalysts -Transforming from a Challenge to a Toolbox. Chem. Rev. 2015, 115, 2818-2882.

(416) Hurst, N. W.; Gentry, S. J.; Jones, A.; McNicol, B. D. Temperature Programmed Reduction. Catal. Rev. Sci. Eng. 1982, 24, 233-309.

(417) Lonyi, F.; Valyon, J. On the Interpretation of the $\mathrm{NH}_{3}-\mathrm{TPD}$ Patterns of $\mathrm{H}-\mathrm{ZSM}-5$ and $\mathrm{H}-$ Mordenite. Microporous Mesoporous Mater. 2001, 47, 293-301.

(418) Bifulco, G.; Dambruoso, P.; Gomez-Paloma, L.; Riccio, R. Determination of Relative Configuration in Organic Compounds by NMR Spectroscopy and Computational Methods. Chem. Rev. 2007, 107, 3744-3779.

(419) Kruk, M.; Jaroniec, M. Gas Adsorption Characterization of Ordered Organic-Inorganic Nanocomposite Materials. Chem. Mater. 2001, 13, 3169-3183. 
(420) Gleaves, J. T.; Ebner, J. R.; Kuechler, T. C. Temporal Analysis of Products (TAP) - A Unique Catalyst Evaluation System with Submillisecond Time Resolution. Catal. Rev. Sci. Eng. 1988, 30, 49-116.

(421) Zsako, J. Kinetic Analysis of Thermogravimetric Data. J. Phys. Chem. 1968, 72, 2406-2411.

(422) Gao, X. T.; Wachs, I. E. Investigation of Surface Structures of Supported Vanadium Oxide Catalysts by UV-Vis-NIR Diffuse Reflectance Spectroscopy. J. Phys. Chem. B 2000, 104, 12611268.

(423) Ankudinov, A. L.; Ravel, B.; Rehr, J. J.; Conradson, S. D. Real-Space Multiple-Scattering Calculation and Interpretation of X-ray-Absorption Near-Edge Structure. Phys. Rev. B 1998, 58, 7565-7576.

(424) Fadley, C. S. Angle-Resolved X-ray Photoelectron-Spectroscopy. Prog. Surf. Sci. 1984, 16, $275-$ 388.

(425) Zachariasen, W. H. A General Theory of X-ray Diffraction in Crystals. Acta Cryst. 1967, 23, 558-564. 


\section{AUTHOR INFORMATION}

\section{Corresponding Author}

*E-mail: jpr@chem.ethz.ch. Fax: +41 446331405.

\section{Notes}

The authors declare no competing financial interest.

\section{Biographies}

Ronghe Lin (Fujian, China, 1982) studied Chemical Engineering at Taiyuan University of Technology, China. He completed his $\mathrm{PhD}$ degree in 2010 studying catalyst design for methane oxybromination under the supervision of Prof. Y. J. Ding at Dalian Institute of Chemical Physics, Chinese Academy of Sciences. He then joined the group of Prof. Ding as a scientist and was promoted to an associate professor in 2013. Since 2015, he has been working as a postdoctoral fellow in the group of Prof. J. Pérez-Ramírez at ETH Zurich. Currently, his research interest mainly focuses on the development of novel catalysts and their applications in halogen-mediated functionalization of light hydrocarbons.

Amol P. Amrute (Amravati, India, 1983) studied Chemistry at the SGB Amravati University, India. He earned his PhD degree at ETH Zurich, Switzerland in 2013 under the supervision of Prof. J. PérezRamírez. His PhD work embraced the development and discovery of novel families of catalysts for the valorization of $\mathrm{HCl}$ byproduct of chemical industry via its oxidation to $\mathrm{Cl}_{2}$. He then moved to a chemical company and returned back to academia in 2015 as a postdoctoral fellow in the group of Prof. Pérez-Ramírez at ETH Zurich. His current research activities entail the development of new catalysts for halogen-mediated transformations of light hydrocarbons to value-added chemicals and fuels, e.g., via oxybromination and oxychlorination reactions.

Javier Pérez-Ramírez (Benidorm, Spain, 1974) studied Chemical Engineering at the University of Alicante, Spain and earned his PhD degree at TU Delft, Netherlands in 2002. Since 2010, he is full professor of Catalysis Engineering at the Institute for Chemical and Bioengineering of the ETH Zurich. He pursues the discovery, understanding and technical development of new catalytic materials and 
reactor engineering concepts favoring more sustainable manufacturing processes within the present and future chemical industry. Current topics of interest include hierarchically-structured zeolites, fundamentals of catalyst scale up, halogen-mediated alkane functionalization, and the conversion of renewables and $\mathrm{CO}_{2}$ to valuable chemicals. He has published around 400 articles and is co-inventor of 15 patents, several of which are under industrial exploitation. His contributions have been recognized by several awards, most recently the Otto-Roelen-Medal (2012), the EFCATS Young Researcher Award (2013), and the Beilby Medal and Prize (2014). 


\section{Graphical Abstract}

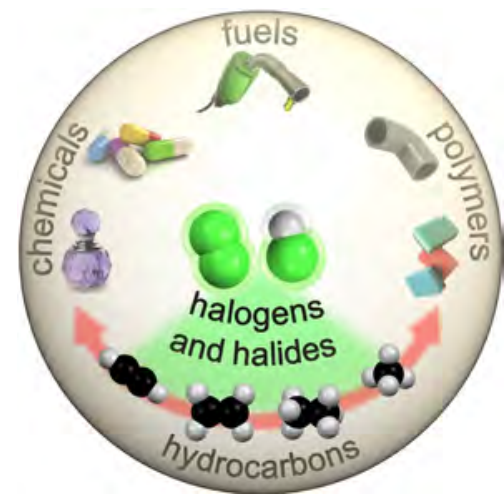

